Cochrane Database of Systematic Reviews

\title{
Phosphodiesterase-4 inhibitors for chronic obstructive pulmonary disease (Review)
}

Janjua S, Fortescue R, Poole P

Janjua S, Fortescue R, Poole P.

Phosphodiesterase-4 inhibitors for chronic obstructive pulmonary disease.

Cochrane Database of Systematic Reviews 2020, Issue 5. Art. No.: CD002309. DOI: 10.1002/14651858.CD002309.pub6.

www.cochranelibrary.com 
TABLE OF CONTENTS

HEADER

ABSTRACT

PLAIN LANGUAGE SUMMARY

SUMMARY OF FINDINGS

Figure 4.

BACKGROUND

OBJECTIVES

METHODS

RESULTS

Figure 1.

Figure 2.

Figure 3.

Figure 5.

Figure 6.

Figure 7.

Figure 8.

DISCUSSION

AUTHORS' CONCLUSIONS

ACKNOWLEDGEMENTS

REFERENCES

CHARACTERISTICS OF STUDIES

DATA AND ANALYSES

Analysis 1.1. Comparison 1: PDE4 inhibitor versus placebo (2020 update), Outcome 1: FEV 1 (by drug)

Analysis 1.2. Comparison 1: PDE4 inhibitor versus placebo (2020 update), Outcome 2: FVC

Analysis 1.3. Comparison 1: PDE4 inhibitor versus placebo (2020 update), Outcome 3: PEF

Analysis 1.5. Comparison 1: PDE4 inhibitor versus placebo (2020 update), Outcome 5: SGRQ symptom score .........................

Analysis 1.6. Comparison 1: PDE4 inhibitor versus placebo (2020 update), Outcome 6: Number of participants with 1 or more exacerbations (by drug)

Analysis 1.7. Comparison 1: PDE4 inhibitor versus placebo (2020 update), Outcome 7: Exacerbation rate (inverse variance) .... Analysis 1.8. Comparison 1: PDE4 inhibitor versus placebo (2020 update), Outcome 8: Borg Scale ......................................... Analysis 1.9. Comparison 1: PDE4 inhibitor versus placebo (2020 update), Outcome 9: Shortness of Breath Questionnaire ..... Analysis 1.10. Comparison 1: PDE4 inhibitor versus placebo (2020 update), Outcome 10: Summary symptom score ................ Analysis 1.11. Comparison 1: PDE4 inhibitor versus placebo (2020 update), Outcome 11: Breathlessness Cough and Sputum Scale (BCSS) (tetomilast $50 \mu \mathrm{g}$ )

Analysis 1.12. Comparison 1: PDE4 inhibitor versus placebo (2020 update), Outcome 12: 6-minute walk test ........................... Analysis 1.13. Comparison 1: PDE4 inhibitor versus placebo (2020 update), Outcome 13: Number of participants experiencing an adverse event

Analysis 1.14. Comparison 1: PDE4 inhibitor versus placebo (2020 update), Outcome 14: Number of participants experiencing an adverse event (roflumilast $500 \mu \mathrm{g}$ vs $250 \mu \mathrm{g}$ )

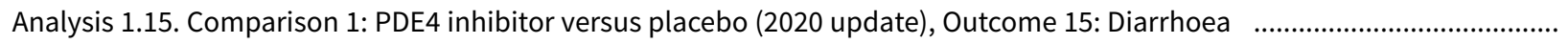

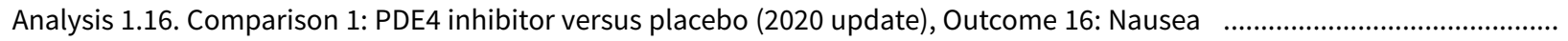

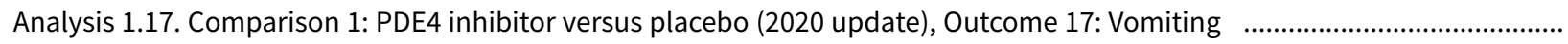

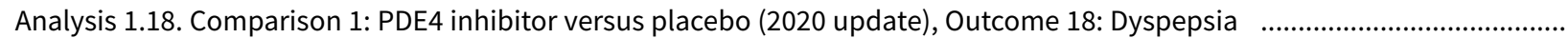

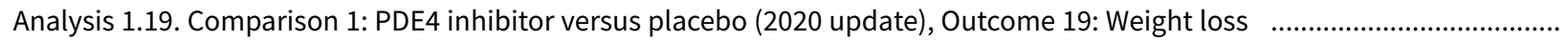
Analysis 1.20. Comparison 1: PDE4 inhibitor versus placebo (2020 update), Outcome 20: Withdrawals due to adverse events ... Analysis 1.21. Comparison 1: PDE4 inhibitor versus placebo (2020 update), Outcome 21: Headache

Analysis 1.22. Comparison 1: PDE4 inhibitor versus placebo (2020 update), Outcome 22: Abdominal pain ...............................

Analysis 1.23. Comparison 1: PDE4 inhibitor versus placebo (2020 update), Outcome 23: Influenza-like symptoms .................. Analysis 1.24. Comparison 1: PDE4 inhibitor versus placebo (2020 update), Outcome 24: Upper respiratory tract infection ..... Analysis 1.25. Comparison 1: PDE4 inhibitor versus placebo (2020 update), Outcome 25: Psychiatric adverse events 
Analysis 1.26. Comparison 1: PDE4 inhibitor versus placebo (2020 update), Outcome 26: Anxiety or anxiety disorder (roflumilast)

Analysis 1.27. Comparison 1: PDE4 inhibitor versus placebo (2020 update), Outcome 27: Depression (roflumilast) .................. Analysis 1.28. Comparison 1: PDE4 inhibitor versus placebo (2020 update), Outcome 28: Insomnia and sleep disorders (roflumilast)

Analysis 1.29. Comparison 1: PDE4 inhibitor versus placebo (2020 update), Outcome 29: Serious adverse events ................... Analysis 1.30. Comparison 1: PDE4 inhibitor versus placebo (2020 update), Outcome 30: Mortality

Analysis 1.31. Comparison 1: PDE4 inhibitor versus placebo (2020 update), Outcome 31: FEV (by mean COPD severity) .......... Analysis 1.32. Comparison 1: PDE4 inhibitor versus placebo (2020 update), Outcome 32: FEV (roflumilast $500 \mu \mathrm{g} \mathrm{vs} 250 \mu \mathrm{g}$ ) ... Analysis 1.33. Comparison 1: PDE4 inhibitor versus placebo (2020 update), Outcome 33: FEV (by study duration) ................. Analysis 1.34. Comparison 1: PDE4 inhibitor versus placebo (2020 update), Outcome 34: FEV (additional medication) ........... Analysis 1.35. Comparison 1: PDE4 inhibitor versus placebo (2020 update), Outcome 35: FEV (random-effects model) ........... Analysis 1.36. Comparison 1: PDE4 inhibitor versus placebo (2020 update), Outcome 36: FEV 1 (published vs unpublished) ..... Analysis 1.37. Comparison 1: PDE4 inhibitor versus placebo (2020 update), Outcome 37: SGRQ total score (by mean COPD severity)

Analysis 1.38. Comparison 1: PDE4 inhibitor versus placebo (2020 update), Outcome 38: SGRQ total score (by duration) ........ Analysis 1.39. Comparison 1: PDE4 inhibitor versus placebo (2020 update), Outcome 39: SGRQ total score (by published vs unpublished)

Analysis 1.40. Comparison 1: PDE4 inhibitor versus placebo (2020 update), Outcome 40: Number of participants on roflumilast with 1 or more exacerbations (additional medication)

Analysis 1.41. Comparison 1: PDE4 inhibitor versus placebo (2020 update), Outcome 41: FVC ML (roflumilast $500 \mu$ g, endpoint)

Analysis 1.42. Comparison 1: PDE4 inhibitor versus placebo (2020 update), Outcome 42: FEV 1 (by unknown COPD severity) .... Analysis 1.43. Comparison 1: PDE4 inhibitor versus placebo (2020 update), Outcome 43: FEV 1 (by duration, endpoint) ........... Analysis 1.44. Comparison 1: PDE4 inhibitor versus placebo (2020 update), Outcome 44: FEV (random-effects model, endpoint data)

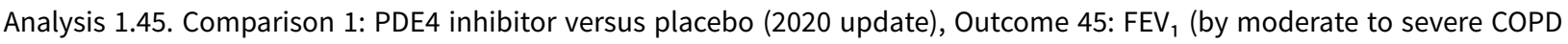
severity, endpoint)

Analysis 1.46. Comparison 1: PDE4 inhibitor versus placebo (2020 update), Outcome 46: FEV 1 (roflumilast $500 \mu$ g, endpoint) ... Analysis 1.47. Comparison 1: PDE4 inhibitor versus placebo (2020 update), Outcome 47: $\mathrm{FEV}_{1} \mathrm{ML}$ (additional medication (PDE $\mathrm{i}$ only) endpoint)

Analysis 1.48. Comparison 1: PDE4 inhibitor versus placebo (2020 update), Outcome 48: FEV 1 (published, endpoint) ..............

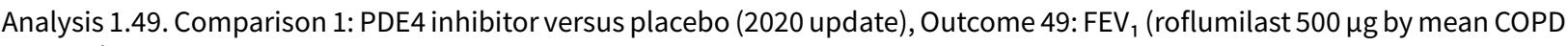
severity)

Analysis 1.50. Comparison 1: PDE4 inhibitor versus placebo (2020 update), Outcome 50: FEV 1 (unknown additional medication)

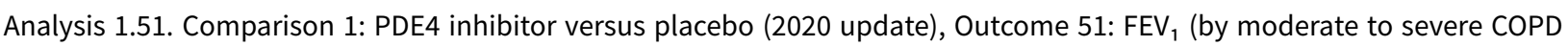
severity, roflumilast $500 \mu \mathrm{g}$ endpoint)

Analysis 1.52. Comparison 1: PDE4 inhibitor versus placebo (2020 update), Outcome 52: FEV 1 (by unknown COPD severity, roflumilast $500 \mu \mathrm{g}$ )

ADDITIONAL TABLES

APPENDICES

WHAT'S NEW

HISTORY CONTRIBUTIONS OF AUTHORS

DECLARATIONS OF INTEREST

SOURCES OF SUPPORT

DIFFERENCES BETWEEN PROTOCOL AND REVIEW

INDEX TERMS 
[Intervention Review]

\section{Phosphodiesterase-4 inhibitors for chronic obstructive pulmonary disease}

Sadia Janjua ${ }^{1}$, Rebecca Fortescue ${ }^{1}$, Phillippa Poole ${ }^{2}$

${ }^{1}$ Cochrane Airways, Population Health Research Institute, St George's, University of London, London, UK. 2Department of Medicine, University of Auckland, Auckland, New Zealand

Contact address: Phillippa Poole, p.poole@auckland.ac.nz.

Editorial group: Cochrane Airways Group.

Publication status and date: New search for studies and content updated (no change to conclusions), published in Issue 5, 2020.

Citation: Janjua S, Fortescue R, Poole P. Phosphodiesterase-4 inhibitors for chronic obstructive pulmonary disease. Cochrane Database of Systematic Reviews 2020, Issue 5. Art. No.: CD002309. DOI: 10.1002/14651858.CD002309.pub6.

Copyright ( 2020 The Cochrane Collaboration. Published by John Wiley \& Sons, Ltd.

\section{A B S T R A C T}

\section{Background}

Chronic obstructive pulmonary disease (COPD) is associated with cough, sputum production or dyspnoea, and a reduction in lung function, quality of life, and life expectancy. Apart from smoking cessation, no other treatments that slow lung function decline are available. Roflumilast and cilomilast are oral phosphodiesterase-4 $\left(\mathrm{PDE}_{4}\right)$ inhibitors proposed to reduce the airway inflammation and bronchoconstriction seen in COPD. This Cochrane Review was first published in 2011, and was updated in 2017 and 2020.

\section{Objectives}

To evaluate the efficacy and safety of oral $\mathrm{PDE}_{4}$ inhibitors for management of stable COPD.

\section{Search methods}

We identified randomised controlled trials (RCTs) from the Cochrane Airways Trials Register (date of last search 9 March 2020). We found other trials at web-based clinical trials registers.

\section{Selection criteria}

We included RCTs if they compared oral $\mathrm{PDE}_{4}$ inhibitors with placebo in people with COPD. We allowed co-administration of standard COPD therapy.

\section{Data collection and analysis}

We used standard Cochrane methods. Two independent review authors selected trials for inclusion, extracted data, and assessed risk of bias. We resolved discrepancies by involving a third review author. We assessed our confidence in the evidence by using GRADE recommendations. Primary outcomes were change in lung function (minimally important difference (MID) $=100 \mathrm{~mL}$ ) and quality of life (scale 0 to 100; higher score indicates more limitations).

\section{Main results}

We found 42 RCTs that met the inclusion criteria and were included in the analyses for roflumilast (28 trials with 18,046 participants) or cilomilast (14 trials with 6457 participants) or tetomilast (1 trial with 84 participants), with a duration between six weeks and one year or longer. These trials included people across international study centres with moderate to very severe COPD (Global Initiative for Chronic Obstructive Lung Disease (GOLD) grades II to IV), with mean age of 64 years.

We judged risks of selection bias, performance bias, and attrition bias as low overall amongst the 39 published and unpublished trials. 


\section{Lung function}

Treatment with a $\mathrm{PDE}_{4}$ inhibitor was associated with a small, clinically insignificant improvement in forced expiratory volume in one second $\left(\mathrm{FEV}_{1}\right)$ over a mean of 40 weeks compared with placebo (mean difference (MD) $49.33 \mathrm{~mL}, 95 \%$ confidence interval (Cl) 44.17 to 54.49 ; participants $=20,815$; studies $=29$; moderate-certainty evidence). Forced vital capacity (FVC) and peak expiratory flow (PEF) were also improved over 40 weeks (FVC: MD $86.98 \mathrm{~mL}$, 95\% Cl 74.65 to 99.31; participants = 22,108; studies = 17; high-certainty evidence; PEF: MD $6.54 \mathrm{~L} / \mathrm{min}, 95 \% \mathrm{Cl} 3.95$ to 9.13 ; participants = 4245; studies = 6; low-certainty evidence).

\section{Quality of life}

Trials reported improvements in quality of life over a mean of 33 weeks (St George's Respiratory Questionnaire (SGRQ) MD -1.06 units, 95\% $\mathrm{Cl}-1.68$ to -0.43 ; participants $=7645$; moderate-certainty evidence).

\section{Incidence of exacerbations}

Treatment with a $\mathrm{PDE}_{4}$ inhibitor was associated with a reduced likelihood of COPD exacerbation over a mean of 40 weeks (odds ratio (OR) $0.78,95 \% \mathrm{Cl} 0.73$ to 0.84 ; participants $=20,382$; studies $=27$; high-certainty evidence), that is, for every 100 people treated with $\mathrm{PDE}_{4}$ inhibitors, five more remained exacerbation-free during the study period compared with those given placebo (number needed to treat for an additional beneficial outcome (NNTB) $20,95 \% \mathrm{Cl} 16$ to 27). No change in COPD-related symptoms nor in exercise tolerance was found.

\section{Adverse events}

More participants in the treatment groups experienced an adverse effect compared with control participants over a mean of 39 weeks (OR $1.30,95 \% \mathrm{Cl} 1.22$ to 1.38 ; participants $=21,310$; studies $=30$; low-certainty evidence). Participants experienced a range of gastrointestinal symptoms such as diarrhoea, nausea, vomiting, or dyspepsia. Diarrhoea was more commonly reported with $\mathrm{PDE}_{4}$ inhibitor treatment (OR 3.20, $95 \% \mathrm{Cl} 2.74$ to 3.50; participants $=20,623$; studies $=29$; high-certainty evidence), that is, for every 100 people treated with $\mathrm{PDE}_{4}$ inhibitors, seven more suffered from diarrhoea during the study period compared with those given placebo (number needed to treat for an additional harmful outcome (NNTH) 15, 95\% Cl 13 to 17). The likelihood of psychiatric adverse events was higher with roflumilast 500 $\mu \mathrm{g}$ than with placebo (OR $2.13,95 \% \mathrm{Cl} 1.79$ to 2.54 ; participants $=11,168$; studies $=15$ (COPD pool data); moderate-certainty evidence). Roflumilast in particular was associated with weight loss during the trial period and with an increase in insomnia and depressive mood symptoms.

Participants treated with $\mathrm{PDE}_{4}$ inhibitors were more likely to withdraw from trial participation; on average, $14 \%$ in the treatment groups withdrew compared with $8 \%$ in the control groups.

\section{Mortality}

No effect on mortality was found (OR $0.98,95 \% \mathrm{Cl} 0.77$ to 1.24 ; participants $=19,786$; studies $=27$; moderate-certainty evidence), although mortality was a rare event during these trials.

\section{Authors' conclusions}

For this current update, five new studies from the 2020 search contributed to existing findings but made little impact on outcomes described in earlier versions of this review.

$\mathrm{PDE}_{4}$ inhibitors offered a small benefit over placebo in improving lung function and reducing the likelihood of exacerbations in people with COPD; however, they had little impact on quality of life or on symptoms. Gastrointestinal adverse effects and weight loss were common, and the likelihood of psychiatric symptoms was higher, with roflumilast $500 \mathrm{\mu g}$.

The findings of this review provide cautious support for the use of $\mathrm{PDE}_{4}$ inhibitors in COPD. In accordance with GOLD 2020 guidelines, they may have a place as add-on therapy for a subgroup of people with persistent symptoms or exacerbations despite optimal COPD

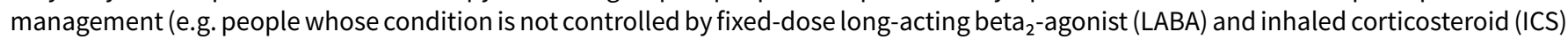
combinations). More longer-term trials are needed to determine whether or not $\mathrm{PDE}_{4}$ inhibitors modify FEV ${ }_{1}$ decline, hospitalisation, or mortality in COPD.

\section{PLAIN LANGUAGE SUMMARY}

Phosphodiesterase-4 inhibitors for people with chronic obstructive pulmonary disease (COPD)

\section{Background}

COPD is a progressive lung condition caused by damage from harmful chemicals breathed in and is predominantly seen in people who smoke tobacco. These chemicals cause inflammation and lung damage and increase mucus production in the lungs. This leads to periods of breathlessness and coughing called exacerbations (or flare-ups). Exacerbations make it harder for people to do their day-to-day tasks. Exacerbations become more frequent and severe over time. People vary in terms of how they are affected by COPD. This is related in part to 
the severity of the disease but also to differences in response to medicines, as well as fitness and co-existent conditions. For most people, the only way to prevent further lung damage is to stop smoking.

Medicines prescribed to manage COPD generally aim to improve symptoms, reduce exacerbations, or both. In early stages, taking bronchodilators makes breathing easier by relaxing muscles in the lungs and widening airways, allowing more air to move freely into and out of the lungs.

Some long-acting agents may reduce exacerbations. For example, steroid inhalers reduce inflammation in the lungs and thus modestly reduce the number of exacerbations.

Phosphodiesterase-4 ( $\left.\mathrm{PDE}_{4}\right)$ inhibitors are a relatively new class of medicines marketed to improve COPD. They have both bronchodilator and anti-inflammatory effects. Two currently available medicines - roflumilast and cilomilast - are taken as a tablet. We collated and analysed results of existing trials to define the benefits and risks of $\mathrm{PDE}_{4}$ inhibitors in COPD.

\section{Key results}

Data analysis included 42 studies in 24,587 adults with moderate to very severe disease who discontinued other regular COPD medications. Some trials allowed people to carry on using their usual COPD medicines. Most trials were funded by manufacturers of $\mathrm{PDE}_{4}$ inhibitors.

$\mathrm{PDE}_{4}$ inhibitors provided a small benefit in improving lung function measurements (forced expiratory volume in one second ( $F E V_{1}$ ), forced vital capacity (FVC), and peak expiratory flow (PEF)). $\mathrm{PDE}_{4}$ inhibitors also reduced the likelihood of COPD-related exacerbations. We found that 28 out of 100 people taking $\mathrm{PDE}_{4}$ inhibitors every day for a year would experience at least one exacerbation, which was five fewer than for people who did not receive these medicines.

$\mathrm{PDE}_{4}$ inhibitors provided a small benefit in reducing breathlessness and improving quality of life. Around $5 \%$ to $10 \%$ of people who received roflumilast or cilomilast reported side effects such as diarrhoea, nausea, and vomiting. We expected that 11 out of 100 people taking PDE $_{4}$ inhibitors every day for 39 weeks would experience an episode of diarrhoea, which was seven more than for those not receiving PDE inhibitors. We found that 7 people out of 100 were likely to experience a psychiatric event with roflumilast $500 \mu \mathrm{g}$. A two- to three-fold increase in risk of sleep or mood disturbance was found with roflumilast $500 \mu \mathrm{g}$, although overall the total number of reported incidents was low. There was no effect on death rates. Effects were the same regardless of the severity of COPD, or whether other medicines for COPD were being taken.

\section{Quality of the evidence}

We were moderately certain about data for lung function and quality of life. We were highly certain of evidence for side effects such as diarrhoea and of data for exacerbations.

Results seen in trials published in journals by pharmaceutical companies show greater benefit of these medicines than those that were unpublished. Psychiatric adverse effects data remain unpublished.

\section{Conclusions}

We support the use of $\mathrm{PDE}_{4}$ inhibitors for COPD, but with caution. $\mathrm{PDE}_{4}$ inhibitors provided a small benefit in improving lung function and reducing the likelihood of COPD exacerbations, but they had little impact on quality of life and COPD symptoms. Side effects including diarrhoea and weight loss were common.

$\mathrm{PDE}_{4}$ inhibitors may be best used as add-on therapy for a subgroup of people with persistent symptoms or exacerbations despite otherwise

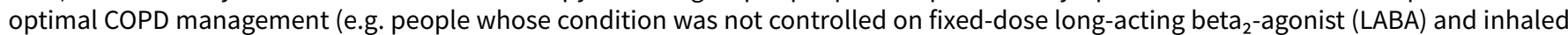
corticosteroid (ICS) combinations). This is in accordance with GOLD 2020 guidelines. Longer-term trials are necessary to get a more accurate estimate of the benefits and safety of these medicines over time, including determining whether they slow COPD disease progression. 


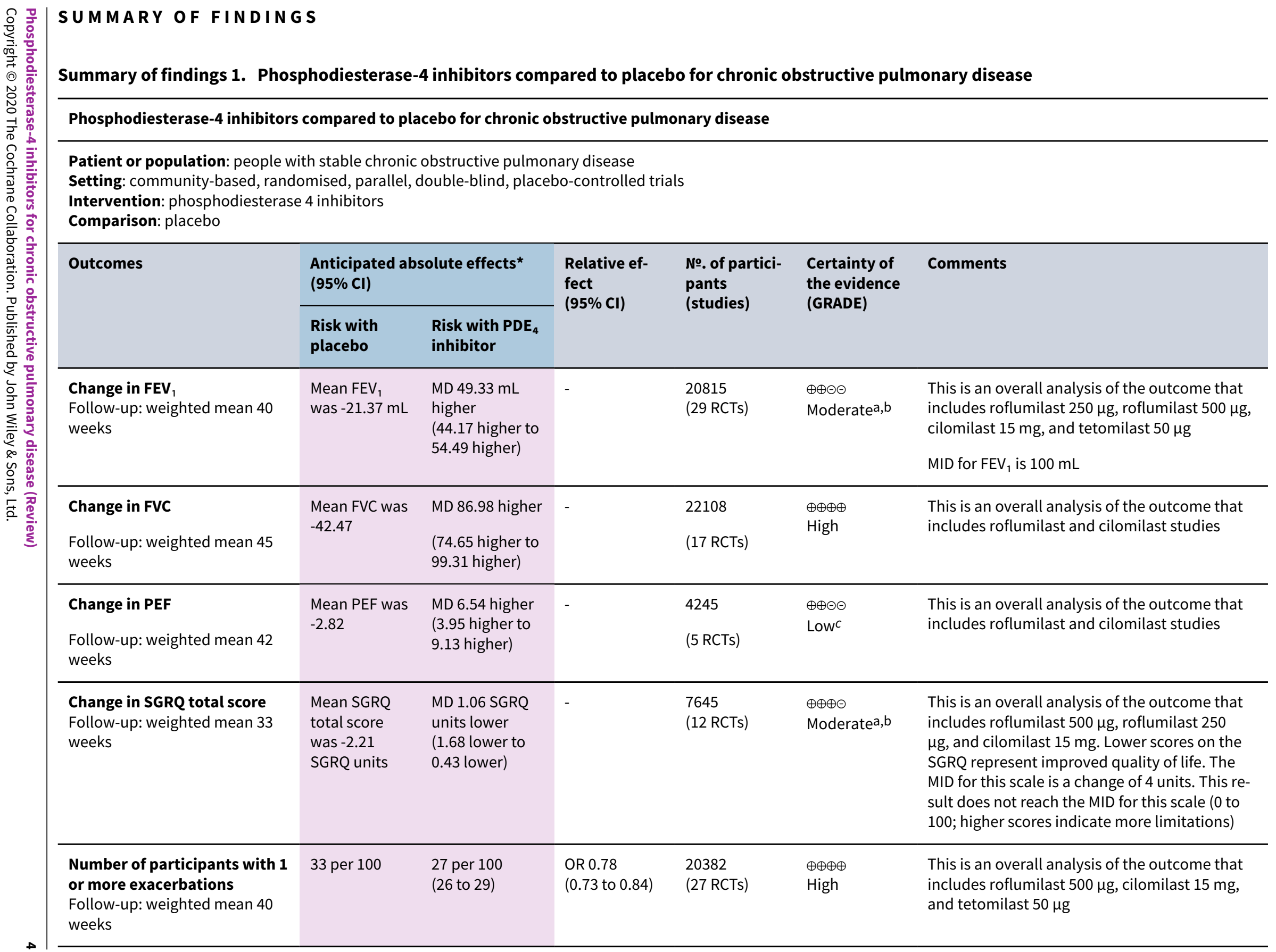




\begin{tabular}{|c|c|c|c|c|c|c|}
\hline $\begin{array}{l}\text { Number of participants expe- } \\
\text { riencing an adverse event } \\
\text { Follow-up: weighted mean } 39 \\
\text { weeks }\end{array}$ & 63 per 100 & $\begin{array}{l}69 \text { per } 100 \\
(68 \text { to } 71)\end{array}$ & $\begin{array}{l}\text { OR } 1.30 \\
\text { (1.22 to } 1.38)\end{array}$ & $\begin{array}{l}21310 \\
\text { (30 RCTs) }\end{array}$ & $\begin{array}{l}\oplus \oplus \oplus \ominus \\
\text { Lowb,c }\end{array}$ & $\begin{array}{l}\text { This is an overall analysis of the outcome that } \\
\text { includes roflumilast } 500 \mu \mathrm{g} \text {, cilomilast } 15 \mathrm{mg} \text {, } \\
\text { and tetomilast } 50 \mu \mathrm{g} \text {, and participants who } \\
\text { reported COPD exacerbations as an adverse } \\
\text { event }\end{array}$ \\
\hline $\begin{array}{l}\text { Gastrointestinal adverse ef- } \\
\text { fects: diarrhoea } \\
\text { Follow-up: weighted mean } 39 \\
\text { weeks }\end{array}$ & 4 per 100 & $\begin{array}{l}11 \text { per } 100 \\
(10 \text { to } 12)\end{array}$ & $\begin{array}{l}\text { OR } 3.10 \\
\text { (2.74 to } 3.50)\end{array}$ & $\begin{array}{l}20623 \\
\text { (29 RCTs) }\end{array}$ & $\begin{array}{l}\oplus \oplus \oplus \oplus \\
\mathrm{High} b\end{array}$ & $\begin{array}{l}\text { This is an overall analysis of the outcome that } \\
\text { includes roflumilast } 500 \mu \mathrm{g} \text {, cilomilast } 15 \mathrm{mg} \text {, } \\
\text { and tetomilast } 50 \mu \mathrm{g} \text {. Diarrhoea was the most } \\
\text { commonly reported gastrointestinal side ef- } \\
\text { fect. See Figure } 4 \text {. Weight loss was more com- } \\
\text { mon and may be a result of diarrhoea }\end{array}$ \\
\hline $\begin{array}{l}\text { Psychiatric adverse effects } \\
\text { (roflumilast } 500 \mu \mathrm{g} \text { ) } \\
\text { Follow-up: } 6 \text { to } 52 \text { weeks }\end{array}$ & 3 per 100 & $\begin{array}{l}7 \text { per } 100 \text { ( } 6 \text { to } \\
8)\end{array}$ & $\begin{array}{l}\text { OR } 2.13(1.79 \\
\text { to } 2.54)\end{array}$ & $\begin{array}{l}11168(14 \\
\text { studies) }\end{array}$ & $\begin{array}{l}\oplus \oplus \oplus \ominus \\
\text { Moderated }\end{array}$ & $\begin{array}{l}\text { Pooled data from FDA website, not individual } \\
\text { trial reports }\end{array}$ \\
\hline $\begin{array}{l}\text { Mortality } \\
\text { Follow-up: weighted mean } 40 \\
\text { weeks }\end{array}$ & 1 per 100 & $\begin{array}{l}1 \text { per } 100 \\
(1 \text { to } 2)\end{array}$ & $\begin{array}{l}\text { OR } 0.98 \\
\text { (0.77 to } 1.24)\end{array}$ & $\begin{array}{l}19786 \\
\text { (27 RCTs) }\end{array}$ & $\begin{array}{l}\oplus \oplus \oplus \ominus \\
\text { Moderate } e\end{array}$ & $\begin{array}{l}\text { This is an overall analysis of the outcome that } \\
\text { includes roflumilast } 500 \mu \mathrm{gg} \text {, cilomilast } 15 \mathrm{mg} \text {, } \\
\text { and tetomilast } 50 \mu \mathrm{g}\end{array}$ \\
\hline
\end{tabular}

*The risk in the intervention group (and its $95 \%$ confidence interval) is based on the assumed risk in the comparison group and the relative effect of the intervention (and its $95 \% \mathrm{Cl})$.

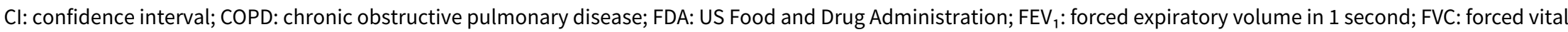
capacity; MD: mean difference; MID: minimally important difference; OR: odds ratio; PEF: peak expiratory flow; PDE 4 : phosphodiesterase-4 inhibitor; RCT: randomised controlled trial; RR: risk ratio; SGRQ: St George's Respiratory Questionnaire.

\section{GRADE Working Group grades of evidence.}

High certainty: we are very confident that the true effect lies close to that of the estimate of the effect.

Moderate certainty: we are moderately confident in the effect estimate: the true effect is likely to be close to the estimate of the effect, but there is a possibility that it is substantially different.

Low certainty: our confidence in the effect estimate is limited: the true effect may be substantially different from the estimate of the effect.

Very low certainty: we have very little confidence in the effect estimate: the true effect is likely to be substantially different from the estimate of effect.

aThe outcome was downgraded by 1 point due to moderate heterogeneity across studies $\left(I^{2}=30 \%\right.$ to $\left.60 \%\right)$.

bAlthough some publication bias was found on further investigation through a sensitivity analysis, we did not consider the removal of studies suspected of publication bias to have a large enough impact on the overall effect estimate and Cls. Therefore, we did not downgrade for publication bias.

cThe outcome was downgraded by 2 points due to substantial heterogeneity across studies $\left(I^{2}=50 \%\right.$ to $\left.90 \%\right)$.

$d$ Based on data from the combined COPD safety pool. Individual study data not obtained.

eThe outcome was downgraded by 1 point due to a small number of events, leading to wide confidence intervals. 


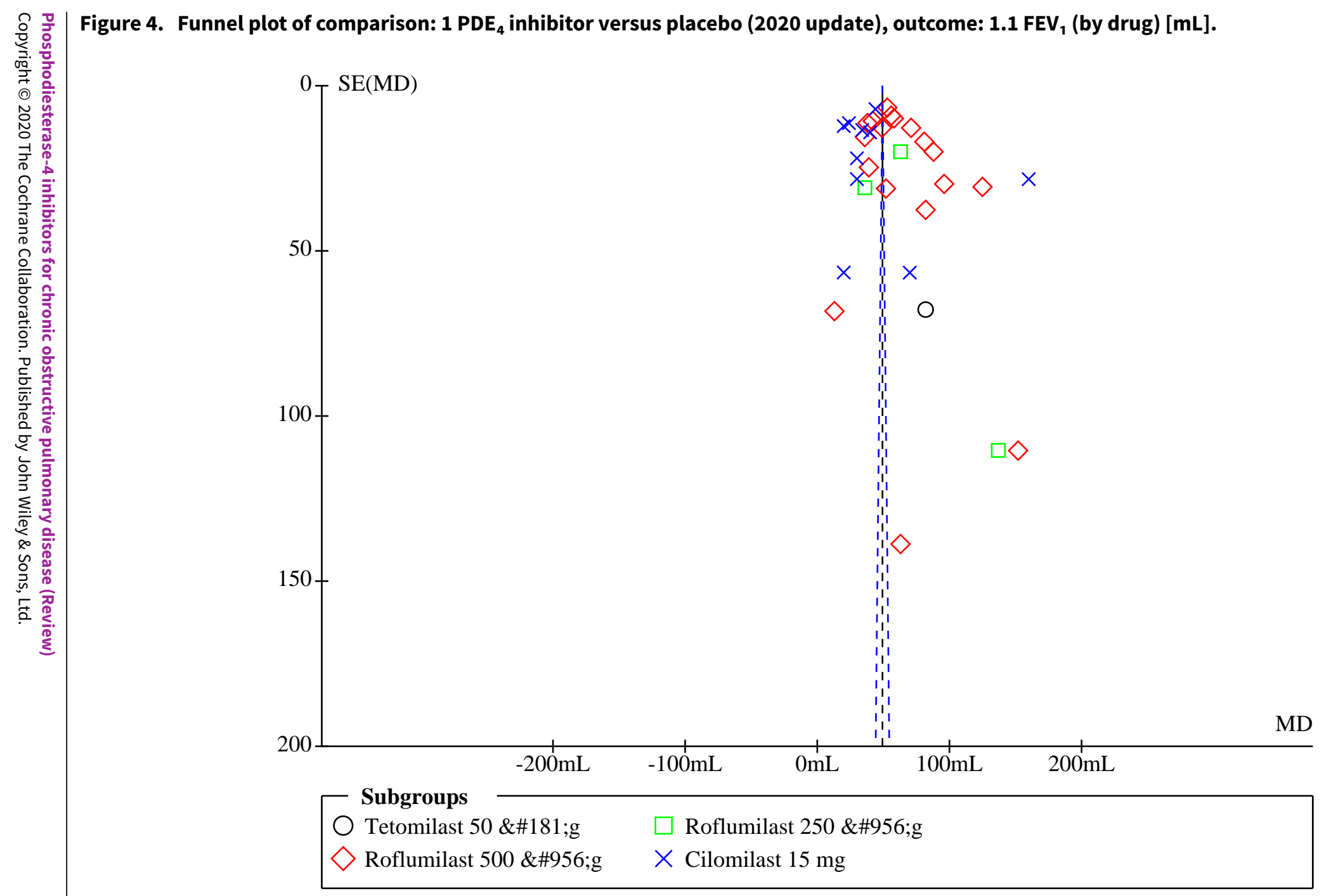




\section{B A C K G R O U N D}

\section{Description of the condition}

Chronic obstructive pulmonary disease (COPD) is one of the leading causes of global morbidity and mortality, resulting in a growing social and economic burden (GOLD 2020). In 2002, COPD was estimated to be the fifth leading cause of death, responsible for approximately $4.8 \%$ of total deaths worldwide, and it is projected to rise to fourth position by the year 2030 (Mathers 2005).

COPD is an overarching term that includes two lung conditions: chronic bronchitis and emphysema. These lung conditions cause narrowing of the airways and overinflation of the alveoli, leading to difficulty in breathing. Diagnosis of COPD by the Global Initiative for Chronic Obstructive Lung Disease (GOLD) says that it is a "heterogeneous disease that is characterized by persistent respiratory symptoms and airflow limitation that is due to airway and/or alveolar abnormalities usually caused by exposure to noxious particles or gases and influenced by host factors including abnormal lung development" (GOLD 2020). COPD may be punctuated by periods of acute worsening of respiratory symptoms, called exacerbations. Besides exposures, host factors predispose individuals to develop COPD. Comorbidities contribute to overall severity and mortality in individual people (GOLD 2020). Diagnosis is based on a history of exposure to risk factors for this disease and symptoms of cough and sputum production or dyspnoea (shortness of breath). Spirometry is required for diagnosis, with airflow obstruction confirmed by a post-bronchodilator forced expiratory volume in one second $\left(\mathrm{FEV}_{1}\right) /$ forced vital capacity (FVC) of 0.7 or lower (Celli 2004). Life expectancy is reduced among people diagnosed with COPD, and although prognosis is variable, age and $\mathrm{FEV}_{1}$ are the strongest predictors of mortality.

The predominant risk factor for COPD is tobacco smoking, with other environmental pollutants also known to contribute. Cigarette smoke leads to activation of macrophages and CD8 T lymphocytes that release inflammatory mediators and cytokines. The process also involves neutrophil attraction and cell apoptosis (Barnes 2000). To date, smoking cessation is the only intervention known to slow the decline in lung function associated with COPD (GOLD 2020).

Pharmacotherapy is commonly used to treat people with COPD, with effects on symptoms, quality of life, or frequency and severity of exacerbations (Celli 2004; GOLD 2020). Mainstays of treatment include short- and long-acting inhaled beta ${ }_{2}$-agonists (LABAs) and anticholinergics, corticosteroids, and methylxanthines. Triple therapy with inhaled corticosteroids, LABAs, and long-acting muscarinic antagonists (LAMAs) can improve $\mathrm{FEV}_{1}$, reduce exacerbations, and improve patient-reported outcomes (GOLD 2020). New approaches to treatment are needed, as no individual agent slows the decline in lung function or survival. In the TORCH study (Calverley 2007), a combination of salmeterol $50 \mu \mathrm{g}$ and fluticasone $500 \mu \mathrm{g}$ twice daily reduced the risk of death by $17 \%$ compared with placebo over the three-year trial period; however, this finding did not reach the pre-defined level of statistical significance for the study.

An exacerbation of COPD is an acute and sustained increase in symptoms that results in the need for additional therapy (GOLD 2020). Risk of exacerbation is significantly increased in more severe cases of COPD. Exacerbations have a negative impact on quality of life and lead to more rapid COPD progression, as well as to higher healthcare utilisation and associated costs. A greater impact on health is seen in a subgroup of people with COPD who are more susceptible to exacerbations (defined as "frequent exacerbators"), who have at least two treated exacerbations per year (Le Rouzic 2018).

Common triggers are respiratory viral infection, bacterial infection, and air pollution (Wedzicha 2007; White 2003), which may lead to increased airway inflammation, production of mucus, acute deterioration in lung function, hyperinflation from gas trapping, or a combination of these symptoms (Van Geffen 2015). These processes contribute to symptoms of increased dyspnoea and cough, as well as to changes in the character or volume of sputum.

\section{Description of the intervention}

The intervention is an oral medicine that is a selective inhibitor of the isoenzyme phosphodiesterase-4 $\left(\mathrm{PDE}_{4}\right)$. This isoenzyme has a role in airway inflammation and bronchoconstriction, both of which are pathological features of COPD (Boswell-Smith 2006). Two medicines in this class that have been studied are roflumilast and cilomilast.

\section{How the intervention might work}

Cyclic adenosine monophosphate (CAMP) is a secondary messenger that suppresses the activity of inflammatory cells and mediates the process of smooth muscle relaxation in the airways. Phosphodiesterases, in turn, hydrolyse and turn off the biological activity of cAMP (Boswell-Smith 2006). Therefore, inhibitors of phosphodiesterase action should theoretically provide improvements in the extent of airway narrowing and damage from inflammation.

Non-selective phosphodiesterase (PDE) inhibitors such as theophylline, a methylxanthine, have been used for years for treatment of people with COPD. These are recommended by current international guidelines as part of adjunctive therapy to long-acting bronchodilators (GOLD 2020). Limitations to their use include a narrow therapeutic margin and the frequency of adverse effects, which may occur even when the plasma level is within the therapeutic range (Boswell-Smith 2006). Common adverse effects associated with theophylline include headache, nausea, vomiting, diarrhoea, restlessness, nervousness, insomnia, and gastrointestinal effects (Barnes 2003). Less common, but more serious, are increased risks of cardiac arrhythmia and seizure (Barnes 2003). Some of the adverse effects associated with theophylline have been attributed to its non-selective PDE inhibition and concurrent adenosine receptor antagonism (Barnes 2005).

The isoenzyme $\mathrm{PDE}_{4}$ is the predominant isoenzyme involved in metabolising CAMP in immune and inflammatory immune cells, such as neutrophils, macrophages, $T$ cells, and endothelial cells in COPD; and in airway smooth muscle and pulmonary nerves (Agusti 2005; Boswell-Smith 2006; Torphy 1998; Vignola 2004). Inhibition of $\mathrm{PDE}_{4}$ leads to elevation of CAMP in inflammatory and immunomodulatory cells, resulting in suppression of inflammatory cell function, relaxation of airways smooth muscle, and modulation of pulmonary nerves (Boswell-Smith 2006; Essayan 2001; Torphy 1999). Thus, $\mathrm{PDE}_{4}$ is an attractive target for inhibition in COPD. 
Furthermore, central nervous system (CNS) and cardiovascular adverse effects experienced by patients treated with the nonselective PDE inhibitor, theophylline, are the result of adenosine receptor antagonism. This feature is not present with $\mathrm{PDE}_{4}$-specific inhibitors (Vignola 2004).

\section{Why it is important to do this review}

The development of selective $\mathrm{PDE}_{4}$ inhibitors offers new hope for therapy offering both anti-inflammatory and bronchodilatory effects in COPD, with fewer of the adverse effects encountered with non-selective inhibitors. Additionally, $\mathrm{PDE}_{4}$ inhibitors may be easier to use because they provide less pharmacokinetic variability and lower potential for drug interactions compared with theophylline (Barnes 2005).

Several $\mathrm{PDE}_{4}$ inhibitors have been developed, with some progressing to phase 3 clinical trials. These include the secondgeneration $\mathrm{PDE}_{4}$ inhibitors roflumilast (Nycomed, formerly Altana) and cilomilast (GlaxoSmithKline).

Earlier studies of roflumilast have shown significant improvement in pre-bronchodilator $\mathrm{FEV}_{1}$ and reduced annual rates of exacerbation among people with severe to very severe COPD who also have chronic bronchitis (Calverley 2009). Roflumilast may be considered in people taking triple inhaled therapy who still have exacerbations, $\mathrm{FEV}_{1}$ less than $50 \%$ predicted, and chronic bronchitis, especially if they have had a hospitalisation in the last year (GOLD 2020).

This review update focuses on effects of $\mathrm{PDE}_{4}$ inhibitors for treatment of people with stable COPD, using clinically important outcomes. Collating this evidence into a systematic review allows an assessment as to whether or not the theoretical benefits of $\mathrm{PDE}_{4}$ inhibitors translate into useful clinical effects, and may suggest the potential place of $\mathrm{PDE}_{4}$ inhibitors within the increasing pharmacopoeia of COPD treatments.

\section{O B JECTIVES}

To evaluate the efficacy and safety of oral $\mathrm{PDE}_{4}$ inhibitors for management of stable COPD.

\section{METHODS}

\section{Criteria for considering studies for this review \\ Types of studies}

We included randomised controlled trials (RCTs) that compared orally administered $\mathrm{PDE}_{4}$ inhibitors with placebo. We included any long-term treatment trials but excluded single-dose trials, as well as trials in acute exacerbations of COPD. We also excluded crossover trials to reduce non-random sources of bias between studies.

\section{Types of participants}

Adults (over 18 years of age) with COPD, as defined by the American Thoracic Society, the European Respiratory Society, or GOLD, with airflow obstruction evident by spirometry with post-bronchodilator $\mathrm{FEV}_{1} / \mathrm{FVC}$ of 0.7 or less (GOLD 2020). We considered trials that included participants with both COPD and asthma only if data from participants with COPD could be extracted separately from the study report or through correspondence with the study authors. We excluded ex vivo experiments and trials with participants requiring mechanical ventilation on presentation.

\section{Types of interventions}

We included trials if they compared outcomes for participants who received an orally administered $\mathrm{PDE}_{4}$ inhibitor with those for control participants who received placebo.

\section{Types of outcome measures}

\section{Primary outcomes}

- Changes in lung function from baseline including forced expiratory volume in one second $\left(\mathrm{FEV}_{1}\right)$, forced vital capacity (FVC), or peak expiratory flow (PEF)

- Quality of life (e.g. total score on St George's Respiratory Questionnaire (SGRQ))

\section{Secondary outcomes}

- Incidence of COPD exacerbations

- Symptoms (breathlessness on Borg and other scales and Shortness of Breath Questionnaire; composite measures (summary symptom score))

- Exercise tolerance (six-minute walk test)

- Adverse events (number of participants experiencing one or more adverse event, e.g. gastrointestinal, central nervous system (CNS), and cardiovascular adverse events; change in weight; withdrawal rates)

- Serious adverse events

- Mortality

\section{Search methods for identification of studies}

\section{Electronic searches}

The previously published version included searches up to October 2016. We updated the search for this version from 2016 to 9 March 2020.

We identified trials from the Cochrane Airways Trials Register (Cochrane Airways 2019), which is maintained by the Information Specialist for the Group. The Cochrane Airways Specialised Register contains studies identified from several sources.

- Monthly searches of the Cochrane Central Register of Controlled Trials (CENTRAL), in the Cochrane Library, through the Cochrane Register of Studies Online (crso.cochrane.org).

- Weekly searches of MEDLINE Ovid SP 2016 to March 2020.

- Weekly searches of Embase Ovid SP 2016 to March 2020.

- Monthly searches of PsycINFO Ovid SP 2016 to March 2020.

- Monthly searches of the Cumulative Index to Nursing and Allied Health Literature (CINAHL) EBSCO 2016 to March 2020.

- Monthly searches of the Allied and Complementary Medicine Database (AMED) EBSCO.

- Handsearches of proceedings of major respiratory conferences.

Studies contained in the Trials Register are identified through search strategies based on the scope of Cochrane Airways. Details of these strategies, as well as a list of handsearched conference proceedings, are provided in Appendix 1 . See Appendix 2 for search terms used to identify studies for this review. 
We also searched the following trials registries.

- US National Institutes of Health Ongoing Trials Register ClinicalTrials.gov (www.clinicaltrials.gov/).

- World Health Organization International Clinical Trials Registry Platform (apps.who.int/trialsearch/).

We searched the Cochrane Airways Trials Register and additional sources to March 2020, with no restriction on language or type of publication. The original strategy for this review, which was more sensitive but less specific, is provided in Appendix 3.

\section{Searching other resources}

We checked the reference lists of all primary studies and review articles for additional references and the websites of clinical trials registries for unpublished trial data. We searched relevant manufacturers' websites for study information and PubMed for errata or retractions from included studies published in full text (www.ncbi.nlm.gov/pubmed).

\section{Data collection and analysis}

\section{Selection of studies}

Two review authors (SJ, RF) independently screened the titles and abstracts of search results and coded them as 'retrieved' (eligible or potentially eligible/unclear) or 'did not retrieve'. We retrieved the full-text study reports of all potentially eligible studies, and two review authors (SJ, RF) independently screened them for inclusion, recording reasons for exclusion of ineligible studies. We resolved any disagreements through discussion. We identified and excluded duplicates and collated multiple reports of the same study, so that each study, rather than each report, was the unit of interest in the review. We recorded the selection process in sufficient detail to complete a PRISMA flow diagram and Characteristics of excluded studies table (Moher 2009). We categorised references according to trial name (by drug name and number, or by author and year).

\section{Data extraction and management}

For the current update, we used an Excel spreadsheet to extract data and assess risk of bias for each included study. One review author (SJ) extracted data on characteristics of included studies (methods, participants, interventions, outcomes) and results of the included studies. We contacted sponsors of the included studies for unpublished data and searched the sponsor's website for further details of outcomes if needed.

We extracted the following data.

- Methods: study design, total duration of study, details of any 'run-in' period, number of study centres and locations, study setting, withdrawals, and date of study.

- Participants: N, mean age, severity of condition, baseline lung function, inclusion criteria, and exclusion criteria.

- Interventions: intervention, comparison, concomitant medications, and excluded medications.

- Outcomes: primary and secondary outcomes specified and collected, and time points reported.

- Notes: funding for studies and notable conflicts of interest of trial authors.
Two review authors (SJ, RF) independently extracted outcome data from the included studies. We noted in the Characteristics of included studies table if outcome data were not reported in a useable way. We resolved any disagreements by consensus. One review author (SJ) transferred data into the Review Manager 5 file (RevMan 2014). We double-checked that data were entered correctly by comparing data presented in the systematic review against the study reports. A third review author (PP) spot-checked study characteristics for accuracy against the study report.

\section{Assessment of risk of bias in included studies}

Two review authors (SJ, RF) independently assessed risk of bias for each study using the criteria outlined in the Cochrane Handbook for Systematic Reviews of Interventions (Higgins 2019). We resolved disagreements by discussion. We assessed risk of bias according to the following domains.

- Random sequence generation.

- Allocation concealment.

- Blinding of participants and personnel.

- Incomplete outcome data.

- Selective outcome reporting.

- Other bias.

We judged each potential source of bias as high, low, or unclear, and we provided a quote from the study report together with a justification for our judgement in the 'Risk of bias' table. We summarised 'Risk of bias' judgements across different studies for each of the domains listed. We considered blinding separately for different key outcomes when necessary. When information on risk of bias related to unpublished data or correspondence with trialists, we noted this in the 'Risk of bias' table.

When considering treatment effects, we took into account the risk of bias for studies that contributed to that outcome.

\section{Assessment of bias in conducting the systematic review}

We conducted the review according to the published protocol and justified any deviations from it in the Differences between protocol and review section of this systematic review.

\section{Measures of treatment effect}

The outcomes included in this review were either dichotomous or continuous. For dichotomous outcomes, we recorded the number of participants with one or more outcome events by allocated treatment group.

We undertook meta-analyses only when this was meaningful, that is, when treatments, participants, and the underlying clinical question were similar enough for pooling to make sense. We expressed results for pooled outcomes with dichotomous variables using a fixed-effect odds ratio (OR) with $95 \%$ confidence interval (Cl). Results for continuous variables were expressed as mean differences (MDs) using a fixed-effect or standardised mean difference (SMD), with $95 \% \mathrm{Cl}$. We considered a $\mathrm{P}$ value less than 0.05 statistically significant. We combined rate ratios on a natural logarithm scale and weighted them by the inverse of the variance of the log rate ratio. We used intention-to-treat or 'full analysis set' analyses when they were reported (i.e. analyses for which data had been imputed for participants who were randomly assigned but 
did not complete the study) instead of completer or per-protocol analyses.

For change in $\mathrm{FEV}_{1}$, we used $100 \mathrm{~mL}$ as the minimally important difference (MID). For SGRQ, the scale was measured from 0 to 100 , with higher scores indicating more limitations. A change in score of 4 units was considered as the MID.

We presented the data as forest plots when possible to show size and direction of effect for treatments with $95 \% \mathrm{Cls}$ (certainty) using Review Manager 5 (RevMan 2014).

When a single study reported multiple trial arms, we included only the relevant arms. We reported details of the additional arms in the Characteristics of included studies table. When two comparisons (e.g. intervention $A$ versus placebo and intervention $B$ versus placebo) are combined in the same meta-analysis, we will combine the active arms or will halve the control group to avoid doublecounting.

If adjusted analyses were available (ANOVA or ANCOVA), we used these as a preference in our meta-analyses. If both change from baseline and endpoint scores were available for continuous data, we used change from baseline unless there was low correlation between measurements among participants. If a study reported outcomes at multiple time points, we used the latest time point. If studies reported post-treatment follow-up, we extracted this information and reported it narratively.

\section{Unit of analysis issues}

For dichotomous outcomes, we used participants, rather than events, as the unit of analysis (e.g. number of participants experiencing an adverse event rather than the number of adverse events). However, if a study reported rate ratios, we analysed them on this basis.

\section{Dealing with missing data}

We contacted the respective pharmaceutical companies for missing trial data. In particular, Nycomed and Forest Laboratories provided us with some study details and results extracted from published articles and abstracts that were not identified in our initial search.

We contacted investigators or study sponsors to verify key study characteristics and to obtain missing numerical outcome data when possible (e.g. when a study was identified as an abstract only). When this was not possible, and missing data were thought to introduce serious bias, we took this into consideration when performing the GRADE assessment for affected outcomes.

\section{Assessment of heterogeneity}

We used the $I^{2}$ statistic, along with $P$ values (Higgins 2003), to measure heterogeneity among the trials in each analysis. For $\mathrm{I}^{2}$, we employed the following criteria.

- $0 \%$ to $40 \%$ : might not be important.

- $30 \%$ to $60 \%$ : may represent moderate heterogeneity.

- $50 \%$ to $90 \%$ : may represent substantial heterogeneity.

- $75 \%$ to $100 \%$ : considerable heterogeneity.

In the case of substantial heterogeneity, we reported it and explored possible causes by conducting pre-specified subgroup analysis.

\section{Assessment of reporting biases}

We compared available published outcomes with prescribed methods and, when available, original study protocols. If we were able to pool more than 10 studies, we created and examined a funnel plot to explore possible small-study and publication biases.

\section{Data synthesis}

We used a fixed-effect model and performed a sensitivity analysis by using a random-effects model.

\section{'Summary of findings' tables}

We assessed the certainty of evidence for change in FEV lung function, change in quality of life, COPD exacerbations, adverse events, diarrhoea, and all-cause mortality. We conducted assessments according to recommendations put forth by the GRADE Working Group (Guyatt 2008) and presented in Summary of findings 1 . We used the five GRADE considerations (risk of bias, consistency of effect, imprecision, indirectness, and publication bias) to assess the quality of a body of evidence related to studies that contributed data for the pre-specified outcomes. We used the methods and recommendations described in Higgins 2019, employing GRADEpro GDT software (GRADEpro GDT 2015). We justified all decisions to downgrade the certainty of evidence by using footnotes and made comments to aid the reader's understanding of the review when necessary. We applied the clinical importance of results using published minimal important differences (MIDs), when available (e.g. SGRQ has well-established MIDs in the literature).

\section{Subgroup analysis and investigation of heterogeneity}

We planned to carry out the following subgroup analyses.

- Severity of airflow obstruction at baseline $\left(\mathrm{FEV}_{1} \%\right.$ predicted GOLD grade II $50 \%$ to $80 \%$, grade III $30 \%$ to $50 \%$, grade IV $<30 \%$ ) (GOLD 2020).

- Drug (e.g. roflumilast, cilomilast).

- Dose (e.g. roflumilast $250 \mu \mathrm{g}$ or $500 \mu \mathrm{g})$.

- Duration of therapy ( $\leq 12$ weeks; 24 to 26 weeks; 52 weeks; > 52 weeks).

- Concomitant therapy (inhaled or oral corticosteroids, inhaled long-acting beta $_{2}$-agonists, or anticholinergics, or both).

We used the formal test for subgroup interactions in Review Manager 5 (RevMan 2014).

\section{Sensitivity analysis}

We planned to carry out the following sensitivity analyses, removing the following from the primary outcome analyses.

- Studies with high risk of bias in one or more domains.

We planned to compare results from a fixed-effect model by using a random-effects model.

We did not anticipate the large number of unpublished trials at the protocol stage. Consequently, we undertook a sensitivity analysis of effect sizes for the primary outcomes reported in published and unpublished trials. 


\section{RESULTS}

\section{Description of studies}

\section{Results of the search}

See Figure 1 for study flow diagram (Moher 2009).

\section{Figure 1. Flow diagram.}

37 studies
included in
previous versions
of review (2011,
2013 , and 2016)

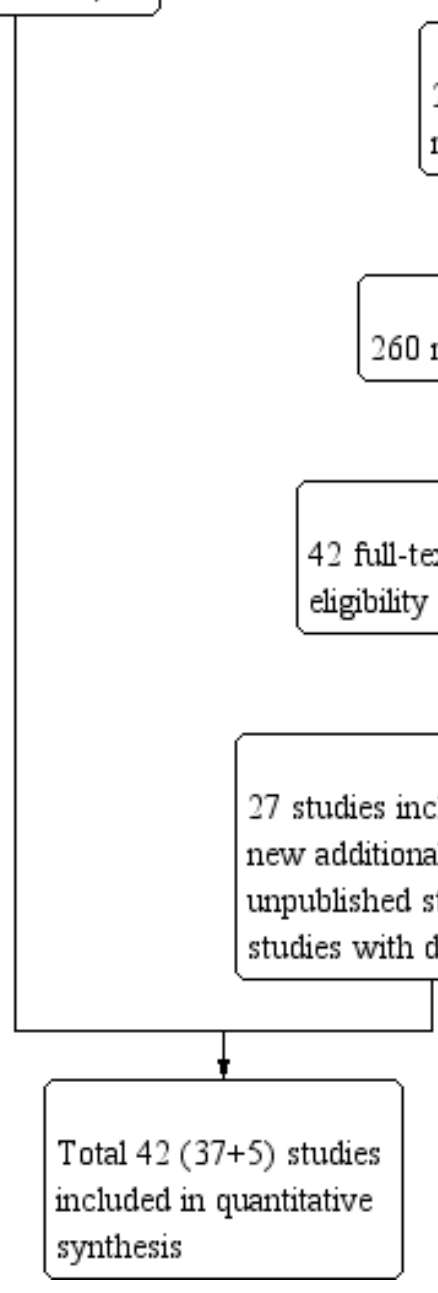

From the previous updates (2011 to 2016), 37 studies were included in the review (reference to 2011, 2013, and 2016 reviews). From the current database update search (2016-2020), 261 abstracts were identified, one of which was a duplicate and was removed. Full texts for 42 relevant references were assessed further for inclusion (Table 1). Of 27 references that were selected for inclusion, 18 references were new additional references to already included studies, one of which was a new additional reference to an ongoing study that had already been identified previously. Four unpublished trials met the inclusion criteria; however, the data for these trials were not available (NCT01595750; NCT00671073; NCT01701934; EUCTR2004-004442-40-GB). Five new trials were identified that met the inclusion criteria and were included in the analyses (Kavitha 2018; Liu 2018; NCT00874497 (EMPHASIS); RO-2455-402RD (ROBERT); Urban 2018 (ELASTIC)).

\section{Included studies}

Details of the 42 studies included in this review are described in detail in the Characteristics of included studies section. 
Of the 42 studies, 27 studies examined roflumilast (COPD safety pool; Kavitha 2018; Liu 2018; RO-2455-301-RD (ACROSS); RO-2455-402-RD (ROBERT); RO-2455-404-RD (REACT); Roflumilast DAL-MD-01; Roflumilast FK1 101; Roflumilast FK1 103; Roflumilast FLUI-2011-77; Roflumilast IN-108; Roflumilast JP-706; Roflumilast M2-107; Roflumilast M2-110; Roflumilast M2-111; Roflumilast M2-111+M2-112; Roflumilast M2-112; Roflumilast M2-118; Roflumilast M2-119; Roflumilast M2-121; Roflumilast M2-124; Roflumilast M2-124+M2-125; Roflumilast M2-125; Roflumilast M2-127; Roflumilast M2-128; Roflumilast ROF-MD-07(RE2SPOND); Urban 2018 (ELASTIC)), 14 trials studied cilomilast (Cilomilast 039; Cilomilast 042; Cilomilast 076; Cilomilast 091; Cilomilast 103657; Cilomilast 110; Cilomilast 111; Cilomilast 121; Cilomilast 156; Cilomilast 157; Cilomilast 168; Cilomilast 180; Cilomilast 181; Compton 2001), and one trial explored the use of tetomilast (NCT00874497 (EMPHASIS)).

Most of the roflumilast trials were funded by pharmaceutical companies including AstraZeneca and GlaxoSmithKline. Three trials did not report funding information (Kavitha 2018; Liu 2018; Roflumilast FK1 103). One study was funded by Ludwig Boltzmann Institute (Urban 2018 (ELASTIC)). All cilomilast studies were funded by GlaxoSmithKline, and one tetomilast study was funded by Otsuka Pharmaceutical Development \& Commercialization, Inc (NCT00874497 (EMPHASIS)).

Almost all studies used inclusion criteria of spirometry and a history of smoking. Only 6 of the 39 studies mandated a history of exacerbation in the previous year (Cilomilast 103657; Cilomilast 121; NCT00874497 (EMPHASIS); Roflumilast M2-124; Roflumilast M2-125; Urban 2018 (ELASTIC)).

The mean age of participants in these trials ranged from 60 to 70 years, with the proportion of male participants between $49 \%$ and $96 \%$. Mean FEV 1 (\% predicted) in trials that reported it ranged from $33 \%$ to $51 \%$. Most trials included participants at all stages of COPD; however limitation to those with severe and very severe COPD occurred in RO-2455-301-RD (ACROSS), RO-2455-404-RD (REACT), Roflumilast DAL-MD-01, Roflumilast M2-111, Roflumilast M2-112, Roflumilast M2-124, Roflumilast M2-125, and Roflumilast ROFMD-07(RE2SPOND).

\section{Roflumilast studies}

Most of the trials were designed as randomised, double-blind, placebo-controlled studies, apart from Urban 2018 (ELASTIC), which was triple-blinded, and Kavitha 2018, which was assumed to have no blinding. All studies before 2013, apart from Roflumilast JP-706, were included in combined safety figures for roflumilast that have been made available through publications on the FDA website (https://www.accessdata.fda.gov/drugsatfda_docs/ nda/2011/0225220rig1s000MedR.pdf). Combined safety figures also include participants in two other 24-week studies (Roflumilast M2-110; Roflumilast M2-121), for which results have not been published (roflumilast $500 \mu \mathrm{g}$ : 5970; roflumilast $250 \mu \mathrm{g}$ : 1002; placebo: 5682).

All studies compared $500 \mu \mathrm{g}$ of roflumilast in the intervention group with placebo, with the exception of one study, which was an early-dose selection study comparing participants who were given roflumilast $250 \mu \mathrm{g}$ and $500 \mu \mathrm{g}$ for 24 weeks (Roflumilast M2-107). The duration of roflumilast treatment in studies ranged from 12 to 52 weeks.
The history of roflumilast studies can be explained in order of publication. The first published $\mathrm{PDE}_{4}$ inhibitor study for COPD treatment was 52 weeks in duration and allowed concomitant corticosteroid use (Roflumilast M2-112). Subsequently, results of a replicate study were published (Roflumilast M2-111). Another two studies were completed that investigated the effects of roflumilast for 52 weeks in participants with severe to very severe COPD with associated chronic bronchitis who were at risk of exacerbations (Roflumilast M2-124; Roflumilast M2-125).

Two studies evaluated the add-on use of roflumilast with longacting bronchodilator agents (Roflumilast M2-127; Roflumilast M2-128), the first with salmeterol and the second with tiotropium. Both studies ran for 24 weeks. A further two studies - RO-2455-404RD (REACT) and Roflumilast ROF-MD-07(RE2SPOND) - added roflumilast or placebo to a fixed-dose ICS/LABA combination. Roflumilast M2-118 was a 12-week study that focused on airway physiology during rest and exercise in participants with moderate to severe disease. Roflumilast M2-119 investigated pulmonary function and safety in a group of participants recruited at centres across the Asia-Pacific regions. Roflumilast DAL-MD-01 was mainly aimed at investigating effects on sputum and other biomarkers. Roflumilast FLUI-2011-77 explored the airway architecture using imaging techniques.

Three more large RCTs were completed - RO-2455-301RD (ACROSS), RO-2455-404-RD (REACT), and Roflumilast ROFMD-07(RE2SPOND). RO-2455-301-RD (ACROSS) was carried out across three centres in mainland China, Hong Kong, and Singapore and investigated the effects and safety of roflumilast over 24 weeks. Both RO-2455-404-RD (REACT) and Roflumilast ROFMD-07(RE2SPOND) were 52-week multi-centre trials investigating effects on rates of moderate and severe exacerbations.

Four additional trials were completed in 2017 and 2018 Kavitha 2018, Liu 2018 RO-2455-402-RD (ROBERT), RO-2455-402-RD (ROBERT), and Urban 2018 (ELASTIC). RO-2455-402-RD (ROBERT) was a multi-centre study carried out across Denmark, Germany, Poland, Sweden, and United Kingdom for 16 weeks. The primary aim of this study was to investigate effects on inflammatory markers and changes in lung function. Urban 2018 (ELASTIC) was an Austrian study carried out over 26 weeks, primarily to assess effects of subclinical atherosclerosis and markers of inflammation, but also lung function, exercise, and health impact, in participants with stable COPD. Kavitha 2018, a 12-week single-centre study in India investigating effects of roflumilast on change in pulmonary function of participants with moderate to severe disease taking a combined LABA and tiotropium metered-dose inhaler. Liu 2018 was a 52-week single-centre study in China that primarily investigated change in lung function among participants with moderate to severe disease.

Two trials were reported only as conference posters: Roflumilast FK1 101 and Roflumilast FK1 103. The first compared roflumilast $500 \mu \mathrm{g}$, roflumilast $250 \mu \mathrm{g}$, and placebo for 26 weeks; the second compared roflumilast $500 \mu \mathrm{g}$ once daily for 24 weeks with roflumilast $500 \mu \mathrm{g}$ once daily for 12 weeks, then with placebo once daily for the following 12 weeks.

Unpublished results were identified for two other studies: Roflumilast IN-108 compared the safety and efficacy of roflumilast $250 \mu \mathrm{g}$ and $500 \mu \mathrm{g}$ in participants recruited from five centres across India; however, no inclusion criteria were stated, concomitant 
medications were poorly described, and only 15 participants in the placebo group completed the protocol. Roflumilast JP-706 was a 24-week study sponsored by a different collaborator that, in addition to treatment effects, monitored pharmacokinetic levels of roflumilast and its metabolite roflumilast- $\mathrm{N}$-oxide.

In the three studies that compared $500 \mu \mathrm{g}$ or $250 \mu \mathrm{g}$ with placebo, the placebo group was halved to avoid double counting (Roflumilast FK1 101; Roflumilast IN-108; Roflumilast M2-107).

NCT02671942 2016 was identified as an ongoing trial - a Chinese study designed to assess whether altering the standard $500-\mu \mathrm{g}$ dose improved tolerability of roflumilast. NCT02451540 (reported as ongoing in the 2016 update) was carried out in Belgium to assess effects of roflumilast on lung function (as measured by functional respiratory imaging) in COPD patients taking LABA/LAMA therapy. This study was reported in the trials registry as being terminated early as no new investigational product could be delivered to the study site.

Further information for three unpublished trials could not be found upon contact with authors (NCT00671073; NCT01595750; NCT01701934).

\section{Cilomilast studies}

No new studies were identified for the current update.

Data were derived mainly from phase 3 clinical trials and from one phase 2/3 trial. These included unpublished studies. All used a 15mg dose twice daily, except for Compton 2001.

Compton 2001 was a parallel, six-week, dose-ranging study comparing placebo with $5 \mathrm{mg}, 10 \mathrm{mg}$, and $15 \mathrm{mg}$ of cilomilast, with $\mathrm{FEV}_{1}$ as the primary outcome. Pivotal efficacy studies included Cilomilast 039, Cilomilast 042, Cilomilast 091, and Cilomilast 156, all of which were 24 weeks in duration. Cilomilast 121 (phase 2/3, 24 weeks), Cilomilast 157 (52 weeks), and Cilomilast 103657 (24 weeks) followed the pivotal efficacy studies and were smaller in sample size.
Cilomilast 039 and Cilomilast 156 were conducted in North America, and Cilomilast 042 and Cilomilast 091 were conducted in the European Union. Here, primary study outcomes were change in $\mathrm{FEV}_{1}$, lung function, and SGRQ quality of life score. Cilomilast 076, Cilomilast 110 , Cilomilast 111 , and Cilomilast 168 were supporting studies, all of which lasted less than 24 weeks, with average trial duration of 10.8 weeks, for which neither FEV ${ }_{1}$ lung function nor SGRQ was the primary outcome. Cilomilast 180 (18 weeks) had a primary lung function endpoint - functional residual capacity; Cilomilast 181 (13 weeks) assessed the number of inflammatory cells in a bronchial biopsy.

\section{Tetomilast studies}

One new tetomilast study was identified - a phase 2a multicentre, randomised, double-blind, placebo-controlled study that assessed efficacy and safety in patients with emphysema who had at least one previous exacerbation (NCT00874497 (EMPHASIS)). Study duration was 104 weeks, and the dose of tetomilast was $50 \mu \mathrm{g}$. The primary outcome was change in $\mathrm{FEV}_{1}$ (NCT00874497 (EMPHASIS)).

One unpublished study on oglemilast was identified by the search (NCT00671073); however, no further information could be obtained from trial authors on contact.

\section{Excluded studies}

We excluded 15 additional references from the 2020 update at fulltext review, as they did not meet the inclusion criteria. We have provided reasons for exclusion of these 15 studies (see Excluded studies).

\section{Risk of bias in included studies}

An overview of risk of bias in individual studies is provided in Figure 2; support for judgements for individual studies is provided under Characteristics of included studies. 
Figure 2. Methodological quality summary: review authors' judgements about each methodological quality item for each included study.

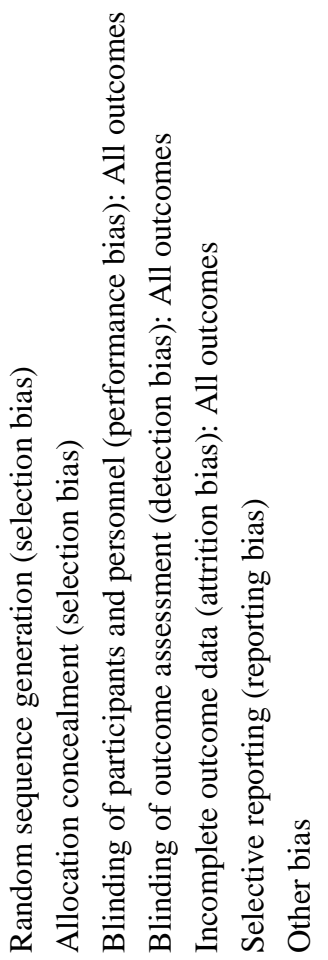

Cilomilast 039

Cilomilast 042

Cilomilast 076

Cilomilast 091

Cilomilast 103657

Cilomilast 110

Cilomilast 111

Cilomilast 121

Cilomilast 156

Cilomilast 157

Cilomilast 168

Cilomilast 180

Cilomilast 181

Compton 2001

COPD safety pool

Kavitha 2018

Liu 2018

NCT00874497 (EMPHASIS)

RO-2455-301-RD (ACROSS)

RO-2455-402-RD (ROBERT)

RO-2455-404-RD (REACT)

Roflumilast DAL-MD-01

Roflumilast FK1 101
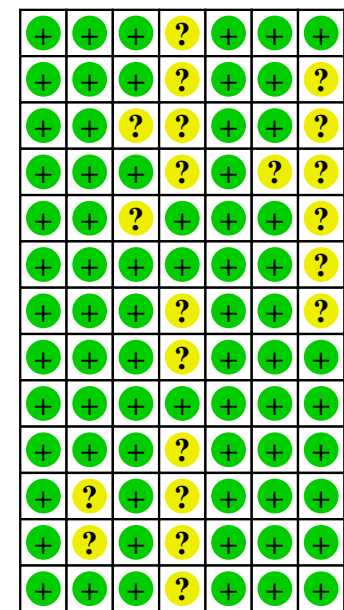
Figure 2. (Continued)

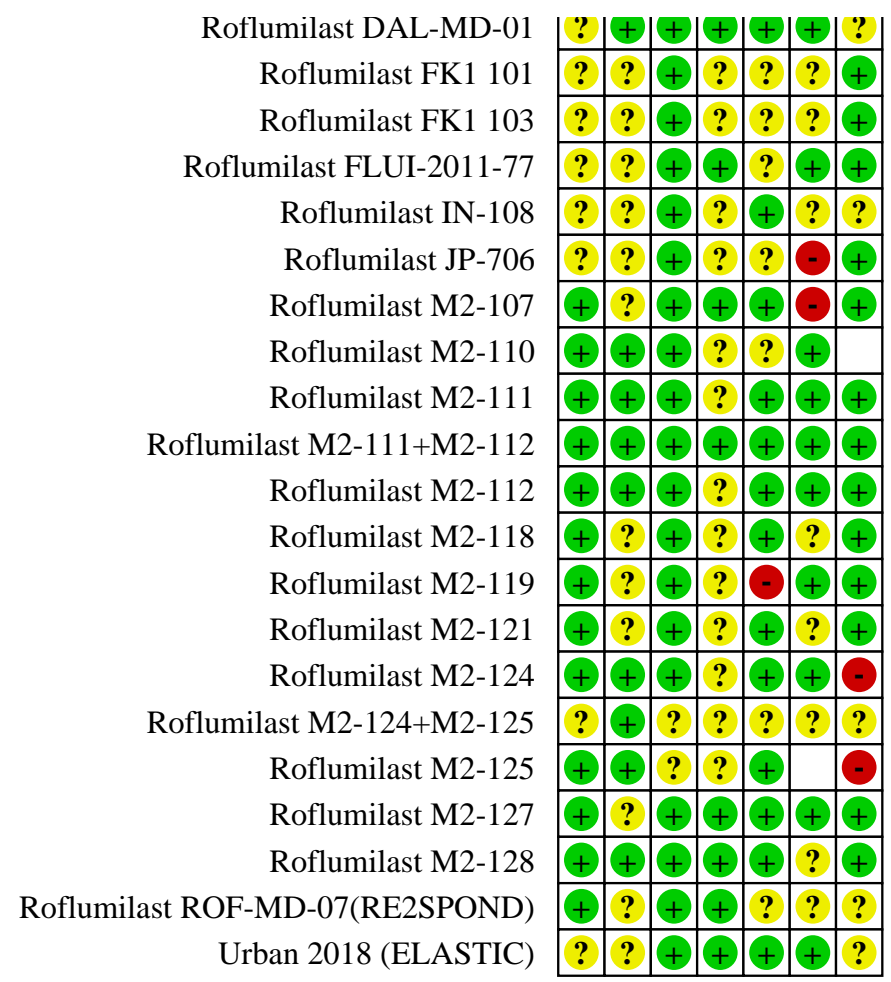

\section{Allocation}

We assessed 12 out of 24 roflumilast studies as having low risk of bias for allocation concealment. Information about allocation concealment for cilomilast studies was limited in publications, but we have considered that this is unlikely to be a source of bias because these studies were sponsored, and standard methods would have been used to minimise the risk of selection bias. We therefore judged the risk of selection bias as low, although allocation concealment is marked as unclear in many of these studies. We considered the only study for tetomilast as having low risk of bias for this domain.

\section{Blinding}

All studies included in this review were double-blind RCTs, with the exception of Kavitha 2018, which failed to report blinding. We regarded overall risk of performance bias and detection bias as low.

\section{Incomplete outcome data}

The rate of withdrawal and dropout was reported in 28 of the 39 studies and was generally less than $20 \%$ for randomly assigned participants. However, two studies reported higher rates of attrition (NCT00874497 (EMPHASIS); Roflumilast M2-119). NCT00874497 (EMPHASIS) reported that $54 \%$ of participants in both tetomilast and placebo groups did not complete treatments. In addition, five more participants in the tetomilast group than in the placebo group discontinued treatment due to adverse events. Similarly, in Roflumilast M2-119, more participants in the roflumilast group than in the placebo group discontinued ( $20 \%$ versus $8 \%$ ). We judged these two studies to be at high risk of bias. We judged the remaining nine studies as having unclear risk of bias due to lack of information about the flow of participants throughout the duration of these studies.

\section{Selective reporting}

We identified 27 published and 12 unpublished trials. We performed analyses of differences in treatment effect between published and unpublished treatment groups for primary outcomes and reported this information in the subgroup and sensitivity analyses below.

\section{Other potential sources of bias}

We did not consider sponsorship as necessarily increasing the risk of bias when studies were well designed.

For some trials, we noted minor differences in baseline characteristics such as age, gender, $\mathrm{FEV}_{1}$, and smoking history.

\section{Effects of interventions}

See: Summary of findings 1 Phosphodiesterase- 4 inhibitors compared to placebo for chronic obstructive pulmonary disease

\section{Primary outcomes}

\section{Change in FEV,}

We included 32 studies in the main analysis (participants = 20,815). Eighteen studies compared roflumilast $500 \mu \mathrm{g}$ with placebo (RO-2455-301-RD (ACROSS); RO-2455-402-RD (ROBERT); RO-2455-404-RD (REACT); Roflumilast DAL-MD-01; Roflumilast FK1 101; Roflumilast FK1 103; Roflumilast FLUI-2011-77; Roflumilast IN-108; Roflumilast M2-107; Roflumilast M2-111; 
Roflumilast M2-112; Roflumilast M2-118; Roflumilast M2-119; Roflumilast M2-124; Roflumilast M2-125; Roflumilast M2-127; Roflumilast M2-128; Roflumilast ROF-MD-07(RE2SPOND), three studies compared roflumilast $250 \mu \mathrm{g}$ with placebo (Roflumilast FK 1 101; Roflumilast IN-108; Roflumilast M2-107), 10 studies compared cilomilast $15 \mathrm{mg}$ with placebo (Cilomilast 039; Cilomilast 042; Cilomilast 076; Cilomilast 091; Cilomilast 103657; Cilomilast 110; Cilomilast 121; Cilomilast 156; Cilomilast 157; Compton 2001), and one study compared tetomilast $50 \mu \mathrm{g}$ with placebo (NCT00874497 (EMPHASIS)).

For RO-2455-402-RD (ROBERT), we calculated standard deviations (SDs) using the RevMan calculator and the number of participants in each treatment group. We did not have change from baseline data for each treatment group; therefore, we used the reported mean difference value between groups (0.063) as the MD for the roflumilast group and an MD of zero for the placebo group.

Urban 2018 (ELASTIC) was not included in the meta-analysis as the data were skewed and were analysed on a log-scale as a percentage difference. Similarly, Liu 2018 could not be included in the analysis because reporting of standard errors was unclear, and we received no further correspondence from trial authors on request. Kavitha 2018 reported the outcome separately as endpoint data.

\section{Main analysis}

Note that an increase in $\mathrm{FEV}_{1}$ represents an improvement in lung function.

Based on the 32 trials that reported this outcome, results showed improvement in $\mathrm{FEV}_{1}$ from baseline among $\mathrm{PDE}_{4}$ inhibitor-treated participants compared with controls at a mean of 40.17 weeks' duration (mean difference (MD) $49.33 \mathrm{~mL}, 95 \%$ confidence interval (CI) 44.17 to 54.49; participants $=20,815$; studies $=32 ; \mathrm{I}^{2}=45 \%$; moderate-certainty evidence) (Analysis 1.1; Figure 3; Summary of findings 1). Effects on $\mathrm{FEV}_{1}$ with $500 \mu \mathrm{g}$ or $250 \mu \mathrm{g}$ roflumilast, respectively, were improved (roflumilast $500 \mu \mathrm{g}$ : MD $55.18 \mathrm{~mL}, 95 \%$ $\mathrm{Cl} 48.65$ to 61.71 ; participants $=14,384$; studies $=18 ; \mathrm{I}^{2}=21 \%$; studies $=17 ; \mathrm{I}^{2}=26 \%$ ) (roflumilast $250 \mu \mathrm{g}$ : MD $56.88 \mathrm{~mL}, 95 \% \mathrm{Cl}$ 24.38 to 89.38 ; participants $=1033$; studies $=3 ; I^{2}=0 \%$ ). Similar improvement was observed with cilomilast $15 \mathrm{mg}$ (MD $38.15 \mathrm{~mL}$, $95 \% \mathrm{Cl} 29.41$ to 46.90 ; participants $=5322$; studies $=10 ; \mathrm{I}^{2}=62 \%$ ). There was only one small study, with wide uncertainty about effects with tetomilast (MD $82.00 \mathrm{~mL}, 95 \% \mathrm{Cl}-50.84$ to 214.84 ; participants = 76) (Analysis 1.1). 
Figure 3. Forest plot of comparison: $1 \mathrm{PDE}_{4}$ inhibitor versus placebo (2020 update), outcome: $1.1 \mathrm{FEV}_{1}$ (by drug) $[\mathrm{mL}]$.

\begin{tabular}{|c|c|c|c|c|c|c|c|c|}
\hline & PDE4i treatmen & & & lacebo & & & Mean Difference & Mean Difference \\
\hline Study or Subgroup & $\operatorname{Mean}[\mathrm{mL}] \quad$ SD $[\mathrm{mL}]$ & Total & Mean $[\mathrm{mL}]$ & $\mathrm{SD}[\mathrm{mL}]$ & Total & Weight & IV, Fixed, 95\% CI [mL] & IV, Fixed, 95\% CI $[\mathrm{mL}]$ \\
\hline
\end{tabular}

1.1.1 Tetomilast $50 \mu \mathrm{g}$

NCT00874497 (EMPHASIS)

Subtotal (95\% CI)

Heterogeneity: Not applicable

Test for overall effect: $\mathrm{Z}=1.21(\mathrm{P}=0.23)$

\subsubsection{Roflumilast $500 \mu \mathrm{g}$}

RO-2455-301-RD (ACROSS)

RO-2455-402-RD (ROBERT) (1)

RO-2455-404-RD (REACT)

Roflumilast DAL-MD-01

Roflumilast FK1 101 (2)

Roflumilast FK1 103

Roflumilast FLUI-2011-77

Roflumilast IN-108 (2)

Roflumilast M2-107 (2)

Roflumilast M2-111

Roflumilast M2-112

Roflumilast M2-118

Roflumilast M2-119

Roflumilast M2-124

Roflumilast M2-125

Roflumilast M2-127

Roflumilast M2-128

Roflumilast ROF-MD-07(RE2SPOND)

Subtotal (95\% CI)

Heterogeneity: $\mathrm{Chi}^{2}=21.53, \mathrm{df}=17(\mathrm{P}=0.20) ; \mathrm{I}^{2}=21 \%$

Test for overall effect: $\mathrm{Z}=16.56(\mathrm{P}<0.00001)$

\subsubsection{Roflumilast $250 \mu \mathrm{g}$}

Roflumilast FK1 101 (2)

Roflumilast IN-108 (2)

Roflumilast M2-107 (2)

$-1201.1$

$\begin{array}{lllll}48 & -83 & 324.1 & 28 & 0.2 \% \\ \mathbf{4 8} & & & \mathbf{2 8} & \mathbf{0 . 2 \%}\end{array}$

$82.00[-50.84,214.84]$

$82.00[-50.84,214.84]$

Subtotal (95\% CI)

Heterogeneity: $\mathrm{Chi}^{2}=1.08, \mathrm{df}=2(\mathrm{P}=0.58) ; \mathrm{I}^{2}=0 \%$

Test for overall effect: $\mathrm{Z}=3.43(\mathrm{P}=0.0006)$

\subsubsection{Cilomilast $15 \mathrm{mg}$}

\section{Cilomilast 039}

Cilomilast 042

Cilomilast 076

Cilomilast 091

Cilomilast 103657

Cilomilast 110

Cilomilast 121

Cilomilast 156

Cilomilast 157

Compton 2001

Subtotal (95\% CI)

Heterogeneity: $\mathrm{Chi}^{2}=23.75, \mathrm{df}=9(\mathrm{P}=0.005) ; \mathrm{I}^{2}=62 \%$

Test for overall effect: $\mathrm{Z}=8.55(\mathrm{P}<0.00001)$

Total (95\% CI)

Heterogeneity: $\mathrm{Chi}^{2}=56.15, \mathrm{df}=31(\mathrm{P}=0.004) ; \mathrm{I}^{2}=45 \%$

$\begin{array}{rrr}49 & 159.5692 & 313 \\ 63 & 861 & 77 \\ 52 & 194.9638 & 928 \\ 41 & 91 & 11 \\ 09 & 273 & 169 \\ 78 & 240 & 200 \\ 66 & 120 & 30 \\ 28 & 486 & 42 \\ 49 & 283 & 555 \\ 30 & 182 & 545 \\ 9 & 303 & 760 \\ 55 & 282 & 127 \\ 54 & 289 & 189 \\ 46 & 218 & 745 \\ 33 & 189 & 730 \\ 39 & 192 & 456 \\ 65 & 229 & 365 \\ 53 & 160.836 & 1178 \\ & & \mathbf{7 4 2 0}\end{array}$

$\begin{array}{rrrr}-22 & 159.5692 & 313 & 4.3 \% \\ 0 & 861 & 77 & 0.0 \% \\ -4 & 196.3246 & 941 & 8.5 \% \\ 28 & 250 & 16 & 0.1 \% \\ 57 & 213 & 86 & 0.7 \% \\ 39 & 245 & 186 & 1.1 \% \\ -59 & 71 & 11 & 0.7 \% \\ -124 & 281 & 12 & 0.1 \% \\ -39 & 189 & 140 & 1.7 \% \\ -12 & 178 & 596 & 6.1 \% \\ -27 & 302 & 753 & 2.9 \% \\ -27 & 311 & 123 & 0.5 \% \\ -42 & 298 & 201 & 0.8 \% \\ 8 & 218 & 745 & 5.4 \% \\ -25 & 194 & 766 & 7.1 \% \\ -10 & 193 & 460 & 4.3 \% \\ -16 & 229 & 364 & 2.4 \% \\ 0 & 160.836 & 1174 & 15.8 \% \\ & & \mathbf{6 9 6 4} & \mathbf{6 2 . 5 \%}\end{array}$

$71.00[46.00,96.00]$ $63.00[-208.97,334.97]$ $56.00[38.26,73.74]$ $13.00[-120.78,146.78]$ $52.00[-9.00,113.00]$ $39.00[-9.44,87.44]$ $125.00[64.96,185.04]$ $152.00[-64.52,368.52]$ $88.00[48.83,127.17]$ $42.00[21.08,62.92]$ $36.00[5.52,66.48]$ $82.00[8.34,155.66]$ $96.00[37.74,154.26]$ $38.00[15.86,60.14]$

$58.00[38.59,77.41]$ $49.00[24.07,73.93]$ $81.00[47.75,114.25]$ $53.00[40.00,66.00]$ $55.18[48.65,61.71]$

$36.00[-24.52,96.52]$ $137.00[-79.38,353.38]$ $63.00[23.84,102.16]$ $56.88[24.38,89.38]$

$40.00[12.30,67.70]$ $30.00[-13.04,73.04]$ $20.00[-90.83,130.83]$ $30.00[-25.40,85.40]$ $44.00[30.13,57.87]$ $70.00[-40.92,180.92]$ $20.00[-3.93,43.93]$ $24.00[1.82,46.18]$ $34.00[7.70,60.30]$ $160.00[104.53,215.47]$ 38.15 [29.41 , 46.90]

11330 $9485100.0 \%$ $49.33[44.17,54.49]$ Test for overall effect: $Z=18.73(\mathrm{P}<0.00001)$

Test for subgroup differences: $\mathrm{Chi}^{2}=9.80, \mathrm{df}=3(\mathrm{P}=0.02), \mathrm{I}^{2}=69.4 \%$

Fixed, 95\% CI [mL]

\section{Footnotes}

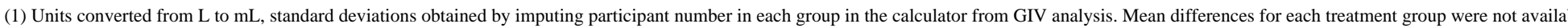

(2) The participant number in the placebo group was halved to avoid double counting 
Moderate and high levels of heterogeneity seen amongst roflumilast $500 \mu \mathrm{g}$ and cilomilast studies, respectively, can be explained in part by investigation of differences between these two $\mathrm{PDE}_{4}$ inhibitors (for subgroup analyses, see below).

We investigated publication bias amongst the studies included in the analysis (Figure 4). Four studies were outliers and were

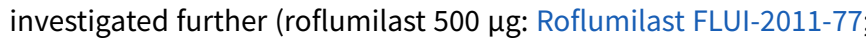
Roflumilast IN-108; roflumilast $250 \mu \mathrm{g}$ : Roflumilast IN-108; cilomilast $15 \mathrm{mg}$ : Compton 2001). These studies were small in population size and contributed very little weight to the overall analysis. In addition, removing these studies from the sensitivity analysis did not have a large impact on the overall effect estimate. We did not downgrade the outcome in our GRADE assessment for this reason (Summary of findings 1 ).

\section{Studies not included in the main analysis}

Kavitha 2018 reported $\mathrm{FEV}_{1}$ at endpoint but did not report the units. It is unclear whether the outcome was reported as litres or millilitres, and trial authors reported much greater improvement compared to authors of another study, which reported improvement of $60 \mathrm{~mL}$ (see Kavitha 2018 risk of bias assessment for explanation). Trial authors did not respond when contacted for further information.

\section{Change in FVC from baseline}

We included 17 trials in the analysis (Cilomilast 039; Cilomilast 042; Cilomilast 091; Cilomilast 103657; Cilomilast 156; Compton 2001; RO-2455-301-RD (ACROSS); RO-2455-402-RD (ROBERT); RO-2455-404-RD (REACT); Roflumilast M2-107; Roflumilast M2-112; Roflumilast M2-119; Roflumilast M2-124; Roflumilast M2-125; Roflumilast M2-127; Roflumilast M2-128; Roflumilast ROFMD-07(RE2SPOND)).

Treatment with $\mathrm{PDE}_{4}$ inhibitor was associated with greater change in FVC from baseline compared to placebo (MD 86.98, 95\% Cl 74.65 to 99.31 ; participants $=22,108$; studies $=17 ; I^{2}=0 \%$; high-certainty evidence) with no heterogeneity amongst the 17 trials (Analysis 1.2; Summary of findings 1 ).

\section{Studies not included in the main analysis}

Kavitha 2018 reported FVC at endpoint but did not report the units. It is unclear whether the outcome was reported as litres or millilitres; therefore, we did not include this study in the analysis. Trial authors did not respond when contacted for further information.

\section{Change in PEF from baseline}

We included six studies in the analysis (Compton 2001; Roflumilast

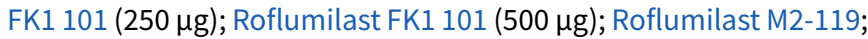
Roflumilast M2-124; Roflumilast M2-125). Roflumilast FK1 101 compared one placebo group with roflumilast $250 \mu \mathrm{g}$ or $500 \mu \mathrm{g}$; therefore, the number of participants in the placebo group was halved to avoid double counting, and the study was added to the analysis twice to represent higher and lower doses of roflumilast.

Change in PEF was greater with roflumilast treatment overall than with placebo (MD $6.54 \mathrm{~L} / \mathrm{min}, 95 \% \mathrm{Cl} 3.95$ to 9.13; participants $=4245 ;$ studies $=6 ; I^{2}=74$; low-certainty evidence) (Analysis 1.3; Summary of findings 1 ). On further analysis of doses, we noted improvement in PEF with roflumilast $500 \mu \mathrm{g}$ but not with roflumilast $250 \mu \mathrm{g}$ when compared with placebo. Upon further investigation, when Compton 2001 was taken out of the analysis, the heterogeneity was zero.

\section{Change in quality of life}

\section{St George's Respiratory Questionnaire (SGRQ)}

Note that a decrease in SGRQ total score represents improvement in quality of life.

We included 12 studies in the analysis for this outcome (participants $=7645$ ) $($ Cilomilast 039; Cilomilast 042; Cilomilast 091; Cilomilast 103657; Cilomilast 121; Cilomilast 156; Cilomilast 157; Compton 2001; Roflumilast DAL-MD-01; Roflumilast M2-107 (250 $\mu \mathrm{g})$; Roflumilast M2-107 (500 $\mu \mathrm{g})$; Roflumilast M2-112).

Roflumilast M2-107 reported data for $250 \mu \mathrm{g}$ and for $500 \mu \mathrm{g}$ roflumilast compared to one placebo group; therefore, the number of participants in the placebo group was halved to avoid double counting, and the study was included in the analysis twice (Analysis 1.4).

We noted a small decrease in total score on the SGRQ from baseline to mean 33 weeks' duration among participants treated with $\mathrm{PDE}_{4}$ inhibitors compared with those given the control intervention (MD -1.06 units, $95 \% \mathrm{Cl}-1.68$ to -0.43 ; participants $=7645$; studies $=$ $13 ; I^{2}=47 \%$; moderate-certainty evidence (Analysis 1.4; Figure 5; Summary of findings 1). Moderate levels of heterogeneity amongst roflumilast and cilomilast studies can be explained further by subgroup analysis (see below). 
Figure 5. Forest plot of comparison: $1 \mathrm{PDE}_{4}$ inhibitor versus placebo (2020 update), outcome: 1.4 SGRQ total score.

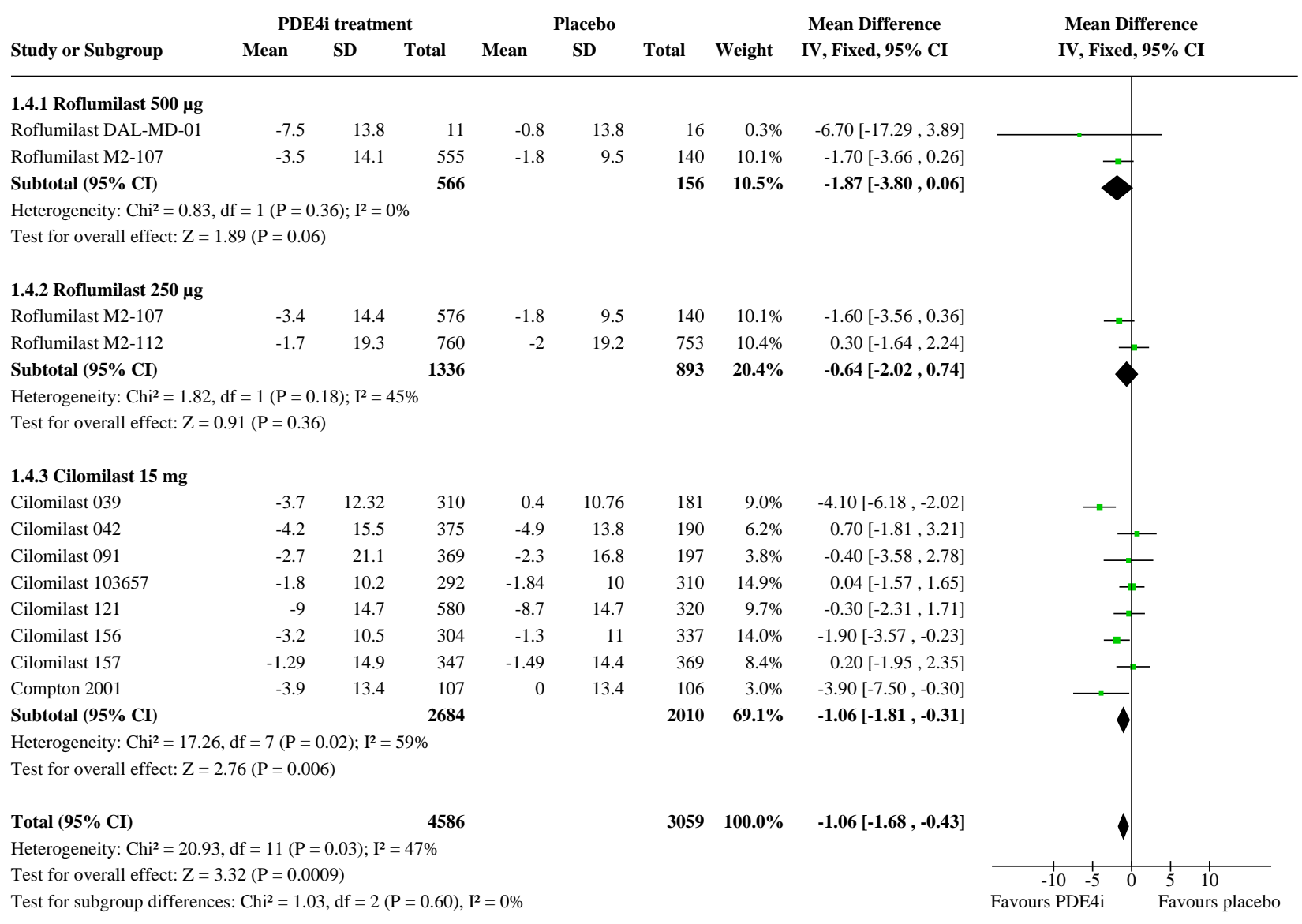

Improvement in symptoms (reported as SGRQ symptom score) was uncertain amongst two studies (Roflumilast M2-107; Compton 2001) (MD -1.53 units, $95 \% \mathrm{Cl}-4.11$ to 1.06 ; participants = 1048; studies = 2; Analysis 1.5).

We did not include outcome data for Roflumilast M2-111, as data were provided in the form of a 'repeated measures analysis', and pooled data did not equal the sum of numbers in each of the individual studies. Liu 2018 was also not included in the analysis due to unclear reporting of standard errors and no response from trial authors.

\section{Secondary outcomes}

\section{Incidence of COPD exacerbations}

We included 27 trials in the analysis (participants = 20,382) (Cilomilast 039; Cilomilast 042; Cilomilast 076; Cilomilast 091; Cilomilast 111; Cilomilast 121; Cilomilast 156; Cilomilast 157; Cilomilast 168; Cilomilast 180; Liu 2018; NCT00874497 (EMPHASIS); RO-2455-301-RD (ACROSS); RO-2455-402-RD (ROBERT); RO-2455-404-RD (REACT); Roflumilast
FK1 101 (500 $\mu \mathrm{g})$; Roflumilast IN-108; Roflumilast JP-706; Roflumilast M2-107; Roflumilast M2-111+M2-112; Roflumilast M2-119; Roflumilast M2-124; Roflumilast M2-125; Roflumilast M2-127; Roflumilast M2-128; Roflumilast ROF-MD-07(RE2SPOND); Urban 2018 (ELASTIC); .

Use of $\mathrm{PDE}_{4}$ inhibitors was associated with a reduction in the numbers of participants experiencing one or more COPD exacerbations at a mean duration of 40 weeks (odds ratio (OR) $0.78,95 \% \mathrm{Cl} 0.73$ to 0.84 ; high-certainty evidence; Analysis 1.6 ; Summary of findings 1 ). This is a relative reduction of more than $20 \%$ from a representative risk of 33 per 100 on placebo to 27 per 100 on $\mathrm{PDE}_{4}$ inhibitors over a weighted mean of 40 weeks (Summary of findings 1 ), and the number needed to treat for an additional beneficial outcome (NNTB) was 20 ( $95 \% \mathrm{Cl} 16$ to 27 ) (Figure 6). There was little heterogeneity among trials $\left(\mathrm{I}^{2}=6 \%\right)$, and a reduction in people experiencing COPD exacerbations was seen with both roflumilast and cilomilast. Tetomilast revealed wide uncertainty about the number of participants experiencing one or more COPD exacerbations; only one study contributed to this result (Analysis 1.6). 
Figure 6. In the control group, 33 out of 100 people had an exacerbation of COPD over 40 weeks of treatment, compared to 27 (95\% Cl 26 to 29) out of 100 people in the active treatment group.

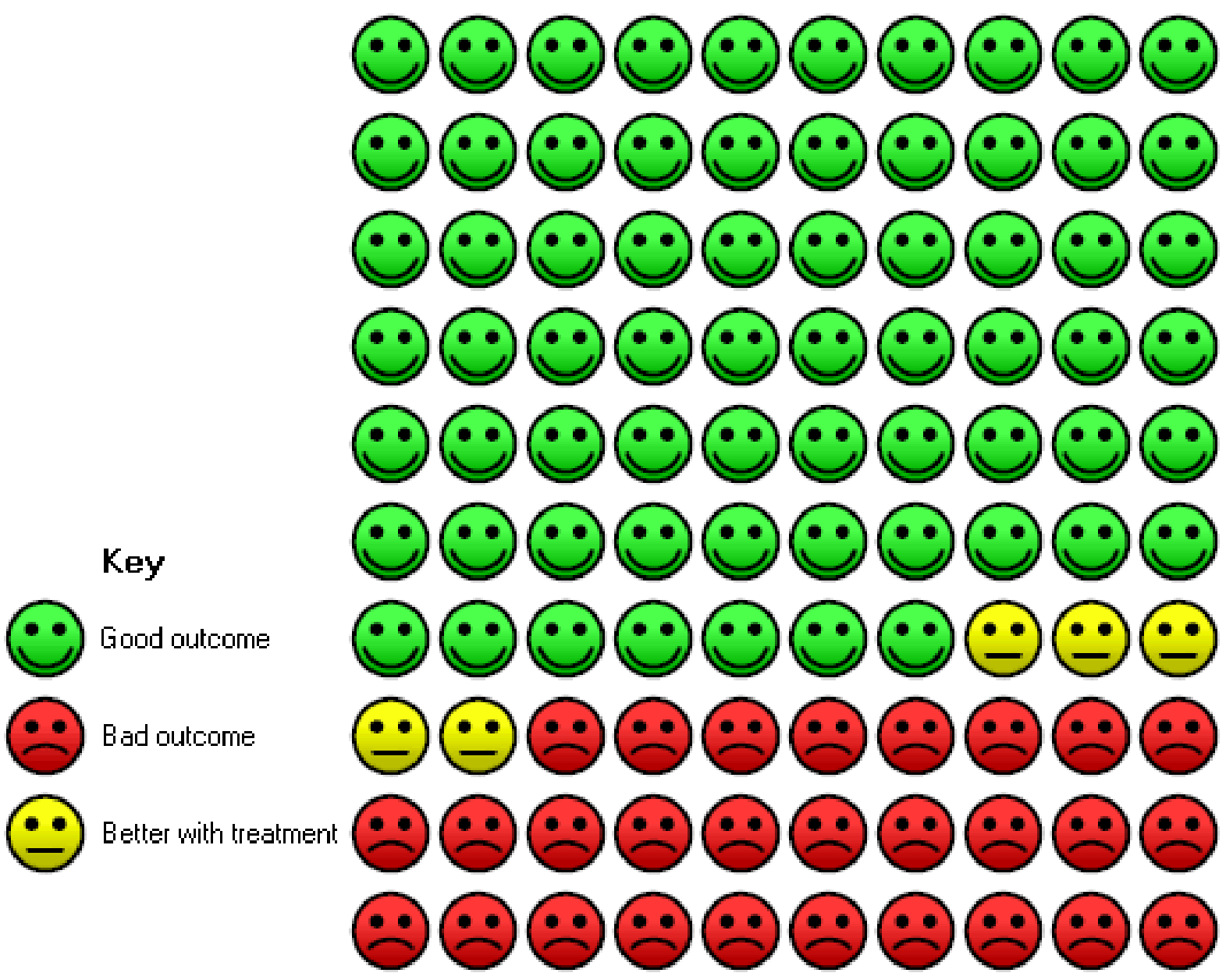

\section{Exacerbation rates}

Nine studies reported exacerbation rates and the number of exacerbations experienced on average per participant per year (Cilomilast 157; RO-2455-402-RD (ROBERT); Roflumilast M2-111; Roflumilast M2-112; Roflumilast M2-124; Roflumilast M2-125; Roflumilast M2-127; Roflumilast M2-128; Roflumilast ROFMD-07(RE2SPOND)) (Analysis 1.7). We observed a small benefit with treatment, representing a $12 \%$ reduction in the exacerbation rate $(0.88,95 \% \mathrm{Cl} 0.83$ to 0.93$)$.

Roflumilast FK1 101 reported that the probability of experiencing an exacerbation was reduced by $8 \%$ with $250 \mu \mathrm{g}$ of roflumilast and by $48 \%$ with $500 \mu \mathrm{g}$, although the absolute value was not reported and it was not stated whether this result was significant.

Four studies reported reduction in severe exacerbation rates per participant per year with $\mathrm{PDE}_{4}$ inhibitor compared with placebo (Cilomilast 039; RO-2455-404-RD (REACT); Roflumilast M2-124+M2-125; Roflumilast ROF-MD-07(RE2SPOND)). Cilomilast $15 \mathrm{mg}$ resulted in a $45 \%$ reduction in severe exacerbations $(P=$ 0.001) (Cilomilast 039). In studies using roflumilast $500 \mu \mathrm{g}$, the reduction in the rate of severe exacerbations ranged from $8.5 \%$ to $24.3 \%$ across studies (Table 2 ).

\section{Symptoms (breathlessness on Borg or other symptom scales)}

We included a total of 14 studies (participants $=10,701$ ) that reported results on the Borg Scale (Analysis 1.8), the Shortness of Breath Questionnaire (Analysis 1.9), the Summary Symptom Scale (Analysis 1.10), or the Breathlessness, Cough, and Sputum Scale (BCSS) (Analysis 1.11) (Borg Scale: Cilomilast 039; Cilomilast 042; Cilomilast 091; Cilomilast 111; Cilomilast 156; Cilomilast 180; Shortness of Breath Questionnaire: Roflumilast M2-127; Roflumilast M2-128; Summary Symptom Scale: Cilomilast 039; Cilomilast 042; Cilomilast 091; RO-2455-404-RD (REACT); Roflumilast ROF-MD-07(RE2SPOND); BCSS: NCT00874497 (EMPHASIS)).

Overall, the mean difference in change from baseline with $\mathrm{PDE}_{4}$ inhibitor treatment compared with the control intervention on COPD-related symptoms at mean duration of 21 weeks was small, regardless of the scale used to measure it. The only effect was seen in one trial of cilomilast - for breathlessness scored on a Borg Scale (MD - $0.19,95 \% \mathrm{Cl}-0.33$ to -0.05 ) (Analysis 1.8). This is a small absolute difference so is of doubtful clinical relevance. Results showed no difference with $\mathrm{PDE}_{4}$ inhibitor in effects on the Summary Symptom Scale (standardised mean difference (SMD) -0.02, 95\% $\mathrm{Cl}-0.07$ to 0.03 ; participants $=6186$; studies $\left.=5 ; \mathrm{I}^{2}=19 \%\right)$, the Shortness of Breath Questionnaire (MD $-1.09,95 \% \mathrm{Cl}-2.47$ to 0.28 ; 
participants $=1633$; studies $=2 ; I^{2}=81 \%$ ), or the BCSS (Analysis 1.11).

\section{Exercise tolerance (six-minute walk test)}

We included six studies that reported the six-minute walk test (6MWT) (participants $=2055$ ) (Cilomilast 039; Cilomilast 042; Cilomilast 091; Cilomilast 111; Roflumilast DAL-MD-01; Urban 2018 (ELASTIC)).

Exercise tolerance was measured on the 6MWT in six trials (two roflumilast and four cilomilast trials). We found uncertainty in walk test distance at a mean duration of 21 weeks between $\mathrm{PDE}_{4}$ inhibitor and placebo groups (MD 3.50; $95 \% \mathrm{Cl}-5.84$ to 12.85 ) (Analysis 1.12).

\section{Adverse events}

We included 30 studies in the overall analysis (participants $=$ 21,310) (Cilomilast 039; Cilomilast 042; Cilomilast 076; Cilomilast 091; Cilomilast 103657; Cilomilast 110; Cilomilast 111; Cilomilast 121; Cilomilast 156; Cilomilast 157; Cilomilast 168; Cilomilast 180; Cilomilast 181; Compton 2001; NCT00874497 (EMPHASIS); RO-2455-301-RD (ACROSS); RO-2455-402-RD (ROBERT); RO-2455-404-RD (REACT); Roflumilast DAL-MD-01; Roflumilast FK1 101; Roflumilast IN-108; Roflumilast JP-706; Roflumilast M2-107; Roflumilast M2-111+M2-112; Roflumilast M2-119; Roflumilast M2-124+M2-125; Roflumilast M2-127; Roflumilast M2-128; Roflumilast ROF-MD-07(RE2SPOND); Urban 2018 (ELASTIC)).

Overall, the likelihood of a participant experiencing an adverse event at a mean duration of 38 weeks was higher with $\mathrm{PDE}_{4}$ inhibitor treatment than with placebo $(\mathrm{OR} 1.30,95 \% \mathrm{Cl} 1.22$ to 1.38 ; participants $=21,310$; studies $=30 ; I^{2}=64 \%$; low certainty evidence)
(Analysis 1.13; Summary of findings 1). This effect was seen for both roflumilast and cilomilast but not for tetomilast, as we found only one study for this $\mathrm{PDE}_{4}$ inhibitor.

\section{Adverse events: roflumilast $500 \mu \mathrm{g}$ versus roflumilast $250 \mu \mathrm{g}$}

The higher dose of roflumilast $(500 \mu \mathrm{g})$ was associated with more adverse events than the lower dose $(250 \mu \mathrm{g})$; however, this finding was based on only four trials and confidence intervals were wide (OR $1.21,95 \% \mathrm{Cl} 1.01$ to 1.46 ) (Analysis 1.14).

We found a range of adverse effects that occurred more frequently in $\mathrm{PDE}_{4}$ inhibitor-treated participants, which are described below.

\section{Gastrointestinal adverse effects (diarrhoea, nausea, vomiting,} dyspepsia, weight loss)

Diarrhoea was more commonly experienced in $\mathrm{PDE}_{4}$ inhibitortreated groups than in placebo groups (OR $3.10,95 \% \mathrm{Cl} 2.74$ to 3.50; participants $=20,623$; studies $=29 ; \mathrm{I}^{2}=12 \%$; high-certainty evidence) (Analysis 1.15; Summary of findings 1).

Nausea was also reported as an increased side effect (OR 3.79, 95\% $\mathrm{Cl} 3.24$ to 4.43; participants $=20,949$; studies $=28 ; \mathrm{I}^{2}=24 \%$ ) (Analysis 1.16), as were vomiting (OR $3.95,95 \% \mathrm{Cl} 2.78$ to 5.60 ; participants $=5986 ;$ studies $=12 ; 1^{2}=0 \%$ ) (Analysis 1.17 ) and dyspepsia (OR $3.17,95 \% \mathrm{Cl} 2.33$ to 4.30 ; participants $=6247$; studies $=13 ; \mathrm{I}^{2}=0 \%$ ) (Analysis 1.18). Weight loss was commonly reported and was an increased adverse effect (OR 3.72, 95\% $\mathrm{Cl} 3.09$ to 4.47; participants $=12,462$; studies $=12 ; I^{2}=24 \%$ ) (Analysis 1.19).

More than $10 \%$ of participants in the $\mathrm{PDE}_{4}$ inhibitor group experienced gastrointestinal side effects; diarrhoea was the most frequently reported symptom (Figure 7 ) (number needed to treat for an additional harmful outcome (NNTH) 14, 95\% Cl 12 to 17). 
Figure 7. In the control group, 4 out of 100 people had a diarrhoea episode over 39 weeks of treatment, compared to $11(95 \% \mathrm{Cl} 10$ to 12$)$ out of 100 people in the active treatment group.

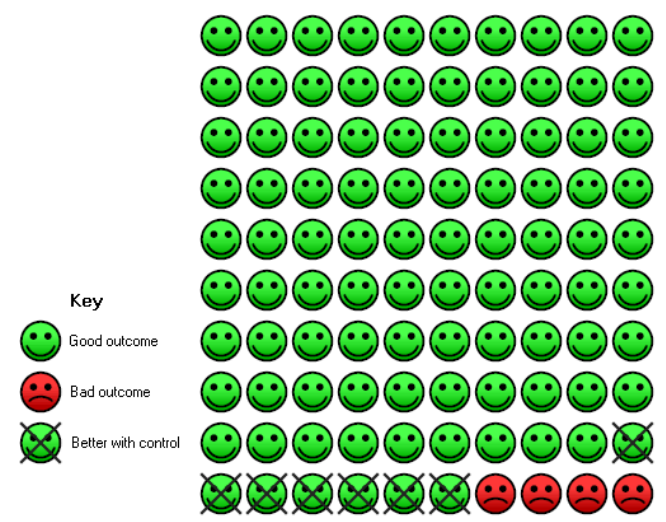

\section{Withdrawals}

An increase in withdrawals attributed to adverse events was recorded for both roflumilast and cilomilast treatment groups (OR $1.89,95 \% \mathrm{Cl} 1.73$ to 2.07 ; participants $=21,358$; studies $=31 ;\left.\right|^{2}=$ 21\%) (Analysis 1.20).

\section{Headache}

We found 23 studies that reported a higher proportion of participants experiencing headache as an adverse effect when taking a $\mathrm{PDE}_{4}$ inhibitor $(\mathrm{OR} 1.69,95 \% \mathrm{Cl} 1.46$ to 1.94; participants = 19,$215 ; I^{2}=23 \%$ ) (Analysis 1.21). Participants in the roflumilast 500 $\mu \mathrm{g}$ treatment group were more likely to experience headache than those given placebo $(\mathrm{OR} 2.13,95 \% \mathrm{Cl} 1.74$ to 2.59 ; participants = 13,565 ; studies $\left.=12 ; I^{2}=0 \%\right)$ (Analysis 1.21).

\section{Abdominal pain}

Fifteen studies reported abdominal pain as an adverse effect in the $\mathrm{PDE}_{4}$ inhibitor treatment group (OR 2.02, 95\% Cl 1.62 to 2.52; participants $=8329$; studies $=15 ; I^{2}=0 \%$ ) (Analysis 1.22 ). A greater likelihood of abdominal pain was noted for participants in the roflumilast treatment group compared with the placebo group (OR 2.77, $95 \% \mathrm{Cl} 1.38$ to 5.56; participants = 2641; studies $=3$ ). Participants were also more likely to experience abdominal pain with cilomilast than with placebo (OR $1.97,95 \% \mathrm{Cl} 1.55$ to 2.49; participants $=5604$; studies $=11$ ), although the magnitude of effect was smaller compared to that seen with roflumilast (Analysis 1.22).

\section{Influenza-like symptoms}

There was uncertainty in the incidence of influenza-like symptoms between $\mathrm{PDE}_{4}$ inhibitors (OR 1.09, 95\% Cl 0.87 to 1.36; participants $=11,460$; studies $=10$ ), as confidence intervals crossed the line of no effect (Analysis 1.23).

\section{Upper respiratory tract infection}

There was uncertainty in the incidence of upper respiratory tract infection between $\mathrm{PDE}_{4}$ inhibitor and placebo treatment groups (OR 0.91, $95 \% \mathrm{Cl} 0.81$ to 1.04 ; participants $=17,022$; studies $=23$ ), as confidence intervals crossed the line of no effect (Analysis 1.24).

\section{Psychiatric adverse effects: COPD safety pool}

We recorded the number of psychiatric adverse events from pooled data derived from all parallel-design, double-blind studies investigating roflumilast collated and presented to the FDA. This included data from the 15 fully published trials but excluded results from Roflumilast JP-706, which was conducted by a different study collaborator. These results reported symptoms of depression separately from depressed mood, depressive symptoms, or major depression. The likelihood of experiencing a psychiatric adverse event was greater in the roflumilast $500 \mu \mathrm{g}$ treatment group than in the placebo group (OR 2.13, 95\% $\mathrm{Cl} 1.79$ to 2.54) (Analysis 1.25; Summary of findings 1 ). This was reported in three out of 100 people in the placebo group compared to seven out of 100 in the $\mathrm{PDE}_{4}$ inhibitor-treated group (95\% $\mathrm{Cl} 6$ to 8) (NNTH $28,95 \% \mathrm{Cl} 21$ to 39). The likelihood of experiencing a psychiatric adverse event was uncertain with $250 \mu \mathrm{g}$ roflumilast compared with placebo, as 
the confidence interval crossed the line of no effect (OR $0.87,95 \%$ $\mathrm{Cl} 0.56$ to 1.33 ) (Analysis 1.25).

An increase in symptoms of anxiety (OR $1.81,95 \% \mathrm{Cl} 1.26$ to 2.62) (Analysis 1.26) and depression (OR 1.59, 95\% Cl 1.11 to 2.27) (Analysis 1.27) was associated with roflumilast $500 \mu \mathrm{g}$ compared with placebo. Uncertainty about symptoms of anxiety (OR 0.94 , $95 \% \mathrm{Cl} 0.40$ to 2.21 ) or depression (OR $0.56,95 \% \mathrm{Cl} 0.20$ to 1.56 ) was greater with roflumilast $250 \mu \mathrm{g}$ compared with placebo, as confidence intervals crossed the line of no effect in both analyses (Analysis 1.26; Analysis 1.27).

Three reports described completed suicides and two suicide attempts in roflumilast-treated participants compared to none in participants given placebo (roflumilast COPD safety database, $n=$ 12,054).

In more recent roflumilast trials, the numbers of participants experiencing insomnia and sleep disorders taking roflumilast 500 $\mu \mathrm{g}$ were greater than among those taking placebo (OR 2.67, 95\% Cl 2.11 to 3.38 ) (Analysis 1.28), but results with $250 \mu \mathrm{g}$ roflumilast were uncertain, as the confidence interval crossed the line of no effect (Analysis 1.28).

\section{Serious adverse events}

Treatment was found to have no effect on serious adverse events (OR 0.99, 95\% Cl 0.91 to 1.07; participants $=19,191$; studies $=29 ; \mathrm{I}^{2}$ $=54 \%$ ) (Analysis 1.29).

\section{Mortality}

Mortality was a relatively rare event during these trials, results showed no effect of treatment for this outcome (OR $0.98,95 \% \mathrm{Cl}$ 0.77 to 1.24 ; participants $=19,786$; studies $=27 ; 1^{2}=0 \%$; moderatecertainty evidence) (Analysis 1.30; Summary of findings 1 ).

\section{Subgroup and sensitivity analyses}

\section{Primary outcome: FEV}

A moderate but significant level of heterogeneity was evidence for the change in $\mathrm{FEV}_{1}$ outcome when all trials were pooled $\left(\mathrm{I}^{2}=\right.$ $45 \%)$. We analysed the data further by performing subgroup and sensitivity analyses.

\section{Subgroup analysis: COPD severity}

To see whether the size of the treatment effect varied with COPD severity, we conducted subgroup analyses of trials for which the mean per cent predicted $\mathrm{FEV}_{1}$ at baseline was available (Analysis 1.31). Effects seen in both old GOLD grade I or II ( $\mathrm{FEV}_{1} \geq 50 \%$ ) predicted and old GOLD grade III or IV $\left(\mathrm{FEV}_{1}<50 \%\right)$ were statistically significant and of similar magnitude (MD 52.78, 95\% Cl 46.73 to 58.83; test for subgroup differences: $\left.\mathrm{Chi}^{2}=0.03, \mathrm{df}=1(\mathrm{P}=0.87)\right)$.
Subgroup analysis: dose (roflumilast $500 \mu \mathrm{g}$ versus roflumilast $250 \mu \mathrm{g}$ )

For dose effects of roflumilast, both roflumilast $500 \mu \mathrm{g}$ and roflumilast $250 \mu \mathrm{g}$ were associated with a similar change in $\mathrm{FEV}_{1}$ (roflumilast $500 \mu \mathrm{g}$ : MD 55.18, 95\% Cl 48.65 to 61.71 ; participants $=14,384$; studies $=18 ; \mathrm{I}^{2}=21 \%$; roflumilast $250 \mu \mathrm{g}$ : MD 56.88, 95\% $\mathrm{Cl} 24.38$ to 89.38; participants $=1033$; studies $=3 ; \mathrm{I}^{2}=0 \%$ ) (test for subgroup differences: $\mathrm{Chi}^{2}=0.01, \mathrm{df}=2(\mathrm{P}=0.92)$ ) (Analysis 1.1; Figure 3).

\section{Subgroup analysis: duration of treatment}

For $\mathrm{FEV}_{1}$, the size of the treatment effect, that is, the mean difference between $\mathrm{PDE}_{4}$ and placebo groups, was numerically greater in short studies of 6 to 12 weeks (MD 101.71, 95\% Cl 70.96 to 132.46; participants $=1191$; studies $=8$ ) than in studies of 24 to 26 weeks (MD 46.14, 95\% Cl 38.44 to 53.84; participants = 8086; studies $=13$ ) and studies of 52 weeks (MD $48.77,95 \% \mathrm{Cl} 41.44$ to 56.10 ; participants $=10,662$; studies $=7$ ). However this difference between subgroups may be a chance finding (test for subgroup differences: $\mathrm{Chi}^{2}=5.11, \mathrm{df}=6(\mathrm{P}=0.53)$ ) (Analysis 1.33).

\section{Subgroup analysis: concomitant therapies (roflumilast versus cilomilast)}

With respect to $\mathrm{PDE}_{4}$ inhibitor use with concomitant therapies (Analysis 1.34), the largest increases in $\mathrm{FEV}_{1}$ were seen in two trials where participants were taking regular, long-acting bronchodilators: in one trial, salmeterol (Roflumilast M2-127), and in the other, tiotropium (Roflumilast M2-128) (MD $60.52 \mathrm{~mL}$, $95 \% \mathrm{Cl} 40.57$ to 80.46 ). The next largest improvements were seen in trials for which all concomitant medications (including long-acting bronchodilators if previously received) were continued (RO-2455-301-RD (ACROSS); RO-2455-404-RD (REACT); Roflumilast ROF-MD-07(RE2SPOND) (MD $56.58 \mathrm{~mL}, 95 \% \mathrm{Cl} 46.91$ to 66.25) (Analysis 1.34). A similar improvement in $\mathrm{FEV}_{1}$ was seen when participants were taking corticosteroids (MD $42.26 \mathrm{~mL}, 95 \% \mathrm{Cl} 25.46$ to 59.05) (Analysis 1.34). Improvements in $\mathrm{FEV}_{1}$ were also noted in trials where only a $\mathrm{PDE}_{4}$ inhibitor was taken (apart from short-

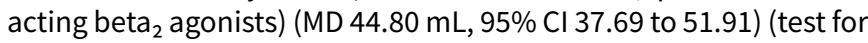
subgroup differences: $\mathrm{Chi}^{2}=5.61, \mathrm{df}=3(\mathrm{P}=0.13)$ (Analysis 1.34).

\section{Sensitivity analysis}

Using a random-effects model made no difference in levels of statistical significance nor degree of heterogeneity for the change in $\mathrm{FEV}_{1}$ (MD 51.49, 95\% Cl 42.87 to 60.10 ; Analysis 1.35). Too many 'Risk of bias' domains were judged to be at 'unclear' risk of bias for subgroup analysis to be conducted according to study quality. Of note, some effect sizes were greater in the published trials, for example, the treatment effect on $\mathrm{FEV}_{1}$ was MD $55.75 \mathrm{~mL}(95 \% \mathrm{Cl}$ 49.45 to 62.06 ) in the 20 published trials, and MD 35.05 ( $95 \% \mathrm{CI} 25.70$ to 44.40 ) in the nine unpublished trials (Analysis 1.36), which was significantly different (test for subgroup differences: $\mathrm{Chi}^{2}=12.94$, $\mathrm{df}=1(\mathrm{P}=0.0003))$. This is illustrated in the funnel plot, with more unpublished studies showing a smaller treatment effect (Figure 8). 
Figure 8. Funnel plot of comparison: $2 \mathrm{PDE}_{4}$ inhibitor versus placebo (2020 update), outcome: $2.36 \mathrm{FEV}_{1}$ (published versus unpublished).

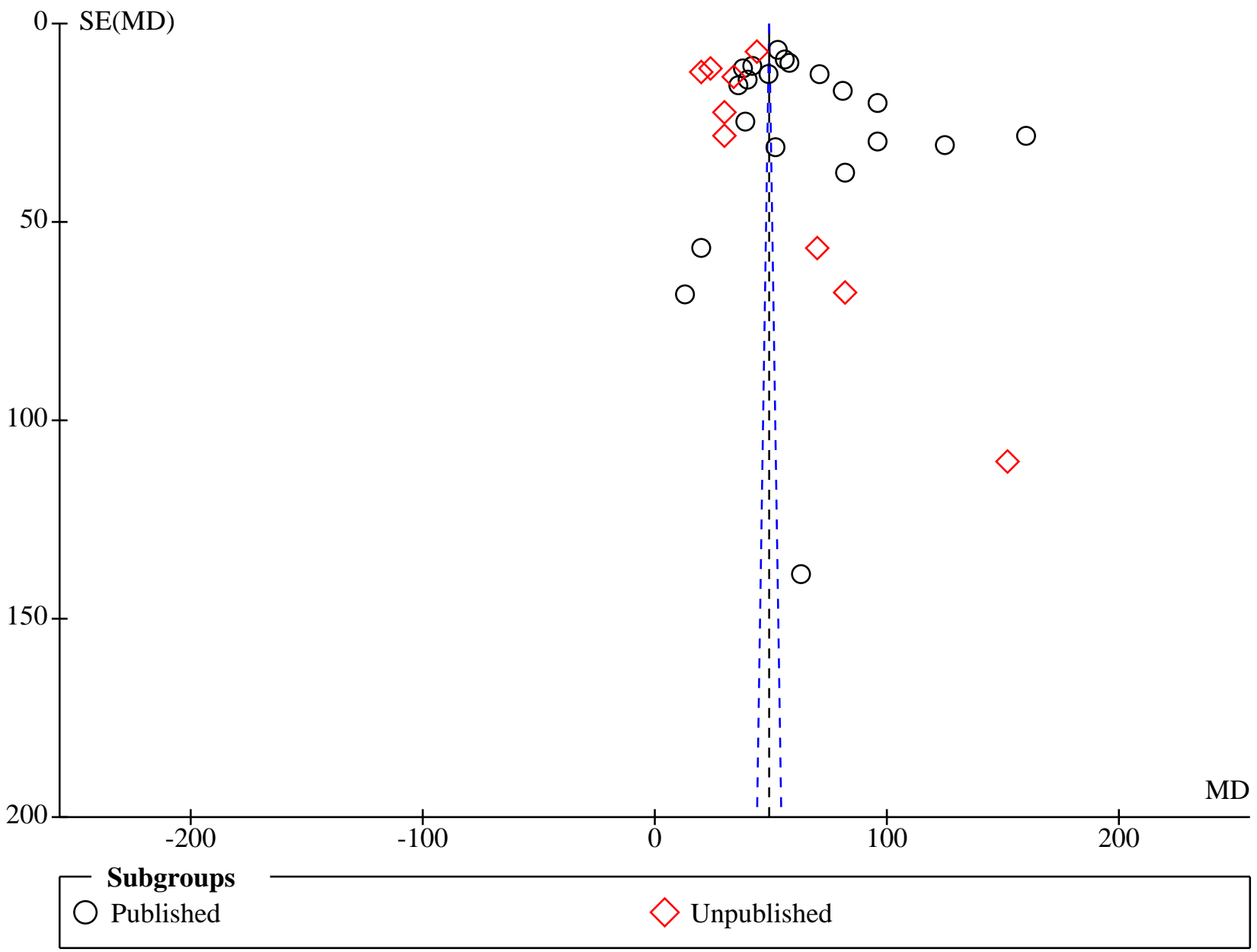

By visual analysis of the forest plot and sequential elimination, we identified the six-week Compton 2001 cilomilast trial as a major contributor to the heterogeneity of pooled $\mathrm{FEV}_{1}$ results. When this trial was removed, the overall $I^{2}$ statistic decreased from $45 \%$ to $26 \%$, and in the cilomilast subgroup from $62 \%$ to $0 \%$. It is notable that this study had the shortest treatment duration (six weeks) and showed the greatest improvement from baseline in $\mathrm{FEV}_{1}$ lung function in the treatment group across all studies.

\section{Primary outcome: SGRQ}

\section{Subgroup analysis: COPD severity}

Although quality of life was improved in participants with GOLD grade I or II COPD severity, and with GOLD grade III or IV COPD severity (MD -1.56 units, $95 \% \mathrm{Cl}-2.39$ to -0.74 ; participants $=4851$; studies $=8)$ (test for subgroup differences: $\mathrm{Chi}^{2}=0.02, \mathrm{df}=1(\mathrm{P}$ $=0.89)$ ) (Analysis 1.37), overall heterogeneity was high $\left(I^{2}=55 \%\right)$. Studies in which participants had grade I or II COPD severity were similar $\left(I^{2}=0 \%\right)$, but variation was observed amongst studies in which participants had grade III or IV COPD severity $\left(I^{2}=73 \%\right)$ (Analysis 1.37).

\section{Subgroup analysis: duration of treatment}

It is notable that in two trials with a duration of one year that reported total SGRQ, the change in quality of life seen with treatment compared with control was uncertain (MD 0.26, 95\% Cl -1.18 to 1.69 ) (Analysis 1.38). However, quality of life was improved among participants taking a $\mathrm{PDE}_{4}$ inhibitor for less than 12 weeks (MD $-4.19,95 \% \mathrm{Cl}-7.60$ to -0.78 ) and for 24 to 26 weeks (MD -1.18, $95 \% \mathrm{Cl}-1.94$ to -0.42 ). A significantly greater treatment effect was noted in short studies ( 6 to 12 weeks) compared with studies of 24 to 52 weeks. A high level of heterogeneity $\left(1^{2}=57 \%\right)$ was observed amongst studies providing 24 to 26 weeks of treatment (test for subgroup differences: $\mathrm{Chi}^{2}=6.50, \mathrm{df}=2(\mathrm{P}=0.04)$ ) (Analysis 1.38).

\section{Sensitivity analysis}

Analysis revealed a difference in effect size of the total SGRQ score between published and unpublished trials (MD -1.98, 95\% Cl -3.07 to -0.89 versus $\mathrm{MD}-0.43,95 \% \mathrm{Cl}-1.26$ to 0.40 ) (test for subgroup differences: $\mathrm{Chi}^{2}=4.94, \mathrm{df}=1(\mathrm{P}=0.03)$ ) (Analysis 1.39). 


\section{Secondary outcome: exacerbations}

\section{Subgroup analysis: additional medications}

When investigating whether other additional medication made any difference, we found similar efficacy for both roflumilast and cilomilast, specifically when use of concomitant long-acting bronchodilators was permitted (OR $0.79,95 \% \mathrm{Cl} 0.73$ to 0.85 ) (test for subgroup differences: $\mathrm{Chi}^{2}=1.53, \mathrm{df}=3(\mathrm{P}=0.67)$ ) (Analysis 1.40).

\section{DISCUSSION}

\section{Summary of main results}

This systematic review evaluated randomised controlled trials (RCTs) that assessed the efficacy and safety of oral phosphodiesterase $4\left(\mathrm{PDE}_{4}\right)$ inhibitors in people with chronic obstructive pulmonary disease (COPD). The conclusions of this review remain unchanged following the addition of new studies for the 2020 update, reporting small improvements in lung function and quality of life and decreased exacerbations.

\section{Lung function}

Based on data from 32 trials (low-certainty evidence), we found that both roflumilast and cilomilast led to greater improvements in lung function from baseline, as measured by forced expiratory volume in one second $\left(\mathrm{FEV}_{1}\right)$, forced vital capacity (FVC), or peak expiratory flow rate (PEF), compared with placebo (Summary of findings 1 ). Furthermore, improvement in lung function was seen regardless of the severity of the disease. This improvement in $\mathrm{FEV}_{1}$ lung function occurred whether or not $\mathrm{PDE}_{4}$ inhibitor treatment was given in addition to other COPD treatments, such as long-acting beta ${ }_{2}-$ agonists (LABAs) or anticholinergics or inhaled corticosteroids (ICSs).

Greater improvement in $\mathrm{FEV}_{1}$ was observed in studies of shorter duration (Analysis 1.33); this could be due to a limited shortterm response to $\mathrm{PDE}_{4}$ inhibitor treatment, as might be seen with tachyphylaxis, and needs further investigation.

The mean change in $\mathrm{FEV}_{1}$ was less than what is usually considered a minimum clinically important difference (MCID) $(100 \mathrm{~mL}$; Donohue 2005), but it was comparable to that seen with other COPD treatments in recent large RCTs. For example, mean improvement in $\mathrm{FEV}_{1}$ of $49 \mathrm{~mL}$ with treatment, as seen in moderate to severe COPD in this review, is of similar magnitude to that seen with fluticasone $(47 \mathrm{~mL})$, salmeterol $(42 \mathrm{~mL})$, and fluticasone and salmeterol combined $(92 \mathrm{~mL})$ in the TORCH 2007 study among people with severe COPD.

\section{Quality of life}

Data show only a small improvement in quality of life as assessed by St George's Respiratory Questionnaire (SGRQ) total score. Quality of life had been chosen as a primary outcome because of concerns as to whether or not the adverse effects of $\mathrm{PDE}_{4}$ inhibitors might outweigh any beneficial COPD-related events. The average change in SGRQ total score was 1.06 units (over a duration between 6 and 12 months) (Summary of findings 1 ) and was of similar magnitude among trials of participants with milder or more severe COPD. Although this improvement was statistically significant, a change of greater than four units is usually regarded as the MCID (Jones 2005). Although symptom scores were marginally better in the treatment groups, no change was seen in exercise tolerance, suggesting that improvements in respiratory symptoms may not necessarily translate into enhanced physical functioning. Fewer trials were assessable for these outcomes, raising the possibility of type 1 or type 2 error.

\section{Exacerbations}

A second major finding, based on data from 27 trials (moderatecertainty evidence; Summary of findings 1 ), was that participants were more likely to be exacerbation-free while being treated with $\mathrm{PDE}_{4}$ inhibitors compared with those given control interventions. Overall, participants were $22 \%$ less likely to have an exacerbation, translating to a number needed to treat for an additional beneficial outcome (NNTB) of around 20 (95\% confidence interval (CI) 16 to 26) for one person to be exacerbation-free in the study period (Figure 6; Summary of findings 1). Although the likelihood of an individual experiencing an exacerbation was lowered with $\mathrm{PDE}_{4}$ inhibitor treatment, the decrease in the overall rate of exacerbations was less marked, with a relative reduction of $13 \%$.

Taken together, results for lung function and exacerbations suggest that $\mathrm{PDE}_{4}$ inhibitors in people with COPD are acting independently of other treatments, particularly bronchodilators. This is an encouraging finding that could be consistent with a broad anti-inflammatory effect (Fabbri 2009). On the other hand, short-duration studies showed more favourable results than longer studies, but the reasons for this are unclear. Significant heterogeneity was noted among trials, suggesting that unmeasured differences between trials may be having an impact.

\section{Adverse events}

Adverse events were more likely among roflumilast- and cilomilasttreated participants than among those receiving placebo (very low-certainty evidence; Summary of findings 1), particularly gastrointestinal effects such as diarrhoea, nausea, vomiting, and dyspepsia.

Participants in treatment groups were more likely to withdraw from trials because of adverse events; on average, $14 \%$ in the treatment groups withdrew compared with $8 \%$ in the control groups. Similarly, there was a slight excess in the total numbers of participants in the treatment groups experiencing any adverse event compared with numbers in the control groups (Analysis 1.13). As this analysis included symptoms as well as exacerbations, which were reduced among treatment groups, the analysis will tend to underestimate the excess of non-COPD-related adverse events occurring with $\mathrm{PDE}_{4}$ inhibitor treatment.

It is notable that treatment with roflumilast was associated with an increased incidence of weight loss. Whether this was due to anorexia from gastrointestinal adverse effects or from another effect is not yet clear. Also not clear is whether cilomilast has the same effect, as this has not been studied. Weight loss may be a beneficial effect for people with COPD who are obese. In contrast, low body mass in the later stages of COPD is associated with a worse prognosis and is notoriously difficult to reverse (GOLD 2020). This adverse effect warrants further investigation. It is reassuring that there was no increase in serious adverse events nor in mortality, although trials were of relatively short duration and analyses were underpowered to report on the latter outcome.

Although the lower dose $(250 \mu \mathrm{g})$ of roflumilast produced similar improvements in $\mathrm{FEV}_{1}$ (Analysis 1.32) and was associated with 
slightly fewer adverse events than the larger dose (Analysis 1.14), the lower dose was associated with a smaller reduction in rates of exacerbation when compared with the higher dose in the only trial that reported this (Roflumilast FK1 101). Moreover, data on the lower dose were available from a limited number of studies, and this has not been studied as add-on therapy to other bronchodilators.

Awareness of the risk of psychiatric adverse events associated with roflumilast treatment is growing (Analysis 1.25; Summary of findings 1), in particular the increased likelihood of experiencing sleep disturbances, anxiety, and depressed mood. It should be noted that we found three reports of completed suicides and two of suicide attempts among roflumilast-treated participants compared to none in participants given placebo (roflumilast COPD safety database).

\section{Mortality}

Mortality was a rare event, and there was no difference between participants treated with a $\mathrm{PDE}_{4}$ inhibitor and those given placebo (Analysis 1.30; Summary of findings 1 ).

\section{Overall completeness and applicability of evidence}

We have reviewed all known published and unpublished trials identified through standard Cochrane searches, as well as those obtained from the trials register for the National Institutes of Health (NIH) and from pharmaceutical websites.

We have not been able to verify the pooled endpoint data for psychiatric (treatment possibly harmful) and cardiovascular adverse events (treatment possibly beneficial), as we obtained this information from reports on the US Food and Drug Administration (FDA) website and from White 2013, respectively.

To ensure that our Cochrane systematic review accurately reflects all known outcomes of roflumilast therapy, for previous updates we approached the manufacturer of roflumilast for study-level data on each of the cardiovascular outcomes (cardiovascular death, nonfatal myocardial infarction, and non-fatal stroke), as well as the composite outcome, major adverse cardiovascular events (MACE). This would have allowed us to perform comparisons both within (i.e. between roflumilast and placebo groups) and among the studies. Unfortunately, our request for individual trial data was refused, with the following reasons cited.

- It is inappropriate from a statistical perspective to look into individual trials with too small a sample size for this kind of relatively rare endpoint.

- It was part of the retrospective analyses to evaluate the whole data set with a sufficiently broad database and not to go into perstudy data that would comprise numbers in each treatment arm that were too low for conclusive interpretation.

- In none of the studies was blinded adjudication of events implemented as a prospective analysis, which would have required a data release in terms of transparency for each individual study (this is why it was not mentioned in the original publications of individual trials).

In response to the statement by representatives of Takeda Pharmaceuticals Limited, we have urged that these issues be reconsidered for future studies, and that study data be made more widely available. Finally, caution must be used when interpreting associations between COPD exacerbations and MACE, because although treatment groups were matched at baseline, it cannot be assumed that these groups are equivalent when the focus is only on groups of participants who experienced exacerbations. These concerns could not be assessed in this review, as further study data were not provided.

\section{Certainty of the evidence}

For the key outcomes of changes in lung function and quality of life, greater beneficial effects of $\mathrm{PDE}_{4}$ inhibitors were reported in published than in unpublished studies, raising concerns about publication bias. When investigating publication bias further for each outcome, we found that eliminating from the analyses studies with suspected publication bias did not significantly alter overall effect estimates or confidence intervals for lung function or quality of life. Similarly, this was apparent when adverse events were investigated.

We identified a moderate level of heterogeneity for both of the primary outcomes for this review, which is not fully explained by subgroup or sensitivity analyses according to study duration or concomitant medication use. This suggests that unknown factors that may impact effect size have led us to downgrade the quality of evidence and the certainty of our findings (Summary of findings 1). In contrast, the blinded design of studies comparing roflumilast or cilomilast with placebo protected against detection bias in our view. The certainty of evidence for a reduction in exacerbation was therefore higher for this comparison. On balance, we believe the true beneficial effect of $\mathrm{PDE}_{4}$ inhibitors is likely to be no greater than we have reported and is probably less; equally, the harms of $\mathrm{PDE}_{4}$ treatment may have been understated (due in part to higher withdrawal rates in active treatment arms). On the other hand, as subgroup analyses for COPD severity are based on the mean predicted lung function for the study group and not for individual participants, we cannot rule out benefit for individuals of a specific COPD phenotype.

\section{Addition of new trials}

The 2020 update of this review included four studies on roflumilast $500 \mu \mathrm{g}$ and one study on tetomilast (Kavitha 2018; Liu 2018; NCT00874497 (EMPHASIS); RO-2455-402-RD (ROBERT); Urban 2018 (ELASTIC)). Data from these new trials did not affect the results already yielded by analyses. Kavitha 2018 and Liu 2018 were not included in the analyses for lung function, as the units for this endpoint were unclear even though we contacted trial authors for clarification. Data from Liu 2018 were not included in the metaanalysis for SGRQ due to unclear data units in the publication.

\section{Potential biases in the review process}

Potential biases in the review process were minimised by doublechecking of data extraction and input. The review authors have no conflicts of interest to declare.

\section{Agreements and disagreements with other studies or reviews}

Several other meta analyses have been conducted, including Luo 2016, Yuan 2016, and Shen 2018. Each of these included fewer studies than the present review but presented findings and conclusions that were similar. Our findings are also similar to those 
presented by Wedzicha 2016 and show effects on exacerbations similar to those described in Rabe 2017.

In a post hoc pooled analysis $(n=5595)$ of four trials in this review (Rennard 2014), roflumilast was seen to improve transition dyspnoea index (TDI) focal scores of breathlessness versus placebo at week 52 (treatment difference $0.327 ; P<0.0001$ ). Roflumilast was associated with more TDI responders and fewer TDI deteriorators ( $\geq 1$-unit increase or decrease from baseline, respectively) versus placebo at week 52 ( $P<0.01$, both). Rates of MACE in COPD participants treated with $\mathrm{PDE}_{4}$ inhibitors have been meta-analysed and reported in White 2013. This review found that risk of cardiovascular death, non-fatal myocardial infarction, or non-fatal stroke, when combined into a composite outcome MACE, was reduced in the roflumilast group compared with the placebo group (hazard ratio $0.65,95 \% \mathrm{Cl} 0.45$ to $0.93 ; \mathrm{P}=0.019$ ). On the other hand, hazard ratios for treatment effects for each of these types of events individually were statistically different. Cardiovascular events were higher among participants with baseline cardiovascular risk factors than among those without baseline cardiovascular risk (defined as the presence of hypertension, diabetes mellitus, hyperlipidaemia, and/or a history of heart disease). In addition, it was found that the difference between treatment and placebo was statistically significant only for the group of participants without baseline risk factors. Event rates in a subgroup of trials that were one year in duration show no significant differences between treatment and placebo groups in the proportion of participants who reported a MACE, even when divided into those who did or did not experience a COPD exacerbation. Similarly, between participants with and without MACE events, the proportions of participants experiencing exacerbations were similar ( $43.2 \%$ and $42.1 \%$, respectively).

\section{AUTHORS' CONCLUSIONS}

\section{Implications for practice}

Phosphodiesterase-4 ( $\left.\mathrm{PDE}_{4}\right)$ inhibitors are oral medicines that may be taken in combination with other standard chronic obstructive pulmonary disease (COPD) treatments. Most evidence has been gathered for roflumilast at a dose of $500 \mu \mathrm{g}$ daily and cilomilast at $15 \mathrm{mg}$ twice daily.

$\mathrm{PDE}_{4}$ inhibitors join an increasing list of treatments for COPD that improve short-term lung function and reduce exacerbations, but they have not been shown to increase life expectancy. Most trials to date have been one year in duration (with the exception of one study of nearly two years' duration). In contrast to longacting bronchodilators, $\mathrm{PDE}_{4}$ inhibitors have minimal benefit for symptoms on a day-to-day basis, or for quality of life, and are often associated with adverse effects, especially gastrointestinal effects and headaches. Roflumilast is associated with greater weight loss and increased psychiatric symptoms compared with placebo. Findings of this review provide cautious support for the use of $\mathrm{PDE}_{4}$ inhibitors in COPD. In accordance with GOLD 2020 guidelines, $\mathrm{PDE}_{4}$ inhibitors may have a place as add-on therapy for a subgroup of people with persistent symptoms or exacerbations despite optimal COPD management (e.g. people who are not controlled on fixeddose long-acting beta ${ }_{2}$-agonist (LABA) and inhaled corticosteroid (ICS) combinations).

\section{Implications for research}

This review has highlighted several possible topics for further study.
- Effects of $\mathrm{PDE}_{4}$ inhibitors on forced expiratory volume in one second $\left(\mathrm{FEV}_{1}\right)$ decline and mortality in studies of longer duration.

- Effects of $\mathrm{PDE}_{4}$ inhibitors at shorter time points in longerduration studies on FEV . $_{1}$

- Subgroup analysis of participants with/without chronic bronchitis and with/without a history of exacerbations.

- Effects of $\mathrm{PDE}_{4}$ inhibitors among participants with frequent exacerbations.

- Effects of $\mathrm{PDE}_{4}$ inhibitors on healthcare utilisation, including hospitalisation (incidence and bed days).

- Direct comparison of $\mathrm{PDE}_{4}$ inhibitors and inhaled corticosteroids (ICSs) when used as add-on therapies to tiotropium, to longacting beta ${ }_{2}$-agonists (LABA), or to all three (triple inhaled therapies).

- Direct comparison of tiotropium or LABA, or both, as add-on therapies to $\mathrm{PDE}_{4}$ inhibitors ( \pm ICS).

- Effects of roflumilast on quality of life.

- Better characterisation of the weight loss seen with $\mathrm{PDE}_{4}$ inhibitors in COPD.

- Better description of the nature of effects on exacerbations that do occur.

- Use of $\mathrm{PDE}_{4}$ inhibitors in acute exacerbations.

- Cost-effectiveness of $\mathrm{PDE}_{4}$ inhibitors.

- Increased exercise tolerance data for roflumilast.

- Increased data on tetomilast.

- Whether there is any benefit on cardiovascular outcomes for $\mathrm{PDE}_{4}$ inhibitors in COPD.

- Use of effects of $\mathrm{PDE}_{4}$ inhibitors to better understand the pathophysiology of COPD.

- Further evaluation of roflumilast $250 \mu \mathrm{g}$ versus $500 \mu \mathrm{g}$ daily.

- Subgroup analysis of participants based on their weight.

- Use of CAT score as an outcome.

- Responder analyses (e.g. proportion of participants achieving a minimum clinically important difference).

\section{ACKNOWLEDGEMENTS}

The Background and Methods sections of this review are based on a standard template used by Cochrane Airways.

This review is dedicated to Professor Peter Black (deceased January 2010), who led development of the protocol and the early part of the review. Peter made significant contributions through research, teaching, and clinical practice to furthering of evidence-based management of airways diseases.

We thank Claire Arandjus for her contribution to protocol development.

We thank Jimmy Chong for his contributions to the previous update of this review.

We thank Bonnie Leung for her contributions to the previous update of this review.

We thank Professor Milo Puhan for assistance in locating reports on the FDA website. 
We thank Nycomed and Forest Laboratories for confirming some study details and results extracted from published articles and abstracts.

We thank GlaxoSmithKline (GSK) for study summaries available via the GSK online clinical study register.

The review authors and the Cochrane Airways editorial team are grateful to the following peer reviewers for their time and comments.

- Dr PW Ind, Adjunct Reader NHLI, Hon Consultant Respiratory Physician, Imperial College NHS Healthcare Trust, UK.
- Professor Peter Calverley, Institute of Ageing and Chronic Disease, University of Liverpool, UK.

- Sarah Hodgkinson, Cochrane Central Executive Team.

This update was funded by the National Institute for Health Research Systematic Reviews Programme (project number $16 / 114 / 21)$. This project was also supported by the National Institute for Health Research (NIHR) via Cochrane Infrastructure funding to the Cochrane Airways Group. The views and opinions expressed therein are those of the authors and do not necessarily reflect those of the Health Research Systematic Reviews Programme, NIHR, NHS, or the Department of Health. 


\section{RE F E R E N C E S}

\section{References to studies included in this review}

\section{Cilomilast 039 \{published data only\}}

. A randomized, 24-week, double-blind, placebo-controlled, parallel-group study to evaluate the efficacy, safety and tolerability of cilomilast ( $15 \mathrm{mg}$ twice daily) in patients with chronic obstructive pulmonary disease (207499/039). gskclinicalstudyregister.com/study/207499/039\#rs (first received 28 September 2008).

Edelson JD, Compton C, Nieman R, Robinson CB, Amit O, Bagchi I, et al. Cilomilast (Ariflo), a potent selective phosphodiesterase 4 inhibitor, reduces exacerbations in COPD patients: results of a 6 month trial. American Journal of Respiratory and Critical Care Medicine 2001; 163(5 Suppl):A771.

Edelson JD, Compton C, Nieman R, Robinson CB, Watt R, Amit $\mathrm{O}$, et al. Cilomilast (Ariflo) improves health status in patients with COPD: results of a 6-month trial. American Journal of Respiratory and Critical Care Medicine 2001; 163(5 Suppl):A277.

* Rennard SI, Schachter N, Strek M, Rickard K, Amit O. Cilomilast for COPD: results of a 6-month, placebo controlled study of a potent, selective inhibitor of phosphodiesterase 4 . Chest 2006; 129(1):55-66.

\section{Cilomilast 042 \{unpublished data only\}}

. A randomized, 24-week, double-blind, placebo-controlled, parallel-group study to evaluate the efficacy, safety and tolerability of cilomilast (15 mg twice daily) in patients with chronic obstructive pulmonary disease. gsk-clinicalstudyregister.com/study/207499/042? search=study\&search_terms=cilomilast\&search=Search\#rs (first received 28 September 2008).

\section{Cilomilast 076 \{published and unpublished data\}}

* . A 12-week, multicentre, double-blind, placebo-controlled, parallel-group study to evaluate the anti-inflammatory activity of SB207499 $15 \mathrm{mg}$ twice daily in patients with chronic obstructive pulmonary disease. gsk-clinicalstudyregister.com/ files/pdf/24047.pdf (first received 28 September 2008).

Gamble E, Grootendorst DC, Brightling CE, Troy S, Qiu Y, Zhu J, et al. Antiinflammatory effects of the phosphodiesterase-4 inhibitor cilomilast (Ariflo) in chronic obstructive pulmonary disease. American Journal of Respiratory and Critical Care Medicine 2003; 168:976-82.

\section{Cilomilast 091 \{unpublished data only\}}

. A randomized, 24-week, double-blind, placebo-controlled, parallel-group study followed by a 2-week, randomized, double-blind, run-out phase to evaluate the efficacy, safety, tolerability and discontinuation of SB207499 (15 mg twice daily) in patients with chronic obstructive pulmonary disease. gsk-clinicalstudyregister.com/study/207499/091? search=study\&search_terms=SB207499\#rs (first received 28 September 2008).

\section{Cilomilast 103657 \{unpublished data only\}}

. GSK CTR-657. A randomized, 24-week, double-blind, placebocontrolled, parallel-group study to evaluate the efficacy, safety and tolerability of cilomilast (15 mg BID) in patients with chronic obstructive pulmonary disease (COPD). gskstudyregister.com/study?uniqueStudyld=CIL103657 (first received 24 August 2016).

\section{Cilomilast 110 \{unpublished data only\}}

. A 12-week, multicenter, double-blind, placebo-controlled, parallel-group study to evaluate the anti-inflammatory activity of cilomilast $15 \mathrm{mg}$ twice daily in patients with chronic obstructive pulmonary disease. gsk-studyregister.com/ study/5979 (first received 11 December 2008).

\section{Cilomilast 111 \{published and unpublished data\}}

* . A 12-week, randomized, double-blind, placebo-controlled, parallel-group study to investigate the effect of cilomilast (15 $\mathrm{mg}$ twice daily) on trapped gas volume in patients with chronic obstructive pulmonary disease. gsk-clinicalstudyregister.com/ files/pdf/24050.pdf (first received 28 September 2008).

* Zamel N, McClean P, Zhu J, Schryver B, Madan A, Robinson CB, et al. Effect of cilomilast (Ariflo) on trapped gas volume and indices of hyperinflation in patients with chronic obstructive pulmonary disease. American Journal of Respiratory and Critical Care Medicine 2002; 165(Suppl 8):A226.

\section{Cilomilast 121 \{unpublished data only\}}

. A randomized, 24-week, double-blind, placebo-controlled, parallel-group study to evaluate the efficacy, safety and tolerability of cilomilast (15 mg BID) in patients with chronic obstructive pulmonary disease. h/s3.amazonaws.com/ctrgsk-7381/207499_121/430f519b-3d76-4244-9417-3bc801497511/ ef158d16-ce04-46dd-8358-456dfee5641f/24042-v1.pdf (first received 28 September 2008).

\section{Cilomilast 156 \{unpublished data only\}}

. A randomized, 24-week, double-blind, placebo-controlled, parallel-group study to evaluate the efficacy, safety and tolerability of cilomilast (15 mg BID) in patients with chronic obstructive pulmonary disease. s3.amazonaws.com/ctrgsk-7381/207499_156/7dd49801-f278-4112-bbe8-f8ef3c62ce78/ f7a0f0ba-f28a-4666-b76a-f155eec89363/gsk-207499-156clinical-study-report-redact-v1.pdf (first received 20 May 2015).

\section{Cilomilast 157 \{unpublished data only\}}

. A randomised, double-blind, placebo-controlled, parallel-group study to evaluate the efficacy, safety and tolerability of oral cilomilast ( $15 \mathrm{mg}$ bd) when given as maintenance treatment for 12 months to subjects with chronic obstructive pulmonary disease. s3.amazonaws.com/ ctr-gsk-7381/207499_157/37e6fc79-d3ca-46e1-b07ac7c7995d5c69/31ef48f1-c164-406b-b9db-cf88a0d606dc/ gsk-207499-157-clinical-study-report-redact-v1.pdf (first received 28 September 2008). 
Cilomilast 168 \{published and unpublished data\}

* . A randomized, 12-week, double-blind, placebo-controlled, parallel-group study to evaluate the safety and tolerability of cilomilast $15 \mathrm{mg}$ twice daily in patients with chronic obstructive pulmonary disease. gsk-clinicalstudyregister.com/files/ pdf/24054.pdf (first received 28 September 2008).

Reisner C, Zhu J, Morris A, Lim J, Knobil K. Assessment of cardiac events via 24-hour electrocardiographic (Holter) monitoring with cilomilast in chronic obstructive pulmonary disease. European Respiratory Journal 2003; 22(Suppl 45):P522.

Reisner C, Zhu J, Morris A, Lim J, Knobil K. Assessment of cardiac events via 24-hour electrocardiographic (Holter) monitoring with cilomilast in chronic obstructive pulmonary disease. In: American Thoracic Society 99th International Conference; 2003 May 16-21; Seattle. 2003.

\section{Cilomilast 180 \{unpublished data only\}}

. An 18-week randomized, double-blind, placebo-controlled, multicenter study designed to compare treatment with cilomilast to that with placebo for changes in ventilatory mechanics and function (both at rest and during exercise), as well as related exertional dyspnea and exercise performance, in hyperinflated patients with stable COPD. s3.amazonaws.com/ ctr-gsk-7381/207499_180/07613483-8e07-4a60-9f7cfc673665e770/b6f75a99-2ac4-4a74-9b06-b5f74ec8c056/ gsk-207499-180-clinical-study-report-redact-v1.pdf (first received 20 November 2008).

\section{Cilomilast 181 \{unpublished data only\}}

. A 13-week randomised, double-blind, parallel group, multicentre study to compare the bronchial anti-inflammatory activity of oral cilomilast (15 mg bd) with placebo twice daily in subjects with chronic obstructive pulmonary disease. s3.amazonaws.com/ctr-gsk-7381/207499_181/ ac461889-1b68-44f0-a3ef-e3f7a9c76c93/cdcf6d43-b6ec-4d91a018-d183ceb8b804/gsk-207499-181-clinical-study-reportredact-v1.pdf (first received 28 September 2008).

\section{Compton 2001 \{published and unpublished data\}}

Compton CH, Gubb J, Cedar E, Bakst A, Nieman RB, Amit O, et al. SB 207499, a second generation, oral $\mathrm{PDE}_{4}$ inhibitor, improves health status in patients with COPD. In: European Respiratory Society Annual Congress; 1999 Oct 9-13; Madrid. 1999:P2237.

* Compton CH, Gubb J, Nieman R, Edelson J, Amit O, Bakst A, et al. Cilomilast, a selective phosphodiesterase-4 inhibitor for treatment of patients with chronic obstructive pulmonary disease: a randomised, dose-ranging study. Lancet 2001; 358(9278):265-70.

\section{COPD safety pool \{published data only\}}

Durmowicz AG. Cross discipline team leader review, application number 0225220rig1s000. www.accessdata.fda.gov/ drugsatfda_docs/nda/2011/0225220rig1s000CrossR.pdf (accessed prior to 14 February 2020).

\section{Kavitha 2018 \{published data only\}}

Kavitha DM, Sarumathy S, Sasidharan SL, Shaik M, Sandeep G, Rajasekhar V, et al. A clinical study on safety and efficacy of formoterol and tiotropium combination compared to formoterol and tiotropium with roflumilast combination in treatment of moderate to severe chronic obstructive pulmonary disease patients. Asian Journal of Pharmaceutical and Clinical Research 2018; 11(3):184-6.

\section{Liu 2018 \{published data only\}}

, , YG MB, , , , et al. Effect and safety of roflumilast for chronic obstructive pulmonary disease in Chinese patients. Medicine 2018; 97(9):e9864.

\section{NCT00874497 (EMPHASIS) \{published data only\}}

. Pilot study of tetomilast in chronic obstructive pulmonary disease (COPD) associated with emphysema (EMPHASIS) [A multicentre, randomised, double-blind, placebo-controlled pilot study to assess the pharmacodynamics, efficacy and safety of $50 \mathrm{mg}$ tetomilast administered as oral tablets in patients with chronic obstructive pulmonary disease associated with emphysema]. clinicaltrials.gov/ct2/show/NCT00874497 (first received 2 April 2009).

\section{RO-2455-301-RD (ACROSS) \{published data only\}}

. A chronic obstructive pulmonary disease (COPD) trial investigating roflumilast on safety and effectiveness in China, Hong Kong and Singapore. https://clinicaltrials.gov/show/ NCT01313494 2011.

Zheng J, Yang J, Zhou X, Zhao L, Hui F, Wang H, et al. Roflumilast for the treatment of COPD in an Asian population: a randomized, double-blind, parallel-group study. Chest 2014; 145(1):44-52. [CENTRAL: 978808] [EMBASE: 2014049205] [4900126000007427] [PMID: 24135893]

\section{RO-2455-402-RD (ROBERT) \{published data only\}}

. A 16-week, randomised, placebo-controlled, double-blind, and parallel group trial to assess the anti-inflammatory effects of roflumilast in chronic obstructive pulmonary disease. The ROBERT study. clinicaltrialsregister.eu/ctr-search/ trial/2011-000582-13/results (first received 4 January 2012).

. Trial to assess the anti-inflammatory effects of roflumilast in chronic obstructive pulmonary disease. https:// clinicaltrials.gov/show/NCT01509677.

Rabe KF, Hanauer G, Strigun A, Alagappan V. Effect of roflumilast on the serum metabolome of COPD patients. American Journal of Respiratory and Critical Care Medicine 2018; 197:A7429.

Rabe KF, Henrik W, Baraldo S, Pedersen F, Biondini D, Bagul N. Anti-inflammatory effects of roflumilast in chronic obstructive pulmonary disease (ROBERT): a 16-week, randomised, placebocontrolled trial. Lancet Respiratory Medicine 2018; 6:827-36.

Rabe KF, Saetta M, Watz H, Baraldo S, Hanauer G, , et al. Reduction in airway eosinophils in patients with COPD treated with roflumilast for 16 weeks: a double-blind, parallel-group, randomised, placebo-controlled biopsy trial. American Journal for Respiratory and Critical Care Medicine 2017; 195:A7569.

RO-2455-404-RD (REACT) \{published data only\}

Calverley PM, Rabe KF, Goehring U, Kristiansen S, Kristiansen S, Martinez FJ. Does roflumilast decrease exacerbations in severe 
COPD patients not controlled by inhaled combination therapy? The REACT study protocol. International Journal of COPD 2012; 7(1):375-82.

Kiff C, Ruiz S, Varol N, Gibson D, Davies A, Purkayastha D. Costeffectiveness of roflumilast as add-on to triple inhaled therapy versus triple inhaled therapy in patients with severe and very severe chronic obstructive pulmonary disease associated with chronic bronchitis in the UK. International Journal of Chronic Obstructive Pulmonary Disease 2018; 13(5):2707-20. [DOI: 10.2147\%2FCOPD.S167730]

* Martinez FJ, Calverley PMA, , Brose M, Fabbri LM, Rabe KF. Effect of roflumilast on exacerbations in patients with severe chronic obstructive pulmonary disease uncontrolled by combination therapy (REACT): a multicentre randomised controlled trial. Lancet 2015; 385(9971):857-66.

. Effect of roflumilast on exacerbation rate in patients with COPD treated with fixed combinations of LABA and ICS. A 52-week, randomised double-blind trial with roflumilast $500 \mu \mathrm{g}$ versus placebo. The REACT trial. clinicaltrials.gov/show/NCT01329029 (first received 30 March 2011).

\section{Roflumilast DAL-MD-01 \{published data only\}}

* Wells JM, Jackson PL, Viera L, Bhatt SP, Gautney J, Handley G, et al. A randomized, placebo-controlled trial of roflumilast. Effect on proline-glycine-proline and neutrophilic inflammation in chronic obstructive pulmonary disease. American Journal of Respiratory and Critical Care Medicine 2015; 192(8):934-42. [CENTRAL: 1077156] [EMBASE: 2015481225] [PMID: 26151090]

Wells JM, Viera L, Gautney J, Handley GH, Jackson PL, Bhatt SP, et al. A randomized, placebo-controlled trial of roflumilast on markers of inflammation in chronic obstructive pulmonary disease (COPD). American Journal of Respiratory and Critical Care Medicine 2015; 191(Meeting Abstracts):A3643. [EMBASE: 72051470]

\section{Roflumilast FK1 101 \{published and unpublished data\}}

Bredenbroker D, Syed J, Leichtl S, Rathgeb F, Wurst W. Roflumilast, a new, orally active phosphodiesterase 4 inhibitor, is effective in the treatment of chronic obstructive pulmonary disease. In: European Respiratory Society Annual Congress; 2002 14-18 Sep; Stockholm. 2002.

* Bredenbroker D, Syed J, Leichtl S, Rathgeb F, Wurst W. Safety of once-daily roflumilast, a new, orally active, selective phosphodiesterase 4 inhibitor, in patients with COPD. American Journal of Respiratory and Critical Care Medicine 2002; 165(Suppl 8):A595.

Leichtl S, Syed J, Bredenbröker D, Rathgeb F, Wurst W. Efficacy of once-daily roflumilast, a new, orally active, selective phosphodiesterase 4 inhibitor, in chronic obstructive pulmonary disease. American Journal of Respiratory and Critical Care Medicine 2002; 165(Suppl 8):A229.

Leichtl S, Syed J, Bredenbroker D, Rathgeb F, Wurst W. Roflumilast, a new, orally active, selective phosphodiesterase 4 inhibitor, is safe and well tolerated in patients with chronic obstructive pulmonary disease. In: European Respiratory Society Annual Congress; 2002 Sep 14-17; Stockholm. 2002.

\section{Roflumilast FK1 103 \{published and unpublished data\}}

Boszormenyi-Nagy G, Pieters WR, Steffen H, Timar M, Vinkler I, Teichmann P, et al. The effect of roflumilast treatment and subsequent withdrawal in patients with COPD. In: American Thoracic Society International Conference; 2005 May 20-25; San Diego. 2005.

* Rabe K, Similowski T, Bredenbröker D, Teichmann P, Böszörményi-Nagy G. Onset of action and effect of withdrawal of roflumilast in COPD. In: European Respiratory Society Annual Congress; 2011 Sep 24-28; Amsterdam. 2011.

\section{Roflumilast FLUI-2011-77 \{published data only\}}

De Backer J, Vos W, Claes R, Hufkens A, Bedert L, De Backer W. A double blind placebo controlled study to assess the effect of roflumilast in addition to LABA/LAMA/ICS treatment in COPD patients using novel biomarkers. American Journal of Respiratory and Critical Care Medicine 2014; 189:A3773. [CENTRAL: 1035550]

De Backer J, Vos W, Van Holsbeke C, Claes R, Hufkens A, Verplancke V, et al. A double blind placebo controlled study to assess the effect of roflumilast in addition to LABA/LAMA/ICS treatment in COPD patients using novel biomarkers. American Journal of Respiratory and Critical Care Medicine 2014; 44(Suppl 58):4670. [CENTRAL: 1053499] [EMBASE: 72043284]

* De Backer W, Vos W, Van Holsbeke C, Vinchurkar S, Claes R, Hufkens A, et al. The effect of roflumilast in addition to LABA/ LAMA/ICS treatment in COPD patients. European Respiratory Journal 2014; 44(2):527-9. [CENTRAL: 998328] [EMBASE: 2014530222] [PMID: 24791831]

\section{Roflumilast IN-108 \{unpublished data only\}}

Brown P. Clinical pharmacology and biopharmaceutics review(s). Application number 0225220rig1s000. accessdata.fda.gov/drugsatfda_docs/ nda/2011/022522Orig1s000ClinPharmR.pdf (accessed 9 October 2019).

\section{Roflumilast JP-706 \{unpublished data only\}}

Brown P. Clinical pharmacology and biopharmaceutics review(s). Application number 0225220rig1s000. www.accessdata.fda.gov/drugsatfda_docs/ nda/2011/0225220rig1s000ClinPharmR.pdf (accessed 9 October 2019).

\section{Roflumilast M2-107 \{published and unpublished data\}}

Bateman ED, Holmes M, Muir JF, Andrae K, Witte S, Bredenbroeker $D$. Safety profile of roflumilast, a novel, selective phosphodiesterase 4 inhibitor, in patients with moderate to severe COPD. In: American Thoracic Society 100th International Conference; 2004 May 21-26; Orlando. 2004.

O'Donnell D, Muir JF, Jenkins C, Plit P, Brockhaus F, Witte S, et al. Roflumilast, a novel selective phosphodiesterase 4 inhibitor, improves quality of life and lowers exacerbation rate in patients with moderate to severe COPD [Abstract]. In: American Thoracic Society 100th International Conference; 2004 May 21-26; Orlando. 2004 Orlando. 
Rabe F, O'Donnell D, Muir F, Jenkins C, Witte S, Bredenbroeker D, et al. Roflumilast an oral once daily PDE4 inhibitor improves lung function and reduces exacerbation rates in patients with COPD. European Respiratory Journal 2004; 24(Suppl 48):21s.

* Rabe KF, Bateman ED, O'Donnell D, Witte S, Bredenbröker D, Bethke TD. Roflumilast - an oral anti-inflammatory treatment for chronic obstructive pulmonary disease: a randomised controlled trial. Lancet 2005; 36(9485):563-71.

Rabe KF, Chapman KR, Joubert J, Vetter N, Witte S, Bredenboecker D. Roflumilast, a novel, selective phosphodiesterase 4 inhibitor, improves lung function in patients with moderate to severe COPD. In: American Thoracic Society 100th International Conference; 2004 May 21-26; Orlando. 2004.

Rabe KF, O'Donnell D, Bateman ED, Andrae K, Witte S, Bredenbroeker $\mathrm{D}$. Roflumilast improves lung function and quality of life in chronic obstructive pulmonary disease. Chest 2004; 126(4 Suppl):709S-a.

\section{Roflumilast M2-110 \{unpublished data only\}}

. Effect of roflumilast on pulmonary function and respiratory symptoms in patients with chronic obstructive pulmonary disease (COPD) (BY217/M2-110) [A 24 week, placebo-controlled, randomized, parallel group study comparing roflumilast 500 mcg daily vs placebo on pulmonary function and respiratory symptoms in patients with chronic obstructive pulmonary disease (COPD)]. clinicaltrials.gov/ct2/show/study/ NCT00062582 (accessed prior to 23 June 2017).

Roflumilast M2-111 \{published data only\} . OPUS study: effect of roflumilast on exacerbation rate in patients with chronic obstructive pulmonary disease (BY217/ M2-111). https://clinicaltrials.gov/show/NCT00076089 .

* Rennard SI, Calverley PM, Goehring UM, Bredenbroker D, Martinez FJ. Reduction of exacerbations by the PDE4 inhibitor roflumilast - the importance of defining different subsets of patients with COPD. Respiratory Research 2011; 12:18. [1465-993X: (Electronic). 1465-9921 (Linking)] [http:// filehosting.pharmacm.com/DownloadService.ashx? client=CTR_MED_7111\&studyid=4477\&filename=BY217-M2-111RDS-2008-12-23.pdf ]

Rennard SI, Calverley PMA, Rempel A, Bredenbroker D, Martinez FJ. The effect of roflumilast treatment on exacerbations in patients with COPD results of a pooled analysis of two 1-year studies. In: American Thoracic Society International Conference; 2008 May 16-21; Toronto. 2008.

Rusch H, Gooss A, Bethke TD, Rennard S. Efficacy of roflumilast when used with concomitant inhaled corticosteroids from the OPUS/RATIO studies. Respiration 2011; 82(1):67-107.

\section{Roflumilast M2-111+M2-112 \{published data only\}}

* Rennard SI, Calverley PM, Goehring UM, Bredenbroker D, Martinez FJ. Reduction of exacerbations by the PDE4 inhibitor roflumilast - the importance of defining different subsets of patients with COPD. Respiratory Research 2011; 12:18. [1465-993X: (Electronic). 1465-9921 (Linking)]
Rennard SI, Calverley PMA, Rempel A, Bredenbroker D, Martinez FJ. The effect of roflumilast treatment on exacerbations in patients with COPD results of a pooled analysis of two 1-year studies. In: American Thoracic Society International Conference; 2008 May 16-21; Toronto. 2008.

Rusch H, Gooss A, Bethke TD, Rennard S. Efficacy of roflumilast when used with concomitant inhaled corticosteroids from the OPUS/RATIO studies. Respiration 2011; 82(1):67-107.

\section{Roflumilast M2-112 \{published and unpublished data\}}

Calverley PM, Fabbri LM, Teichmann P, Bredenbroeker D. Effect of roflumilast on lung function and exacerbations in patients with chronic obstructive pulmonary disease: results of a one year study. Thorax 2005; 2(Suppl II):ii42.

* Calverley PM, Sanchez-Toril F, Mclvor A, Teichmann P, Bredenbroeker D, Fabbri LM. Effect of 1-year treatment with roflumilast in severe chronic obstructive pulmonary disease. American Journal of Respiratory and Critical Care Medicine 2007; 176(2):154-61.

Calverley PM, Sanchez-Toril F, Mclvor RA, Teichmann P, Bredenbroeker D, Fabbri LM. Effect of roflumilast on lung function: a 1-year study in patients with severe to very severe COPD. In: Proceedings of the American Thoracic Society; 2006 May 19-24; San Diego. 2006.

Fabbri LM, Sanchez-Toril F, Mclvor RA, Teichmann P, Bredenbroeker D, Calverley PM. Effect of roflumilast on exacerbations: a 1-year study in patients with severe to very severe COPD. In: American Thoracic Society Conference; 2006 May 19-24; San Diego. 2006.

Mclvor RA, Calverley PM, Sanchez-Toril F, Teichmann P, Bredenbroeker D, Fabbri LM. Effect of roflumilast on quality of life: a 1-year study in patients with severe to very severe COPD. In: American Thoracic Society Conference; 2006 May 19-24; San Diego. Vol. 3. 2006:A850.

Rennard SI, Calverley PM, Goehring UM, Bredenbroker D, Martinez FJ. Reduction of exacerbations by the PDE4 inhibitor roflumilast - the importance of defining different subsets of patients with COPD. Respiratory Research 2011; 12:18. [1465-993X: (Electronic). 1465-9921 (Linking)]

Rusch H, Gooss A, Bethke TD, Rennard S. Efficacy of roflumilast when used with concomitant inhaled corticosteroids from the OPUS/RATIO studies. Respiration 2011; 82(1):67-107.

Rutten-van Molken M, Van Nooten F, Lindermann M, Caser M. The 1-year cost effectiveness of roflumilast for the treatment of severe to very severe COPD patients. European Respiratory Journal 2007; 30(Suppl 51):194s, P1188.

Rutten-van Molken MP, Nooten FE, Lindemann M, Caeser M, Calverley PM. A 1-year prospective cost-effectiveness analysis of roflumilast for the treatment of patients with severe chronic obstructive pulmonary disease. PharmacoEconomics 2007; 25(8):695-711. [CENTRAL: 610748] [PMID: 17640111] 
Roflumilast M2-118 \{published data only\}

O'Donnell DE, Bredenbroker D, Brose M, Webb KA. Physiological effects of roflumilast at rest and during exercise in COPD.

European Respiratory Journal 2012; 39(5):1104-12.

[ES:1399-3003: IL:0903-1936]

\section{Roflumilast M2-119 \{published data only\}}

Hui D, Mahayiddin A, Roa C, Kwa KH, Bredenbröker D, Goehring UM, et al. Roflumilast in Asian patients with COPD: a randomised placebo-controlled trial. In: European Respiratory Society Annual Congress; 2011 Sep 24-28; Amsterdam. 2011.

Lee JS, Hong YK, Park TS, Lee SW, , . Efficacy and safety of roflumilast in Korean patients with COPD. Yonsei Medical Journal 2016; 57(4):928-35. [CENTRAL: 1158901] [EMBASE: 20160381439] [PMID: 27189287]

* Lee SD, Hui DS, Mahayiddin AA, Roa CC, Kwa KH, Goehring UM, et al. Roflumilast in Asian patients with COPD: a randomized placebo-controlled trial. Respirology 2011; 16(8):1249-57.

\section{Roflumilast M2-121 \{unpublished data only\}}

. The HERO-study: effects of roflumilast in patients with COPD (Chronic Obstructive Pulmonary Disease) (BY217/M2-121) [A 24-week, double blind, randomized study to investigate the effect of $500 \mu \mathrm{g}$ roflumilast tablets once daily versus placebo on parameters indicative of hyperinflation in patients with chronic obstructive pulmonary disease]. clinicaltrials.gov/ct2/show/ NCT00108823 (first received 19 April 2005).

Roflumilast M2-124 \{published and unpublished data\}

* Calverley PM, Rabe KF, , Kristiansen S, Fabbri LM, Martinez FJ, et al. Roflumilast in symptomatic chronic obstructive pulmonary disease: two randomised clinical trials. Lancet 2009; 374(9691):685-94.

Martinez F, Hanania N, AURA Study Team. Efficacy and safety of the phosphodiesterase-4 inhibitor roflumilast in patients with symptomatic chronic obstructive pulmonary disease in the M2-124 study. Chest 2009; 136(4):3S-e.

. Effect of roflumilast on exacerbation rate in patients with chronic obstructive pulmonary disease (COPD): the AURA study (BY217/M2-124). https://clinicaltrials.gov/show/NCT00297102.

Nowak D, Ehlken B, Kotchie R, Wecht S, Magnussen H. Roflumilast in combination with long-acting bronchodilators. Deutsche Medizinische Wochenschrift 2013; 138(4):119-25.

\section{Roflumilast M2-124+M2-125 \{published data only\}}

Bateman ED, Rabe KF, Calverley PMA, Goehring UM, Brosee M, Bredenbroker $\mathrm{D}$, et al. Roflumilast with long-acting beta2agonists for COPD: influence of exacerbation history. European Respiratory Journal 2011; 38(3):553-60.

Calverley P, Fabbri L, Rabe K, Goehring UM, Martinez F. Efficacy of the PDE4 inhibitor roflumilast in COPD patients with chronic bronchitis. In: European Respiratory Society Annual Congress; 2009 Sep 12-16; Vienna. 2009.

Calverley P, Martinez F, Goehring UM, Bredenbröker D, Brose M, Vogelmeier C. Impact of roflumilast treatment on the rate and duration of exacerbations and overall steroid load in patients with COPD. In: European Respiratory Society Annual Congress; 2011 Sep 24-28; Amsterdam. 2011.

* Calverley PM, Rabe KF, , Kristiansen S, Fabbri LM, Martinez FJ, et al. Roflumilast in symptomatic chronic obstructive pulmonary disease: two randomised clinical trials. Lancet 2009; 374(9691):685-94.

Calverley PMA, Rabe KF, Goehring UM, Kristiansen S, Fabbri LM, Martinez FJ. Erratum: Roflumilast in symptomatic chronic obstructive pulmonary disease: two randomised clinical trials (The Lancet (2009) 374 (685-694)). Lancet 2010; 376(9747):1146.

Gooss A, Rusch H, Bethke TD, Hanania N. Efficacy of roflumilast in patients receiving concomitant treatments for chronic obstructive pulmonary disease over 12 months. Respiration 2011; 82(1):67-107.

Hanania NA, Brose M, Larsson T, Rabe KF. Efficacy of roflumilast in patients receiving concomitant treatments for chronic obstructive pulmonary disease over 12 months. American Journal of Respiratory and Critical Care Medicine 2010; 181:A4435.

Hanania NA, Calverley PMA, Dransfield MT, Karpel JP, Brose M, $\mathrm{Zhu} \mathrm{H}$, et al. Pooled subpopulation analyses of the effects of roflumilast on exacerbations and lung function in COPD. Respiratory Medicine 2014; 108(2):366-75. [CENTRAL: 985699] [EMBASE: 2014100136] [PMID: 24120253]

Kaplan A, Calverley P. Efficacy of roflumilast in patients with symptomatic chronic obstructive pulmonary disease (COPD) receiving concomitant bronchodilator treatments. Primary Care Respiratory Journal 2010; 19(2):A13 [50].

Martinez F, Fabbri L, Rabe K, , Calverley P. Safety of the PDE4 inhibitor roflumilast in COPD patients with chronic bronchitis [Abstract]. In: European Respiratory Society Annual Congress; 2009 Sep 12-16; Vienna. 2009.

Martinez FJ, Rabe KF, Goehring UM, Lakkis H, Rowe P, Palm U. Roflumilast prolongs time to first and subsequent exacerbations in patients with severe to very severe COPD. American Journal of Respiratory and Critical Care Medicine 2011; 183(1 MeetingAbstracts):A5373. [CENTRAL: 1031450] [EMBASE: 70849677]

Martinez FJ, Rabe KF, Wouters EFM, Brose M, Goehring U, Fabbri LM, et al. Time course and reversibility of weight decrease with roflumilast, a phosphodiesterase 4 inhibitor. American Journal of Respiratory and Critical Care Medicine 2010; 181(1 Meeting Abstracts):A4441. [CENTRAL: 1031630] [EMBASE: 70841891]

Nowak D, Ehlken B, Kotchie R, Wecht S, Magnussen H. Roflumilast in combination with long-acting bronchodilators. Deutsche Medizinische Wochenschrift 2013; 138(4):119-25.

Wedzicha JA, Rabe KF, Martinez FJ, Bredenbroker D, Brose M, Goehring UM, et al. Efficacy of roflumilast in the COPD frequent exacerbator phenotype. Chest 2013; 143(5):1302-11. [CENTRAL: 870960] [PMID: 23117188] 
Roflumilast M2-125 \{published data only\}

Andrew M, Fernando J, HERMES Study Team. Efficacy and safety of the phosphodiesterase 4 inhibitor roflumilast in patients with symptomatic chronic obstructive pulmonary disease in the M2-125 study. Chest 2009; 136(4):93S-94.

* Calverley PM, Rabe KF, , Kristiansen S, Fabbri LM, Martinez FJ, et al. Roflumilast in symptomatic chronic obstructive pulmonary disease: two randomised clinical trials. Lancet 2009; 374(9691):685-94.

Nowak D, Ehlken B, Kotchie R, Wecht S, Magnussen $\mathrm{H}$. Roflumilast in combination with long-acting bronchodilators. Deutsche Medizinische Wochenschrift 2013; 138(4):119-25.

\section{Roflumilast M2-127 \{published data only\}}

Chapman KR, Mclvor A, Maltais F, EOS Study Team. Additional clinical benefit in patients with chronic obstructive pulmonary disease treated with roflumilast and salmeterol. Chest 2009; 136(4):3S-f.

Chapman KR, Rabe KF. Efficacy and safety of roflumilast in patients with chronic obstructive pulmonary disease (COPD) concomitantly treated with tiotropium or salmeterol. Primary Care Respiratory Journal 2010; 19(2):A12 [44].

* Fabbri LM, Calverley PM, Izquierdo-Alonso JL, Bundschuh DS, Brose M, Martinez FJ, et al. Roflumilast in moderate-to-severe chronic obstructive pulmonary disease treated with long acting bronchodilators: two randomised clinical trials. Lancet 2009; 374(9691):695-703.

Izquierdo JL, MacNee W, Biermann E, , Mclvor A. The PDE4 inhibitor roflumilast provides additional clinical benefit in COPD patients receiving salmeterol. In: European Respiratory Society Annual Congress; 2009 Sep 12-16; Vienna. 2009.

Martinez F, Mclvor A, Brose M, Larsson T, Goehring UM. Benefit of roflumilast therapy added to salmeterol in patients with varying chronic obstructive pulmonary disease severity. Chest 2010; 138(4):467A

. Effect of roflumilast on lung function in chronic obstructive pulmonary disease (COPD) patients treated with salmeterol: the EOS study (BY217/M2-127). https://clinicaltrials.gov/show/ NCT00313209.

Sun S, Rennard S, Calverley P, Tourkodimitris S, Rowe P, Creanga $D$, et al. Effect of roflumilast treatment on dyspnea in patients with chronic obstructive pulmonary disease. Journal of Hospital Medicine 2012; 7(Suppl 2):S85-6.

Sun S, Rennard S, Calverley P, Tourkodimitris S, Rowe P, Creanga $D$, et al. Effect of roflumilast treatment on health related quality of life in patients with chronic obstructive pulmonary disease. Journal of Hospital Medicine 2012; 7(Suppl 2):S81-2.

\section{Roflumilast M2-128 \{published data only\}}

Chapman KR, Rabe KF. Efficacy and safety of roflumilast in patients with chronic obstructive pulmonary disease (COPD) concomitantly treated with tiotropium or salmeterol. Primary Care Respiratory Journal 2010; 19(2):A12 [44].
* Fabbri LM, Calverley PM, Izquierdo-Alonso JL, Bundschuh DS, Brose M, Martinez FJ, et al. Roflumilast in moderate-to-severe chronic obstructive pulmonary disease treated with long acting bronchodilators: two randomised clinical trials. Lancet 2009; 374(9691):695-703.

Fabbri LM, Martinez FJ, , Brose M, Lakkis H, Rowe P. Roflumilast treatment with concomitant tiotropium: effect on lung function in severe COPD patients. Journal of General Internal Medicine 2012; 27:S303. [CENTRAL: 980891] [EMBASE: 71296919]

Paggiaro P, Foden A. Improvements in breathlessness in patients with chronic obstructive pulmonary disease treated with roflumilast and tiotropium. Chest 2009; 136(4):3S-g, 4.

Rabe K, Paggiaro P, Bernabeu L, Brose M, , Fabbri L. Roflumilast, a PDE4 inhibitor, improves lung function in patients with COPD treated with tiotropium. In: European Respiratory Society Annual Congress; 2009 Sep 12-16; Vienna. 2009.

Rennard SI, Sun S, Tourkodimitris S, Creanga D, Goehring UM, Bredenbroeker D. Effect of roflumilast treatment added to tiotropium on dyspnea in patients with chronic obstructive pulmonary disease. American Journal of Respiratory and Critical Care Medicine 2012; 185(Meeting Abstracts):A2261.

Wouters EFM, Teichmann P, Brose M, Rabe KF, Fabbri LM. Effects of roflumilast, a phosphodiesterase 4 inhibitor, on body composition in chronic obstructive pulmonary disease. American Journal of Respiratory and Critical Care Medicine 2010; 181(Meeting Abstracts):A4473.

Roflumilast ROF-MD-07(RE2SPOND) \{published data only\}

Ferguson GT, Rennard SI, Hanania NA, Zhu H, Siddiqui S, Sacks $\mathrm{H}$. Roflumilast treatment in COPD patients taking a fixeddose combination of long-acting $\beta 2$ agonist (LABA) and inhaled corticosteroid (ICS): rationale and design of a prospective randomized controlled trial. American Journal of Respiratory and Critical Care Medicine 2012; 185(Meeting Abstracts):A2946.

Martinez FJ, Calverley PMA, , Hodge R, Fabbri LM, Rabe KF. Effect of roflumilast on exacerbations in patients with severe COPD and a prior history of hospitalization taking combination therapy. European Respiratory Journal 2015; 46:OA482.

* Martinez FJ, Rabe KF, Sethi S, Pizzichini E, Mclvor A, Anzueto A, et al. Effect of roflumilast and inhaled corticosteroid/longacting beta2-agonist on chronic obstructive pulmonary disease exacerbations (RE(2)SPOND). A randomized clinical trial. American Journal of Respiratory and Critical Care Medicine 2016; 194(5):559-67. [PMID: 27585384]

. A 52-week, double-blind, randomized, placebo-controlled, parallel-group study to evaluate the effect of roflumilast $500 \mu \mathrm{g}$ on exacerbation rate in subjects with chronic obstructive pulmonary disease (COPD) treated with a fixeddose combination of long-acting beta agonist and inhaled corticosteroid (LABA/ICS). www.who.int/trialsearch/Trial2.aspx? TrialID=PER-114-11

Rennard SI, Martinez FJ, Rabe KF, Sethi S, Pizzichini E, Mclvor A, et al. Effect of roflumilast in COPD patients receiving inhaled corticosteroid/long-acting beta2-agonist fixeddose combination: RE2SPOND rationale and study design. 
International Journal of Chronic Obstructive Pulmonary Disease 2016; 11(1):1921-8. [CENTRAL: 1180201] [EMBASE: 20160624756] [PMID: 27574416]

Rennard SI, Martinez FJ, Sethi S, Zhu H, Haberman R, Zovko E. Effects of roflumilast in COPD patients receiving ICS/LABA fixed-dose combination: rationale and design of a prospective randomized controlled trial. American Journal of Respiratory and Critical Care Medicine 2015; 191(Meeting Abstracts):A5790. [CENTRAL: 1101144] [EMBASE: 72053688]

Sethi S, Martinez FJ, Rabe KF, Pizzichini E, Mclvor A, Anzueto A, et al. Effect of roflumilast on cough and sputum in patients with severe or very severe chronic obstructive pulmonary disease (COPD) receiving inhaled combination therapy: evaluation of the exacerbation of chronic pulmonary disease tool-patient reported outcomes (exact-pro) subdomain scores. American Journal of Respiratory and Critical Care Medicine 2017; 195:A1335.

White WB, Kowey PR, Zhu H, Siddiqui S, Rowe P. Evaluation of major adverse cardiac events (MACE) in a one-year, placebocontrolled study of roflumilast in patients with chronic obstructive pulmonary disease (COPD): rationale and design. American Journal of Respiratory and Critical Care Medicine 2013; 187(Meeting Abstracts):A1484. [CENTRAL: 870804]

Urban 2018 (ELASTIC) \{published data only\}

Urban M, Kreibich N, , Burghuber OC. Effects of roflumilast on subclinical atherosclerosis in COPD - a randomised controlled trial [Effects of the anti-inflammatory drug "ROFLUMILAST" on markers of early atherosclerosis in chronic obstructive pulmonary disease]. clinicaltrialsregister.eu/ctr-search/ trial/2011-004152-19/AT (first received 17 February 2012).

* Urban M, Kreibich N, , Burghuber OC. Effects of roflumilast on subclinical atherosclerosis in COPD - a randomised controlled trial. European Respiratory Journal 2017; 50:PA693.

\section{References to studies excluded from this review}

\section{Borker 2003 \{published data only\}}

Borker RD, Morris A, Lim J, Zhu J, Reisner C. Effect of cilomilast on quality of life improvement/deterioration and non-drug costs in patients with chronic obstructive pulmonary disease. Chest 2003; 124(4):170S-b,171.

\section{CTRI/2012/09/002961 \{published data only\}}

. A randomized, open labelled, multi centric parallel group three arms clinical study to evaluate the efficacy and safety of roflumilast $500 \mathrm{mcg}$ tablet in chronic obstructive pulmonary disorder. who.int/trialsearch/Trial2.aspx? TrialID=CTRI/2012/09/002961 (first received 5 September 2012).

\section{CTRI/2014/01/004370 \{published data only\}}

. A clinical trial study of oral Roflumilast $0.5 \mathrm{mg}$ Tablet and combination therapy of Roflumilast $0.5 \mathrm{mg}$ tablet plus Salmeterol $25 \mathrm{mcg}$ oral inhaler and combination therapy of Roflumilast $0.5 \mathrm{mg}$ tablet plus Tiotropium $9 \mathrm{mcg}$ oral inhaler in adult patients with chronic obstructive pulmonary disease [An open-label, prospective, three arm, parallel group, randomized, multicentric phase-III clinical study to evaluate the efficacy and safety between monotherapy of oral Roflumilast $0.5 \mathrm{mg}$ Tablet and combination therapy of Roflumilast $0.5 \mathrm{mg}$ tablet plus Salmeterol $25 \mathrm{mcg}$ oral inhaler and combination therapy of Roflumilast $0.5 \mathrm{mg}$ tablet plus Tiotropium $9 \mathrm{mcg}$ oral inhaler in adult patients with chronic obstructive pulmonary disease]. who.int/trialsearch/Trial2.aspx?TrialID=CTRI/2014/01/004370 (first received 31 January 2014).

\section{Ferguson 2003 \{published data only\}}

Ferguson G, Fischer TL, Morris A, Zhu J, Barnhart F, Reisner C. Cardiovascular safety of cilomilast in patients with chronic obstructive pulmonary disease. Chest 2003; 124(4):171S.

\section{Fischer 2003 \{published data only\}}

Fischer T, Borker R, Barnhart F, Morris A, Zhu J. Effect of cilomilast on chronic obstructive pulmonary disease patients with impaired quality of life. Chest 2003; 124(4):129S.

\section{Grootendorst 2001 \{published data only\}}

Grootendorst DC, Gauw SA, Kelly J, Murdoch RD, Sterk PJ, Rabe KF. First dose bronchodilating effect of phosphodiesterase-4 (PDE-4) inhibition by cilomilast (Ariflo) with or without co-administration of salbutamol and/or ipratropium in COPD patients. European Respiratory Journal 2001; 18(Suppl 33):1:35s

\section{Grootendorst 2002 \{published data only\}}

Grootendorst DC, Gauw SA, Verhoosel R, Van der Veen $\mathrm{H}$, Van der Linden A, Moesker $\mathrm{H}$, et al. Effect of a PDE4 inhibitor (Bay 19-8004) on FEV1 and airway inflammation in patients with COPD. American Journal of Respiratory and Critical Care Medicine 2002; 165(8 Suppl):A226.

\section{Grootendorst 2003 \{published data only\}}

Grootendorst DC, Gauw SA, Baan R, Kelly J, Murdoch RD, Sterk PJ, et al. Does a single dose of the phosphodiesterase 4 inhibitor, cilomilast (15mg), induce bronchodilation in patients with chronic obstructive pulmonary disease? Pulmonary Pharmacology and Therapeutics 2003; 16(2):115-20.

\section{Grootendorst 2007 \{published data only\}}

Grootendorst DC, Gauw SA, Verhoosel RM, Sterk PJ, Hospers JJ, Bredenbröker D, et al. Reduction in sputum neutrophil and eosinophil numbers by the PDE4 inhibitor roflumilast in patients with COPD. Thorax 2007; 62(12):1081-7.

\section{GSK256066 \{published data only\}}

Lazaar AL, Mistry S, Barrett C, Lulic-Burns Z. A four-week randomized study of the safety and tolerability of the inhaled PDE4 inhibitor GSK256066 in COPD. American Journal of Respiratory and Critical Care Medicine 2010; 181(Meeting Abstracts):A4444.

\section{Kelsen 2002 \{published data only\}}

Kelsen SG, Rennard SI, Chodosh S, Schryver B, Vleisides C, Zhu J. COPD exacerbation in a 6-month trial of cilomilast (Ariflo), a potent, selective phosphodiesterase 4 inhibitor. American Journal of Respiratory and Critical Care Medicine 2002; 165(Suppl 8):A271. 
Knobil 2003 \{published data only\}

Knobil K, Morris A, Zhu J, Fischer T, Reisner C. Cilomilast is efficacious in chronic obstructive pulmonary disease. In: American Thoracic Society 99th International Conference; 2003 May 16-21; Seattle. 2003:A035; Poster D92.

* Reisner C, Morris A, Zhu J, Fischer T, Knobil K. Cilomilast is efficacious in chronic obstructive pulmonary disease. European Respiratory Journal 2003; 22(Suppl 45):P530.

Lim 2004 \{published data only\}

Lim S, Zhu J, Lake P. Cilomilast decreases exacerbations and maintains lung function in patients with poorly reversible COPD. European Respiratory Journal 2004; 24(Suppl 48):88s.

\section{NCT00246935 \{published data only\}}

. Long-term study of safety and efficacy of roflumilast in Japanese patients older than 40 years with chronic obstructive pulmonary disease (APTA-2217-08) [A long-term study of APTA-2217 in patients with chronic obstructive pulmonary disease]. clinicaltrials.gov/show/nct00246935 (first received 1 November 2005).

\section{NCT01849341 \{published data only\}}

. Roflumilast safety administered once a day on alternate days for two weeks compared to the usual dosage once daily [Clinical trial phase III blind, parallel group to analyze differences in the safety of roflumilast administered once a day on alternate days for two weeks compared to the usual dosage once daily]. clinicaltrials.gov/show/NCT01849341 (first received 8 May 2013).

\section{NCT01973998 \{published data only\}}

. Effects of roflumilast in hospitalized chronic obstructive pulmonary disease (COPD) on mortality and re-hospitalization. clinicaltrials.gov/show/nct01973998 (first received 1 November 2013).

\section{NCT02018432 \{published data only\}}

. Strategy to improve adherence of roflumilast [Adherence to therapy in COPD patients under dose escalation of roflumilast]. clinicaltrials.gov/show/nct02018432 (first received 23 December 2013).

\section{Nieman 1999 \{unpublished data only\}}

Nieman RB, Taneja DT, Amit O, Benincosa LJ, Compton CH, Bethala VK, et al. The effects of low dose SB207499, a second generation, oral PDE4 inhibitor, in patients with COPD. In: European Respiratory Society Congress; 1999 Oct 9-13; Madrid. 1999.

\section{Pascoe 2007 \{unpublished data only\}}

Pascoe SJ, Bonner J, Hauffe S, Bohnemeier H. Gradual dose escalation of QAK423, a novel PDE4 inhibitor, significantly improves the tolerability. In: American Thoracic Society International Conference; 2007 May 18-23; San Francisco. 2007.

\section{Rabe 2017 \{published data only\}}

Rabe KF, Calverley PMA, Martinez FJ, Fabbri LM. Effect of roflumilast in patients with severe COPD and a history of hospitalisation. European Respiratory Journal 2017; 50(1):1700158.

\section{Reisner 2003 \{published data only\}}

Reisner C, Morris A, Barnhart F, Fischer TL, Acusta A, Darken P. Cilomilast reduces exacerbations in patients with chronic obstructive pulmonary disease. Chest 2003; 124:4.

Rennard 2008 \{published data only\}

Rennard S, Knobil K, Rabe KF, Morris A, Schachter N, Locantore $\mathrm{N}$, et al. The efficacy and safety of cilomilast in COPD. Drugs 2008; 68(Suppl 2):3-57.

\section{Roflumilast JP708 \{unpublished data only\}}

Brown P. Center for drug evaluation and research application number: 0225220rig1s000. Pharmacology review. www.accessdata.fda.gov/drugsatfda_docs/ nda/2011/022522Orig1s000PharmR.pdf (accessed prior to 28 June 2017).

\section{Sadigov 2014 \{published data only\}}

Sadigov A, Akhundov S, Bagirov R. Analysis of chronic obstructive pulmonary disease exacerbations with the triple therapy compared with dual and single bronchodilator therapy: which treatment is better for patients with severe disease? Chest 2014; 145(3):425A. [CENTRAL: 991341] [EMBASE: 71429002]

* Sadigov AS, Bagirov R, Abbasov C. Analysis of chronic obstructive pulmonary disease exacerbations with the triple therapy compared with dual treatment: is it better treatment tool for patients with severe disease? American Journal of Respiratory and Critical Care Medicine 2014; 189:A3770. [CENTRAL: 1035664] [EMBASE: 72043281]

\section{Sadigov 2015 \{published data only\}}

Sadigov A, Huseynova S. Efficacy and safety of dual antiinflammatory combination of fluticasone and roflumilast for the treatment of COPD: is dual better than single? American Journal of Respiratory and Critical Care Medicine 2015; 191(Meeting Abstracts):A3968. [CENTRAL: 1101148] [EMBASE: 72051845]

\section{SB207499/040 \{unpublished data only\}}

. A multicentre, open-label extension study to evaluate the safety, tolerability and efficacy of oral SB-207499 (15 mg twice daily) in patients with chronic obstructive pulmonary disease. www.gsk-clinicalstudyregister.com/files/pdf/24044.pdf (first received 28 September 2008).

\section{SB207499/041 \{unpublished data only\}}

. A multicenter open-label extension study to evaluate the safety, tolerability and efficacy of oral cilomilast (15 mg twice daily) in patients with chronic obstructive pulmonary disease. www.gsk-clinicalstudyregister.com/files/pdf/24045.pdf (first received 28 September 2008).

\section{Song 2005 \{published data only\}}

Song Y, Wang C, Liao X, Wang Y, Li Q, Zhao Z, et al. Improvement in lung residual volume in patients with COPD roles of antiinflammation activity of cilomilast. Respiratory 2005; 10(Suppl 3):A135. 
Spencer 2002 \{published data only\}

Spencer MD, Zhu J, Izard D. The direct costs of exacerbations in COPD and the effect of cilomilast treatment. European Respiratory Journal 2002; 20(Suppl 38):245s.

\section{Vestbo 2007 \{published data only\}}

Vestbo J, Tan L, Atkinson G. A 6 week study of the efficacy and safety of UK 500,001 dry powder for inhalation (DPI) in adults with chronic obstructive pulmonary disease. European Respiratory Journal 2007; 30(Suppl 51):612s [P3598].

\section{Vestbo 2009 \{published data only\}}

Vestbo J, Tan L, Atkinson G, Ward J. A controlled trial of 6weeks' treatment with a novel inhaled phosphodiesterase type-4 inhibitor in COPD. European Respiratory Journal 2009; 33(5):1039-44.

\section{Wang 2005 \{published data only\}}

Wang C, Song Y, Liao X. Efficacy and anti-inflammation activity of a selective phospodiesterase-4 inhibitor cilomilast in treatment of COPD. Chest 2005; 128(4):262S-a.

\section{Watz 2013 \{published data only\}}

Watz H, Mistry SJ, Lazaar AL, IPC101939 investigators. Safety and tolerability of the inhaled phosphodiesterase 4 inhibitor GSK256066 in moderate COPD. Pulmonary Pharmacology and Therapeutics 2013; 26(5):588-95. [CENTRAL: 872117] [EMBASE: 2013527752] [PMID: 23701917]

\section{Watz 2016 \{published data only\}}

. Study to evaluate how to optimise the use of roflumilast in subjects who have a lung disease called chronic obstructive pulmonary disease (COPD) [A multicenter, randomized, double-blind phase 3 study to evaluate tolerability and pharmacokinetics of $500 \mu \mathrm{g}$ roflumilast once daily with an up-titration regimen in COPD, including an open-label downtitration period evaluating tolerability and pharmacokinetics of $250 \mu \mathrm{g}$ roflumilast once daily in subjects not tolerating 500 $\mu \mathrm{g}$ roflumilast once-daily]. clinicaltrialsregister.eu/ctr-search/ trial/2013-001788-21/results (first received 6 February 2014).

Facius A, Bagul N, Gardiner P, Watz H. Pharmacokinetics and pharmacodynamics of a 4-week up-titration regimen of roflumilast in the optimize study OS. Pneumologie 2018; 72(Suppl 1):S92.

, Bagul N, Gardiner P, Watz H. Pharmacokinetics of a 4-week up-titration regimen of roflumilast in the optimize study. American Journal of Respiratory and Critical Care Medicine. 2017; 195:A1337.

. Evaluation of tolerability and pharmacokinetics of roflumilast, $250 \mu \mathrm{g}$ and $500 \mu \mathrm{g}$, as add-on to standard COPD treatment to treat severe COPD (OPTIMIZE). clinicaltrials.gov/ct2/show/ NCT02165826 (first received 18 June 2014).

Watz H, Bagul N, Nip K, Sun R, , Calverley P, et al. Tolerability of different dosing regimens of roflumilast in severe COPD (OPTIMIZE). European Respiratory Journal 2016; 48:PA308.

* Watz H, Bagul N, Rabe KF, Rennard S, Alagappan VKT, Roman J, et al. Use of a 4-week up-titration regimen of roflumilast in patients with severe COPD. International Journal of Chronic Obstructive Pulmonary Disease 2018; 13:813-22.

\section{References to studies awaiting assessment}

Barnes 2014 \{published data only\}

Barnes NC, Saetta M, Rabe KF. Implementing lessons learned from previous bronchial biopsy trials in a new randomized controlled COPD biopsy trial with roflumilast. BMC Pulmonary Medicine 2014; 14(1):9. [CENTRAL: 973300] [EMBASE: 2014126619] [PMID: 24484726]

EUCTR2004-004442-40-GB \{published data only\}

$.500 \mu \mathrm{g}$ roflumilast once daily in combination with $50 \mu \mathrm{g}$ salmeterol twice daily versus $50 \mu \mathrm{g}$ salmeterol twice daily alone over 52 weeks in patients with COPD. who.int/trialsearch/ Trial2.aspx?TrialID=EUCTR2004-004442-40-GB (first received 23 February 2005).

\section{Mahmud 2013 \{published data only\}}

Mahmud AM, Hossain A, Hassan R, Khan AS, Bennoor KS, Shaheen M, et al. Placebo controlled study of roflumilast in Bangladeshi COPD patients. Respirology 2013; 18(Suppl 4):125 [PS160]. [CENTRAL: 980913] [EMBASE: 71371785]

\section{NCT00671073 \{published data only\}}

. Study to assess efficacy and safety of oglemilast in patients with chronic obstructive pulmonary disease (COPD). clinicaltrials.gov/show/NCT00671073 (first received 2 May 2008).

\section{NCT01595750 \{published data only\}}

. Randomized, double-blind, placebo-controlled study to evaluate the effect of roflumilast on endothelial function in patients with chronic obstructive pulmonary disease (REVASC) [Randomized, double-blind, placebo-controlled study to evaluate the effect of roflumilast on endothelial function in patients with chronic obstructive pulmonary disease]. clinicaltrials.gov/show/NCT01595750 (first received 10 May 2012).

\section{NCT01701934 \{published data only\}}

. Impact of roflumilast on visceral adiposity and metabolic profile in chronic obstructive pulmonary disease (RAMBO). clinicaltrials.gov/show/NCT01701934 (first received 5 October 2012).

\section{References to ongoing studies}

\section{NCT02451540 2015 \{published data only\}}

. Placebo controlled study to assess the effect of Roflumilast in hyperinflated COPD patients in addition to LABA/LAMA therapy using functional respiratory imaging. clinicaltrialsregister.eu/ ctr-search/trial/2015-000053-21/BE (first received 14 April 2015).

. Evaluation of the effect of roflumilast in hyperinflated COPD patients using functional respiratory imaging [Placebo controlled study to assess the effect of roflumilast in hyperinflated COPD patients in addition to LABA/LAMA therapy using functional respiratory imaging]. clinicaltrials.gov/show/ NCT02451540 (first received 7 May 2015). 
NCT02671942 2016 \{published data only\}

. A multicenter randomized double-blind clinical study evaluated the safety, pharmacokinetic and pharmacodynamic characteristics of roflumilast in COPD patients. clinicaltrials.gov/ show/NCT02671942 (first received 25 January 2016).

\section{Additional references}

\section{Agusti 2005}

Agusti A. COPD, a multicomponent disease: implications for management. Respiratory Medicine 2005; 99(6):670-82.

\section{Barnes 2000}

Barnes P. Medical progress: chronic obstructive pulmonary disease. New England Journal of Medicine 2000; 343:269-80.

\section{Barnes 2003}

Barnes P. Theophylline: new perspectives for an old drug. American Journal of Respiratory and Critical Care Medicine 2003; 167(6):813-8.

\section{Barnes 2005}

Barnes P. Theophylline in chronic obstructive pulmonary disease: new horizons. Proceedings of the American Thoracic Society 2005; 2(4):334-9.

\section{Boswell-Smith 2006}

Boswell-Smith V, Spina D, Page C. Phosphodiesterase inhibitors. British Journal of Pharmacology 2006; 147:s252-7.

\section{Calverley 2007}

Calverley PM, Anderson JA, Celli B, Ferguson GT, Jenkins C, Jones PW, et al. Salmeterol and fluticasone propionate and survival in chronic obstructive pulmonary disease. New England Journal of Medicine 2007; 356(8):775-89.

\section{Calverley 2009}

Calverley PM, Rabe KF, Goehring UM, Kristiansen S, Fabbri LM, Martinez FJ. Roflumilast in symptomatic chronic obstructive pulmonary disease: two randomised clinical trials. Lancet 2009; 374:685-94.

\section{Celli 2004}

Celli B, MacNee W. Standards for the diagnosis and treatment of patients with COPD: a summary of the ATS/ERS position paper. European Respiratory Journal 2004; 23(6):932-46.

\section{Cochrane Airways 2019}

Cochrane Airways Trials Register. airways.cochrane.org/trialsregister (accessed 7 May 2019).

\section{Donohue 2005}

Donohue J. Minimal clinically important differences in COPD lung function. COPD 2005; 2:111-24.

\section{Essayan 2001}

Essayan D. Cyclic nucleotide phosphodiesterases. Journal of Allergy and Clinical Immunology 2001; 108(5):671-80.

\section{Fabbri 2009}

Fabbri LM, Calverley PM, Izquierdo-Alonso JL, Bundschuh DS, Brose M, Martinez FJ, et al. Roflumilast in moderate-to-severe chronic obstructive pulmonary disease treated with long acting bronchodilators: two randomised clinical trials. Lancet 2009; 374(9691):695-703.

\section{GOLD 2020}

From the global strategy for the diagnosis, management and prevention of COPD, global initiative for chronic obstructive lung disease (GOLD) 2020. goldcopd.org (accessed 11 February 2020).

\section{GRADEpro GDT 2015 [Computer program]}

McMaster University (developed by Evidence Prime) GRADEpro GDT. Version accessed 31 May 2017. Hamilton (ON): McMaster University (developed by Evidence Prime), 2015.Available at gradepro.org.

\section{Guyatt 2008}

Guyatt GH, Oxman AD, Vist GE, Kunz R, Falck-Ytter Y, AlonsoCoello $P$, Schünemann HKJ. GRADE: an emerging consensus on rating quality of evidence and strength of recommendations. British Medical Journal 2008; 336:924.

\section{Higgins 2003}

Higgins JT, Thompson SG, Deeks JJ, Altman DG. Measuring inconsistency in meta-analyses. BMJ 2003; 327:557-60.

\section{Higgins 2019}

Higgins JT, Savović J, Page MJ, Elbers RG, Sterne AC. Chapter 8. Assessing risk of bias in a randomized trial. In: Higgins JT, Thomas J, Chandler J, Cumpston M, Li T, Page MJ, Welch VA (editors). Cochrane Handbook for Systematic Reviews of Interventions version 6.0 (updated July 2019). Cochrane, 2019. Available from www.training.cochrane.org/handbook.

\section{Jones 2005}

Jones P. St. George's Respiratory Questionnaire: MCID. COPD 2005; 2:75-9.

\section{Le Rouzic 2018}

Le Rouzic O, Roche N, Cortot AB, Tillie-Leblond I, Masure F, . Defining the "frequent exacerbator" phenotype in COPD. Chest Journal 2018; 153(5):1106-15.

\section{Luo 2016}

Luo J, Wang K, Liu D, Liang BM, Liu CT. Can roflumilast, a phosphodiesterase-4 inhibitor, improve clinical outcomes in patients with moderate-to-severe chronic obstructive pulmonary disease? A meta-analysis. Respiratory Research 2016; 17:17.

\section{Mathers 2005}

Mathers C, Loncar D. Updated projections of global mortality and burden of disease, 2002-2030: data sources, methods and results. Evidence and Information for Policy Working Paper. who.int/healthinfo/statistics/bod_projections2030_paper.pdf (accessed prior to 28 June 2017). 


\section{Moher 2009}

Moher D, Liberati A, Tetzlaff J, Altman DG, the PRISMA Group (2009). Preferred Reporting Items for Systematic Reviews and Meta-Analyses: The PRISMA Statement. PLoS Medicine 6;7:e1000097. [DOI: 10.1371/journal.pmed1000097]

\section{Rennard 2014}

Rennard SI, Sun SX, Tourkodimitris S, Rowe P, Goehring UM, Bredenbröker $\mathrm{D}$, et al. Roflumilast and dyspnea in patients with moderate to very severe chronic obstructive pulmonary disease: a pooled analysis of four clinical trials. International Journal of Chronic Obstructive Pulmonary Disease 2014; 9:657-73.

\section{RevMan 2014 [Computer program]}

Nordic Cochrane Centre, The Cochrane Collaboration Review Manager 5 (RevMan 5). Version 5.3. Copenhagen: Nordic Cochrane Centre, The Cochrane Collaboration, 2014.

\section{Shen 2018}

Shen LF, Lv XD, Chen WY, Yang Q, Fang ZX, Lu WF. Effect of roflumilast on chronic obstructive pulmonary disease: a systematic review and meta-analysis. Irish Journal of Medical Science 2018; 187(3):731-8.

\section{TORCH 2007}

Calverley P, Anderson J, Celli B, Ferguson GT, Jenkins C, Jones P, et al. Salmeterol and fluticasone propionate and survival in chronic obstructive pulmonary disease. New England Journal of Medicine 2007; 356(8):775-89.

\section{Torphy 1998}

Torphy T. Phosphodiesterase isozymes: molecular targets for novel antiasthma agents. American Journal of Respiratory and Critical Care Medicine 1998; 157(2):351-70.

\section{Torphy 1999}

Torphy T, Barnette M, Underwood D, Griswold DE, Christensen SB, Murdoch RD, et al. Ariflo (SB 207499), a second generation phosphodiesterase 4 inhibitor for the treatment of asthma and COPD: from concept to clinic. Pulmonary Pharmacology and Therapeutics 1999; 12(2):131-5.

\section{Van Geffen 2015}

Van Geffen WH, Slebos DJ, Kerstjens HA. Hyperinflation in COPD exacerbations. Lancet Respiratory Medicine 2015; 12:e43-44.

\section{Vignola 2004}

Vignola A. PDE4 inhibitors in COPD - a more selective approach to treatment. Respiratory Medicine 2004; 98(6):495-503.

\section{Wedzicha 2007}

Wedzicha JA, Seemungal TA. COPD exacerbations: defining their cause and prevention. Lancet 2007; 370:786-96.

\section{Wedzicha 2016}

Wedzicha JA, Calverley PMA, Rabe KF. Roflumilast: a review of its use in the treatment of COPD. International Journal of Chronic Obstructive Pulmonary Disease 2016; 11:81-90.

\section{White 2003}

White AJ, Gompertz S, Stockley RA. Chronic obstructive pulmonary disease. 6: the aetiology of exacerbations of chronic obstructive pulmonary disease. Thorax 2003; 58:73-80.

\section{White 2013}

White W, Cooke G, Kowey P, Calverley P, Bredenbröker D, Goehring $U$, et al. Cardiovascular safety in patients receiving roflumilast for the treatment of chronic obstructive pulmonary disease. Chest 2013; 144(3):758-65.

\section{Yuan 2016}

Yuan L, Dai X, Yang M, Cai Q, Shao N. Potential treatment benefits and safety of roflumilast in COPD: a systematic review and meta-analysis. International Journal of Chronic Obstructive Pulmonary Disease 2016; 11:1477-83.

\section{References to other published versions of this review Chong 2013}

Chong J, Leung B, Poole P. Phosphodiesterase 4 inhibitors for chronic obstructive pulmonary disease. Cochrane Database of Systematic Reviews 2013, Issue 11. [DOI: 10.1002/14651858.CD002309.pub4]

* Indicates the major publication for the study

\section{CHARACTERISTICS OF STUDIES}

Characteristics of included studies [ordered by study ID]

Cilomilast 039

\section{Study characteristics}

Study design: parallel-group study
Rethods $\quad$ Randomisation: randomised, double-blind, placebo-controlled trial

Trial duration: 24 weeks

Intention-to-treat analysis: stated 
Cilomilast 039 (Continued)

Participants

Setting: 102 centres in Canada, Mexico, and the USA

Participants: 647 (15 mg cilomilast: 431, placebo: 216)

Baseline characteristics: mean age 65 years, $62 \%$ male, mean FEV $1 \%$ predicted $49.7 \%$, mean smoking history 59.9 pack-years for cilomilast and 56.1 pack-years for placebo, or current smokers ( $44 \%$ and $47 \%$, respectively)

Inclusion criteria: $\mathrm{FEV}_{1} / \mathrm{FVC} \leq 0.7, \mathrm{FEV}_{1} 30 \%$ to $70 \%$ with smoking history $>10$ pack-years or current smokers

Exclusion criteria: active tuberculosis, lung cancer, bronchiectasis

Total numbers of participant withdrawals: 137 (32\%) and 52 (24\%) from treatment and control groups, respectively

Run-in: 4 weeks, single-blind. Placebo tablets to assess suitability
- Cilomilast $15 \mathrm{mg}$ twice daily
- Placebo twice daily
Concomitant medication
- Short-acting anticholingeric: "the only other permitted medications for the treatment of airways dis-
ease were stable doses of Ipratropium, via a metered-dose inhaler, and mucolytic agents"
- SABA: "...the short-acting $\beta_{2}$-agonist albuterol, which was administered via a metered-dose inhaler,
was supplied for the relief of acute respiratory symptoms"
- Corticosteroid: none
- LABA: none

Outcomes

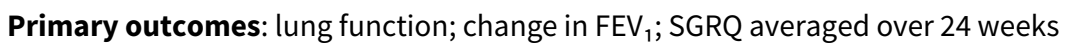

Secondary outcomes: incidence rate of COPD exacerbations; adverse events; FVC at trough; 6MWT; post-exercise dyspnoea

Notes Funded by GlaxoSmithKline

\section{Risk of bias}

\begin{tabular}{lll}
\hline Bias & Authors' judgement & Support for judgement \\
\hline $\begin{array}{l}\text { Random sequence genera- } \\
\text { tion (selection bias) }\end{array}$ & Low risk & $\begin{array}{l}\text { Assumed that the randomisation process was adequate due to pharma spon- } \\
\text { sorship }\end{array}$ \\
\hline $\begin{array}{l}\text { Allocation concealment } \\
\text { (selection bias) }\end{array}$ & Low risk & $\begin{array}{l}\text { Assumed that the allocation concealment method was adequate due to phar- } \\
\text { maceutical sponsorship }\end{array}$ \\
\hline $\begin{array}{l}\text { Blinding of participants } \\
\begin{array}{l}\text { and personnel (perfor- } \\
\text { mance bias) } \\
\text { All outcomes }\end{array}\end{array}$ & Low risk & The trial was double-blinded \\
\hline
\end{tabular}

\begin{tabular}{|c|c|c|}
\hline $\begin{array}{l}\text { Blinding of outcome as- } \\
\text { sessment (detection bias) } \\
\text { All outcomes }\end{array}$ & Unclear risk & Assumed that this would be low risk; however, no available information \\
\hline $\begin{array}{l}\text { Incomplete outcome data } \\
\text { (attrition bias) } \\
\text { All outcomes }\end{array}$ & Low risk & $\begin{array}{l}\text { "The primary reasons for the withdrawal of subjects from the study prior to } \\
\text { randomisation were the failure to meet inclusion/exclusion criteria (15.4\%) } \\
\text { and the presence of adverse effects, including COPD exacerbations (8.5\%). }\end{array}$ \\
\hline
\end{tabular}


Cilomilast 039 (Continued)

More subjects receiving cilomilast than placebo withdrew from the double-blind phase of study $(31.8 \%(n=137)$ versus $24.1 \%(n=52) "$

\begin{tabular}{|c|c|c|}
\hline $\begin{array}{l}\text { Selective reporting (re- } \\
\text { porting bias) }\end{array}$ & Low risk & $\begin{array}{l}\text { Outcomes were reported as planned. Trial information was reported on the } \\
\text { GSK website }\end{array}$ \\
\hline Other bias & Low risk & $\begin{array}{l}\text { Baseline anticholinergic, beta }{ }_{2} \text {-agonist, or corticosteroid use } 54 \% \text { in cilomi- } \\
\text { last, } 58 \% \text { placebo used ipratropium; } 99 \% \text { in cilomilast, } 100 \% \text { placebo used al- } \\
\text { buterol; } 9 \% \text { in cilomilast, } 12 \% \text { placebo used salmeterol; } 7 \% \text { in cilomilast, } 8 \% \\
\text { placebo used triamcinolone; } 6 \% \text { in cilomilast, } 7 \% \text { placebo used beclometha- } \\
\text { sone }\end{array}$ \\
\hline
\end{tabular}

Cilomilast 042

\section{Study characteristics}

\begin{tabular}{|c|c|}
\hline Methods & $\begin{array}{l}\text { Study design: parallel-group study } \\
\text { Randomisation: randomised, double-blind, placebo-controlled trial } \\
\text { Trial duration: } 24 \text { weeks } \\
\text { Intention-to-treat analysis: stated }\end{array}$ \\
\hline Participants & $\begin{array}{l}\text { Setting: } 98 \text { centres in Australia and New Zealand, Germany, Spain, South Africa, and the UK } \\
\text { Participants: } 700 \text { ( } 15 \text { mg cilomilast: } 474 \text {, placebo: } 226 \text { ) } \\
\text { Baseline characteristics: mean age } 64.6 \text { years, } 80 \% \text { male, mean } \mathrm{FEV}_{1} \% \text { predicted } 49 \% \text { with } 5.1 \% \text { re- } \\
\text { versibility, DLCO } 71 \% \text { predicted, also with higher rates of chronic bronchitis } 80.1 \% .45 \% \text { active smokers } \\
\text { Inclusion criteria: aged } 40 \text { to } 80 \text { years, } F E V_{1} / F V C \leq 0.7, F E V_{1} 30 \% \text { to } 70 \% \text { with smoking history > } 10 \\
\text { pack-years } \\
\text { Exclusion criteria: active tuberculosis, lung cancer, bronchiectasis } \\
\text { Total numbers of participant withdrawals: } 122(26 \%) \text { and } 51(23 \%) \text { from treatment and control } \\
\text { groups, respectively }\end{array}$ \\
\hline Interventions & $\begin{array}{l}\text { Run-in: } 4 \text { weeks, single-blind with placebo } \\
\text { - Cilomilast } 15 \text { mg twice daily } \\
\text { - Placebo twice daily } \\
\text { Concomitant medication } \\
\text { - Short-acting anticholingeric: } 2 \% \text { in cilomilast, } 3 \% \text { placebo used salbutamol; } 3 \% \text { in cilomilast, } 1 \% \\
\text { placebo used ipratropium } \\
\text { - SABA: "albuterol MDI was used as rescue medication" } \\
\text { - Corticosteroid: none } \\
\text { - LABA: none }\end{array}$ \\
\hline
\end{tabular}

Outcomes

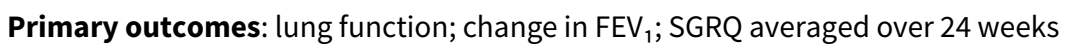

Secondary outcomes: incidence rate of COPD exacerbations; summary symptom score; FVC at trough; 6MWT; post-exercise dyspnoea

Notes Funded by GlaxoSmithKline


Cilomilast 042 (Continued)

\section{Risk of bias}

\begin{tabular}{|c|c|c|}
\hline Bias & Authors' judgement & Support for judgement \\
\hline $\begin{array}{l}\text { Random sequence genera- } \\
\text { tion (selection bias) }\end{array}$ & Low risk & $\begin{array}{l}\text { Assumed that the randomisation method was adequate due to pharma spon- } \\
\text { sorship }\end{array}$ \\
\hline $\begin{array}{l}\text { Allocation concealment } \\
\text { (selection bias) }\end{array}$ & Low risk & $\begin{array}{l}\text { Assumed that the allocation concealment method was adequate due to phar- } \\
\text { maceutical company sponsorship }\end{array}$ \\
\hline $\begin{array}{l}\text { Blinding of participants } \\
\text { and personnel (perfor- } \\
\text { mance bias) } \\
\text { All outcomes }\end{array}$ & Low risk & The trial was double-blinded \\
\hline $\begin{array}{l}\text { Blinding of outcome as- } \\
\text { sessment (detection bias) } \\
\text { All outcomes }\end{array}$ & Unclear risk & Assumed that this would be low risk; however, no available information \\
\hline $\begin{array}{l}\text { Incomplete outcome data } \\
\text { (attrition bias) } \\
\text { All outcomes }\end{array}$ & Low risk & $\begin{array}{l}\text { Total numbers of participants withdrawn } 51(23 \%) \text { placebo, } 122(26 \%) \text { cilomi- } \\
\text { last, primarily due to adverse events, of which most were not from COPD exac- } \\
\text { erbations }\end{array}$ \\
\hline $\begin{array}{l}\text { Selective reporting (re- } \\
\text { porting bias) }\end{array}$ & Low risk & $\begin{array}{l}\text { Outcomes were reported as planned. Trial information was reported on the } \\
\text { GSK website }\end{array}$ \\
\hline Other bias & Unclear risk & $\begin{array}{l}\text { No information on baseline anticholinergic, beta }{ }_{2} \text {-agonist, or corticosteroid } \\
\text { use }\end{array}$ \\
\hline
\end{tabular}

Cilomilast 076

\section{Study characteristics}

\begin{tabular}{ll}
\hline Methods & Study design: parallel-group study \\
& Randomisation: randomised, double-blind, placebo-controlled trial \\
& Trial duration: 12 weeks \\
& Analysis was done on per-protocol population \\
\hline Participants & Setting: not stated \\
& Participants: 59 ( 15 mg cilomilast: 29 , placebo: 30$)$ \\
& Baseline characteristics: mean age 61 to 62 years, $81 \%$ male, $53 \%$ active smokers, mean 46 pack- \\
years, $53 \%$ to $58 \%$ FEV 1 predicted & Inclusion criteria: aged 40 to 80 years, fixed airflow obstruction, smoking history > 10 pack-years \\
& Exclusion criteria: not stated \\
& $\begin{array}{l}\text { Total numbers of participant withdrawals: } 4 \text { (14\%) and } 2 \text { (7\%) from treatment and control groups, } \\
\text { respectively }\end{array}$ \\
\hline Run-in: 4 weeks, single-blind with placebo \\
- Cilomilast 15 mg twice daily
\end{tabular}


Cilomilast 076 (Continued)

- Placebo twice daily

\section{Concomitant medication}

- Short-acting anticholingeric: "14 of 59 used ipratropium bromide at a constant dosage (8 in the placebo group, 6 in the cilomilast group)"

- SABA: "all patients were given albuterol for use as required"

- Corticosteroid: none

- LABA: none

Used alongside SABA (available to all) and anticholingeric drugs (offered to 24\%)

\begin{tabular}{ll}
\hline Outcomes & Primary outcome: change in neutrophil percentage in induced sputum \\
& Secondary outcomes: $\mathrm{FEV}_{1}$; numbers of subepithelial CD8+ cells, CD $68+$ cells, epithelial, and subep- \\
& ithelial neutrophils
\end{tabular}

Notes Funded by GlaxoSmithKline

\section{Risk of bias}

\begin{tabular}{|c|c|c|}
\hline Bias & Authors' judgement & Support for judgement \\
\hline $\begin{array}{l}\text { Random sequence genera- } \\
\text { tion (selection bias) }\end{array}$ & Low risk & $\begin{array}{l}\text { Assumed that the randomisation process was adequate due to pharmaceutical } \\
\text { company sponsorship }\end{array}$ \\
\hline $\begin{array}{l}\text { Allocation concealment } \\
\text { (selection bias) }\end{array}$ & Low risk & $\begin{array}{l}\text { Assumed that the allocation concealment method was adequate due to phar- } \\
\text { maceutical company sponsorship }\end{array}$ \\
\hline $\begin{array}{l}\text { Blinding of participants } \\
\text { and personnel (perfor- } \\
\text { mance bias) } \\
\text { All outcomes }\end{array}$ & Unclear risk & The trial was double-blinded \\
\hline $\begin{array}{l}\text { Blinding of outcome as- } \\
\text { sessment (detection bias) } \\
\text { All outcomes }\end{array}$ & Unclear risk & Assumed that this would be low risk; however, no available information \\
\hline $\begin{array}{l}\text { Incomplete outcome data } \\
\text { (attrition bias) } \\
\text { All outcomes }\end{array}$ & Low risk & $\begin{array}{l}\text { "One patient was lost to follow-up } 3 \text { days after randomisation and another } \\
\text { withdrawn for non-compliance } 32 \text { days after randomisation. Four patients } \\
\text { were withdrawn after adverse events" }\end{array}$ \\
\hline $\begin{array}{l}\text { Selective reporting (re- } \\
\text { porting bias) }\end{array}$ & Low risk & $\begin{array}{l}\text { Outcomes were reported as planned. Trial information was reported on the } \\
\text { GSK website }\end{array}$ \\
\hline Other bias & Unclear risk & $\begin{array}{l}\text { No information on baseline anticholinergic, beta }{ }_{2} \text {-agonist, or corticosteroid } \\
\text { use }\end{array}$ \\
\hline
\end{tabular}

\section{Cilomilast 091}

\section{Study characteristics}

$\begin{array}{ll}\text { Methods } & \text { Study design: parallel-group study } \\ \text { Randomisation: randomised, double-blind, placebo-controlled trial }\end{array}$

Trial duration: 24 weeks 
Cilomilast 091 (Continued)

Intention-to-treat analysis: stated

Participants Setting: 110 centres in Belgium, Finland, France, Italy, the Netherlands, Norway, Portugal, Spain, and the UK

Participants: 711 (15 mg cilomilast: 469, placebo: 242)

Baseline characteristics: mean age 64.6 years, $86 \%$ male, mean $\mathrm{FEV}_{1} \%$ predicted $53 \%$ with $5.0 \%$ reversibility, $38 \%$ active smokers

Inclusion criteria: $\mathrm{FEV}_{1} / \mathrm{FVC} \leq 0.7$ with smoking history $>10$ pack-years

Exclusion criteria: active tuberculosis, lung cancer, bronchiectasis

Total numbers of participant withdrawals: $121(26 \%)$ and $63(26 \%)$ from treatment and control groups, respectively

Run-in: 4 weeks, single-blind with placebo
Interventions $\quad$ Cilomilast $15 \mathrm{mg}$ twice daily
- Placebo twice daily
Concomitant medication
- Short-acting anticholingeric: $0.9 \%$ in cilomilast, $4 \%$ placebo used salbutamol; $1 \%$ in cilomilast, $3 \%$
placebo used ipratropium
- SABA: "albuterol MDI was used as rescue medication"
- LABA: none

\begin{tabular}{ll}
\hline Outcomes & Primary outcomes: lung function; change in $\mathrm{FEV}_{1} ; \mathrm{SGRQ}$ averaged over 24 weeks \\
& $\begin{array}{l}\text { Secondary outcomes: incidence rate of COPD exacerbations; summary symptom score; FVC at trough; } \\
\text { 6MWT; post-exercise dyspnoea }\end{array}$ \\
\hline Notes & Funded by GlaxoSmithKline
\end{tabular}

Risk of bias

\begin{tabular}{lll}
\hline Bias & Authors' judgement & Support for judgement \\
\hline $\begin{array}{l}\text { Random sequence genera- } \\
\text { tion (selection bias) }\end{array}$ & Low risk & $\begin{array}{l}\text { Assumed that the randomisation process was adequate due to pharmaceutical } \\
\text { company sponsorship }\end{array}$ \\
\hline $\begin{array}{l}\text { Allocation concealment } \\
\text { (selection bias) }\end{array}$ & Low risk & $\begin{array}{l}\text { Assumed that the allocation concealment method was adequate due to phar- } \\
\text { maceutical company sponsorship }\end{array}$ \\
\hline $\begin{array}{l}\text { Blinding of participants } \\
\text { and personnel (perfor- } \\
\text { mance bias) } \\
\text { All outcomes }\end{array}$ & Low risk & The trial was double-blinded \\
\hline
\end{tabular}

\begin{tabular}{lll}
\hline $\begin{array}{l}\text { Blinding of outcome as- } \\
\text { sessment (detection bias) } \\
\text { All outcomes }\end{array}$ & Unclear risk & Assumed that this would be low risk; however, no available information \\
\hline $\begin{array}{l}\text { Incomplete outcome data } \\
\begin{array}{l}\text { (attrition bias) } \\
\text { All outcomes }\end{array}\end{array}$ & Low risk & $\begin{array}{l}\text { Total numbers of participants withdrawn } 63(26 \%) \text { placebo, } 121(26 \%) \text { cilomi- } \\
\text { last, primarily due to adverse events, of which most were not due to COPD ex- } \\
\text { acerbations }\end{array}$ \\
\hline
\end{tabular}


Cilomilast 091 (Continued)

\begin{tabular}{|c|c|c|}
\hline $\begin{array}{l}\text { Selective reporting (re- } \\
\text { porting bias) }\end{array}$ & Unclear risk & $\begin{array}{l}\text { Outcomes were reported as planned. Trial information was reported on the } \\
\text { GSK website only }\end{array}$ \\
\hline
\end{tabular}

(porting bias)

Other bias

Unclear risk

No information on baseline anticholinergic, beta ${ }_{2}$-agonist, or corticosteroid use

Cilomilast 103657

\section{Study characteristics}

Study design: parallel-group study
Randomisation: randomised, double-blind, placebo-controlled trial
Trial duration: 24 weeks
Intention-to-treat analysis: stated

\section{Participants}

\section{Setting: 103 centres in the USA}

Participants: 613 (15 mg cilomilast: 296, placebo: 317)

Baseline characteristics: mean age 63.2 years placebo, 63.1 years cilomilast, $47 \%$ male placebo, $46 \%$ male cilomilast. Mean $\mathrm{FEV}_{1} \%$ predicted not available

Inclusion criteria: aged $\geq 40$ years, $\mathrm{FEV}_{1} / \mathrm{FVC} \leq 0.7$ with smoking history $>10$ pack-years, $\leq 70 \%$ postalbuterol reversibility, $\leq 15 \%$ or $\leq 200 \mathrm{~mL}$ (or both) post-albuterol $\mathrm{FEV}_{1} \leq 70 \%$ of predicted normal, $\geq 1$ COPD exacerbation within 12 months before screening

\section{Exclusion criteria: not stated}

Total numbers of participant withdrawals: 105 (35\%) and 76 (24\%) from treatment and control groups, respectively

\begin{tabular}{l} 
Run-in: not stated \\
- Cilomilast $15 \mathrm{mg}$ twice daily \\
- Placebo twice daily \\
Concomitant medication \\
- Short-acting anticholingeric: no information available \\
- SABA: no information available \\
- Corticosteroid: no information available \\
\hline
\end{tabular}

Outcomes

Primary outcomes: change from baseline to endpoint in trough pre-bronchodilator $\mathrm{FEV}_{1}$; change in total SGRQ score averaged over 24 weeks

Secondary outcomes: changes from baseline in clinic trough FVC; time to first level 2 or level 3 COPD exacerbation

Notes Funded by GlaxoSmithKline

\section{Risk of bias}

Bias Authors' judgement Support for judgement




\section{Cilomilast 103657 (Continued)}

$\begin{array}{ll}\begin{array}{l}\text { Random sequence genera- } \\ \text { tion (selection bias) }\end{array} & \text { Low risk }\end{array}$
tion (selection bias) $\quad$ process because of pharmaceutical company sponsorship

\begin{tabular}{|c|c|c|}
\hline $\begin{array}{l}\text { Allocation concealment } \\
\text { (selection bias) }\end{array}$ & Low risk & $\begin{array}{l}\text { Assumed that trialists used a robust method to carry out the randomisation } \\
\text { process because of pharmaceutical company sponsorship }\end{array}$ \\
\hline
\end{tabular}
(selection bias) process because of pharmaceutical company sponsorship

\begin{tabular}{|c|c|c|}
\hline $\begin{array}{l}\text { Blinding of participants } \\
\text { and personnel (perfor- } \\
\text { mance bias) } \\
\text { All outcomes }\end{array}$ & Unclear risk & $\begin{array}{l}\text { The trial was double-blinded (participants and investigator). It is not clear if } \\
\text { the investigator was administering the treatment }\end{array}$ \\
\hline
\end{tabular}

\begin{tabular}{|c|c|c|}
\hline $\begin{array}{l}\text { Blinding of outcome as- } \\
\text { sessment (detection bias) } \\
\text { All outcomes }\end{array}$ & Low risk & Assumed that this would be low risk; however, no available information \\
\hline $\begin{array}{l}\text { Incomplete outcome data } \\
\text { (attrition bias) } \\
\text { All outcomes }\end{array}$ & Low risk & $\begin{array}{l}\text { Total numbers of participants withdrawn } 76(24 \%) \text { placebo, } 105(35 \%) \text { cilomi- } \\
\text { last }\end{array}$ \\
\hline $\begin{array}{l}\text { Selective reporting (re- } \\
\text { porting bias) }\end{array}$ & Low risk & $\begin{array}{l}\text { Outcomes were reported as planned. The trial was registered at clinicaltrial- } \\
\text { s.gov }\end{array}$ \\
\hline Other bias & Unclear risk & $\begin{array}{l}\text { No information on baseline anticholinergic, beta }{ }_{2} \text {-agonist, or corticosteroid } \\
\text { use }\end{array}$ \\
\hline
\end{tabular}

Cilomilast 110

\section{Study characteristics}

\begin{tabular}{|c|c|}
\hline Methods & $\begin{array}{l}\text { Study design: parallel-group study } \\
\text { Randomisation: randomised, double-blind, placebo-controlled trial } \\
\text { Trial duration: } 12 \text { weeks } \\
\text { Analysis was done on per-protocol population }\end{array}$ \\
\hline Participants & $\begin{array}{l}\text { Setting: } 10 \text { centres in the USA } \\
\text { Participants: } 65 \text { ( } 15 \text { mg cilomilast: } 31 \text {, placebo: } 34 \text { ) } \\
\text { Baseline characteristics: mean age } 64.4 \text { years placebo and } 66.1 \text { years cilomilast, } 67 \% \text { male placebo } \\
\text { and } 84 \% \text { male cilomilast, mean } \mathrm{FEV}_{1} \% \text { predicted not available } \\
\text { Inclusion criteria: aged } 40 \text { to } 80 \text { years, } F E V_{1} / F V C \leq 0.7 \text { with smoking history > } 10 \text { pack-years, post-salbu- } \\
\text { tamol reversibility } \leq 15 \% \text { or } 200 \mathrm{~mL} \text {, post-salbutamol FEV } \geq 1.0 \mathrm{~L} \text { and between } 30 \% \text { and } 70 \% \text { predicted } \\
\text { Exclusion criteria: not stated } \\
\text { Total numbers of participant withdrawals: } 1(3 \%) \text { and } 1(3 \%) \text { from treatment and control groups, re- } \\
\text { spectively }\end{array}$ \\
\hline Interventions & $\begin{array}{l}\text { Run-in: not stated } \\
\text { - Cilomilast } 15 \mathrm{mg} \text { twice daily } \\
\text { - Placebo twice daily } \\
\text { Concomitant medication }\end{array}$ \\
\hline
\end{tabular}


Cilomilast 110 (Continued)

- Short-acting anticholingeric: no information available

- SABA: no information available

- Corticosteroid: no information available

- LABA: no information available

Outcomes

Primary outcome: change from baseline at endpoint in neutrophils as a percentage of total cells in induced sputum

Secondary outcomes: FVC at trough; sputum macrophages, eosinophils, and lymphocytes as a percentage of total cells in induced sputum; total cell counts in induced sputum

Notes Funded by GlaxoSmithKline

\section{Risk of bias}

\begin{tabular}{|c|c|c|}
\hline Bias & Authors' judgement & Support for judgement \\
\hline $\begin{array}{l}\text { Random sequence genera- } \\
\text { tion (selection bias) }\end{array}$ & Low risk & $\begin{array}{l}\text { Assumed that trialists used a robust method to carry out the randomisation } \\
\text { process because of pharmaceutical sponsorship }\end{array}$ \\
\hline $\begin{array}{l}\text { Allocation concealment } \\
\text { (selection bias) }\end{array}$ & Low risk & $\begin{array}{l}\text { Assumed that trialists used a robust method to carry out the randomisation } \\
\text { process because of pharmaceutical sponsorship }\end{array}$ \\
\hline $\begin{array}{l}\text { Blinding of participants } \\
\text { and personnel (perfor- } \\
\text { mance bias) } \\
\text { All outcomes }\end{array}$ & Low risk & The trial was double-blinded \\
\hline $\begin{array}{l}\text { Blinding of outcome as- } \\
\text { sessment (detection bias) } \\
\text { All outcomes }\end{array}$ & Low risk & Assumed that this would be low risk; however, no available information \\
\hline $\begin{array}{l}\text { Incomplete outcome data } \\
\text { (attrition bias) } \\
\text { All outcomes }\end{array}$ & Low risk & Total numbers of participants withdrawn $1(3 \%)$ placebo, $1(3 \%)$ cilomilast \\
\hline $\begin{array}{l}\text { Selective reporting (re- } \\
\text { porting bias) }\end{array}$ & Low risk & $\begin{array}{l}\text { Outcomes were reported as planned. Trial information was reported on the } \\
\text { GSK website only }\end{array}$ \\
\hline Other bias & Unclear risk & $\begin{array}{l}\text { No information on baseline anticholinergic, } \text { beta }_{2} \text {-agonist, or corticosteroid } \\
\text { use }\end{array}$ \\
\hline
\end{tabular}

Cilomilast 111

\section{Study characteristics}

$\begin{array}{ll}\text { Methods } & \text { Study design: parallel-group study } \\ \text { Randomisation: randomised, double-blind, placebo-controlled trial }\end{array}$

Trial duration: 12 weeks

Intention-to-treat analysis: stated

Petting: 32 centres in the USA, Canada, and Australia
Participants: 156 (15 mg cilomilast: 79 , placebo: 77 )


Baseline characteristics: mean age 64.2 years placebo and 65 years cilomilast, $66 \%$ male placebo and $65 \%$ male cilomilast, mean $\mathrm{FEV}_{1} \%$ predicted not available

Inclusion criteria: aged 40 to 80 years, $\mathrm{FEV}_{1} / \mathrm{FVC} \leq 0.7$ with smoking history $>10$ pack-years, post-salbutamol reversibility $\leq 15 \%$ or $200 \mathrm{~mL}$, post-salbutamol $\mathrm{FEV}_{1} \geq 1.0 \mathrm{~L}$ and between $30 \%$ and $70 \%$ predicted, baseline RV (from plethysmography) $\geq 120 \%$ predicted RV

Exclusion criteria: not stated

Total numbers of participant withdrawals: $15(19 \%)$ and 14 (18\%) from treatment and control groups, respectively

Run-in: not stated
- Cilomilast $15 \mathrm{mg}$ twice daily
- Placebo twice daily
Concomitant medication
- Short-acting anticholingeric: no information available
- SABA: no information available
- Corticosteroid: no information available
- LABA: no information available

Outcomes Primary outcome: change from baseline to endpoint in volume of trapped gas (D)

Secondary outcomes: lung volume measurements, including SVC and RV; 6MWT; exertional dyspnoea

Notes $\quad$ Funded by GlaxoSmithKline

\section{Risk of bias}

\begin{tabular}{|c|c|c|}
\hline Bias & Authors' judgement & Support for judgement \\
\hline $\begin{array}{l}\text { Random sequence genera- } \\
\text { tion (selection bias) }\end{array}$ & Low risk & $\begin{array}{l}\text { Assumed that trialists used a robust method to carry out the randomisation } \\
\text { process because of pharmaceutical sponsorship }\end{array}$ \\
\hline $\begin{array}{l}\text { Allocation concealment } \\
\text { (selection bias) }\end{array}$ & Low risk & $\begin{array}{l}\text { Assumed that trialists used a robust method to carry out the allocation con- } \\
\text { cealment process because of pharmaceutical sponsorship }\end{array}$ \\
\hline $\begin{array}{l}\text { Blinding of participants } \\
\text { and personnel (perfor- } \\
\text { mance bias) } \\
\text { All outcomes }\end{array}$ & Low risk & The trial was double-blinded \\
\hline $\begin{array}{l}\text { Blinding of outcome as- } \\
\text { sessment (detection bias) } \\
\text { All outcomes }\end{array}$ & Unclear risk & Assumed that this would be low risk; however, no available information \\
\hline $\begin{array}{l}\text { Incomplete outcome data } \\
\text { (attrition bias) } \\
\text { All outcomes }\end{array}$ & Low risk & $\begin{array}{l}\text { Total numbers of participants withdrawn } 14(18 \%) \text { placebo, } 15 \text { (19\%) cilomi- } \\
\text { last }\end{array}$ \\
\hline $\begin{array}{l}\text { Selective reporting (re- } \\
\text { porting bias) }\end{array}$ & Low risk & $\begin{array}{l}\text { Outcomes were reported as planned. Trial information was reported on the } \\
\text { GSK website only }\end{array}$ \\
\hline Other bias & Unclear risk & $\begin{array}{l}\text { No information on baseline anticholinergic, beta }{ }_{2} \text {-agonist, or corticosteroid } \\
\text { use }\end{array}$ \\
\hline
\end{tabular}


Cilomilast 121

\section{Study characteristics}

\begin{tabular}{|c|c|}
\hline Methods & $\begin{array}{l}\text { Study design: parallel-group study } \\
\text { Randomisation: randomised, double-blind, placebo-controlled trial } \\
\text { Trial duration: } 24 \text { weeks } \\
\text { Intention-to-treat analysis: stated }\end{array}$ \\
\hline Participants & $\begin{array}{l}\text { Setting: } 22 \text { centres in China } \\
\text { Participants: } 1018 \text { ( } 15 \text { mg cilomilast: } 678 \text {, placebo: } 340 \text { ) } \\
\text { Baseline characteristics: mean age } 63.9 \text { years placebo and } 64.6 \text { years cilomilast, } 91 \% \text { male placebo } \\
\text { and } 93 \% \text { male cilomilast, mean } \mathrm{FEV}_{1} \% \text { predicted not available } \\
\text { Inclusion criteria: aged } 40 \text { to } 75 \text { years, } F E V_{1} / F V C \leq 0.7 \text { with smoking history }>10 \text { pack-years, docu- } \\
\text { mented history of COPD exacerbations each year for } 3 \text { years before screening, } \geq 1 \text { exacerbation in the } \\
\text { last year that required oral corticosteroids or antibiotics, post-salbutamol reversibility } \leq 15 \% \text { or } 200 \\
\text { mL, post-salbutamol FEV } 121.0 \text { L and between } 25 \% \text { and } 70 \% \text { predicted, } \% \text { predicted } \mathrm{FRC} \geq 120 \% \text { from } \\
\text { plethysmography } \\
\text { Exclusion criteria: not stated } \\
\text { Total numbers of participant withdrawals: } 124(18 \%) \text { and } 35(10 \%) \text { from treatment and control } \\
\text { groups, respectively }\end{array}$ \\
\hline Interventions & $\begin{array}{l}\text { Run-in: not stated } \\
\text { - Cilomilast } 15 \text { mg twice daily } \\
\text { - Placebo twice daily } \\
\text { Concomitant medication } \\
\text { - Short-acting anticholingeric: no information available } \\
\text { - SABA: no information available } \\
\text { - Corticosteroid: no information available } \\
\text { - LABA: no information available }\end{array}$ \\
\hline
\end{tabular}

Outcomes

Primary outcome: change from baseline to endpoint in trough pre-bronchodilator FEV $\mathrm{F}_{1}$

Secondary outcomes: time to first level 2 or level 3 COPD exacerbation (level 2 is defined as acute worsening of COPD that requires additional treatment or hospital outpatient visit; level 3 is hospital admission for treatment); change from baseline to endpoint RV and FRC; change from baseline total score on SGRQ

\begin{tabular}{lll}
\hline Notes & Funded by GlaxoSmithKline \\
\hline Risk of bias & Authors' judgement & Support for judgement \\
\hline Bias & Low risk & $\begin{array}{l}\text { Assumed that trialists used a robust method to carry out the randomisation } \\
\text { process because of pharmaceutical company sponsorship }\end{array}$ \\
\hline $\begin{array}{l}\text { Random sequence genera- } \\
\text { tion (selection bias) }\end{array}$ & $\begin{array}{l}\text { Assumed that trialists used a robust method to carry out the allocation con- } \\
\text { cealment process because of pharmaceutical company sponsorship }\end{array}$ \\
\hline $\begin{array}{l}\text { Allocation concealment } \\
\text { (selection bias) }\end{array}$ & Low risk & \\
\hline
\end{tabular}


Cilomilast 121 (Continued)

Blinding of participants Low risk The trial was double-blind and personnel (performance bias)

All outcomes

\begin{tabular}{lll}
\hline $\begin{array}{l}\text { Blinding of outcome as- } \\
\text { sessment (detection bias) } \\
\text { All outcomes }\end{array}$ & Unclear risk & Assumed that this would be low risk; however, no available information \\
\hline $\begin{array}{l}\text { Incomplete outcome data } \\
\text { (attrition bias) } \\
\text { All outcomes }\end{array}$ & Low risk & $\begin{array}{l}\text { Total numbers of participants withdrawn } 35 \text { (10\%) placebo, 124 (18\%) cilomi- } \\
\text { last }\end{array}$ \\
\hline $\begin{array}{l}\text { Selective reporting (re- } \\
\text { porting bias) }\end{array}$ & Low risk & $\begin{array}{l}\text { Outcomes were reported as planned. Trial information was reported on the } \\
\text { GSK website only }\end{array}$ \\
\hline Other bias & Low risk & $\begin{array}{l}\text { No information on baseline anticholinergic, beta }{ }_{2} \text {-agonist, or corticosteroid } \\
\text { use }\end{array}$ \\
\hline
\end{tabular}

Cilomilast 156

\section{Study characteristics}

\begin{tabular}{|c|c|}
\hline Methods & $\begin{array}{l}\text { Study design: parallel-group study } \\
\text { Randomisation: randomised, double-blind, placebo-controlled trial } \\
\text { Trial duration: } 24 \text { weeks } \\
\text { Intention-to-treat analysis: stated }\end{array}$ \\
\hline Participants & $\begin{array}{l}\text { Setting: } 132 \text { centres in USA and Canada } \\
\text { Participants: } 825 \text { ( } 15 \text { mg cilomilast: } 418 \text {, placebo: } 407) \\
\text { Baseline characteristics: mean age } 64.4 \text { years placebo and } 64.5 \text { years cilomilast, } 62 \% \text { male placebo } \\
\text { and } 56 \% \text { male cilomilast, > 50\% predicted } \mathrm{FEV}_{1} \text { for both groups } \\
\text { Inclusion criteria: aged } 40 \text { to } 80 \text { years, } F E V_{1} / F V C \leq 0.7 \text { with smoking history }>10 \text { pack-years, post-salbu- } \\
\text { tamol reversibility } \leq 15 \% \text { or } 200 \mathrm{~mL} \text {, post-salbutamol FEV } 121.0 \mathrm{~L} \text { and between } 30 \% \text { and } 70 \% \text { predicted } \\
\text { Exclusion criteria: not stated } \\
\text { Total numbers of participant withdrawals: } 143(34 \%) \text { and } 96(24 \%) \text { from treatment and control } \\
\text { groups, respectively }\end{array}$ \\
\hline Interventions & $\begin{array}{l}\text { Run-in: not stated } \\
\text { - Cilomilast } 15 \text { mg twice daily } \\
\text { - Placebo twice daily } \\
\text { Concomitant medication } \\
\text { - Short-acting anticholingeric } 8.1 \% \text { in cilomilast, } 8.6 \% \text { placebo used salbutamol; } 1.7 \% \text { in cilomilast, } 2 \% \\
\text { placebo used ipratropium bromide } \\
\text { - SABA: "albuterol MDI was used as rescue medication" } \\
\text { - Corticosteroid: none }\end{array}$ \\
\hline
\end{tabular}


Cilomilast 156 (Continued)

Outcomes
Primary outcomes: change from baseline to endpoint in trough pre-bronchodilator $\mathrm{FEV}_{1}$; change in total SGRQ score averaged over 24 weeks

Secondary outcomes: post-exercise breathlessness; clinic trough FVC; time to first level 2 or level 3 COPD exacerbation

Notes Funded by GlaxoSmithKline

\section{Risk of bias}

\begin{tabular}{|c|c|c|}
\hline Bias & Authors' judgement & Support for judgement \\
\hline $\begin{array}{l}\text { Random sequence genera- } \\
\text { tion (selection bias) }\end{array}$ & Low risk & $\begin{array}{l}\text { The randomisation code was provided by RAMOS (registration and medication } \\
\text { ordering system) }\end{array}$ \\
\hline $\begin{array}{l}\text { Allocation concealment } \\
\text { (selection bias) }\end{array}$ & Low risk & No further information on allocation concealment method \\
\hline $\begin{array}{l}\text { Blinding of participants } \\
\text { and personnel (perfor- } \\
\text { mance bias) } \\
\text { All outcomes }\end{array}$ & Low risk & Patients and personnel did not know which treatment had been allocated \\
\hline $\begin{array}{l}\text { Blinding of outcome as- } \\
\text { sessment (detection bias) } \\
\text { All outcomes }\end{array}$ & Low risk & Outcome assessors did not know which treatment had been allocated \\
\hline $\begin{array}{l}\text { Incomplete outcome data } \\
\text { (attrition bias) } \\
\text { All outcomes }\end{array}$ & Low risk & $\begin{array}{l}\text { Total numbers of participants withdrawn } 96(24 \%) \text { placebo, } 143(34 \%) \text { cilomi- } \\
\text { last }\end{array}$ \\
\hline $\begin{array}{l}\text { Selective reporting (re- } \\
\text { porting bias) }\end{array}$ & Low risk & $\begin{array}{l}\text { Outcomes were reported as planned. Trial information was reported on the } \\
\text { GSK website only }\end{array}$ \\
\hline Other bias & Low risk & $\begin{array}{l}\text { No information on baseline anticholinergic, beta }{ }_{2} \text {-agonist, or corticosteroid } \\
\text { use }\end{array}$ \\
\hline
\end{tabular}

\section{Cilomilast 157}

\section{Study characteristics}

Methods

Study design: parallel-group study

Randomisation: randomised, double-blind, placebo-controlled trial

Trial duration: 52 weeks

Intention-to-treat analysis: stated

Participants Setting: 137 centres from 18 countries

Participants: 907 (15 mg cilomilast: 455, placebo: 452)

Baseline characteristics: mean age 63.3 years placebo and 64.6 years cilomilast, $73 \%$ male placebo and $78 \%$ male cilomilast, $42 \%$ current smokers

Inclusion criteria: aged 40 to 80 years, $\mathrm{FEV}_{1} / \mathrm{FVC} \leq 0.7$ with smoking history $>10$ pack-years, poor reversibility of airway obstruction defined by $\leq 10 \%$ predicted normal or $\leq 200 \mathrm{~mL}$ (or both) increase in 
$\mathrm{FEV}_{1}$ after administration of salbutamol $400 \mu \mathrm{g}$ via MDI at screening, post-salbutamol $\mathrm{FEV}_{1}$ between $30 \%$ and $70 \%$ predicted normal at screening

Exclusion criteria: not stated

Total numbers of participant withdrawals: $167(37 \%)$ and $121(27 \%)$ from treatment and control groups, respectively

Run-in: not stated
- Cilomilast $15 \mathrm{mg}$ twice daily
- Placebo twice daily
Concomitant medication
- Short-acting anticholingeric: no information available
- SABA: no information available
- Corticosteroid: no information available
- LABA: no information available

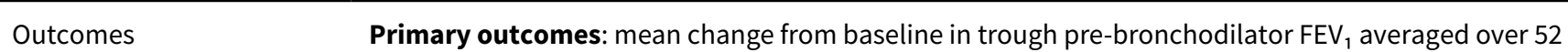
weeks; incidence rate of level 2 (moderate) and level 3 (severe) COPD exacerbations during treatment period

Secondary outcomes: time to first level 2 or level 3 COPD exacerbation; quality of life determined by SGRQ

Notes Funded by GlaxoSmithKline

\section{Risk of bias}

\begin{tabular}{|c|c|c|}
\hline Bias & Authors' judgement & Support for judgement \\
\hline $\begin{array}{l}\text { Random sequence genera- } \\
\text { tion (selection bias) }\end{array}$ & Low risk & $\begin{array}{l}\text { Randomisation code was generated via the pharmaceutical company's coding } \\
\text { memo system in blocks }\end{array}$ \\
\hline $\begin{array}{l}\text { Allocation concealment } \\
\text { (selection bias) }\end{array}$ & Low risk & No further information on allocation concealment method \\
\hline $\begin{array}{l}\text { Blinding of participants } \\
\text { and personnel (perfor- } \\
\text { mance bias) } \\
\text { All outcomes }\end{array}$ & Low risk & Patients and investigator were blinded \\
\hline $\begin{array}{l}\text { Blinding of outcome as- } \\
\text { sessment (detection bias) } \\
\text { All outcomes }\end{array}$ & Unclear risk & Assumed that this would be low risk; however, no available information \\
\hline $\begin{array}{l}\text { Incomplete outcome data } \\
\text { (attrition bias) } \\
\text { All outcomes }\end{array}$ & Low risk & $\begin{array}{l}\text { Total numbers of participants withdrawn } 121(27 \%) \text { placebo, } 167 \text { (37\%) cilomi- } \\
\text { last }\end{array}$ \\
\hline $\begin{array}{l}\text { Selective reporting (re- } \\
\text { porting bias) }\end{array}$ & Low risk & $\begin{array}{l}\text { Outcomes were reported as planned. Trial information was reported on the } \\
\text { GSK website only }\end{array}$ \\
\hline Other bias & Low risk & $\begin{array}{l}\text { No information on baseline anticholinergic, beta }{ }_{2} \text {-agonist, or corticosteroid } \\
\text { use }\end{array}$ \\
\hline
\end{tabular}


Cilomilast 168

\section{Study characteristics}

\begin{tabular}{|c|c|c|}
\hline Methods & \multicolumn{2}{|c|}{$\begin{array}{l}\text { Study design: parallel-group study } \\
\text { Randomisation: randomised, double-blind, placebo-controlled trial } \\
\text { Trial duration: } 12 \text { weeks } \\
\text { Intention-to-treat analysis: not stated }\end{array}$} \\
\hline Participants & \multicolumn{2}{|r|}{$\begin{array}{l}\text { ilomilast: } 203 \text {, placebo: } 103) \\
\text { mean age } 64.3 \text { years placebo and } 65.0 \text { years cilomilast, } 64 \% \text { male placebo } \\
\text { uterol } \mathrm{FEV}_{1} / \mathrm{FVC} \leq 0.7 \text {, post-albuterol } \mathrm{FEV}_{1} \text { between } 30 \% \text { and } 70 \% \text { predicted } \\
\text { ted } \\
\text { pant withdrawals: } 61(30 \%) \text { and } 14(14 \%) \text { from treatment and control }\end{array}$} \\
\hline Interventions & \multicolumn{2}{|c|}{$\begin{array}{l}\text { Run-in: not stated } \\
\text { - Cilomilast } 15 \mathrm{mg} \text { twice daily } \\
\text { - Placebo twice daily } \\
\text { Concomitant medication } \\
\text { - Short-acting anticholingeric: no information available } \\
\text { - SABA: no information available } \\
\text { - Corticosteroid: no information available } \\
\text { - LABA: no information available }\end{array}$} \\
\hline Outcomes & \multicolumn{2}{|c|}{$\begin{array}{l}\text { Primary outcome: no primary efficacy or safety analyses defined; descriptive statistics of change from } \\
\text { baseline in minimum and maximum heart rate via } 24 \text {-hour Holter monitoring reported } \\
\text { Secondary outcome: no secondary efficacy or safety analyses defined }\end{array}$} \\
\hline Notes & \multicolumn{2}{|c|}{ Funded by GlaxoSmithKline } \\
\hline \multicolumn{3}{|l|}{ Risk of bias } \\
\hline Bias & Authors' judgement & Support for judgement \\
\hline $\begin{array}{l}\text { Random sequence genera- } \\
\text { tion (selection bias) }\end{array}$ & Low risk & $\begin{array}{l}\text { The randomisation sequence was generated by the pharmaceutical compa- } \\
\text { ny's biometrics unit }\end{array}$ \\
\hline $\begin{array}{l}\text { Allocation concealment } \\
\text { (selection bias) }\end{array}$ & Unclear risk & No further information on allocation concealment method \\
\hline $\begin{array}{l}\text { Blinding of participants } \\
\text { and personnel (perfor- } \\
\text { mance bias) } \\
\text { All outcomes }\end{array}$ & Low risk & The trial was double-blind \\
\hline
\end{tabular}


Cilomilast 168 (Continued)

Blinding of outcome as- Unclear risk Assumed that this would be low risk; however, no available information sessment (detection bias)

All outcomes

\begin{tabular}{|c|c|c|}
\hline $\begin{array}{l}\text { Incomplete outcome data } \\
\text { (attrition bias) } \\
\text { All outcomes }\end{array}$ & Low risk & $\begin{array}{l}\text { Total numbers of participants withdrawn } 14(14 \%) \text { placebo, } 61(30 \%) \text { cilomi- } \\
\text { last }\end{array}$ \\
\hline $\begin{array}{l}\text { Selective reporting (re- } \\
\text { porting bias) }\end{array}$ & Low risk & $\begin{array}{l}\text { Outcomes were reported as planned. Trial information was reported on the } \\
\text { GSK website only }\end{array}$ \\
\hline Other bias & Low risk & $\begin{array}{l}\text { No information on baseline anticholinergic, beta }{ }_{2} \text {-agonist, or corticosteroid } \\
\text { use }\end{array}$ \\
\hline
\end{tabular}

Cilomilast 180

\section{Study characteristics}

\begin{tabular}{|c|c|}
\hline Methods & $\begin{array}{l}\text { Study design: parallel-group study } \\
\text { Randomisation: randomised, double-blind, placebo-controlled trial } \\
\text { Trial duration: } 18 \text { weeks } \\
\text { Intention-to-treat analysis: stated }\end{array}$ \\
\hline Participants & $\begin{array}{l}\text { Setting: } 34 \text { centres in the USA, Canada, and South America } \\
\text { Participants: } 199 \text { ( } 15 \text { mg cilomilast: } 97 \text {, placebo: } 102 \text { ) } \\
\text { Baseline characteristics: mean age } 64.7 \text { years placebo and } 63.7 \text { years cilomilast, } 76 \% \text { male placebo } \\
\text { and } 69 \% \text { male cilomilast } \\
\text { Inclusion criteria: age } \geq 40 \text { years, } F E V_{1} / F V C \leq 0.7 \text { with smoking history > } 10 \text { pack-years, baseline } \mathrm{FEV}_{1}< \\
70 \% \text { predicted normal, moderate to severe chronic dyspnoea defined by BDI focal score } \leq 7 \text {, evidence } \\
\text { of hyperinflation defined by RFRC } \geq 140 \% \text { predicted, exercise limitation defined as peak symptom limit- } \\
\text { ed VO } \mathrm{O}_{2}<75 \% \\
\text { Exclusion criteria: not stated } \\
\text { Total numbers of participant withdrawals: } 24(25 \%) \text { and } 13(13 \%) \text { from treatment and control } \\
\text { groups, respectively }\end{array}$ \\
\hline Interventions & $\begin{array}{l}\text { Run-in: not stated } \\
\text { - Cilomilast } 15 \mathrm{mg} \text { twice daily } \\
\text { - Placebo twice daily } \\
\text { Concomitant medication } \\
\text { - Short-acting anticholingeric: no information available } \\
\text { - SABA: no information available } \\
\text { - Corticosteroid: no information available } \\
\text { - LABA: no information available }\end{array}$ \\
\hline
\end{tabular}

Outcomes

Primary outcome: change from baseline at endpoint in RFRC 
Secondary outcomes: change from baseline at endpoint in IC during exercise; exertional dyspnoea as measured by the modified Borg Scale

\begin{tabular}{|c|c|c|}
\hline Notes & \multicolumn{2}{|c|}{ Funded by GlaxoSmithKline } \\
\hline \multicolumn{3}{|l|}{ Risk of bias } \\
\hline Bias & Authors' judgement & Support for judgement \\
\hline $\begin{array}{l}\text { Random sequence genera- } \\
\text { tion (selection bias) }\end{array}$ & Low risk & $\begin{array}{l}\text { Patients were randomised via a call to the sponsor's medication ordering sys- } \\
\text { tem, during which the patient's subject number was confirmed and the patient } \\
\text { was provided with a } 6 \text {-digit container number for identification of the initial } \\
\text { bottle of double-blind medication }\end{array}$ \\
\hline $\begin{array}{l}\text { Allocation concealment } \\
\text { (selection bias) }\end{array}$ & Unclear risk & No further information on allocation concealment method. \\
\hline $\begin{array}{l}\text { Blinding of participants } \\
\text { and personnel (perfor- } \\
\text { mance bias) } \\
\text { All outcomes }\end{array}$ & Low risk & $\begin{array}{l}\text { The trial was double blind. Cilomilast and matched placebo tablets were iden- } \\
\text { tical in appearance, and only the double-blind medication included the con- } \\
\text { tainer number }\end{array}$ \\
\hline $\begin{array}{l}\text { Blinding of outcome as- } \\
\text { sessment (detection bias) } \\
\text { All outcomes }\end{array}$ & Unclear risk & Assumed that this would be low risk; however, no available information \\
\hline $\begin{array}{l}\text { Incomplete outcome data } \\
\text { (attrition bias) } \\
\text { All outcomes }\end{array}$ & Low risk & $\begin{array}{l}\text { Total numbers of participants withdrawn } 13(13 \%) \text { placebo, } 24(25 \%) \text { cilomi- } \\
\text { last }\end{array}$ \\
\hline $\begin{array}{l}\text { Selective reporting (re- } \\
\text { porting bias) }\end{array}$ & Low risk & $\begin{array}{l}\text { Outcomes were reported as planned. Trial information was reported on the } \\
\text { GSK website only }\end{array}$ \\
\hline Other bias & Low risk & $\begin{array}{l}\text { No information on baseline anticholinergic, beta }{ }_{2} \text {-agonist, or corticosteroid } \\
\text { use }\end{array}$ \\
\hline
\end{tabular}

Cilomilast 181

\section{Study characteristics}

\begin{tabular}{ll}
\hline Methods & Study design: parallel-group study \\
Randomisation: randomised, double-blind, placebo-controlled trial \\
Trial duration: 13 weeks \\
Analysis was done on the per-protocol population \\
\hline Setting: 27 centres in Australia, Canada, Finland, Ireland, Lithuania, Norway, Romania, Slovakia, Slove- \\
nia, South Africa, Sweden, and the UK \\
Participants: 127 (15 mg cilomilast: 65 , placebo: 62 ) \\
Baseline characteristics: mean age 63.4 years placebo and 61.4 years cilomilast, $76 \%$ male placebo \\
and $72 \%$ male cilomilast
\end{tabular}


Inclusion criteria: aged 40 to 80 years, $\mathrm{FEV}_{1} / \mathrm{FVC} \leq 0.7$ with smoking history $>10$ pack-years, post-bronchodilator $\mathrm{FEV}_{1}$ between $40 \%$ and $80 \%$ predicted normal, poor reversibility of $\leq 10 \%$ or $200 \mathrm{~mL}$ increase in $\mathrm{FEV}_{1}$

\section{Exclusion criteria: not stated}

Total numbers of participant withdrawals: $8(12 \%)$ and $6(10 \%)$ from treatment and control groups, respectively

\begin{tabular}{ll}
\hline Run-in: not stated \\
- Cilomilast $15 \mathrm{mg}$ twice daily \\
- Placebo twice daily \\
Concomitant medication \\
- Short-acting anticholingeric: no information available \\
- SABA: no information available \\
- Corticosteroid: no information available \\
- LABA: no information available
\end{tabular}

Outcomes Primary outcomes: change from baseline at endpoint in CD68+ (macrophages) and CD8+ (cytotoxic T lymphocytes) per unit area of tissue

Secondary outcomes: change from baseline in numbers of subepithelial cells per unit area in biopsy for neutrophil elastase-positive (ne+) cells, CD4+, IL-8 mRNA-positive cells, TNF-alpha mRNA-positive cells

Notes Funded by GlaxoSmithKline

\section{Risk of bias}

\begin{tabular}{|c|c|c|}
\hline Bias & Authors' judgement & Support for judgement \\
\hline $\begin{array}{l}\text { Random sequence genera- } \\
\text { tion (selection bias) }\end{array}$ & Low risk & $\begin{array}{l}\text { A central randomisation schedule that was balanced at site level. An interac- } \\
\text { tive voice response system was used to generate a random number to assign } \\
\text { eligible participants }\end{array}$ \\
\hline $\begin{array}{l}\text { Allocation concealment } \\
\text { (selection bias) }\end{array}$ & Low risk & $\begin{array}{l}\text { Assumed that the allocation concealment method was adequate due to phar- } \\
\text { maceutical company sponsorship }\end{array}$ \\
\hline $\begin{array}{l}\text { Blinding of participants } \\
\text { and personnel (perfor- } \\
\text { mance bias) } \\
\text { All outcomes }\end{array}$ & Low risk & $\begin{array}{l}\text { The trial was double-blind. Participants and personnel were blind to which } \\
\text { treatment they were assigned to. Cilomilast and matched placebo tablets were } \\
\text { identical in appearance, and only the double-blind medication included the } \\
\text { container number }\end{array}$ \\
\hline
\end{tabular}

\begin{tabular}{lll}
\hline $\begin{array}{l}\text { Blinding of outcome as- } \\
\text { sessment (detection bias) } \\
\text { All outcomes }\end{array}$ & Unclear risk & Assumed that this would be low risk; however, no available information \\
\hline $\begin{array}{l}\text { Incomplete outcome data } \\
\text { (attrition bias) } \\
\text { All outcomes }\end{array}$ & Low risk & Total numbers of participants withdrawn 6 (10\%) placebo, 8 (12\%) cilomilast \\
\hline $\begin{array}{l}\text { Selective reporting (re- } \\
\text { porting bias) }\end{array}$ & Low risk & $\begin{array}{l}\text { Outcomes were reported as planned. Trial information was reported on the } \\
\text { GSK website only }\end{array}$ \\
\hline Other bias & Low risk & $\begin{array}{l}\text { No information on baseline anticholinergic, beta } 2 \text {-agonist, or corticosteroid } \\
\text { use }\end{array}$ \\
\hline
\end{tabular}


Compton 2001

\section{Study characteristics}

\begin{tabular}{|c|c|}
\hline Methods & $\begin{array}{l}\text { Study design: parallel-group study } \\
\text { Randomisation: randomised, double-blind, placebo-controlled trial } \\
\text { Trial duration: } 6 \text { weeks } \\
\text { Intention-to-treat analysis: stated }\end{array}$ \\
\hline Participants & $\begin{array}{l}\text { Setting: } 60 \text { centres in Austria, France, Germany, the Netherlands, and the UK } \\
\text { Participants: } 424 \text { (5 mg cilomilast: 109, } 10 \text { mg cilomilast: 102, } 15 \text { mg cilomilast: 107, placebo: 106) } \\
\text { Baseline characteristics: mean age } 62 \text { to } 63 \text { years, } 75 \% \text { to } 78 \% \text { male, mean FEV } 1 \% \text { predicted } 46.8 \% \text {, } \\
\text { mean smoking history } 36 \text { to } 43 \text { (SD } 22.4 \text { ) pack-years } \\
\text { Inclusion criteria: FEV } 1 \text { /FVC } \leq 0.7 \text { with smoking history > } 10 \text { pack-years } \\
\text { Exclusion criteria: asthma, poorly controlled COPD needing hospital visit } 6 \text { weeks before study, recent } \\
\text { COPD exacerbations, recent corticosteroid use } \\
\text { Total numbers of participant withdrawals: } 18(17 \%) \text { and } 17(16 \%) \text { from treatment and control } \\
\text { groups, respectively }\end{array}$ \\
\hline Interventions & $\begin{array}{l}\text { Run-in: } 2 \text { weeks, single-blind, placebo tablets to assess compliance } \\
\text { - Cilomilast } 5 \mathrm{mg}, 10 \mathrm{mg}, 15 \mathrm{mg} \text { twice daily } \\
\text { - Placebo twice daily } \\
\text { Concomitant medication } \\
\text { - Short-acting anticholingeric: } 382(90 \%) \text { participants were given concomitant treatment for COPD dur- } \\
\text { ing the study; } 267(70 \%) \text { salbutamol and } 115(30 \%) \text { ipratropium bromide } \\
\text { - SABA: salbutamol used in } 70 \% \\
\text { - Corticosteroid: none } \\
\text { - LABA: none }\end{array}$ \\
\hline
\end{tabular}

Outcomes

Primary outcomes: lung function: change in $\mathrm{FEV}_{1}$; SGRQ

Secondary outcomes: peak expiratory flow and FVC; first dose effect of active treatment on FEV

Notes

Post-bronchodilator results not given, so pre-bronchodilator values used in analysis. Funded by GlaxoSmithKline

\section{Risk of bias}

\begin{tabular}{lll}
\hline Bias & Authors' judgement & Support for judgement \\
\hline $\begin{array}{l}\text { Random sequence genera- } \\
\text { tion (selection bias) }\end{array}$ & Low risk & $\begin{array}{l}\text { Randomised. Assumed that the randomisation method was adequate due to } \\
\text { pharmaceutical company sponsorship }\end{array}$ \\
\hline $\begin{array}{l}\text { Allocation concealment } \\
\text { (selection bias) }\end{array}$ & Low risk & $\begin{array}{l}\text { Assumed that the allocation concealment method was adequate due to phar- } \\
\text { maceutical company sponsorship }\end{array}$ \\
\hline $\begin{array}{l}\text { Blinding of participants } \\
\text { and personnel (perfor- } \\
\text { mance bias) }\end{array}$ & Low risk & $\begin{array}{l}\text { The trial was double-blinded. Participants were not aware of which treatment } \\
\text { they were receiving because cilomilast and matched placebo tablets were } \\
\text { identical in appearance }\end{array}$ \\
\hline
\end{tabular}


Compton 2001 (Continued)

All outcomes

Blinding of outcome as-
sessment (detection bias) $\quad$ Unclear risk the trial was double-blinded, but it is unclear who assessed the outcomes
sessment (detection bias) All outcomes

\begin{tabular}{|c|c|c|}
\hline $\begin{array}{l}\text { Incomplete outcome data } \\
\text { (attrition bias) } \\
\text { All outcomes }\end{array}$ & Low risk & $\begin{array}{l}\text { "14 patients (13\%) taking cilomilast } 15 \mathrm{mg} \text { had adverse events leading to pa- } \\
\text { tient withdrawal, as did } 12 \text { each in the } 5 \text { and } 10 \mathrm{mg} \text { groups ( } 11 \text { and } 12 \% \text {, re- } \\
\text { spectively) and eight ( } 8 \%) \text { in the placebo group" }\end{array}$ \\
\hline
\end{tabular}

\begin{tabular}{|c|c|c|}
\hline $\begin{array}{l}\text { Selective reporting (re- } \\
\text { porting bias) }\end{array}$ & Unclear risk & $\begin{array}{l}\text { Unclear whether outcomes were assessed as planned; it was not possible to } \\
\text { find the trial in the GSK registry }\end{array}$ \\
\hline Other bias & Low risk & $\begin{array}{l}102(24 \%) \text { participants had been taking long-acting } \beta_{2} \text {-agonists (e.g. salme- } \\
\text { terol, formoterol). } 331(78 \%) \text { individuals had taken other medications for their } \\
\text { COPD, the most common being inhaled steroids; } 229(54 \%) \text { took beclometha- } \\
\text { sone, budesonide, or fluticasone }\end{array}$ \\
\hline
\end{tabular}

\section{COPD safety pool}

\section{Study characteristics}

\begin{tabular}{ll}
\hline Methods & $\begin{array}{l}\text { 14 double-blind and placebo-controlled studies (Roflumilast FK1 101; Roflumilast FK1 103; Roflumilast } \\
\text { IN-108; Roflumilast M2-107; Roflumilast M2-110; Roflumilast M2-111; Roflumilast M2-112; Roflumilast } \\
\text { M2-118; Roflumilast M2-119; Roflumilast M2-121; Roflumilast M2-124; Roflumilast M2-125; Roflumilast } \\
\text { M2-127; Roflumilast M2-128) }\end{array}$ \\
\hline Participants & See individual studies \\
\hline Interventions & Roflumilast $500 \mu$ g once daily \\
& Roflumilast $250 \mu$ g once daily \\
& Placebo once daily \\
\hline
\end{tabular}

Outcomes

Notes

\section{Risk of bias}

\begin{tabular}{lll}
\hline Bias & Authors' judgement & Support for judgement \\
\hline $\begin{array}{l}\text { Random sequence genera- } \\
\text { tion (selection bias) }\end{array}$ & Low risk & Randomised \\
\hline $\begin{array}{l}\text { Allocation concealment } \\
\text { (selection bias) }\end{array}$ & Unclear risk & See individual studies \\
\hline $\begin{array}{l}\text { Blinding of participants } \\
\text { and personnel (perfor- } \\
\text { mance bias) } \\
\text { All outcomes }\end{array}$ & Low risk & The trials were double-blind \\
\hline
\end{tabular}

Blinding of outcome as-
sessment (detection bias) $\quad$ Unclear risk $\quad$ Assumed that this would be low risk; however, no available information


COPD safety pool (Continued)

All outcomes

\begin{tabular}{lll}
\hline $\begin{array}{l}\text { Incomplete outcome data } \\
\text { (attrition bias) } \\
\text { All outcomes }\end{array}$ & Unclear risk & See individual studies \\
\hline $\begin{array}{l}\text { Selective reporting (re- } \\
\text { porting bias) }\end{array}$ & Unclear risk & See individual studies \\
\hline Other bias & Unclear risk & See individual studies \\
\hline
\end{tabular}

\section{Kavitha 2018}

\section{Study characteristics}

Study design: parallel-group study
Randomisation: randomised controlled trial
Trial duration: 12 weeks
Intention-to-treat analysis: not stated

Participants

Setting: 1 pulmonary medicine ward in India

Participants: 61 (intervention: 31; control: 30)

Baseline characteristics: mean age 58 years, mean $\mathrm{FEV}_{1}$ predicted 0.93 , current smokers $33 \%$

Inclusion criteria: Indian ethnicity, age $\geq 40$ years with moderate to severe COPD, current or past smokers, other co-existing conditions

Exclusion criteria: bronchial asthma, other lung diseases, lower respiratory tract infection, pregnant or breastfeeding

Total numbers of participant withdrawals: not stated; assumed 1 person was not included in the analysis

Interventions

\section{Run-in: not stated}

- Roflumilast $500 \mu \mathrm{g}$ once daily with $12 \mu \mathrm{g}$ formoterol and $9 \mu \mathrm{g}$ tiotropium combination metered-dose inhaler once daily

- Formoterol $12 \mu \mathrm{g}$ and $9 \mu \mathrm{g}$ tiotropium combination metered-dose inhaler once daily

\section{Concomitant medication}

- All study participants were taking formoterol $12 \mu \mathrm{g}$ and $9 \mu \mathrm{g}$ tiotropium combination metered-dose inhaler

Outcomes Primary outcomes: lung function ( $\mathrm{FEV}_{1}$ and $\mathrm{FVC}$ ); change in mean $\mathrm{FEV}_{1}$ after treatment

Secondary outcomes: adverse events in the roflumilast treatment group

\begin{tabular}{ll}
\hline Notes & Funding not stated \\
\hline Risk of bias & \\
\hline Bias & Authors' judgement $\quad$ Support for judgement \\
\hline
\end{tabular}


Kavitha 2018 (Continued)

Random sequence genera- High risk Reported as a "randomised control study". No further information about rantion (selection bias) domisation method. Also, groups are not balanced with regards to baseline characteristics. For example, the placebo group includes a high percentage of patients with diabetes

\begin{tabular}{lll}
\hline $\begin{array}{l}\text { Allocation concealment } \\
\text { (selection bias) }\end{array}$ & Unclear risk & Allocation concealment method was not reported \\
\hline $\begin{array}{l}\text { Blinding of participants } \\
\text { and personnel (perfor- }\end{array}$ & High risk & Assumed that there was no blinding of participants or personnel \\
mance bias) & & \\
All outcomes &
\end{tabular}

\begin{tabular}{|c|c|c|}
\hline $\begin{array}{l}\text { Blinding of outcome as- } \\
\text { sessment (detection bias) } \\
\text { All outcomes }\end{array}$ & High risk & Assumed that there was no blinding of the outcome assessor \\
\hline $\begin{array}{l}\text { Incomplete outcome data } \\
\text { (attrition bias) } \\
\text { All outcomes }\end{array}$ & Low risk & $\begin{array}{l}\text { Only } 1 \text { participant in the roflumilast group was lost; however, reasons for attri- } \\
\text { tion were not reported }\end{array}$ \\
\hline $\begin{array}{l}\text { Selective reporting (re- } \\
\text { porting bias) }\end{array}$ & High risk & $\begin{array}{l}\text { Outcomes not reported in the methods, so unclear whether outcomes report- } \\
\text { ed were what they intended to assess. Adverse event data were not report- } \\
\text { ed for the control group, so it is unclear whether there were no events in this } \\
\text { group. Outcome data for FEV } \text {, were not clear, as no units were reported. If it }_{\text {is assumed that trial authors reported litres, then those in the intervention }} \\
\text { group improved by } 660 \mathrm{~mL} \text {, which is large in COPD terms, as it indicates } 28 \% \\
\text { improvement, yet in the discussion, trial authors mention that it is similar to } \\
\text { the } 60 \mathrm{~mL} \text { reported in the Fabbri study }\end{array}$ \\
\hline Other bias & Low risk & $\begin{array}{l}\text { No information on baseline anticholinergic, beta }{ }_{2} \text {-agonist, or corticosteroid } \\
\text { use }\end{array}$ \\
\hline
\end{tabular}

Liu 2018

\section{Study characteristics}

\section{Methods}

Study design: parallel-group study

Randomisation: randomised, double-blind, placebo-controlled trial

Trial duration: 52 weeks

Intention-to-treat analysis: stated

\section{Participants}

Participants: 120 (roflumilast $500 \mu \mathrm{g}: 60$, placebo: 60)

Baseline characteristics: COPD stage II to IV according to GOLD criteria, mean age 65 years, $\mathrm{FEV}_{1} \%$ predicted $<50 \%, 72 \%$ male, smoking history 37 pack-years, $66 \%$ current smokers

Inclusion criteria: aged $\geq 40$ years, post-bronchodilator $\mathrm{FEV}_{1}<50 \%$ predicted, $\mathrm{FEV} 1$ :FVC ratio $70 \%$, post-bronchodilator $\mathrm{FEV}_{1}$ with $30 \%$ to $80 \%$ predicted, COPD history $>12$ months, no medication change for past 3 months

Exclusion criteria: asthma, other lung disease, systemic glucocorticosteroids, SABA 1 month before study, severe mental disorder, pregnant or breastfeeding 
Liu 2018 (Continued)

Total numbers of participant withdrawals: $5(8 \%)$ and $6(10 \%)$ from treatment and control groups, respectively

Interventions $\quad$ Run-in: not stated
- Roflumilast $500 \mu \mathrm{g}$ once daily
Concomitant medication
- Anticholingeric: $40 \%$ of participants were on anticholinergics
- $\beta_{2}$-agonist: $34 \%$ of participants were on $\beta_{2}$-agonists
- Corticosteroid: $18 \%$ of participants were on ICSs
$23 \%$ of participants were on home oxygen therapy

\begin{tabular}{ll}
\hline Outcomes & Primary outcome: change from baseline in lung function (FEV, FVC, and FEF $25 \%-75 \%)^{\text {Secondary outcomes: quality of life (SGRQ); adverse events }}$ \\
\hline Notes & Funding not stated
\end{tabular}

\section{Risk of bias}

\begin{tabular}{lll}
\hline Bias & Authors' judgement & Support for judgement \\
\hline $\begin{array}{l}\text { Random sequence genera- } \\
\text { tion (selection bias) }\end{array}$ & Low risk & $\begin{array}{l}\text { Randomisation was achieved via a computerised number programme generat- } \\
\text { ed by a statistician who was blinded to treatment allocation }\end{array}$ \\
\hline $\begin{array}{l}\text { Allocation concealment } \\
\text { (selection bias) }\end{array}$ & Unclear risk & $\begin{array}{l}\text { Unclear how the allocation sequence was concealed from patients (i.e. no } \\
\text { mention of concealed envelopes or any other method) }\end{array}$ \\
\hline $\begin{array}{l}\text { Blinding of participants } \\
\text { and personnel (perfor- } \\
\text { mance bias) }\end{array}$ & Low risk & $\begin{array}{l}\text { Participants were reported to be blinded to treatment allocation; investiga- } \\
\text { tors, data analysts, and outcome assessors were blinded to treatment alloca- } \\
\text { tion }\end{array}$ \\
\hline
\end{tabular}

\begin{tabular}{|c|c|c|}
\hline $\begin{array}{l}\text { Blinding of outcome as- } \\
\text { sessment (detection bias) } \\
\text { All outcomes }\end{array}$ & Low risk & $\begin{array}{l}\text { Participants were reported to be blinded to treatment allocation; investiga- } \\
\text { tors, data analysts, and outcome assessors were blinded to treatment alloca- } \\
\text { tion }\end{array}$ \\
\hline
\end{tabular}

\begin{tabular}{ll}
\hline $\begin{array}{l}\text { Incomplete outcome data } \\
\text { (attrition bias) }\end{array}$ & $\begin{array}{l}\text { Overall, the number of withdrawals was 9\%; however there was } 1 \text { more with- } \\
\text { drawal in the placebo group compared to the intervention group }\end{array}$
\end{tabular}

\begin{tabular}{|c|c|c|}
\hline $\begin{array}{l}\text { Selective reporting (re- } \\
\text { porting bias) }\end{array}$ & High risk & $\begin{array}{l}\text { Reporting of outcome data for lung function and SGRQ is unclear. Data provid- } \\
\text { ed consist of mean difference and } 95 \% \mathrm{CI} \text { when standard errors should be pro- } \\
\text { vided. A check of the data revealed discrepancies in the numbers. Data for ad- } \\
\text { verse events were also unclear. There was no reference to a protocol, so we do } \\
\text { not know whether outcomes were reported as planned. The paper includes } \\
\text { some confusing statements about follow-up at } 12 \text { weeks vs } 12 \text { months - prob- } \\
\text { ably } 12 \text { months - but then follow-up for another } 3 \text { months. Abstract states that } \\
\text { adverse events were increased, but this is not the same as the data in the pa- } \\
\text { per }\end{array}$ \\
\hline
\end{tabular}

\begin{tabular}{ll}
\hline Other bias $\quad$ Low risk & $\begin{array}{l}\text { No information on baseline anticholinergic, beta }{ }_{2} \text {-agonist, or corticosteroid } \\
\text { use }\end{array}$ \\
\hline
\end{tabular}




\section{Study characteristics}

\begin{tabular}{|c|c|}
\hline Methods & $\begin{array}{l}\text { Study design: parallel-group study } \\
\text { Randomisation: randomised, triple-blind, placebo-controlled trial } \\
\text { Trial duration: } 104 \text { weeks } \\
\text { Intention-to-treat analysis: stated }\end{array}$ \\
\hline Participants & $\begin{array}{l}\text { Setting: } 12 \text { specialist centres across the USA } \\
\text { Participants: } 84 \text { (tetomilast } 25 \mu \mathrm{g}: 51 \text {, placebo: } 33 \text { ) } \\
\text { Baseline characteristics: mean age } 58 \text { years, } 51 \% \text { male } \\
\text { Inclusion criteria: aged } 40 \text { to } 75 \text { years, rating } \geq 1 \text { on Goddart scale for emphysema, FEV } 1 \text { :FVC }>70 \% \text { pre- } \\
\text { dicted, } \geq 1 \text { COPD exacerbation in the past } 12 \text { months } \\
\text { Exclusion criteria: asthma, active tuberculosis/bronchiectasis, respiratory tract infection in past } \\
\text { month before screening, cancer in past } 5 \text { years, cardiovascular/endocrine blood/nervious system disor- } \\
\text { der, uncontrolled COPD exacerbation (level } 2 \text { or } 3 \text { ), recent systemic ICS or immunosuppressant, antico- } \\
\text { agulant } \\
\text { Total numbers of participant withdrawals: } 28 \text { (54\%) and } 18 \text { (54\%) from treatment and control } \\
\text { groups, respectively }\end{array}$ \\
\hline Interventions & $\begin{array}{l}\text { Run-in: } 25 \mu \text { g dose tetomilast for } 2 \text { weeks } \\
\text { Intervention: } 50 \mu \text { g once daily } \\
\text { Comparator: placebo once daily } \\
\text { Concomitant medication } \\
\text { - Short-acting anticholingeric: not stated } \\
\text { - SABA: not stated } \\
\text { - Corticosteroid: not stated } \\
\text { - Long-acting beta } 2 \text {-agonist: not stated }\end{array}$ \\
\hline
\end{tabular}

Outcomes

Primary outcomes: change in $\mathrm{FEV}_{1}$; rate of change in 20th percentile of lung voxels

Secondary outcomes: change in trough $\mathrm{FEV}_{1}$; density mask score based on lung density voxels; rate of change in 20th percentile of lung density voxels expressed in $\mathrm{HU}$ units for whole lung; rate of change in emphysema (observed); change in cumulative frequency of $\mathrm{HU}$; change in computed tomography (derived lung volumes); change in trough RV/TLC; change in trough inspiratory capacity; change in trough functional residual capacity; change in carbon monoxide diffusion capacity; changes in mean specific airway resistance and specific conductance; change in 7-day average total symptom score for dyspnoea, cough, and sputum; change in 7-day mean number of actuations of rescue medications; percentage of participants with COPD exacerbations by group; percentage of participants experiencing a COPD exacerbation

Safety outcomes: adverse events; changes in laboratory parameters, blood pressure, heart rate, physical examination findings, body weight, and BMI

Notes Clinicaltrials.gov identifier: NCT00874497

Funded by Otsuka Pharmaceutical Development \& Commercialization, Inc. 
NCT00874497 (EMPHASIS) (Continued)

\begin{tabular}{lll} 
Bias & Authors' judgement & Support for judgement \\
\hline $\begin{array}{l}\text { Random sequence genera- } \\
\text { tion (selection bias) }\end{array}$ & Low risk & $\begin{array}{l}\text { Assumed that the randomisation method was adequate due to pharmaceuti- } \\
\text { cal company sponsorship }\end{array}$ \\
\hline
\end{tabular}

\begin{tabular}{|c|c|c|}
\hline $\begin{array}{l}\text { Allocation concealment } \\
\text { (selection bias) }\end{array}$ & Low risk & $\begin{array}{l}\text { Assumed that the allocation concealment method was adequate due to phar- } \\
\text { maceutical company sponsorship }\end{array}$ \\
\hline
\end{tabular}

\begin{tabular}{|c|c|c|}
\hline $\begin{array}{l}\text { Blinding of participants } \\
\text { and personnel (perfor- }\end{array}$ & Unclear risk & $\begin{array}{l}\text { The trial was double-blind; participants, care providers, and outcome asses- } \\
\text { sors were blinded }\end{array}$ \\
\hline
\end{tabular}
mance bias)

All outcomes

\begin{tabular}{lll}
\hline $\begin{array}{l}\text { Blinding of outcome as- } \\
\text { sessment (detection bias) } \\
\text { All outcomes }\end{array}$ & Low risk & $\begin{array}{l}\text { The trial was double-blind; participants, care providers, and outcome asses- } \\
\text { sors were blinded }\end{array}$ \\
\hline $\begin{array}{l}\text { Incomplete outcome data } \\
\text { (attrition bias) }\end{array}$ & High risk & $\begin{array}{l}54 \% \text { in each group did not complete treatment and discontinued the trial ear- } \\
\text { All outcomes }\end{array}$ \\
$\begin{array}{l}\text { ly but there were } 5 \text { more adverse events in the tetomilast group vs the place- } \\
\text { bo group. } 4 \text { more people in the intervention arm discontinued because of ear- } \\
\text { ly termination of the trial. Other factors included loss to follow-up, withdraw- } \\
\text { al by either participant, or physician decision. Different numbers were used in } \\
\text { different analyses }\end{array}$
\end{tabular}

\begin{tabular}{lll}
\hline $\begin{array}{l}\text { Selective reporting (re- } \\
\text { porting bias) }\end{array}$ & Low risk & $\begin{array}{l}\text { Outcomes were reported as planned. Trial information was reported on the } \\
\text { GSK website }\end{array}$ \\
\hline Other bias & Unclear risk & $\begin{array}{l}\text { No information on baseline anticholinergic, beta } \text { - }_{\text {-agonist, or corticosteroid }} \\
\text { use }\end{array}$ \\
\hline
\end{tabular}

RO-2455-301-RD (ACROSS)

\section{Study characteristics}

\begin{tabular}{|c|c|}
\hline Methods & $\begin{array}{l}\text { Study design: parallel-group study } \\
\text { Randomisation: randomised, double-blind, placebo-controlled trial } \\
\text { Trial duration: } 24 \text { weeks } \\
\text { Intention-to-treat analysis: stated }\end{array}$ \\
\hline Participants & $\begin{array}{l}\text { Setting: } 43 \text { centres in mainland China, Hong Kong, and Singapore } \\
\text { Participants: } 626 \text { ( } 500 \mu \text { g roflumilast: } 313 \text {, placebo: } 313 \text { ) } \\
\text { Baseline characteristics: mean age } 64 \text { years, } 91 \% \text { male, mean } \mathrm{FEV}_{1} \% \text { predicted } 36 \% \text {, mean smoking } \\
\text { history } 37.2 \text { pack-years for roflumilast and } 37.5 \text { pack-years for placebo or current smokers ( } 24 \% \text { and } \\
29 \% \text {, respectively) } \\
\text { Inclusion criteria: Chinese, Malaysian, or Indian ethnicity, age } 40 \text { to } 80 \text { years with severe or very severe } \\
\text { COPD, } F E V_{1} / F V C \leq 0.7 \text {, post-bronchodilator } F E V_{1} \leq 50 \% \text {. Current smokers or ex-smokers with smoking } \\
\text { history }>10 \text { pack-years or current smokers; } 12 \text {-month history of COPD and } \geq 14 \text { puffs of rescue medica- } \\
\text { tion during the week before randomisation } \\
\text { Exclusion criteria: primary bronchiectasis, cystic fibrosis, bronchiolitis, lung resection, lung cancer, in- } \\
\text { terstitial lung disease, active TB, lower respiratory tract infection, diagnosis of asthma at < } 40 \text { years of } \\
\text { age, } \alpha_{1} \text {-antitrypsin deficiency }\end{array}$ \\
\hline
\end{tabular}


RO-2455-301-RD (ACROSS) (Continued)

Total numbers of participant withdrawals: 67 (21.4\%) and $50(16 \%)$ from treatment and control groups, respectively

Run-in: 4 weeks, single-blind. Placebo tablets to assess suitability
- Roflumilast $500 \mu$ g once daily
- Placebo once daily
Concomitant medication
Participants were allowed to continue taking fixed combinations of ICS plus LABA or LAMA monothera-
py (e.g. tiotropium) if taken at a stable dose for at least 6 months before the run-in period. SAMAs (e.g.
ipratropium) were allowed at a constant daily dose as concomitant medication if taken on a regular ba-
sis for at least 4 weeks before study inclusion. All other COPD treatments were not allowed

Primary outcomes: lung function; change in pre-bronchodilator FEV
Secondary outcomes: changes in post-bronchodilator FEV ${ }_{1}$, FVC, incidence rates of COPD exacerba-
tions, time to first COPD exacerbation, transition dyspnoea index, proportions of participants experi-
encing a COPD exacerbation, adverse events, changes in body weight, laboratory values, vital signs,
and physical examination findings

\begin{tabular}{ll}
\hline Notes & Clinicaltrials.gov identifier: NCT01313494 \\
& Funded by AstraZeneca
\end{tabular}

\section{Risk of bias}

\begin{tabular}{lll}
\hline Bias & Authors' judgement & Support for judgement \\
\hline $\begin{array}{l}\text { Random sequence genera- } \\
\text { tion (selection bias) }\end{array}$ & Low risk & $\begin{array}{l}\text { Investigators used an automated, interactive voice-response system to ran- } \\
\text { domly assign participants. The sponsor generated a list of participant num- } \\
\text { bers using a pseudo-random number generator }\end{array}$ \\
\hline $\begin{array}{l}\text { Allocation concealment } \\
\text { (selection bias) }\end{array}$ & Low risk & $\begin{array}{l}\text { The investigator or anyone at the study site was prevented from knowing the } \\
\text { allocation sequence with code labelling }\end{array}$ \\
\hline
\end{tabular}

Blinding of participants Low risk The trial was double-blinded, and tablets were identical in appearance
and personnel (performance bias)

All outcomes

\begin{tabular}{|c|c|c|}
\hline $\begin{array}{l}\text { Blinding of outcome as- } \\
\text { sessment (detection bias) }\end{array}$ & Low risk & $\begin{array}{l}\text { The trial was double-blinded. The investigator or anyone at the study site was } \\
\text { prevented from knowing the treatment allocation }\end{array}$ \\
\hline
\end{tabular}

All outcomes

\begin{tabular}{lll}
\hline $\begin{array}{l}\text { Incomplete outcome data } \\
\text { (attrition bias) } \\
\text { All outcomes }\end{array}$ & Low risk & $\begin{array}{l}\text { Total numbers of participants that discontinued 50 (16\%) placebo, 67 (21.4\%) } \\
\text { roflumilast }\end{array}$ \\
\hline $\begin{array}{l}\text { Selective reporting (re- } \\
\text { porting bias) }\end{array}$ & Unclear risk & $\begin{array}{l}\text { Outcomes were reported as planned, and the trial was registered at the NCT } \\
\text { website }\end{array}$ \\
\hline
\end{tabular}

\begin{tabular}{ll}
\hline Other bias & LAMA: $17.9 \%$ for placebo; $20.4 \%$ for roflumilast \\
& SAMA: $18.2 \%$ for placebo; $17.3 \%$ for roflumilast \\
& ICS/LABA: $55.9 \%$ for placebo; $59.7 \%$ for roflumilast \\
& No information available. SABA allowed \\
\hline
\end{tabular}




\section{Study characteristics}

\begin{tabular}{|c|c|}
\hline Methods & $\begin{array}{l}\text { Study design: parallel-group study } \\
\text { Randomisation: randomised, double-blind, placebo-controlled trial } \\
\text { Trial duration: } 16 \text { weeks } \\
\text { Intention-to-treat analysis: stated }\end{array}$ \\
\hline Participants & $\begin{array}{l}\text { Setting: } 18 \text { centres in Denmark, Germany, Poland, Sweden, and United Kingdom } \\
\text { Participants: } 158 \text { ( } 500 \mu \mathrm{g} \text { roflumilast: } 79 ; \text { placebo: } 79 \text { ) } \\
\text { Baseline characteristics: mean age } 63 \text { years, } 77 \% \text { male, mean } \mathrm{FEV}_{1} \text { predicted } 60 \% \text {, mean smoking his- } \\
\text { tory longer than } 20 \text { years or current smokers } 54 \% \\
\text { Inclusion criteria: post-bronchodilator } 30 \% \leq \mathrm{FEV}_{1} \leq 8 \% \text { predicted, post-bronchodilator } \mathrm{FEV} / \mathrm{FVC} \text { ra- } \\
\text { tio } \leq 70 \% \text {, current/former smoker history } \geq 20 \text { pack-years; aged } 40 \text { to } 80 \text { years with COPD diagnosed at } \\
\text { least } 12 \text { months before study inclusion, chronic productive cough for } 3 \text { months in each of previous } 2 \\
\text { years } \\
\text { Exclusion criteria: recent COPD exacerbation, ongoing upper or lower respiratory tract infection, asth- } \\
\text { ma (with or without other lung disease), alpha-1-antitrypsin deficiency, bleeding disorder, concomitant } \\
\text { glucocorticosteroids, theophylline, lipoxygenase inhibitors, antiplatelet therapy, leukotriene antago- } \\
\text { nists } \\
\text { Total numbers of participant withdrawals: } 3 \text { (4\%) and } 6 \text { (8\%) from treatment and control groups, re- } \\
\text { spectively }\end{array}$ \\
\hline Interventions & $\begin{array}{l}\text { Run-in: } 6 \text { weeks, single-blind with placebo to assess compliance. ICS and other non-allowed drugs } \\
\text { stopped } \\
\text { - Roflumilast } 500 \mu \text { g once daily } \\
\text { - Placebo once daily } \\
\text { Concomitant medication } \\
\text { - Short-acting anticholingeric: none } \\
\text { - SABA: none } \\
\text { - Corticosteroid: not permitted. } \\
\text { - Long-acting } \beta_{2} \text {-agonist: } 61 \% \text { in the roflumilast group and } 61 \% \text { in the placebo group, respectively }\end{array}$ \\
\hline
\end{tabular}

Outcomes

Primary outcome: change in numbers of CD8 inflammatory cells in bronchial biopsy samples

Secondary outcomes: change in numbers of inflammatory cells measured in submucosa, bronchial epithelium, induced sputum; blood $\mathrm{FEV}_{1}, \mathrm{FVC}$, and $\mathrm{FEV}_{1} / \mathrm{FVC}$ ratio

Safety outcomes: adverse events; changes in laboratory parameters, blood pressure, heart rate, physical examination findings, body weight, and BMI

\begin{tabular}{ll}
\hline Notes & Funded by AstraZeneca \\
\hline Risk of bias & \\
\hline Bias Authors' judgement Support for judgement \\
\hline
\end{tabular}


RO-2455-402-RD (ROBERT) (Continued)

$\begin{array}{ll}\begin{array}{l}\text { Random sequence genera- } \\ \text { tion (selection bias) }\end{array} & \text { Low risk } \\ \end{array}$

$\begin{array}{ll}\begin{array}{l}\text { Allocation concealment } \\ \text { (selection bias) }\end{array} & \text { Low risk } \\ & \begin{array}{l}\text { Both roflumilast and placebo were given as identical yellow, triangular tablets; } \\ \text { blinding was maintained via an interactive voice-response system and an in- } \\ \text { teractive web-response system }\end{array}\end{array}$

Blinding of participants Low risk Participants and investigators were blinded to group assignment
and personnel (perfor-
mance bias)
All outcomes

\begin{tabular}{lll}
\hline $\begin{array}{l}\text { Blinding of outcome as- } \\
\begin{array}{l}\text { sessment (detection bias) } \\
\text { All outcomes }\end{array}\end{array}$ & Low risk & Outcome assessors were blinded \\
\hline $\begin{array}{l}\text { Incomplete outcome data } \\
\text { (attrition bias) } \\
\begin{array}{l}\text { All outcomes } \\
\text { Lew risk }\end{array}\end{array}$ & $\begin{array}{l}\text { Overall the total \% of participants who discontinued was 5.7\%. In the roflumi- } \\
\text { last group, 3.7\% discontinued compared to } 7.59 \% \text { in the placebo group. The } \\
\text { number of adverse events was the same in each group; the numbers not com- } \\
\text { pleting were } 6 \text { in the placebo group and } 3 \text { in the roflumilast group }\end{array}$ \\
\hline $\begin{array}{l}\text { Selective reporting (re- } \\
\text { porting bias) }\end{array}$ & Low risk & $\begin{array}{l}\text { Outcomes were reported as planned. Some of the outcome data were report- } \\
\text { ed in the NCT and EU clinical trials registers }\end{array}$ \\
\hline Other bias & Low risk & $\begin{array}{l}\text { No information on baseline anticholinergic, beta } 2 \text {-agonist, or corticosteroid } \\
\text { use }\end{array}$ \\
\hline
\end{tabular}

\section{RO-2455-404-RD (REACT)}

\section{Study characteristics}

\begin{tabular}{ll} 
Study design: parallel-group study \\
Randomisation: randomised, double-blind, placebo-controlled trial \\
Trial duration: 52 weeks \\
Intention-to-treat analysis: stated \\
\hline
\end{tabular}

Participants Setting: 203 centres in 21 countries (see online appendix)

Participants: 1945 (500 $\mu$ g roflumilast: 969; placebo: 966)

Baseline characteristics: mean age 65 years, $75 \%$ male, mean $\mathrm{FEV}_{1}$ predicted $35 \%$, mean smoking history 48 pack-years for roflumilast and 48 pack-years for placebo or current smokers ( $42 \%$ and $45 \%$, respectively)

Inclusion criteria: $\geq 40$ years of age with a smoking history $\geq 20$ pack-years and a diagnosis of COPD with severe airflow limitation (confirmed by post-bronchodilator $\mathrm{FEV}_{1} / \mathrm{FVC}$ ratio $<0.70$ and post-bronchodilator $\mathrm{FEV}_{1} \leq 50 \%$ predicted), symptoms of chronic bronchitis, history of $\geq 2$ exacerbations in the previous year. Participants must have been taking an ICS-LABA combination for 12 months before the study and a constant dose of an ICS-LABA fixed combination for at least 3 months before enrolment, with placebo tablet compliance of $80 \%$ to $125 \%$ during the 4 -week baseline observation period, and with a total cough and sputum score $\geq 14$ (in which the score was a sum of daily scores on 4-point scales for cough and sputum) recorded in a daily diary during the week preceding the randomisation visit 
R0-2455-404-RD (REACT) (Continued)

Exclusion criteria: COPD exacerbation that was ongoing during the baseline period, diagnosis of asthma or other major lung disease

Total numbers of participant withdrawals: $269(28 \%)$ and $192(20 \%)$ from treatment and control groups, respectively

Run-in: 4 weeks, single-blind. Placebo tablets to assess suitability
- Roflumilast $500 \mu$ g once daily
Concomitant medication
All participants used a fixed-dose ICS-LABA combination during baseline and treatment periods. If a
participant had an exacerbation that needed additional treatment during the study, the investigator
could give up to 40 mg prednisolone, administered systemically, per day for 7 to 14 days. In the case of
purulent sputum or suspected bacterial infection, additional antibiotic therapy was allowed. Use of the
following treatments was not allowed: oral and parenteral glucocorticosteroids (except to treat acute
exacerbations), LABA or ICS monotherapy, SAMA, and any SABA (with the exception of salbutamol) or
oral $\beta_{2}$-agonists. Participants already taking inhaled tiotropium bromide (a LAMA) were allowed to con-
tinue this treatment

Outcomes Primary outcomes: rate of moderate or severe COPD exacerbations per patient per year

Secondary outcomes: change from baseline in post-bronchodilator $\mathrm{FEV}_{1}$, rate of severe COPD exacerbations per patient per year, rate of COPD exacerbations per patient per year (all categories), percentage of participants experiencing $\geq 1$ COPD exacerbation, time to first COPD exacerbation (all categories), time to second moderate or severe COPD exacerbation, time to third moderate or severe COPD exacerbation, number of participants needed to treat to avoid 1 moderate or severe COPD exacerbation derived from exacerbation per patient per year, number of moderate or severe COPD exacerbation days, duration of moderate or severe COPD exacerbations per participant, change from baseline in post-bronchodilator FVC, change from baseline in post-bronchodilator FEF ( $25 \%$ to $75 \%$ vital capacity), change from baseline in post-bronchodilator $\mathrm{FEV}_{6}$, change from baseline in post-bronchodilator $\mathrm{FEV}_{1} / \mathrm{FVC}$, change from baseline in rescue medication use, change from baseline in COPD symptom score, percentage symptom-free days, percentage rescue medication-free days, change from baseline in CAT total score, percentage participants with CAT score improvement, time to mortality (all-cause and COPD exacerbation-related), time to withdrawal (all-cause and COPD exacerbation-related), percentage of participants with major adverse cardiovascular event, time to first major adverse cardiovascular event, percentage of participants with hospitalisation (all-cause), time to first hospitalisation, time to withdrawal due to adverse event, percentage of participants experiencing $\geq 1$ adverse event (treatment-related), change from baseline in body weight, change from baseline in BMI

Notes Clinicaltrials.gov identifier: NCT01329029

Funded by AstraZeneca

\section{Risk of bias}

\begin{tabular}{lll}
\hline Bias & Authors' judgement & Support for judgement \\
\hline $\begin{array}{l}\text { Random sequence genera- } \\
\text { tion (selection bias) }\end{array}$ & Low risk & $\begin{array}{l}\text { Enrolled participants were randomly assigned in a 1:1 ratio, with a block size } \\
\text { of 4, by a computerised central randomisation system, the Interactive Voice } \\
\text { Response System-Interactive Web Response System (PPD Global Limited, } \\
\text { Cambridge, UK) }\end{array}$ \\
\hline $\begin{array}{l}\text { Allocation concealment } \\
\text { (selection bias) }\end{array}$ & Low risk & All parties involved in the study were masked to treatment assignment \\
\hline $\begin{array}{l}\text { Blinding of participants } \\
\text { and personnel (perfor- } \\
\text { mance bias) }\end{array}$ & Low risk & $\begin{array}{l}\text { Roflumilast and placebo were supplied as identical yellow triangular tablets } \\
\text { in wallet cards containing 40 tablets; all parties involved in the study were } \\
\text { masked to treatment assignment }\end{array}$ \\
\hline
\end{tabular}


R0-2455-404-RD (REACT) (Continued)

All outcomes

Blinding of outcome as-
sessment (detection bias) $\quad$ Low risk All parties involved in the study were masked to treatment assignment

sessment (detection bias)

All outcomes

$\begin{array}{ll}\begin{array}{l}\text { Incomplete outcome data } \\ \text { (attrition bias) }\end{array} & \text { Low risk } \\ \text { All outcomes } & \text { and } 192(20 \%) \text { from the placebo group discontinued }\end{array}$

All outcomes

Selective reporting (re- Low risk porting bias)
Outcomes were reported as planned. The trial was registered at the NCT website

LAMA: $69 \%$ for placebo; $70 \%$ for roflumilast. No group differences stated; however 1900 (98\%) of 1935 participants were using a combination of ICS-LABA according to the protocol

Roflumilast DAL-MD-01

\section{Study characteristics}

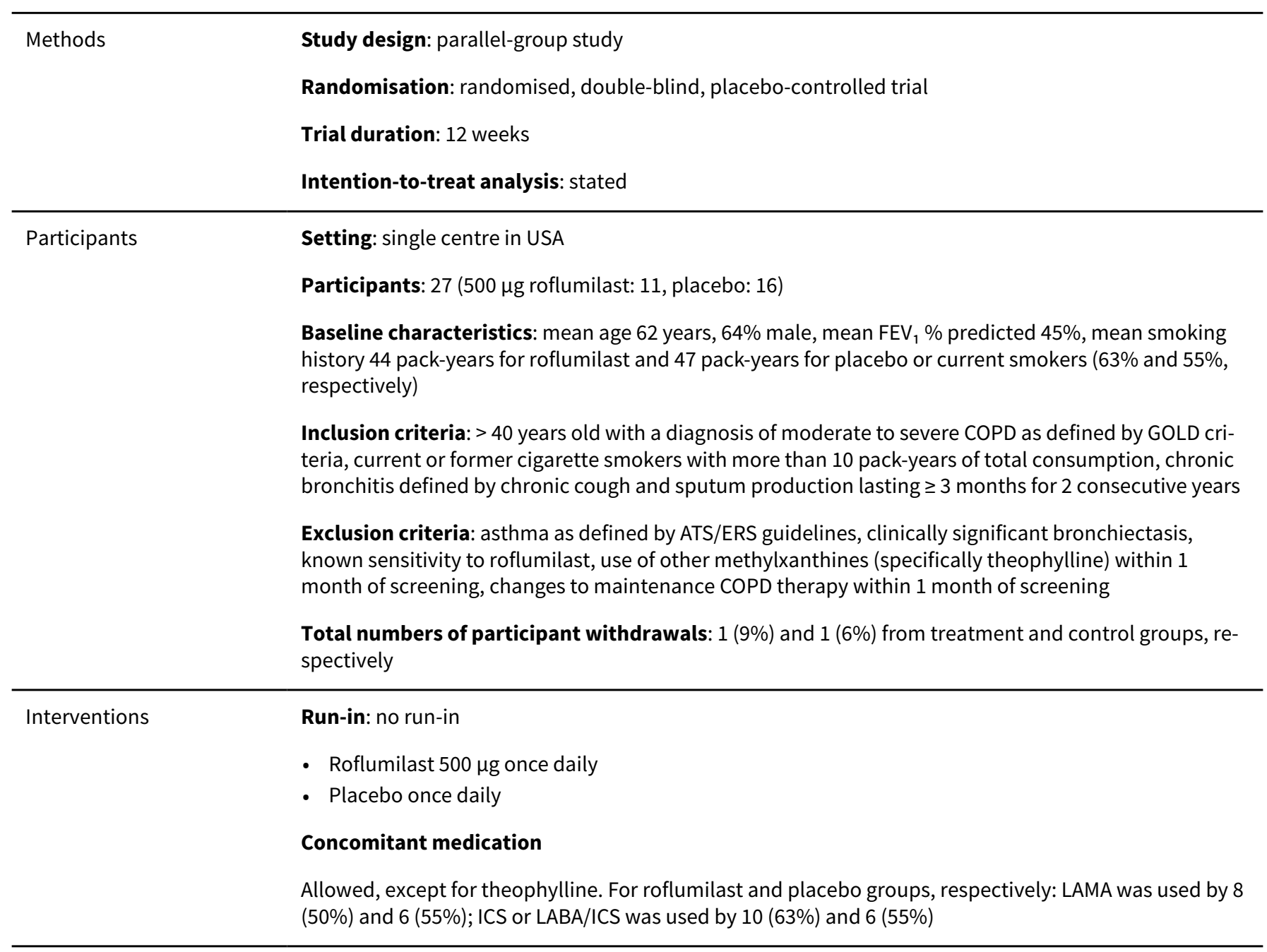


Roflumilast DAL-MD-01 (Continued)

Outcomes

Primary outcome: change in induced sputum AcPGP at 12 weeks post randomisation in an intention-to-treat analysis

Secondary outcomes: changes in plasma AcPGP, sputum neutrophil counts, additional sputum biomarkers, 6MWT, Breathlessness Cough and Sputum Scale, SGRQ scores, changes in post-bronchodilator $\mathrm{FEV}_{1}$ at 12 -week visit

$\begin{array}{ll}\text { Notes } & \begin{array}{l}\text { Clinicaltrials.gov identifier NCT01572948. Funded by Forest Laboratories Inc., University of Alabama at } \\ \text { Birmingham }\end{array}\end{array}$

\section{Risk of bias}

\begin{tabular}{lll}
\hline Bias & Authors' judgement & Support for judgement \\
\hline $\begin{array}{l}\text { Random sequence genera- } \\
\text { tion (selection bias) }\end{array}$ & Unclear risk & $\begin{array}{l}\text { The trial was reported as block randomised with a 1:1 allocation, stratified by } \\
\text { current smoking status and ICS use, but no information about the sequence } \\
\text { generation was provided }\end{array}$ \\
\hline
\end{tabular}

\begin{tabular}{lll}
\hline $\begin{array}{l}\text { Allocation concealment } \\
\text { (selection bias) }\end{array}$ & Low risk & Sealed envelopes were used to conceal allocation \\
\hline $\begin{array}{l}\text { Blinding of participants } \\
\text { and personnel (perfor- } \\
\text { mance bias) }\end{array}$ & Low risk & The trial was triple-blinded (participant, care provider, and investigator) \\
All outcomes & \\
\hline
\end{tabular}

\begin{tabular}{lll}
\hline $\begin{array}{l}\text { Blinding of outcome as- } \\
\text { sessment (detection bias) } \\
\text { All outcomes }\end{array}$ & Low risk & The trial was triple-blinded (participant, care provider, and investigator) \\
\hline $\begin{array}{l}\text { Incomplete outcome data } \\
\begin{array}{l}\text { (attrition bias) } \\
\text { All outcomes }\end{array}\end{array}$ & Low risk & $\begin{array}{l}\text { At follow-up, only 1 participant in each group was lost because of refusal to at- } \\
\text { tend the final visit or inability to be contacted for the final visit }\end{array}$ \\
\hline $\begin{array}{l}\text { Selective reporting (re- } \\
\text { porting bias) }\end{array}$ & Low risk & $\begin{array}{l}\text { Outomes were reported as planned; the trial was registered at clinicaltrial- } \\
\text { s.gov }\end{array}$ \\
\hline Other bias & Unclear risk & None \\
\hline
\end{tabular}

Roflumilast FK1 101

\section{Study characteristics}

\begin{tabular}{ll}
\hline Methods & Study design: parallel-group study \\
Randomisation: randomised, double-blind, placebo-controlled trial \\
Trial duration: 26 weeks \\
Intention-to-treat analysis: stated \\
Setting: not stated \\
Participants: 516 (roflumilast $250 \mu \mathrm{gg}: 175$, roflumilast $500 \mu \mathrm{gg}: 169$, placebo: 172 ) \\
Baseline characteristics: median age 61 to 62 years, $72 \%$ male, mean 38 to 63 pack-years, $53 \%$ current \\
smokers
\end{tabular}


Roflumilast FK1 101 (Continued)

Inclusion criteria: aged 40 to 75 years, $\mathrm{FEV}_{1} / \mathrm{FVC} \leq 0.7$ with smoking history $>10$ pack-years, reversibility $<12 \%$ or $200 \mathrm{~mL}$, post-bronchodilator $\mathrm{FEV}_{1} 35 \%$ to $75 \%$ predicted

Exclusion criteria: not stated

Total numbers of participant withdrawals: not stated

Run-in: 2 weeks with placebo
- Roflumilast $500 \mu \mathrm{g}$ once daily
- Roflumilast $250 \mu \mathrm{g}$ once daily
- Placebo once daily
Concomitant medication
- Short-acting anticholinergic: allowed at a constant daily dose for those treated before with anticholin-
- SABA: salbutamol was allowed as rescue medication
- Corticosteroid: none
- LABA: none

Outcomes

Primary outcomes: post-bronchodilator $\mathrm{FEV}_{1}$ and $\mathrm{FEF}$ between $25 \%$ and $75 \%$ of vital capacity

Secondary outcomes: numbers of moderate or severe COPD exacerbations that required treatment with OCS

Notes Funding not reported

\section{Risk of bias}

\begin{tabular}{lll}
\hline Bias & Authors' judgement & Support for judgement \\
\hline $\begin{array}{l}\text { Random sequence genera- } \\
\text { tion (selection bias) }\end{array}$ & Unclear risk & Reported as randomised. No further information \\
\hline $\begin{array}{l}\text { Allocation concealment } \\
\text { (selection bias) }\end{array}$ & Unclear risk & No available information \\
\hline
\end{tabular}

Blinding of participants Low risk Reported as double-blind
and personnel (perfor-

mance bias)

All outcomes

\begin{tabular}{lll}
\hline Blinding of outcome as- & Unclear risk & No available information \\
sessment (detection bias) & \\
All outcomes &
\end{tabular}

\begin{tabular}{lll}
\hline $\begin{array}{l}\text { Incomplete outcome data } \\
\text { (attrition bias) } \\
\text { All outcomes }\end{array}$ & Unclear risk & No available information \\
\hline $\begin{array}{l}\text { Selective reporting (re- } \\
\text { porting bias) }\end{array}$ & Unclear risk & Unpublished study; no available information \\
\hline Other bias & Low risk & None \\
\hline
\end{tabular}


Roflumilast FK1 103

\section{Study characteristics}

\begin{tabular}{|c|c|}
\hline Methods & $\begin{array}{l}\text { Study design: parallel-group study } \\
\text { Randomisation: randomised, double-blind, placebo-controlled trial } \\
\text { Trial duration: } 24 \text { weeks } \\
\text { Intention-to-treat analysis: stated }\end{array}$ \\
\hline Participants & $\begin{array}{l}\text { Setting: not stated } \\
\text { Participants: } 518 \text { (roflumilast } 500 \mu \mathrm{g}: 200 \text {, placebo: } 186 \text { ) } \\
\text { Baseline characteristics: mean age } 60 \text { years, } 75 \% \text { male, } 62 \% \text { current smokers, average } 35 \text { pack-years } \\
\text { Inclusion criteria: aged } 40 \text { to } 75 \text { years, } F E V_{1} / F V C \leq 0.7 \text {, post-bronchodilator } \mathrm{FEV}_{1} 35 \% \text { to } 75 \% \text { predicted, } \\
\text { FEV }{ }_{1} \text { reversibility } \leq 12 \% \text { and } \leq 200 \mathrm{~mL} \text {, pre-bronchodilator } \mathrm{FEV} / \mathrm{FVC} \leq 70 \% \\
\text { Exclusion criteria: not stated } \\
\text { Total numbers of participant withdrawals; not stated }\end{array}$ \\
\hline Interventions & $\begin{array}{l}\text { Run-in: } 2 \text { weeks with placebo } \\
\text { - Roflumilast } 500 \mu \mathrm{g} \text { once daily for } 24 \text { weeks } \\
\text { - Roflumilast } 500 \mu \mathrm{g} \text { once daily for } 12 \text { weeks. Placebo once daily for following } 12 \text { weeks } \\
\text { Concomitant medication } \\
\text { - Short-acting anticholinergic: all medications were withdrawn except constant-dose short-acting an- } \\
\text { ticholinergics } \\
\text { - SABA: as rescue medication } \\
\text { - Corticosteroid: none } \\
\text { - LABA: none } \\
\text { Used alongside short-acting } \beta_{2} \text {-agonists (available to all) }\end{array}$ \\
\hline
\end{tabular}

\begin{tabular}{ll}
\hline Outcomes & Primary outcomes: results for $12 / 24$-week post-bronchodilator FEV ${ }_{1}$ \\
\hline Notes & Funding not reported \\
\hline
\end{tabular}

\section{Risk of bias}

\begin{tabular}{lll}
\hline Bias & Authors' judgement & Support for judgement \\
\hline $\begin{array}{l}\text { Random sequence genera- } \\
\text { tion (selection bias) }\end{array}$ & Unclear risk & Method of randomisation not stated \\
\hline $\begin{array}{l}\text { Allocation concealment } \\
\text { (selection bias) }\end{array}$ & Unclear risk & No information available \\
\hline
\end{tabular}

Blinding of participants Low risk The trial was double-blind
and personnel (perfor-
mance bias)
All outcomes

\begin{tabular}{|c|c|c|}
\hline $\begin{array}{l}\text { Blinding of outcome as- } \\
\text { sessment (detection bias) } \\
\text { All outcomes }\end{array}$ & Unclear risk & No information available \\
\hline
\end{tabular}


Roflumilast FK1 103 (Continued)
Incomplete outcome data
Unclear risk
No information available
(attrition bias)

All outcomes

\begin{tabular}{lll}
\hline $\begin{array}{l}\text { Selective reporting (re- } \\
\text { porting bias) }\end{array}$ & Unclear risk & No information available \\
\hline Other bias & Low risk & None \\
\hline
\end{tabular}

Roflumilast FLUI-2011-77

\section{Study characteristics}

Study design: parallel-group study
Randomisation: randomised, double-blind, placebo-controlled trial
Trial duration: 26 months
Intention-to-treat analysis: stated
Responder analysis for the most part

\section{Participants}

\section{Setting: 2 centres}

Participants: 41 (500 $\mu$ g roflumilast: 30 , placebo: 11 )

Baseline characteristics: not stated

Inclusion criteria: not stated

Exclusion criteria: not stated

Total numbers of participant withdrawals: not stated

\begin{tabular}{ll}
\hline Interventions & Run-in: not stated \\
& - Roflumilast $500 \mu \mathrm{g}$ once daily \\
& Concomitant medication: not stated \\
\hline Outcomes & Primary outcomes: post bronchodilation: spirometry, body plethysmography, 6MWT, patient-reported \\
& outcomes \\
& Secondary outcomes: not stated \\
\hline Notes & Clinicaltrials.gov identifier NCT01480661 \\
& Funded by Takeda \\
\hline Risk of bias & Authors' judgement Support for judgement \\
\hline Bias & Unclear risk $\quad \begin{array}{l}\text { Reported as block randomised in a 3:1 ratio of roflumilast to placebo, respec- } \\
\text { Random sequence genera- } \\
\text { tion (selection bias) }\end{array}$ \\
\hline
\end{tabular}


Roflumilast FLUI-2011-77 (Continued)

\begin{tabular}{|c|c|c|}
\hline $\begin{array}{l}\text { Allocation concealment } \\
\text { (selection bias) }\end{array}$ & Unclear risk & No information available \\
\hline $\begin{array}{l}\text { Blinding of participants } \\
\text { and personnel (perfor- } \\
\text { mance bias) } \\
\text { All outcomes }\end{array}$ & Low risk & $\begin{array}{l}\text { The trial was reported as triple-blind (participant, care provider, and investiga- } \\
\text { tor) }\end{array}$ \\
\hline $\begin{array}{l}\text { Blinding of outcome as- } \\
\text { sessment (detection bias) } \\
\text { All outcomes }\end{array}$ & Low risk & $\begin{array}{l}\text { The trial was reported as triple-blind (participant, care provider, and investiga- } \\
\text { tor) }\end{array}$ \\
\hline $\begin{array}{l}\text { Incomplete outcome data } \\
\text { (attrition bias) } \\
\text { All outcomes }\end{array}$ & Unclear risk & Assumed that this would be low risk; however, no available information \\
\hline $\begin{array}{l}\text { Selective reporting (re- } \\
\text { porting bias) }\end{array}$ & Low risk & Outcomes reported as intended; trial registered at clinicaltrials.gov \\
\hline Other bias & Low risk & None \\
\hline
\end{tabular}

Roflumilast IN-108

\section{Study characteristics}

Methods

Study design: parallel-group study

Randomisation: randomised, double-blind, placebo-controlled trial

Trial duration: 12 weeks

Intention-to-treat analysis: not stated

Setting: 5 centres in India
Participants
Baseline characteristics: mean age 60 years, $98 \%$ male, $41 \%$ current smokers, post-bronchodilator
$\mathrm{FEV}_{1} 57 \%$ to $61 \%$, average 25 pack-years
Inclusion criteria: not stated
Exclusion criteria: not stated
Total numbers of participant withdrawals: roflumilast $500 \mu \mathrm{g}: 13$ (28\%); roflumilast $200 \mu \mathrm{gg}: 7$ (15\%);
control 10 (40\%)
Run-in: none
- Roflumilast $250 \mu$ once daily
- Roflumilast $500 \mu$ once daily
- Placebo once daily
Concomitant medication
- Short-acting anticholinergic: not stated
- SABA: not stated
- Corticosteroid: none


Roflumilast IN-108 (Continued)

- LABA: not stated

Outcomes Primary outcome: post-bronchodilator FEV

Secondary outcomes: COPD exacerbations, adverse events

\begin{tabular}{|c|c|c|}
\hline Notes & Funded by Forest Lab & atories \\
\hline \multicolumn{3}{|l|}{ Risk of bias } \\
\hline Bias & Authors' judgement & Support for judgement \\
\hline $\begin{array}{l}\text { Random sequence genera- } \\
\text { tion (selection bias) }\end{array}$ & Unclear risk & Reported as randomised. No further information available \\
\hline $\begin{array}{l}\text { Allocation concealment } \\
\text { (selection bias) }\end{array}$ & Unclear risk & No information available \\
\hline $\begin{array}{l}\text { Blinding of participants } \\
\text { and personnel (perfor- } \\
\text { mance bias) } \\
\text { All outcomes }\end{array}$ & Low risk & The trial was reported as double-blind \\
\hline $\begin{array}{l}\text { Blinding of outcome as- } \\
\text { sessment (detection bias) } \\
\text { All outcomes }\end{array}$ & Unclear risk & Assumed that this would be low risk; however, no available information \\
\hline $\begin{array}{l}\text { Incomplete outcome data } \\
\text { (attrition bias) } \\
\text { All outcomes }\end{array}$ & Low risk & Data as above \\
\hline $\begin{array}{l}\text { Selective reporting (re- } \\
\text { porting bias) }\end{array}$ & Unclear risk & No information available \\
\hline Other bias & Unclear risk & None \\
\hline
\end{tabular}

Roflumilast JP-706

\section{Study characteristics}

\begin{tabular}{ll}
\hline Methods & Study design: parallel-group study \\
& Randomisation: randomised, double-blind, placebo-controlled trial \\
& Trial duration: 24 weeks \\
& Intention-to-treat analysis: not stated \\
\hline Participants & Setting: Japan \\
& Participants: 600 (roflumilast $250 \mu g: 205$, roflumilast $500 \mu g: 204$, placebo: 191$)$ \\
& Baseline characteristics: mean age 70 years, $96 \%$ male, post-bronchodilator FEV, not stated, average \\
& 56 pack-years, $37 \%$ current smokers \\
& Inclusion criteria: not stated \\
& Exclusion criteria: not stated
\end{tabular}


Roflumilast JP-706 (Continued)

Total numbers of participant withdrawals: not stated

Run-in: single-blind 4 weeks with placebo
- Roflumilast $500 \mu$ g once daily
- Roflumilast $250 \mu$ g once daily
- Placebo once daily
Concomitant medication
- Short-acting anticholinergic: used at a constant daily dose
- SABA: not stated
- Corticosteroid: not stated

Outcomes Primary outcomes: pulmonary function (FEV 1 pre-bronchodilator, FVC pre- and post-bronchodilator, MMEF pre- and post-bronchodilator)

Secondary outcomes: number of COPD exacerbations, number of days to first COPD exacerbation, adverse events (all-cause and drug-related), serious adverse events (all-cause and drug-related)

Notes Funded by Mitsubishi-Tanabe

\section{Risk of bias}

\begin{tabular}{|c|c|c|}
\hline Bias & Authors' judgement & Support for judgement \\
\hline $\begin{array}{l}\text { Random sequence genera- } \\
\text { tion (selection bias) }\end{array}$ & Unclear risk & Reported as randomised; no further information about randomisation process \\
\hline $\begin{array}{l}\text { Allocation concealment } \\
\text { (selection bias) }\end{array}$ & Unclear risk & No information available \\
\hline $\begin{array}{l}\text { Blinding of participants } \\
\text { and personnel (perfor- } \\
\text { mance bias) } \\
\text { All outcomes }\end{array}$ & Low risk & The trial was reported as double-blinded \\
\hline $\begin{array}{l}\text { Blinding of outcome as- } \\
\text { sessment (detection bias) } \\
\text { All outcomes }\end{array}$ & Unclear risk & Assumed that this would be low risk; however, no available information \\
\hline $\begin{array}{l}\text { Incomplete outcome data } \\
\text { (attrition bias) } \\
\text { All outcomes }\end{array}$ & Unclear risk & Not described \\
\hline $\begin{array}{l}\text { Selective reporting (re- } \\
\text { porting bias) }\end{array}$ & High risk & $\begin{array}{l}\text { No further information available about the trial. No trial registry information } \\
\text { found }\end{array}$ \\
\hline Other bias & Low risk & None \\
\hline
\end{tabular}

Roflumilast M2-107

\section{Study characteristics}

Methods Study design: parallel-group study


Roflumilast M2-107 (Continued)

Randomisation: randomised, double-blind, placebo-controlled trial

Trial duration: 24 weeks

Intention-to-treat analysis: stated

Participants Setting: 159 centres in Australia, Austria, Belgium, Canada, France, Germany, Hungary, Ireland, South
Africa, Spain, and the UK

Participants: 1411 (roflumilast $250 \mu \mathrm{g}: 576$, roflumilast $500 \mu \mathrm{g}$ : 555, placebo: 280)

Baseline characteristics: median age 64 years, $74 \%$ male, post-bronchodilator $\mathrm{FEV}_{1} 51 \%$ for both groups, average 42 pack-years, $45 \%$ current smokers

Inclusion criteria: aged $\geq 40$ with history of COPD $>12$ months, $\mathrm{FEV}_{1}<50 \%$ predicted, $\mathrm{FEV}_{1} / \mathrm{FVC} \leq 0.7$ with smoking history $>10$ pack-years, reversibility $<12 \%$ or $200 \mathrm{~mL}$, mean post-bronchodilator FEV $30 \%$ to $80 \%$ predicted

Exclusion criteria: asthma, lung cancer or bronchiectasis, long-term oxygen treatment, recent exacerbation that required a course of systemic corticosteroids, emergency room treatment or hospital admission within 4 weeks before run-in period

Total numbers of participant withdrawals: $124(22 \%)$ and $32(11 \%)$ from treatment and control groups, respectively

Run-in: 4 weeks with placebo
- Roflumilast $500 \mu \mathrm{g}$ once daily
- Roflumilast $250 \mu \mathrm{g}$ once daily
- Placebo once daily
Concomitant medication
- Short-acting anticholinergic: used at a constant daily dose
- SABA: salbutamol as rescue medication
- Corticosteroid: none
- LABA: none

Outcomes Primary outcomes: post-bronchodilator $\mathrm{FEV}_{1}$; SGRQ total score

Secondary outcomes: change from baseline in pre-bronchodilator $\mathrm{FEV}_{1}$; post-bronchodilator FVC; post-bronchodilator FEV in 6 seconds and FVC; FEF rate between $25 \%$ and $75 \%$ of vital capacity; number of moderate or severe COPD exacerbations

\begin{tabular}{lll}
\hline Notes & Funded by ALTANA Pharma AG \\
\hline Risk of bias & & \\
\hline Bias & Authors' judgement & Support for judgement \\
\hline $\begin{array}{l}\text { Random sequence genera- } \\
\text { tion (selection bias) }\end{array}$ & Low risk & The randomisation sequence was generated by the sponsor in a blind manner \\
\hline $\begin{array}{l}\text { Allocation concealment } \\
\text { (selection bias) }\end{array}$ & Unclear risk & $\begin{array}{l}\text { No information on allocation concealment method, but "no person involved in } \\
\text { data analysis had knowledge of the randomisation sequence" }\end{array}$ \\
\hline $\begin{array}{l}\text { Blinding of participants } \\
\text { and personnel (perfor- } \\
\text { mance bias) } \\
\text { All outcomes }\end{array}$ & Low risk & $\begin{array}{l}\text { The trial was double-blind. Roflumilast and placebo tablets and packaging } \\
\text { were identical, so neither participants nor study personnel were aware of ei- } \\
\text { ther medication allocation }\end{array}$ \\
\hline
\end{tabular}


Roflumilast M2-107 (Continued)
Blinding of outcome as- Low risk sessment (detection bias)
"No person involved in data analysis had knowledge of the randomisation se-
quence"

All outcomes

Roflumilast and placebo tablets and packaging were identical, so the investigator was not aware of either medication allocation

$\begin{array}{ll}\begin{array}{l}\text { Incomplete outcome data } \\ \text { (attrition bias) }\end{array} & \begin{array}{l}100 \text { participants discontinued from the roflumilast } 250 \mu \mathrm{g} \text { group, } 124 \text { from the } \\ \text { roflumilast } 500 \mu \mathrm{g} \text { group, and } 32 \text { from the placebo group }\end{array}\end{array}$

All outcomes roflumilast $500 \mu \mathrm{g}$ group, and 32 from the placebo group

Selective reporting (re- High risk
porting bias)

Selective reporting (re- High risk

porting bias)
There was inconsistency in the quoting of statistical errors. Within the text and in Table 2, data are quoted as "least squares means and SD"; however in Fig- ures 2 and 3, SE bars are shown. It is more likely that results represented SE, not SD. Trial registration was not found

\begin{tabular}{ll}
\hline Other bias $\quad$ Now risk & None \\
\hline
\end{tabular}

Roflumilast M2-110

\title{
Study characteristics
}

Methods

\author{
Study design: parallel-group study \\ Randomisation: randomised, double-blind, placebo-controlled trial \\ Trial duration: 24 weeks \\ Intention-to-treat analysis: not stated
}

Participants $\quad$ Setting: 36 centres in Argentina, Canada, Columbia, Mexico, Peru, and the USA
Participants: 909 participants randomised (roflumilast $500 \mu \mathrm{gg}$ : 449; placebo: 460)

Baseline characteristics: aged between 55 and 74 years (mean age 64.2 years in the roflumilast group and 64.6 years in the placebo group), $88 \%$ participants were white, roflumilast group included $51 \%$ males and the placebo group 55\% males

Inclusion criteria: clinical diagnosis of COPD based on ATS criteria, post-bronchodilator $\mathrm{FEV}_{1} / \mathrm{FVC} \leq$ $70 \%$, post-bronchodilator $\mathrm{FEV}_{1} \geq 30 \%$ and $\leq 80 \%$ predicted, post-bronchodilator $\mathrm{FEV}_{1}$ increase $\leq 12 \%$ or $\leq 200 \mathrm{~mL}$ compared to pre-bronchodilator value, score grade $\geq 1$ on the MRC Dyspnea Scale, currently stable COPD with no change in COPD treatment in the prior 4 weeks

Exclusion criteria: clinical diagnosis of asthma, poorly controlled COPD, regular need for daily oxygen therapy

Total numbers of participant withdrawals: roflumilast group: $15.4 \%$ withdrew due to adverse events, $10.5 \%$ withdrew consent, $2.9 \%$ withdrew due to lack of efficacy; placebo group: $7.6 \%$ withdrew due to adverse events, $8.5 \%$ withdrew consent, $3 \%$ withdrew due to protocol violation

Interventions

Run-in: 4-week single-blind period during which respiratory medication (including ICS, LABA, and longacting anticholinergics) was withdrawn

- Roflumilast $500 \mu \mathrm{g}$ once daily

- Placebo once daily

\section{Concomitant medication}

- Short-acting anticholinergic: none

- SABA: none 
Roflumilast M2-110 (Continued)

- Corticosteroid: none

- LABA: none

\begin{tabular}{|c|c|c|}
\hline Outcomes & \multicolumn{2}{|c|}{$\begin{array}{l}\text { Primary outcomes: pulmonary function tests }\left(\mathrm{FEV}_{1}, \mathrm{FVC}, \mathrm{FEF}, \mathrm{PEF}, \mathrm{FIV}_{1}, \mathrm{FVC}_{\text {in }}\right) \\
\text { Secondary outcomes: exacerbation rate; quality of life; symptoms; use of rescue medication; safety } \\
\text { and tolerability }\end{array}$} \\
\hline Notes & \multicolumn{2}{|c|}{ ClinicalTrials.gov Identifier: NCT00062582. Funded by ALTANA Pharma AG } \\
\hline \multicolumn{3}{|l|}{ Risk of bias } \\
\hline Bias & Authors' judgement & Support for judgement \\
\hline $\begin{array}{l}\text { Random sequence genera- } \\
\text { tion (selection bias) }\end{array}$ & Low risk & $\begin{array}{l}\text { Reported as randomised. Assumed that the randomisation method was ade- } \\
\text { quate due to pharmaceutical company sponsorship }\end{array}$ \\
\hline $\begin{array}{l}\text { Allocation concealment } \\
\text { (selection bias) }\end{array}$ & Low risk & $\begin{array}{l}\text { Assumed that the allocation concealment method was adequate due to phar- } \\
\text { maceutical company sponsorship }\end{array}$ \\
\hline $\begin{array}{l}\text { Blinding of participants } \\
\text { and personnel (perfor- } \\
\text { mance bias) } \\
\text { All outcomes }\end{array}$ & Low risk & The trial was reported as double-blind \\
\hline $\begin{array}{l}\text { Blinding of outcome as- } \\
\text { sessment (detection bias) } \\
\text { All outcomes }\end{array}$ & Unclear risk & Assumed that this would be low risk; however, no available information \\
\hline $\begin{array}{l}\text { Incomplete outcome data } \\
\text { (attrition bias) } \\
\text { All outcomes }\end{array}$ & Unclear risk & $\begin{array}{l}\text { Roflumilast group: } 15.4 \% \text { withdrew due to adverse events, } 10.5 \% \text { withdrew } \\
\text { consent, } 2.9 \% \text { withdrew due to lack of efficacy; placebo group: } 7.6 \% \text { withdrew } \\
\text { due to adverse events, } 8.5 \% \text { withdrew consent, } 3 \% \text { withdrew due to protocol } \\
\text { violation }\end{array}$ \\
\hline $\begin{array}{l}\text { Selective reporting (re- } \\
\text { porting bias) }\end{array}$ & Low risk & $\begin{array}{l}\text { Outcomes were reported as planned. The trial was registered at clinicaltrial- } \\
\text { s.gov }\end{array}$ \\
\hline
\end{tabular}

Roflumilast M2-111

\section{Study characteristics}

$\begin{array}{ll}\text { Methods } & \text { Study design: parallel-group study } \\ \text { Randomisation: randomised, double-blind, placebo-controlled trial }\end{array}$

Trial duration: 52 weeks

Intention-to-treat analysis: stated

Participants

Setting: M2-111 was conducted at 188 centres in 6 countries, and M2-112 at 159 centres in 14 countries

Participants: 1176 participants were randomised in this study (roflumilast: $500 \mu \mathrm{g}$ : 568; placebo: 608)

Baseline characteristics: severe COPD according to GOLD criteria grades III and IV, mean age 64 to 65 years, $72 \%$ male

Inclusion criteria: aged $\geq 40$ years, post-bronchodilator $\mathrm{FEV}_{1}<50 \%$ predicted, reversibility $<15 \%$, mean post-bronchodilator $\mathrm{FEV}_{1} 42 \%, \mathrm{FEV}_{1} / \mathrm{FVC} \leq 0.7$ with smoking history $>10$ pack-years, $40 \%$ current smokers, $60 \%$ ex-smokers, average 46 to 48 pack-years 
Roflumilast M2-111 (Continued)

Exclusion criteria: history of asthma, lung cancer, or bronchiectasis; need for long-term oxygen therapy; known $\alpha_{1}$-antitrypsin deficiency, clinically significant cardiopulmonary comorbidity

Total numbers of participant withdrawals: data combined with M2-112 showing $433(33 \%)$ and 348 $(26 \%)$ from treatment and control groups, respectively

\author{
Interventions Run-in: 4 weeks with placebo \\ - Roflumilast $500 \mu \mathrm{g}$ once daily \\ - Placebo once daily \\ Concomitant medication \\ - Short-acting anticholingeric: 891 patients on short-acting anticholinergics \\ - SABA: salbutamol as rescue medication \\ - Corticosteroid: 943 patients continued corticosteroid use \\ - LABA: none \\ Used alongside corticosteroids, anticholinergics, and rescue short-acting $\beta_{2}$-agonists $54 \%$ overall \\ (available to all)
}

Outcomes Primary outcomes: change from baseline to endpoint in post-bronchodilator FEV ${ }_{1}$; number of moder-
ate or severe exacerbations per patient per year

Secondary outcomes: change from baseline in SGRQ total score; change from baseline in prebronchial $\mathrm{FEV}_{1}$, post-bronchodilator FEV in 6 seconds and in FVC; FEF rate between $25 \%$ and $75 \%$ vital capacity; number of moderate or severe COPD exacerbations requiring systemic corticosteroid treatment per patient per year

Notes NCT00076089/BY217/M2-111. Funded by AstraZeneca

\title{
Risk of bias
}

\begin{tabular}{lll}
\hline Bias & Authors' judgement & Support for judgement \\
\hline $\begin{array}{l}\text { Random sequence genera- } \\
\text { tion (selection bias) }\end{array}$ & Low risk & $\begin{array}{l}\text { The randomisation sequence was generated by a multiplicative congruent } \\
\text { pseudo-random numbers generator programme (programme RANDOM, based } \\
\text { on Fishman and Moore) }\end{array}$ \\
\hline $\begin{array}{l}\text { Allocation concealment } \\
\text { (selection bias) }\end{array}$ & Low risk & $\begin{array}{l}\text { "Each study participant who qualified was assigned a number in sequential or- } \\
\text { der. Code labelling prevented the investigator and the patient from knowing } \\
\text { which drug was administered" }\end{array}$ \\
\hline $\begin{array}{l}\text { Blinding of participants } \\
\text { and personnel (perfor- } \\
\text { mance bias) } \\
\text { All outcomes }\end{array}$ & Low risk & The trial was double-blind \\
\hline
\end{tabular}

$\begin{array}{ll}\text { Blinding of outcome as- } & \text { Unclear risk }\end{array}$ Assumed that this would be low risk; however, no available information
sessment (detection bias)

All outcomes

\begin{tabular}{lll}
\hline $\begin{array}{l}\text { Incomplete outcome data } \\
\text { (attrition bias) } \\
\text { All outcomes }\end{array}$ & Low risk & Data combined with M2-112 \\
\hline $\begin{array}{l}\text { Selective reporting (re- } \\
\text { porting bias) }\end{array}$ & Low risk & $\begin{array}{l}\text { Trial registered at clinicaltrials.gov; outcomes reported as planned. M2-111 } \\
\text { and M2-112 data combined }\end{array}$ \\
\hline
\end{tabular}


Roflumilast M2-111 (Continued)
Other bias
Low risk
None

Roflumilast M2-111+M2-112

\section{Study characteristics}

Methods As described in separate studies above and below

\section{Participants}

Interventions

Outcomes

Notes

\section{Risk of bias}

Bias Authors' judgement Support for judgement

Random sequence genera- Low risk See individual trials

tion (selection bias)

\begin{tabular}{l}
$\begin{array}{l}\text { Allocation concealment } \\
\text { (selection bias) }\end{array}$ Low risk individual trials \\
\hline
\end{tabular}

Blinding of participants $\quad$ Low risk $\quad$ See individual trials
and personnel (perfor-
mance bias)
All outcomes

\begin{tabular}{lll}
\hline $\begin{array}{l}\text { Blinding of outcome as- } \\
\text { sessment (detection bias) } \\
\text { All outcomes }\end{array}$ & Low risk & See individual trials \\
\hline $\begin{array}{l}\text { Incomplete outcome data } \\
\begin{array}{l}\text { (attrition bias) } \\
\text { All outcomes }\end{array}\end{array}$ & Low risk & See individual trials \\
\hline $\begin{array}{l}\text { Selective reporting (re- } \\
\text { porting bias) }\end{array}$ & Low risk & See individual trials \\
\hline Other bias & Low risk & \\
\hline
\end{tabular}

Roflumilast M2-112

\section{Study characteristics}

Methods Study design: parallel-group study

Randomisation: randomised, double-blind, placebo-controlled trial

Trial duration: 52 weeks 
Roflumilast M2-112 (Continued)

Intention-to-treat analysis: stated

Setting: 159 centres in 14 countries
Participants: 1514 (roflumilast $500 \mu \mathrm{g}: 761$, placebo: 753 )
Baseline characteristics: severe COPD according to GOLD criteria grades III and IV, mean age 65 years,
$75 \%$ male
Inclusion criteria: aged $\geq 40$ years, post-bronchodilator FEV $1<50 \%$ predicted, reversibility $<15 \%$,
mean post-bronchodilator FEV $141 \%$, FEV 1 FVC $\leq 0.7$ with smoking history $>10$ pack-years, $37 \%$ current
smokers, $63 \%$ ex-smokers, average 44 pack-years

Exclusion criteria: history of asthma, lung cancer, or bronchiectasis; need for long-term oxygen therapy; known $a_{1}$-antitrypsin deficiency or clinically significant cardiopulmonary comorbidity

Total numbers of participant withdrawals: $217(29 \%)$ and $163(22 \%)$ from treatment and control groups, respectively

\author{
Interventions \\ Run-in: 4 weeks with placebo \\ - Roflumilast $500 \mu \mathrm{g}$ once daily \\ - Placebo once daily \\ Concomitant medication \\ - Short-acting anticholinergic: 891 participants on short-acting anticholinergics \\ - SABA: salbutamol as rescue medication \\ - Corticosteroid: 943 participants continued corticosteroid use \\ - LABA: none \\ Used alongside corticosteroids, anticholinergics, and rescue short-acting $\beta_{2}$-agonists $54 \%$ overall \\ (available to all)
}

Outcomes Primary outcomes: change from baseline to endpoint in post-bronchodilator FEV ${ }_{1}$ and in the number of moderate or severe exacerbations per patient per year

Secondary outcomes: change from baseline in SGRQ total score; change from baseline in prebronchial $\mathrm{FEV}_{1}$; post-bronchodilator FEV in 6 seconds and FVC; FEF rate between $25 \%$ and $75 \%$ of vital capacity; number of moderate or severe COPD exacerbations requiring systemic corticosteroid treatment per patient per year

\begin{tabular}{|c|c|c|}
\hline Notes & \multicolumn{2}{|c|}{ NCT00430729/BY217/M2-112. Funded by AstraZeneca } \\
\hline \multicolumn{3}{|l|}{ Risk of bias } \\
\hline Bias & Authors' judgement & Support for judgement \\
\hline $\begin{array}{l}\text { Random sequence genera- } \\
\text { tion (selection bias) }\end{array}$ & Low risk & $\begin{array}{l}\text { "The randomisation list was generated using a multiplicative congruent pseu- } \\
\text { do-random number generator (program RANDOM, based on Fishman and } \\
\text { Moore)" }\end{array}$ \\
\hline $\begin{array}{l}\text { Allocation concealment } \\
\text { (selection bias) }\end{array}$ & Low risk & $\begin{array}{l}\text { "Each study participant who qualified was assigned a number in sequential or- } \\
\text { der. Code labelling prevented the investigator and the patient from knowing } \\
\text { which drug was administered" }\end{array}$ \\
\hline $\begin{array}{l}\text { Blinding of participants } \\
\text { and personnel (perfor- } \\
\text { mance bias) } \\
\text { All outcomes }\end{array}$ & Low risk & The trial was double-blinded \\
\hline
\end{tabular}


Roflumilast M2-112 (Continued)

Blinding of outcome as- Unclear risk Assumed that this would be low risk; however, no available information sessment (detection bias)

All outcomes

$\begin{array}{ll}\begin{array}{l}\text { Incomplete outcome data Low risk } \\ \text { (attrition bias) }\end{array} & \begin{array}{l}\text { "Over } 70 \% \text { of patients completed the study. The reasons for withdrawal were } \\ \text { All outcomes }\end{array} \\ & \text { quently with roflumilast" } \\ & \text { "Withdrawal due to COPD exacerbations was reported in } 3.5 \text { and } 3.2 \% \text { of pa- } \\ \text { tients in roflumilast and placebo groups, respectively" }\end{array}$

Selective reporting (re- Low risk None
porting bias)

\begin{tabular}{ll}
\hline Other bias $\quad$ Low risk & None \\
\hline
\end{tabular}

\section{Roflumilast M2-118}

\section{Study characteristics}

Study design: parallel-group study
Randomisation: randomised, double-blind, placebo-controlled trial
Trial duration: 12 weeks
Intention-to-treat analysis: stated

Participants Setting: 22 centres in 4 countries

Participants: 250 (roflumilast $500 \mu \mathrm{g}: 127$, placebo: 123)

Baseline characteristics: mean age 60 years, $73 \%$ (roflumilast) vs $84 \%$ (placebo) male, post-bronchodilator $\mathrm{FEV}_{1} 55 \%$ predicted, average 41 pack-years, $53 \%$ current smokers

Inclusion criteria: clinically stable patients $\geq 40$ years of age with smoking history $>10$ pack-years and 12 -month history of COPD. Other inclusion criteria included post-bronchodilator $\mathrm{FEV}_{1} 30 \%$ to $80 \%$ predicted, $\mathrm{FEV}_{1} /$ forced vital capacity $(\mathrm{FVC})<0.7$, and set plethysmographic $\mathrm{FRC}$ and peak oxygen uptake requirements

Exclusion criteria: asthma or lung disease other than COPD, $\alpha_{1}$-antitrypsin deficiency, participation in pulmonary rehabilitation programme within 2 months, supplemental oxygen therapy, significant medical comorbidity that may influence exercise tolerance

Total numbers of participant withdrawals: $16(13 \%)$ and $12(10 \%)$ from treatment and control groups, respectively

Run-in: 2- to 3-week baseline period consisting of 2 familiarisation visits during which a symptom-limited constant work rate cycle exercise test was performed at $75 \%$ of maximum incremental work rate. If a constant work rate endurance time was not produced within 2 minutes at both visits, a third visit was performed. If reproducibility was not achieved at the third visit, the patient was not randomised

- Roflumilast $500 \mu \mathrm{g}$ once daily

- Placebo once daily

\section{Concomitant medication}

- Short-acting anticholingeric: participants could use ipratropium bromide in regular stable doses as needed 
Roflumilast M2-118 (Continued)

- SABA: participants could use short-acting $\beta_{2}$-agonists as needed

- Corticosteroid: ICSs were permitted throughout the study if taken at a constant dosage for $>3$ months before the start of the study

- LABA: none

Outcomes

Primary outcomes: activity-related dyspnoea (TDI); spirometry and body plethysmography; symptom-limited exercise tests

Notes $\quad$ Funded by Nycomed GmbH (Konstanz, Germany)

\section{Risk of bias}

\begin{tabular}{|c|c|c|}
\hline Bias & Authors' judgement & Support for judgement \\
\hline $\begin{array}{l}\text { Random sequence genera- } \\
\text { tion (selection bias) }\end{array}$ & Low risk & $\begin{array}{l}\text { Reported as randomised. Assumed that the randomisation method was ade- } \\
\text { quate due to pharmaceutical company sponsorship }\end{array}$ \\
\hline $\begin{array}{l}\text { Allocation concealment } \\
\text { (selection bias) }\end{array}$ & Unclear risk & No available information \\
\hline $\begin{array}{l}\text { Blinding of participants } \\
\text { and personnel (perfor- } \\
\text { mance bias) } \\
\text { All outcomes }\end{array}$ & Low risk & Trial reported as double-blind \\
\hline $\begin{array}{l}\text { Blinding of outcome as- } \\
\text { sessment (detection bias) } \\
\text { All outcomes }\end{array}$ & Unclear risk & Assumed that this would be low risk; however, no available information \\
\hline $\begin{array}{l}\text { Incomplete outcome data } \\
\text { (attrition bias) } \\
\text { All outcomes }\end{array}$ & Low risk & $\begin{array}{l}\text { Of } 250 \text { randomised participants, } 16 \text { from the roflumilast group and } 12 \text { from the } \\
\text { placebo group discontinued prematurely }\end{array}$ \\
\hline $\begin{array}{l}\text { Selective reporting (re- } \\
\text { porting bias) }\end{array}$ & Unclear risk & Outcomes reported, but no trial protocol found on trial registry websites \\
\hline Other bias & Low risk & None \\
\hline
\end{tabular}

Roflumilast M2-119

\section{Study characteristics}

\begin{tabular}{ll}
\hline Methods & Study design: parallel-group study \\
& Randomisation: randomised, double-blind, placebo-controlled trial \\
& Trial duration: 12 weeks \\
& Intention-to-treat analysis: stated \\
\hline Participants & Setting: 32 centres in 5 countries \\
& Participants: 410 (roflumilast $500 \mu g: 203$, placebo: 207 ) \\
& Baseline characteristics: mean age 68 years, $93 \%$ male, post-bronchodilator FEV, $50.5 \%$ predicted, av- \\
erage 44 pack-years, $69 \%$ current smokers
\end{tabular}


Roflumilast M2-119 (Continued)

Inclusion criteria: former or current smokers with pack-year history $\geq 10$, aged $\geq 40$ years, post-bronchodilator $\mathrm{FEV}_{1} / \mathrm{FVC} \leq 0.7, \mathrm{FEV}_{1} 30 \%$ to $80 \%$ predicted, clinically stable COPD within 4 weeks before baseline

Exclusion criteria: history of asthma or other relevant lung disease, COPD exacerbation within 4 weeks before baseline, need for long-term oxygen therapy, known $a_{1}$-antitrypsin deficiency, clinically significant cardiopulmonary comorbidity

Total numbers of participant withdrawals: $40(20 \%)$ and $18(9 \%)$ from treatment and control groups, respectively

Run-in: 4 weeks with placebo
- Roflumilast $500 \mu \mathrm{g}$ once daily
- Placebo once daily
Concomitant medication
- Short-acting anticholingeric: "short-acting anticholinergics at a constant daily dosage as concomitant
medication if already taken on a regular basis at a constant dosage for at least 4 weeks prior to the
- Study"
- Corticosteroid: none
- LABA: none

Outcomes

Primary outcome: mean change in post-bronchodilator FEV from baseline

Secondary outcomes: mean change in pre-bronchodilator $\mathrm{FEV}_{1}$ from baseline; change in other lung function measures, time to COPD exacerbation; proportion of participants experiencing exacerbations; time to study withdrawal; adverse effects

Notes Clinicaltrials.gov identifier: NCT00242320; BY217/M2-119. Funded by Nycomed GmbH, Konstanz, Ger-
many

\section{Risk of bias}

\begin{tabular}{lll}
\hline Bias & Authors' judgement & Support for judgement \\
\hline $\begin{array}{l}\text { Random sequence genera- } \\
\text { tion (selection bias) }\end{array}$ & Low risk & Computer-generated randomisation list used \\
\hline $\begin{array}{l}\text { Allocation concealment } \\
\text { (selection bias) }\end{array}$ & Unclear risk & Not stated \\
\hline $\begin{array}{l}\text { Blinding of participants } \\
\text { and personnel (perfor- } \\
\text { mance bias) }\end{array}$ & Low risk & Double-blinded \\
All outcomes & & \\
\hline
\end{tabular}

\begin{tabular}{lll}
$\begin{array}{l}\text { Blinding of outcome as- } \\
\text { sessment (detection bias) } \\
\text { All outcomes }\end{array}$ & Unclear risk & Assumed that this would be low risk; however, no available information \\
\hline $\begin{array}{l}\text { Incomplete outcome data } \\
\text { (attrition bias) }\end{array}$ & High risk & $\begin{array}{l}\text { Of the } 411 \text { randomised participants, } 41 \text { from the roflumilast group and } 18 \text { from } \\
\text { the placebo group discontinued during the treatment period (20\% compared } \\
\text { with } 8 \%, \text { respectively) }\end{array}$
\end{tabular}

Selective reporting (re- Low risk porting bias)

Outcomes were reported as planned. The protocol was registered at clincaltrials.gov 
Roflumilast M2-119 (Continued)
Other bias
Low risk
None

Roflumilast M2-121

\section{Study characteristics}

\begin{tabular}{l} 
Study design: parallel-group study \\
Rethods \\
Trial duration: 12 weeks \\
Intention-to-treat analysis: stated \\
\hline
\end{tabular}

\section{Participants}

Setting: 16 centres in 6 countries

Participants: 600 participants (full analysis set; roflumilast $500 \mu \mathrm{g}: 301$, placebo: 299)

Baseline characteristics: median age 65 years, $74 \%$ male, $\mathrm{FEV}_{1} 46 \%$ predicted, 48 mean pack-years

Inclusion criteria: history of COPD $\geq 12$ months as defined by GOLD criteria, age $\geq 40$ years, $\mathrm{FEV}_{1} / \mathrm{FVC}$ ratio (post-bronchodilator) $\leq 70 \%, \mathrm{FEV}_{1}$ (post-bronchodilator) $\leq 65 \%$ predicted, $\mathrm{FRC}$ (post-bronchodilator) $\leq 120 \%$ predicted

Exclusion criteria: COPD exacerbation indicated by treatment with systemic glucocorticosteroids not stopped $\geq 4$ weeks before baseline visit; non-smoker, current smoker, or ex-smoker (smoking cessation $\geq 1$ year ago) with smoking history $<10$ pack-years; any concomitant disease that might interfere with study procedures or evaluation

Total numbers of participant withdrawals: 32 participants withdrew due to COPD exacerbations

Interventions

Run-in: 4-week single-blind placebo tablet once daily in the morning and all disallowed concomitant medications withdrawn

- Roflumilast $500 \mu \mathrm{g}$ once daily

- Placebo

\section{Concomitant medication}

- Short-acting anticholinergic: none

- SABA: none

- Corticosteroid: none

- LABA: none

Secondary outcomes: mean change from randomisation to endpoint in additional pre- and post-bronchodilator spirometric and lung volume parameters; measurement of quality of life parameters; dyspnoea

\section{Risk of bias}

\begin{tabular}{lll}
\hline Bias & Authors' judgement & Support for judgement \\
\hline $\begin{array}{l}\text { Random sequence genera- } \\
\text { tion (selection bias) }\end{array}$ & Low risk & $\begin{array}{l}\text { Reported as randomised. Assumed that the randomisation method was ade- } \\
\text { quate due to pharmaceutical company sponsorship }\end{array}$ \\
\hline
\end{tabular}


Roflumilast M2-121 (Continued)

\begin{tabular}{l}
$\begin{array}{l}\text { Allocation concealment } \\
\text { (selection bias) }\end{array} \quad$ Unclear risk No available information \\
\hline
\end{tabular}

Blinding of participants Low risk $\quad$ Trial reported as double-blind
and personnel (perfor-

\begin{tabular}{|c|c|c|}
\hline $\begin{array}{l}\text { Blinding of outcome as- } \\
\text { sessment (detection bias) } \\
\text { All outcomes }\end{array}$ & Unclear risk & No available information \\
\hline $\begin{array}{l}\text { Incomplete outcome data } \\
\text { (attrition bias) } \\
\text { All outcomes }\end{array}$ & Low risk & $\begin{array}{l}\text { Of } 600 \text { randomised participants, } 13 \text { from the roflumilast group and } 19 \text { from the } \\
\text { placebo group withdrew due to exacerbations }\end{array}$ \\
\hline $\begin{array}{l}\text { Selective reporting (re- } \\
\text { porting bias) }\end{array}$ & Unclear risk & $\begin{array}{l}\text { A publication was not found for this trial; however, study results were obtained } \\
\text { from the trial registry website }\end{array}$ \\
\hline Other bias & Low risk & None \\
\hline
\end{tabular}

Roflumilast M2-124

\section{Study characteristics}

Study design: parallel-group study
Randomisation: randomised, double-blind, placebo-controlled trial
Trial duration: 52 weeks
Intention-to-treat analysis: stated

Setting: 246 centres in 10 countries
Participants: 1513 (roflumilast $500 \mu \mathrm{g}: 760$, placebo: 753 )
Baseline characteristics: mean age 64 years, $71 \%$ male, post-bronchodilator $\mathrm{FEV}_{1} 37.6 \%$ predicted, av-
erage 47 pack-years, $48 \%$ current smokers
Inclusion criteria: former or current smokers with $\geq 20$ pack-year history, aged $\geq 40$ years, post-bron-
chodilator $\mathrm{FEV} / \mathrm{FVC} \leq 0.7$, chronic cough and sputum production, post-bronchodilator $\mathrm{FEV},<50 \%$ pre-
dicted, $\geq 1$ recorded COPD exacerbation requiring systemic glucocorticosteroids or treatment in hospi-
tal in previous year

Exclusion criteria: available in the online web appendix ( $p$ 11)

Total numbers of participant withdrawals: 264 (34\%) and 234 (31\%) from treatment and control groups, respectively

Interventions

Run-in: 4 weeks with placebo

- Roflumilast $500 \mu \mathrm{g}$ once daily

- Placebo once daily

\section{Concomitant medication}

- Short-acting anticholingeric: $31 \%$ of those in the roflumilast group and $32 \%$ in the placebo group

- SABA: "patients could use short acting $\beta_{2}$-agonists as needed" 
Roflumilast M2-124 (Continued)

- Corticosteroid: none

- LABA: "eligible patients were stratified according to their use of long acting $\beta_{2}$-agonists and smoking status"; roflumilast $49 \%$, placebo $51 \%$

Outcomes

Primary outcomes: mean change in pre-bronchodilator $\mathrm{FEV}_{1}$; mean rate of COPD exacerbations requiring oral or parenteral glucocorticosteroids or requiring hospitalisation or leading to death (per patient per year)

Secondary outcomes: mean change in post-bronchodilator $\mathrm{FEV}_{1}$; time to mortality for any reason; natural log-transformed CRP (mg/L); mean TDI focal score

Clinicaltrials.gov identifier: NCT00297102. Funded by AstraZeneca
Adverse event data are pooled with numbers from study M2-125, which followed an identical study de-
sign

\section{Risk of bias}

\begin{tabular}{lll}
\hline Bias & Authors' judgement & Support for judgement \\
\hline $\begin{array}{l}\text { Random sequence genera- } \\
\text { tion (selection bias) }\end{array}$ & Low risk & $\begin{array}{l}\text { A randomisation list was generated via a pseudo-random numbers generator, } \\
\text { and an automated interactive voice-response system was used to randomly } \\
\text { assign participants }\end{array}$ \\
\hline $\begin{array}{l}\text { Allocation concealment } \\
\text { (selection bias) }\end{array}$ & Low risk & All individuals involved in the studies were unaware of treatment assignment \\
\hline $\begin{array}{l}\text { Blinding of participants } \\
\text { and personnel (perfor- } \\
\text { mance bias) } \\
\begin{array}{l}\text { All outcomes } \\
\text { a }\end{array}\end{array}$ & Low risk & $\begin{array}{l}\text { "All individuals involved in the studies were unaware of treatment assignment. } \\
\text { Tablets were identical in appearance. The investigator or anyone at the study } \\
\text { site was prevented from knowing the allocation sequence with code labelling" }\end{array}$
\end{tabular}

\begin{tabular}{lll}
\hline $\begin{array}{l}\text { Blinding of outcome as- } \\
\text { sessment (detection bias) } \\
\text { All outcomes }\end{array}$ & Unclear risk & Assumed that this would be low risk; however, no available information \\
\hline $\begin{array}{l}\text { Incomplete outcome data } \\
\text { (attrition bias) } \\
\text { All outcomes }\end{array}$ & Low risk & $\begin{array}{l}264 \text { participants discontinued from the roflumilast group and 234 discontin- } \\
\text { ued from the placebo group }\end{array}$ \\
\hline $\begin{array}{l}\text { Selective reporting (re- } \\
\text { porting bias) }\end{array}$ & Low risk & Outcomes reported as planned. Trial registered at clinicaltrials.gov \\
\hline $\begin{array}{l}\text { Other bias } \\
\text { High risk }\end{array}$ & $\begin{array}{l}44 \% \text { of participants in both roflumilast and placebo groups received corticos- } \\
\text { teroid pre-treatment }\end{array}$ \\
\hline
\end{tabular}

Roflumilast M2-124+M2-125

\section{Study characteristics}

\begin{tabular}{ll}
\hline Methods & As described in separate studies above and below \\
\hline Participants & \\
\hline Interventions
\end{tabular}


Roflumilast M2-124+M2-125 (Continued)

Outcomes

\section{Notes}

\section{Risk of bias}

\begin{tabular}{lll}
\hline Bias & Authors' judgement & Support for judgement \\
\hline $\begin{array}{l}\text { Random sequence genera- } \\
\text { tion (selection bias) }\end{array}$ & Unclear risk & See individual studies \\
\hline $\begin{array}{l}\text { Allocation concealment } \\
\text { (selection bias) }\end{array}$ & Low risk & See individual studies \\
\hline $\begin{array}{l}\text { Blinding of participants } \\
\text { and personnel (perfor- } \\
\text { mance bias) } \\
\text { All outcomes }\end{array}$ & Unclear risk & See individual studies \\
\hline $\begin{array}{l}\text { Blinding of outcome as- } \\
\text { sessment (detection bias) }\end{array}$ & Unclear risk & \\
All outcomes & & See individual studies \\
\hline $\begin{array}{l}\text { Incomplete outcome data } \\
\text { (attrition bias) } \\
\text { All outcomes }\end{array}$ & Unclear risk & See individual studies \\
\hline $\begin{array}{l}\text { Selective reporting (re- } \\
\text { porting bias) }\end{array}$ & Unclear risk & See individual studies \\
\hline \begin{tabular}{l} 
Other bias \\
\hline
\end{tabular} & Unclear risk & See individual studies \\
\hline
\end{tabular}

Roflumilast M2-125

\section{Study characteristics}

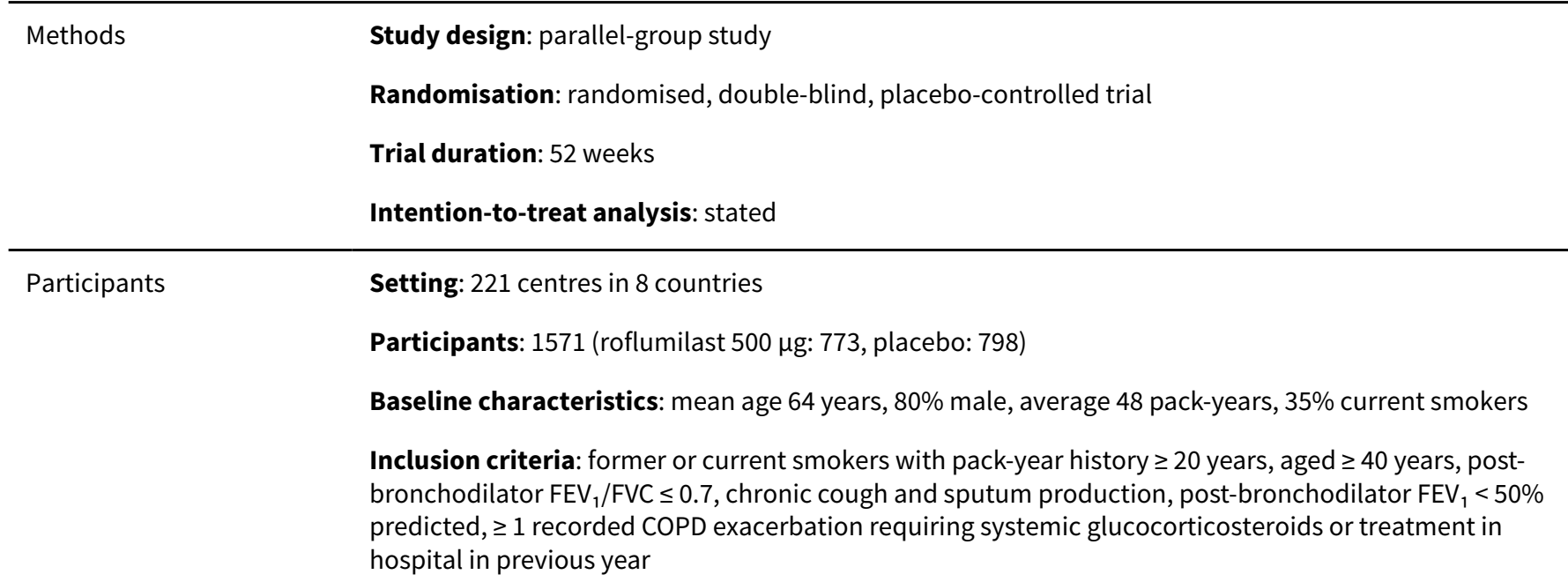

Exclusion criteria: available in the online web appendix ( $p$ 11) 
Roflumilast M2-125 (Continued)

Total numbers of participant withdrawals: $246(32 \%)$ and $248(31 \%)$ from treatment and control groups, respectively

Run-in: 4 weeks with placebo
- Roflumilast $500 \mu$ g once daily
- Placebo once daily
Concomitant medication
- Short-acting anticholingeric: $38 \%$ of those in the roflumilast group and $41 \%$ of the placebo group
- SABA: "patients could use short acting $\beta_{2}$-agonists as needed"
- Corticosteroid: none
- LABA: "eligible patients were stratified according to their use of long acting $\beta_{2}$-agonists and smoking
status"; roflumilast $48 \%$, placebo $51 \%$

Outcomes

Primary outcomes: mean change in pre-bronchodilator $\mathrm{FEV}_{1}$; mean rate of COPD exacerbations (moderate or severe) requiring oral or parenteral glucocorticosteroids or requiring hospitalisation or leading to death (per patient per year)

Secondary outcomes: mean change in post-bronchodilator $\mathrm{FEV}_{1}$; time to mortality for any reason; natural log-transformed CRP ( $\mathrm{mg} / \mathrm{L})$; mean TDI focal score during treatment period

\begin{tabular}{ll}
\hline Notes & Clinicaltrials.gov identifier: NCT00297115; BY217/M2-125. Funded by AstraZeneca \\
Adverse event data are pooled with numbers from study M2-124, which followed an identical study de- \\
sign
\end{tabular}

\section{Risk of bias}

\begin{tabular}{lll}
\hline Bias & Authors' judgement & Support for judgement \\
\hline $\begin{array}{l}\text { Random sequence genera- } \\
\text { tion (selection bias) }\end{array}$ & Low risk & $\begin{array}{l}\text { A randomisation list was generated via a pseudo-random numbers generator, } \\
\text { and an automated interactive voice-response system was used to randomly } \\
\text { assign participants }\end{array}$ \\
\hline $\begin{array}{l}\text { Allocation concealment } \\
\text { (selection bias) }\end{array}$ & Low risk & All individuals involved in the studies were unaware of treatment assignment \\
\hline $\begin{array}{l}\text { Blinding of participants } \\
\text { and personnel (perfor- } \\
\text { mance bias) } \\
\text { All outcomes }\end{array}$ & Unclear risk & $\begin{array}{l}\text { "All individuals involved in the studies were unaware of treatment assignment. } \\
\text { Tablets were identical in appearance. The investigator or anyone at the study } \\
\text { site was prevented from knowing the allocation sequence with code labelling" }\end{array}$ \\
\hline
\end{tabular}

\begin{tabular}{lll}
\hline $\begin{array}{l}\text { Blinding of outcome as- } \\
\text { sessment (detection bias) } \\
\text { All outcomes }\end{array}$ & Unclear risk & Assumed that this would be low risk; however, no available information \\
\hline $\begin{array}{l}\text { Incomplete outcome data } \\
\text { (attrition bias) } \\
\text { All outcomes }\end{array}$ & Low risk & $\begin{array}{l}246 \text { patients discontinued from the roflumilast group and } 248 \text { discontinued } \\
\text { from the placebo group }\end{array}$ \\
\hline Other bias & High risk & $\begin{array}{l}40 \% \text { of participants in both roflumilast and placebo groups received corticos- } \\
\text { teroid pre-treatment }\end{array}$
\end{tabular}


Roflumilast M2-127

\section{Study characteristics}

\begin{tabular}{|c|c|}
\hline Methods & $\begin{array}{l}\text { Study design: parallel-group study } \\
\text { Randomisation: randomised, double-blind, placebo-controlled trial } \\
\text { Trial duration: } 24 \text { weeks } \\
\text { Intention-to-treat analysis: stated }\end{array}$ \\
\hline Participants & $\begin{array}{l}\text { Setting: } 135 \text { centres in } 10 \text { countries } \\
\text { Participants: } 1221 \text { (roflumilast } 500 \mu \mathrm{g} \text { : } 467 \text {, placebo: } 468 \text { ) } \\
\text { Baseline characteristics: mean age } 65 \text { years, } 71 \% \text { male, post-bronchodilator } \mathrm{FEV}_{1} 54.7 \% \text { and } 55.3 \% \\
\text { predicted (roflumilast and placebo), average } 43 \text { pack-years, } 39 \% \text { current smokers } \\
\text { Inclusion criteria: former or current smokers with } \geq 1 \text { year smoking cessation and a pack-year history } \geq \\
\text { 10, aged } \geq 40 \text { years, post-bronchodilator } \mathrm{FEV}_{1} / \mathrm{FVC} \leq 0.7 \text {, post-bronchodilator } \mathrm{FEV} \mathrm{F}_{1} 40 \% \text { to } 70 \% \text { predict- } \\
\text { ed, partial reversibility to albuterol with increase from baseline } \mathrm{FEV} \mathrm{F}_{1} \leq 12 \% \text { or } 200 \mathrm{~mL} \\
\text { Exclusion criteria: available in the online web appendix (p } 10) \\
\text { Total numbers of participant withdrawals: } 107(23 \%) \text { and } 82(18 \%) \text { from treatment and control } \\
\text { groups, respectively }\end{array}$ \\
\hline Interventions & $\begin{array}{l}\text { Run-in: } 4 \text { weeks with placebo once a day } \\
\text { - Roflumilast } 500 \mu \text { g and salmeterol once daily } \\
\text { - Placebo once daily } \\
\text { Concomitant medication } \\
\text { - Short-acting anticholingeric: none } \\
\text { - SABA: participants used short-acting } \beta_{2} \text { as rescue medication } \\
\text { - Corticosteroid: none } \\
\text { - LABA: none }\end{array}$ \\
\hline
\end{tabular}

Outcomes Primary outcomes: change in mean pre-bronchodilator $\mathrm{FEV}_{1}$ from baseline to each post-randomisation visit Secondary outcomes: post-bronchodilator FEV ${ }_{1}$ and FVC; TDI score; SOBQ; rate of COPD exacerbations; use of rescue medication

Notes ClinicalTrials.gov identifier NCT00313209; BY217/M2-127; 2005-005080-28 (EudraCT Number). Funded by Nycomed GmbH, Konstanz, Germany

\section{Risk of bias}

\begin{tabular}{lll}
\hline Bias & Authors' judgement & Support for judgement \\
\hline $\begin{array}{l}\text { Random sequence genera- } \\
\text { tion (selection bias) }\end{array}$ & Low risk & $\begin{array}{l}\text { "The sponsor generated a randomisation list of patient random numbers using } \\
\text { a pseudo-random number generator. The investigator used an automated, in- } \\
\text { teractive voice response system to randomly assign patients" }\end{array}$ \\
\hline $\begin{array}{l}\text { Allocation concealment } \\
\text { (selection bias) }\end{array}$ & Unclear risk & No available information \\
\hline $\begin{array}{l}\text { Blinding of participants } \\
\text { and personnel (perfor- } \\
\text { mance bias) }\end{array}$ & Low risk & All individuals involved in the studies were unaware of treatment assignment \\
\end{tabular}


Roflumilast M2-127 (Continued)

All outcomes

Blinding of outcome as-
sessment (detection bias) $\quad$ Low risk All individuals involved in the studies were unaware of treatment assignment
sessment (detection bias) All outcomes

\begin{tabular}{ll}
\hline $\begin{array}{l}\text { Incomplete outcome data } \\
\text { (attrition bias) }\end{array}$ & Low risk \\
All outcomes & $\begin{array}{l}107 \text { participants discontinued from the roflumilast group and } 82 \text { discontinued } \\
\text { from the placebo group }\end{array}$
\end{tabular}

All outcomes

continued

Selective reporting (re- Low risk porting bias)

Outcomes reported as planned. Trial registered at clincialtrials.gov

\begin{tabular}{ll}
\hline Other bias $\quad$ Low risk & None \\
\hline
\end{tabular}

Roflumilast M2-128

\section{Study characteristics}

\begin{tabular}{ll}
\hline Study design: parallel-group study \\
Randomisation: randomised, double-blind, placebo-controlled trial \\
Trial duration: 24 weeks \\
Intention-to-treat analysis: stated \\
\hline
\end{tabular}

Setting: 85 centres in 7 countries
Participants
Baseline characteristics: mean age 64 years, $71 \%$ male, post-bronchodilator $\mathrm{FEV}_{1} 56.0 \%$ and $56.2 \%$
predicted (roflumilast and placebo), average 44 pack-years, $40 \%$ current smokers
Inclusion criteria: former or current smokers with $\geq 1$ year smoking cessation and a pack-year history $\geq$
10, aged $\geq 40$ years, post-bronchodilator $\mathrm{FEV}{ }_{1} / \mathrm{FVC} \leq 0.7$, post-bronchodilator $\mathrm{FEV}, 40 \%$ to $70 \%$ predict-
ed, partial reversibility to albuterol with increase from baseline $\mathrm{FEV}_{1} \leq 12 \%$ or $200 \mathrm{~mL}$

Exclusion criteria: available in the online web appendix ( $p$ 10)

Total numbers of participant withdrawals: $62(17 \%)$ and $39(11 \%)$ from treatment and control groups, respectively

Run-in: 4 weeks with placebo once a day
- Roflumilast $500 \mu \mathrm{g}$ and tiotropium once daily
- Placebo once daily
Concomitant medication
- Short-acting anticholingeric: none
- SABA: participants used short-acting $\beta_{2}$ as rescue medication
- Corticosteroid: none
- LABA: none

Outcomes

Primary outcomes: change in mean pre-bronchodilator $\mathrm{FEV}_{1}$ from baseline to each post-randomisation visit 
Roflumilast M2-128 (Continued)

Secondary outcomes: post-bronchodilator $\mathrm{FEV}_{1}$ and FVC; TDI score; SOBQ; rate of COPD exacerbations; use of rescue medication

\begin{tabular}{ll}
\hline Notes & Clinicaltrials.gov identifier: NCT0042468; BY217/M2-128. Funded by Nycomed GmbH, Konstanz, Ger- \\
many
\end{tabular}

\section{Risk of bias}

\begin{tabular}{|c|c|c|}
\hline Bias & Authors' judgement & Support for judgement \\
\hline $\begin{array}{l}\text { Random sequence genera- } \\
\text { tion (selection bias) }\end{array}$ & Low risk & $\begin{array}{l}\text { "The sponsor generated a randomisation list of patient random numbers using } \\
\text { a pseudo-random number generator. The investigator used an automated, in- } \\
\text { teractive voice response system to randomly assign patients" }\end{array}$ \\
\hline $\begin{array}{l}\text { Allocation concealment } \\
\text { (selection bias) }\end{array}$ & Low risk & $\begin{array}{l}\text { The investigator or anyone at the study site was prevented from knowing the } \\
\text { allocation sequence with code labelling }\end{array}$ \\
\hline $\begin{array}{l}\text { Blinding of participants } \\
\text { and personnel (perfor- } \\
\text { mance bias) } \\
\text { All outcomes }\end{array}$ & Low risk & $\begin{array}{l}\text { "All individuals involved in the studies were unaware of treatment assignment. } \\
\text { The investigator or anyone at the study site was prevented from knowing the } \\
\text { allocation sequence with code labelling. Tablets were identical in appearance" }\end{array}$ \\
\hline $\begin{array}{l}\text { Blinding of outcome as- } \\
\text { sessment (detection bias) } \\
\text { All outcomes }\end{array}$ & Low risk & $\begin{array}{l}\text { "All individuals involved in the studies were unaware of treatment assignment. } \\
\text { The investigator or anyone at the study site was prevented from knowing the } \\
\text { allocation sequence with code labelling. Tablets were identical in appearance" }\end{array}$ \\
\hline $\begin{array}{l}\text { Incomplete outcome data } \\
\text { (attrition bias) } \\
\text { All outcomes }\end{array}$ & Low risk & $\begin{array}{l}62 \text { participants discontinued from the roflumilast group and } 39 \text { discontinued } \\
\text { from the placebo group }\end{array}$ \\
\hline $\begin{array}{l}\text { Selective reporting (re- } \\
\text { porting bias) }\end{array}$ & Unclear risk & $\begin{array}{l}\text { Outcomes reported as planned. Trial protocol registered at clincialtrials.gov } \\
\text { and at European trial registry }\end{array}$ \\
\hline Other bias & Low risk & None \\
\hline
\end{tabular}

\section{Roflumilast ROF-MD-07(RE2SPOND)}

\section{Study characteristics}

\begin{tabular}{ll}
\hline Methods & Study design: parallel-group study \\
Randomisation: randomised, double-blind, placebo-controlled trial \\
Trial duration: 52 weeks \\
Intention-to-treat analysis: stated
\end{tabular}

Participants

Setting: 338 locations across Australia, Argentina, Canada, Chile, Columbia, Italy, Malaysia, Peru, Phillippines, Romania, Russia, Serbia, Spain, Taiwan, and Ukraine

Participants: 2354 (500 $\mu$ g roflumilast: 1178; placebo: 1176)

Baseline characteristics: mean age 64 years, $68 \%$ male, mean $\mathrm{FEV}_{1} \%$ predicted $33 \%$, mean smoking history 52.2 pack-years for roflumilast and 53.1 pack-years for placebo or current smokers $(39 \%$ and $40 \%$, respectively) 
Roflumilast ROF-MD-07(RE2SPOND) (Continued)

Inclusion criteria: $\geq 40$ years with severe or very severe COPD, chronic bronchitis, $\geq 2$ exacerbations and/or hospitalisations in the previous year, receiving ICS/LABA with or without LAMA daily for $\geq 3$ months

Exclusion criteria: within the 4 weeks before enrolment, had a moderate or severe COPD exacerbation and/or a COPD exacerbation treated with antibiotics or systemic corticosteroids or a lower respiratory tract infection. Other exclusionary criteria included diagnoses of other lung diseases, moderate to severe liver impairment (Child-Pugh B or C), HIV or hepatitis infection, current diagnosis of asthma, cancer in the past 5 years, $a_{1}$-antitrypsin deficiency, clinically significant cardiovascular condition, resting QTc interval $>470 \mathrm{~ms}, \mathrm{BMI} \geq 45 \mathrm{~kg} / \mathrm{m}^{2}$

Total numbers of participant withdrawals: $337(29 \%)$ and 254 (21\%) from treatment and control groups, respectively

Interventions

Run-in: 2 weeks, single-blind. Placebo tablets to assess suitability

- Roflumilast $500 \mu \mathrm{g}$ once daily

- Placebo once daily

\section{Concomitant medication}

ICS/LABA FDC (fluticasone propionate/salmeterol, 250/50 mg (1 inhalation twice a day), or budesonide/formoterol, $160 / 4.5 \mathrm{mg}$ ( 2 inhalations twice a day)). Participants taking fluticasone propionate/salmeterol, $500 / 50 \mathrm{mg}$, at study entry were required to switch to the lower dosage $(250 / 50 \mathrm{mg})$ before entry. Up to $60 \%$ of participants were allowed concomitant LAMA (e.g. tiotropium) if administered for $\geq 3$ months before screening, with no dose change. Those not on LAMA were allowed a SAMA

Outcomes Primary outcome: rate of moderate or severe COPD exacerbations per patient per year

Secondary outcomes: rate of COPD exacerbations leading to hospitalisation or death (severe COPD exacerbations); rate of moderate or severe exacerbations; rate of moderate or severe COPD exacerbations or COPD exacerbations treated with antibiotics; rate of moderate or severe COPD exacerbations treated with antibiotics during the treatment period; mean change in pre-dose $\mathrm{FEV}_{1}$; mean change in pre-dose $\mathrm{FEV}_{1}$ from randomisation over 52 weeks; adverse events; mortality (all-cause); serious adverse events; other adverse events (not including serious events)

Notes Clinicaltrials.gov identifier: NCT01443845. Funded by Astra Zeneca

\section{Risk of bias}

\begin{tabular}{lll}
\hline Bias & Authors' judgement & Support for judgement \\
\hline $\begin{array}{l}\text { Random sequence genera- } \\
\text { tion (selection bias) }\end{array}$ & Low risk & $\begin{array}{l}\text { Reported as randomised. Assumed that the randomisation method was ade- } \\
\text { quate due to pharmaceutical company sponsorship }\end{array}$ \\
\hline $\begin{array}{l}\text { Allocation concealment } \\
\text { (selection bias) }\end{array}$ & Unclear risk & No available information \\
\hline $\begin{array}{l}\text { Blinding of participants } \\
\text { and personnel (perfor- } \\
\text { mance bias) }\end{array}$ & Low risk & Reported as triple-blind (participant, investigator and outcome assessor) \\
$\begin{array}{l}\text { All outcomes } \\
\begin{array}{l}\text { Blinding of outcome as- } \\
\text { sessment (detection bias) } \\
\text { All outcomes }\end{array}\end{array}$ & Low risk & Reported as triple-blind (participant, investigator and outcome assessor) \\
\hline $\begin{array}{l}\text { Incomplete outcome data } \\
\text { (attrition bias) } \\
\text { All outcomes }\end{array}$ & Unclear risk & $\begin{array}{l}337 \text { participants (29\%) discontinued from the roflumilast group and 254 (22\%) } \\
\text { discontinued from the placebo group }\end{array}$ \\
\hline
\end{tabular}


Roflumilast ROF-MD-07(RE2SPOND) (Continued)

Selective reporting (re- Unclear risk $\quad$ Outcomes reported as planned. Trial registered at clinicaltrials.gov porting bias)

Other bias

Unclear risk

$47 \%$ in each treatment group were taking LAMAs. Participants were also using combined LABA/ICS. $65 \%$ in the placebo group were taking fluticasone propionate/salmeterol FDC, and $65 \%$ in the roflumilast group. $35 \%$ of participants in each treatment group were taking budesonide/formoterol FDC

Urban 2018 (ELASTIC)

\section{Study characteristics}

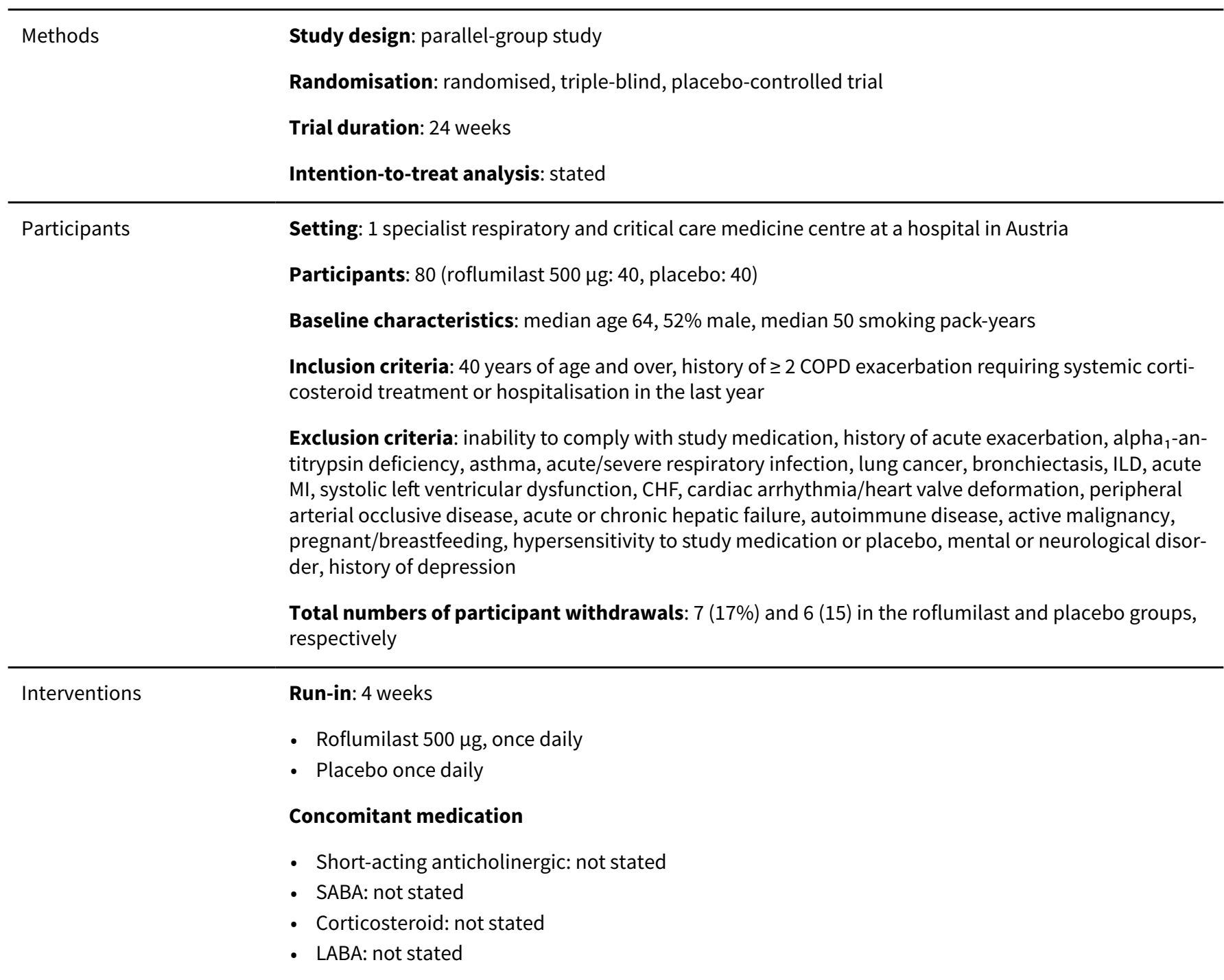

Outcomes

Primary outcome: change in carotid femoral-pulse wave velocity

Secondary outcomes: change in reactive hyperaemia index; change in augmentation index; change in matrix metalloproteinase-9; change in asymmetrical dimethylamine; change in tumour necrosis factor-alpha; change in $\mathrm{FEV}_{1}$; change in 6-minute walk test; change in COPD assessment test 
Urban 2018 (ELASTIC) (Continued)

Notes

Clincaltrials.gov identifier: NCT01630200. Funded by Ludwig Boltzmann Institute for COPD and Respiratory Epidemiology

\section{Risk of bias}

\begin{tabular}{lll}
\hline Bias & Authors' judgement & Support for judgement \\
\hline $\begin{array}{l}\text { Random sequence genera- } \\
\text { tion (selection bias) }\end{array}$ & Unclear risk & Reported as randomised; no further information \\
\hline $\begin{array}{l}\text { Allocation concealment } \\
\text { (selection bias) }\end{array}$ & Unclear risk & No available information \\
\hline $\begin{array}{l}\text { Blinding of participants } \\
\text { and personnel (perfor- } \\
\text { mance bias) }\end{array}$ & Low risk & $\begin{array}{l}\text { "All responsible persons, those administering interventions or assessing the } \\
\text { oll outcomes } \\
\text { to group assignment" }\end{array}$ \\
\hline $\begin{array}{l}\text { Blinding of outcome as- } \\
\text { sessment (detection bias) } \\
\text { All outcomes }\end{array}$ & Low risk & $\begin{array}{l}\text { "All responsible persons, those administering interventions or assessing the } \\
\text { outcomes, and elementally all experimental and control patients were blinded } \\
\text { to group assignment" }\end{array}$ \\
\hline $\begin{array}{l}\text { Incomplete outcome data } \\
\text { (attrition bias) } \\
\text { All outcomes }\end{array}$ & Low risk & $\begin{array}{l}\text { 40 randomised in each group. In the roflumilast group 33/40 completed } \\
\text { (82.5\%), in the placebo arm } 34 / 40 \text { completed (85\%), so similar attrition. Simi- } \\
\text { lar numbers of non-fatal and serious fatal adverse events in each group }\end{array}$ \\
\hline $\begin{array}{l}\text { Selective reporting (re- } \\
\text { porting bias) }\end{array}$ & Low risk & $\begin{array}{l}\text { Study authors reported outcomes as planned; methods and results were pub- } \\
\text { lished on EU trials registry }\end{array}$ \\
\hline $\begin{array}{l}\text { Other bias } \\
\text { Criteria for copD not well defined apart from exacerbations }\end{array}$ \\
\hline
\end{tabular}

6MWT: 6-minute walk test; AcPGP: plasma acetyl-proline-glycine-proline; ATS: American Thoracic Society; BDI: Baseline Dyspnoea Index; BMI: body mass index; BORG Scale: rating of perceived exertion; CAT: COPD Assessment Test; CHF: congestive heart failure; COPD: chronic obstructive pulmonary disease; CRP: C-reactive protein; DLCO: diffusing capacity of the lung for carbon monoxide; EU: European Union;

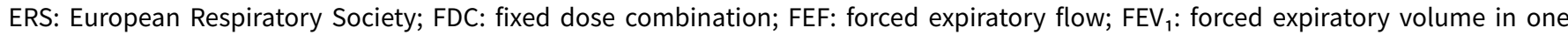
second; $\mathrm{FEV}_{6}$ : forced expiratory volume in six seconds; FIV $_{1}$ : forced expiratory volume in one second; FRC: functional residual capacity; FVC: forced vital capacity; GOLD: Global Initiative for Chronic Obstructive Lung Disease; HU: Hounsfield unit; HIV: human immunodeficiency virus; IC: inspiratory capacity; ICS: inhaled corticosteroid; ILD: interstitial lung disease; LABA: long-acting beta ${ }_{2}$-agonist; LAMA:long-acting muscarinic antagonist; MDI: metered-dose inhaler; MI: myocardial infarction; MMEF: maximal mid-expiratory flow; NCT: national clinical trial; PEF: peak expiratory flow; QTc: corrected Q wave and T wave; RFRC: resting functional residual capacity; RV: residual volume; SABA: short-acting beta ${ }_{2}$-agonist; SAMA: short-acting muscarinic antagonist; SD: standard deviation; SE: standard error; SGRQ: St George's Respiratory Questionnaire; SOBQ: Shortness of Breath Questionnaire; SVC: slow vital capacity; TDI: transition dyspnoea index; TLC: total lung capacity $\mathrm{VO}_{2}$ : oxygen uptake.

\section{Characteristics of excluded studies [ordered by study ID]}

\begin{tabular}{ll}
\hline Study & Reason for exclusion \\
\hline Borker 2003 & Insufficient data; only RR of QoL improvement provided \\
\hline CTRI/2012/09/002961 & No placebo group \\
\hline CTRI/2014/01/004370 & No placebo group \\
\hline Ferguson 2003 & Integrated results from four 24-week cilomilast trials \\
\hline
\end{tabular}




\begin{tabular}{|c|c|}
\hline Study & Reason for exclusion \\
\hline Fischer 2003 & Analysis focused on participants with baseline SGRQ score $\geq$ median SGRQ score only \\
\hline Grootendorst 2001 & Endpoint: first dose bronchodilator effects only \\
\hline Grootendorst 2002 & Treatment Bayer BAY 19-8004; 11 participants; only 1 week in duration \\
\hline Grootendorst 2003 & Endpoint: first dose bronchodilator effects only \\
\hline Grootendorst 2007 & Cross-over design \\
\hline GSK256066 & Phase 2 trial; no primary outcome measure investigating lung function; only 1 trial to date \\
\hline Kelsen 2002 & No study ID or group numbers identified \\
\hline Knobil 2003 & No SD or SE given \\
\hline Lim 2004 & Combining results from 2 pivotal European phase 3 cilomilast trials \\
\hline NCT00246935 & Different regimens of roflumilast; no placebo group \\
\hline NCT01849341 & Different regimens of roflumilast; no placebo group \\
\hline NCT01973998 & Patients were diagnosed with AECOPD \\
\hline NCT02018432 & Different regimens of roflumilast; no placebo group \\
\hline Nieman 1999 & Study 038: insufficient data available for changes in lung function and exacerbation rates \\
\hline Pascoe 2007 & Treatment QAK423 (Novartis), discontinued. Only 1 trial available \\
\hline Rabe 2017 & Editorial letter \\
\hline Reisner 2003 & Combined results; individual studies already included in review \\
\hline Rennard 2008 & Systematic review; relevant individual studies already included in review \\
\hline Roflumilast JP708 & $\begin{array}{l}\text { JP108 is an extension study of APTA-2217-06. After the key open of APTA-2217-06, administration } \\
\text { to placebo group would be terminated. Not all participants enrolled in JP106 continued onto the } \\
\text { JP108 study }\end{array}$ \\
\hline
\end{tabular}

\begin{tabular}{ll}
\hline Sadigov 2014 & No placebo group \\
\hline Sadigov 2015 & Open-label; no placebo group \\
\hline SB207499/040 & $\begin{array}{l}\text { Open-label study; men or women with COPD who successfully completed study } 042 \text { or } 091 \text { in which } \\
\text { participants received cilomilast } 15 \text { mg twice daily or placebo for } 24 \text { weeks in study } 042 \text { and } 26 \\
\text { weeks in study } 091 \text { without tolerability problems. Concomitant COPD medication use allowed; giv- } \\
\text { en placebo or placebo/Ariflo during study period }\end{array}$ \\
\hline SB207499/041 & $\begin{array}{l}\text { Open-label study; men or women with COPD who successfully completed study 039 in which par- } \\
\text { ticipants received cilomilast } 15 \text { mg twice daily or placebo for 24 weeks without tolerability prob- } \\
\text { lems. Concomitant COPD medication use allowed; given placebo or placebo/Ariflo during study pe- } \\
\text { riod }\end{array}$
\end{tabular}




\begin{tabular}{ll}
\hline Study & Reason for exclusion \\
\hline Spencer 2002 & No study identification or group numbers identified \\
\hline Vestbo 2007 & Treatment UK-500,001 (Pfizer); discontinued \\
\hline Vestbo 2009 & Treatment UK-500,001 (Pfizer); discontinued \\
\hline Wang 2005 & Although quoted as significant, mean and SD figures not provided \\
\hline Watz 2013 & Inhaled therapy \\
\hline Watz 2016 & Different regimens of roflumilast \\
\hline
\end{tabular}

AECOPD: acute exacerbation of COPD; COPD: chronic obstructive pulmonary disease; QoL: quality of life; RR: risk ratio; SD: standard deviation; SE: standard error; SGRQ: St George's Respiratory Questionnaire.

\section{Characteristics of studies awaiting classification [ordered by study ID]}

\section{Barnes 2014}

\begin{tabular}{ll}
\hline Methods & $\begin{array}{l}\text { international, 16-week, randomised, double-blind, placebo-controlled, parallel-group study in- } \\
\text { vestigating effects of roflumilast } 500 \mu \text { g once daily vs placebo on inflammatory parameters in } \\
\text { bronchial biopsy tissue specimens, sputum, and blood serum }\end{array}$ \\
\hline Participants & $\begin{array}{l}150 \text { participants with COPD and chronic bronchitis for at least } 12 \text { months will be recruited into the } \\
\text { study and randomised in a 1:1 ratio to receive either roflumilast or placebo }\end{array}$ \\
\hline Interventions & Roflumilast and placebo \\
\hline Outcomes & Primary endpoint will be number of CD8+ cells in bronchial biopsy tissue specimens (submucosa) \\
\hline Notes & Key secondary endpoint will be number of CD68+ cells assessed by indirect immunohistochemistry \\
\hline
\end{tabular}

EUCTR2004-004442-40-GB

\begin{tabular}{ll}
\hline Methods & Randomised controlled trial \\
\hline Participants & Participants with history of moderate to severe COPD for at least 12 months \\
\hline Interventions & Roflumilast and placebo \\
\hline Outcomes & Primary outcome variable will be mean change in post-bronchodilator FEV from baseline $^{\text {Notes }}$ \\
\hline
\end{tabular}

\section{Methods}

Single-blind, randomised, placebo-controlled study carried out in the Department of Respiratory Medicine at National Institute of Diseases of the Chest and Hospital (NIDCH), Dhaka, Bangladesh 
Mahmud 2013 (Continued)

Participants
130 participants were recruited initially and were randomly distributed into Group A, where they received conventional therapy (inhaled salmeterol + fluticasone and tiotropium) and roflumilast ( $0.5 \mathrm{mg}$ once daily), and Group B, where participants were given placebo with conventional therapy

Study duration was 3 months

\begin{tabular}{ll}
\hline Interventions & As above \\
\hline Outcomes & Primary outcome variable was change in mean FEV 1 \\
& Secondary outcome variable was change in mean CAT score from baseline \\
\hline Notes & No data provided; study authors contacted \\
\hline
\end{tabular}

\section{NCT00671073}

\begin{tabular}{ll}
\hline Methods & $\begin{array}{l}\text { Multi-centre double-blind randomised controlled trial over } 12 \text { weeks across USA investigating the } \\
\text { safety and efficacy of various doses of oglemilast }\end{array}$ \\
\hline Participants & $\begin{array}{l}427 \text { participants with COPD, post-bronchodilator } \mathrm{FEV}_{1} / \mathrm{FVC}<70 \%, \text { post-bronchodilator } \mathrm{FEV}_{1}>30 \% \\
\text { and }<80 \%\end{array}$ \\
\hline Interventions & Oglemilast and placebo \\
\hline Outcomes & Primary outcome variable will be pre-bronchodilator morning (trough) FEV at $_{1} 12$ weeks \\
\hline Notes & Secondary endpoint will be pre-bronchodilator FVC at 12 weeks \\
\hline
\end{tabular}

\section{NCT01595750}

\begin{tabular}{ll}
\hline Methods & Single-centre, double-blind randomised controlled trial over 12 weeks in Spain \\
\hline Participants & 150 participants with a diagnosis of COPD, FEV 1 < 70\%; current and former smokers \\
\hline Interventions & Roflumilast and placebo \\
\hline Outcomes & Primary outcome variable will be endothelial function at 12 weeks \\
& $\begin{array}{l}\text { Secondary endpoints include arterial stiffness; serum and plasma inflammation markers; serum } \\
\text { oxidative stress markers; serum endothelial dysfunction markers at } 12 \text { weeks }\end{array}$ \\
\hline Notes & No data provided; awaiting results \\
\hline
\end{tabular}

\section{NCT01701934}

Methods

Triple-blind randomised controlled trial for 26 weeks investigating whether roflumilast could improve metabolic profiles and reduce visceral adiposity in people with COPD 


\section{NCT01701934 (Continued)} $\begin{array}{ll}\text { Participants } & 14 \text { participants with moderate to severe COPD, assigned to either } 500 \mu \text { g roflumilast or placebo for } \\ 26 \text { weeks }\end{array}$

\begin{tabular}{ll}
\hline Interventions & Roflumilast and placebo \\
\hline Outcomes & $\begin{array}{l}\text { Primary outcome variables will be change in body mass index; change in waist circumference; } \\
\text { change in hip-to-waist ratio; change in metabolic profiles; change in body composition; change in } \\
\text { subcutaneous adiposity; change in liver fat }\end{array}$ \\
\hline Notes & No data provided; awaiting results \\
\hline
\end{tabular}

CAT: COPD Assessment Test; COPD: chronic obstructive pulmonary disease; $\mathrm{FEV}_{1}$ : forced expiratory volume in one second; FVC: forced vital capacity.

Characteristics of ongoing studies [ordered by study ID]

\section{NCT02451540 2015}

\begin{tabular}{ll}
\hline Study name & $\begin{array}{l}\text { Evaluation of the effect of roflumilast in hyperinflated COPD patients using functional respiratory } \\
\text { imaging }\end{array}$ \\
\hline Methods & Parallel RCT \\
\hline Participants & 40 people who are stable on LABA/LAMA therapy and who are prone to dynamics hyperinflation \\
\hline Interventions & Roflumilast and placebo \\
\hline Outcomes & Radiological (CT) changes in airway measures \\
& Changes in spirometry and body plethysmography \\
\hline Starting date & September 2015 \\
\hline Contact information & University Hospital of Antwerp \\
\hline Notes & Other Study ID Numbers: FLUI-2014-134, EudraCT \\
& Estimated study completion date: January 2017 \\
\hline
\end{tabular}

\section{NCT02671942 2016}

\begin{tabular}{ll}
\hline Study name & $\begin{array}{l}\text { A multicenter randomised double-blind clinical study evaluated the safety, pharmacokinetic and } \\
\text { pharmacodynamic characteristics of roflumilast in COPD patients }\end{array}$ \\
\hline Methods & Parallel RCT \\
\hline Participants & People with COPD in China \\
\hline Interventions & Roflumilast and placebo \\
\hline Outcomes & Area under the plasma concentration after vs drug dose \\
& Percentage of participants with adverse events of interest \\
& Change in pre-bronchodilator FEV ${ }_{1}$ during the down-titration period \\
\hline
\end{tabular}


NCT02671942 2016 (Continued)

\begin{tabular}{ll} 
Starting date & March 2016 \\
\hline Contact information & Contact: Zheng Jinping \\
\hline Notes & Estimated enrolment: 120 \\
& Estimated study completion date: August 2017
\end{tabular}

COPD: chronic obstructive pulmonary disease; $\mathrm{CT}$ : computed tomography; $\mathrm{FEV}_{1}$ : forced expiratory volume in one second; LABA: long-acting beta $_{2}$-agonist; LAMA:long-acting muscarinic antagonist; RCT: randomised controlled trial.

DATA AND ANALYSES

Comparison 1. $\mathrm{PDE}_{4}$ inhibitor versus placebo (2020 update)

\begin{tabular}{|c|c|c|c|c|}
\hline Outcome or subgroup title & $\begin{array}{l}\text { No. of } \\
\text { studies }\end{array}$ & $\begin{array}{l}\text { No. of } \\
\text { partici- } \\
\text { pants }\end{array}$ & Statistical method & Effect size \\
\hline 1.1 FEV 1 (by drug) & 29 & 20815 & $\begin{array}{l}\text { Mean Difference (IV, Fixed, 95\% } \\
\mathrm{Cl} \text { ) }\end{array}$ & $49.33[44.17,54.49]$ \\
\hline 1.1.1 Tetomilast $50 \mu \mathrm{g}$ & 1 & 76 & $\begin{array}{l}\text { Mean Difference (IV, Fixed, 95\% } \\
\text { CI) }\end{array}$ & $82.00[-50.84,214.84]$ \\
\hline 1.1.2 Roflumilast $500 \mu \mathrm{g}$ & 18 & 14384 & $\begin{array}{l}\text { Mean Difference (IV, Fixed, 95\% } \\
\mathrm{Cl} \text { ) }\end{array}$ & $55.18[48.65,61.71]$ \\
\hline 1.1.3 Roflumilast $250 \mu \mathrm{g}$ & 3 & 1033 & $\begin{array}{l}\text { Mean Difference (IV, Fixed, 95\% } \\
\mathrm{Cl} \text { ) }\end{array}$ & $56.88[24.38,89.38]$ \\
\hline 1.1.4 Cilomilast $15 \mathrm{mg}$ & 10 & 5322 & $\begin{array}{l}\text { Mean Difference (IV, Fixed, 95\% } \\
\mathrm{Cl} \text { ) }\end{array}$ & $38.15[29.41,46.90]$ \\
\hline 1.2 FVC & 17 & 22108 & $\begin{array}{l}\text { Mean Difference (IV, Fixed, 95\% } \\
\mathrm{Cl} \text { ) }\end{array}$ & $86.98[74.65,99.31]$ \\
\hline 1.3 PEF & 5 & 4245 & $\begin{array}{l}\text { Mean Difference (IV, Fixed, 95\% } \\
\mathrm{Cl} \text { ) }\end{array}$ & $6.54[3.95,9.13]$ \\
\hline 1.3.1 Roflumilast $500 \mu \mathrm{g}$ & 4 & 3685 & $\begin{array}{l}\text { Mean Difference (IV, Fixed, 95\% } \\
\mathrm{Cl} \text { ) }\end{array}$ & $5.46[2.74,8.17]$ \\
\hline 1.3.2 Roflumilast $250 \mu \mathrm{g}$ & 1 & 347 & $\begin{array}{l}\text { Mean Difference (IV, Fixed, 95\% } \\
\mathrm{Cl} \text { ) }\end{array}$ & $7.00[-4.05,18.05]$ \\
\hline 1.3.3 Cilomilast $15 \mathrm{mg}$ & 1 & 213 & $\begin{array}{l}\text { Mean Difference (IV, Fixed, 95\% } \\
\mathrm{Cl} \text { ) }\end{array}$ & $34.00[20.14,47.86]$ \\
\hline 1.4 SGRQ total score & 11 & 7645 & $\begin{array}{l}\text { Mean Difference (IV, Fixed, 95\% } \\
\mathrm{Cl} \text { ) }\end{array}$ & $-1.06[-1.68,-0.43]$ \\
\hline 1.4.1 Roflumilast $500 \mu \mathrm{g}$ & 2 & 722 & $\begin{array}{l}\text { Mean Difference (IV, Fixed, 95\% } \\
\mathrm{CI} \text { ) }\end{array}$ & $-1.87[-3.80,0.06]$ \\
\hline
\end{tabular}




\begin{tabular}{|c|c|c|c|c|}
\hline Outcome or subgroup title & $\begin{array}{l}\text { No. of } \\
\text { studies }\end{array}$ & $\begin{array}{l}\text { No. of } \\
\text { partici- } \\
\text { pants }\end{array}$ & Statistical method & Effect size \\
\hline 1.4.2 Roflumilast $250 \mu \mathrm{g}$ & 2 & 2229 & $\begin{array}{l}\text { Mean Difference (IV, Fixed, 95\% } \\
\mathrm{CI})\end{array}$ & $-0.64[-2.02,0.74]$ \\
\hline 1.4.3 Cilomilast $15 \mathrm{mg}$ & 8 & 4694 & $\begin{array}{l}\text { Mean Difference (IV, Fixed, 95\% } \\
\mathrm{CI})\end{array}$ & $-1.06[-1.81,-0.31]$ \\
\hline 1.5 SGRQ symptom score & 2 & 1048 & $\begin{array}{l}\text { Mean Difference (IV, Fixed, 95\% } \\
\mathrm{CI})\end{array}$ & $-1.53[-4.11,1.06]$ \\
\hline 1.5.1 Roflumilast & 1 & 835 & $\begin{array}{l}\text { Mean Difference (IV, Fixed, 95\% } \\
\mathrm{CI})\end{array}$ & $-1.00[-3.78,1.78]$ \\
\hline 1.5.2 Cilomilast & 1 & 213 & $\begin{array}{l}\text { Mean Difference (IV, Fixed, 95\% } \\
\mathrm{CI})\end{array}$ & $-4.80[-11.73,2.13]$ \\
\hline $\begin{array}{l}1.6 \text { Number of participants with } 1 \text { or more } \\
\text { exacerbations (by drug) }\end{array}$ & 27 & 20382 & Odds Ratio (M-H, Fixed, 95\% Cl) & $0.78[0.73,0.84]$ \\
\hline 1.6.1 Roflumilast $500 \mu \mathrm{g}$ & 16 & 14778 & Odds Ratio (M-H, Fixed, 95\% Cl) & $0.79[0.73,0.86]$ \\
\hline 1.6.2 Cilomilast & 10 & 5528 & Odds Ratio (M-H, Fixed, 95\% Cl) & $0.76[0.67,0.85]$ \\
\hline 1.6.3 Tetomilast $50 \mu \mathrm{g}$ & 1 & 76 & Odds Ratio (M-H, Fixed, 95\% Cl) & $2.45[0.26,23.13]$ \\
\hline 1.7 Exacerbation rate (inverse variance) & 9 & & Rate Ratio (IV, Fixed, 95\% CI) & $0.88[0.83,0.93]$ \\
\hline 1.7.1 Roflumilast & 8 & & Rate Ratio (IV, Fixed, 95\% CI) & $0.87[0.82,0.92]$ \\
\hline 1.7.2 Cilomilast & 1 & & Rate Ratio (IV, Fixed, 95\% Cl) & $0.95[0.78,1.17]$ \\
\hline 1.8 Borg Scale & 6 & 2860 & $\begin{array}{l}\text { Mean Difference (IV, Fixed, 95\% } \\
\mathrm{CI})\end{array}$ & $-0.19[-0.33,-0.05]$ \\
\hline 1.8.1 Cilomilast & 6 & 2860 & $\begin{array}{l}\text { Mean Difference (IV, Fixed, 95\% } \\
\mathrm{CI})\end{array}$ & $-0.19[-0.33,-0.05]$ \\
\hline 1.9 Shortness of Breath Questionnaire & 2 & 1633 & $\begin{array}{l}\text { Mean Difference (IV, Fixed, 95\% } \\
\mathrm{CI})\end{array}$ & $-1.09[-2.47,0.28]$ \\
\hline 1.10 Summary symptom score & 5 & 6186 & $\begin{array}{l}\text { Std. Mean Difference (IV, Fixed, } \\
95 \% \mathrm{Cl} \text { ) }\end{array}$ & $-0.02[-0.07,0.03]$ \\
\hline 1.10.1 Roflumilast & 2 & 4287 & $\begin{array}{l}\text { Std. Mean Difference (IV, Fixed, } \\
95 \% \mathrm{Cl})\end{array}$ & $-0.02[-0.08,0.04]$ \\
\hline 1.10.2 Cilomilast & 3 & 1899 & $\begin{array}{l}\text { Std. Mean Difference (IV, Fixed, } \\
95 \% \mathrm{Cl})\end{array}$ & $-0.04[-0.13,0.06]$ \\
\hline $\begin{array}{l}\text { 1.11 Breathlessness Cough and Sputum } \\
\text { Scale (BCSS) (tetomilast } 50 \mu \mathrm{g} \text { ) }\end{array}$ & 1 & & $\begin{array}{l}\text { Mean Difference (IV, Fixed, 95\% } \\
\mathrm{CI} \text { ) }\end{array}$ & Subtotals only \\
\hline 1.11.1 Breathlessness & 1 & 22 & $\begin{array}{l}\text { Mean Difference (IV, Fixed, 95\% } \\
\mathrm{CI})\end{array}$ & $-0.07[-0.77,0.63]$ \\
\hline
\end{tabular}




\begin{tabular}{|c|c|c|c|c|}
\hline Outcome or subgroup title & $\begin{array}{l}\text { No. of } \\
\text { studies }\end{array}$ & $\begin{array}{l}\text { No. of } \\
\text { partici- } \\
\text { pants }\end{array}$ & Statistical method & Effect size \\
\hline 1.11.2 Cough & 1 & 22 & $\begin{array}{l}\text { Mean Difference (IV, Fixed, 95\% } \\
\mathrm{CI})\end{array}$ & $0.23[-0.54,1.00]$ \\
\hline 1.11.3 Sputum & 1 & 22 & $\begin{array}{l}\text { Mean Difference (IV, Fixed, 95\% } \\
\mathrm{CI})\end{array}$ & $-0.16[-0.97,0.65]$ \\
\hline 1.126 -minute walk test & 6 & 2055 & $\begin{array}{l}\text { Mean Difference (IV, Fixed, 95\% } \\
\mathrm{CI} \text { ) }\end{array}$ & $3.50[-5.84,12.85]$ \\
\hline 1.12.1 Roflumilast & 2 & 107 & $\begin{array}{l}\text { Mean Difference (IV, Fixed, 95\% } \\
\mathrm{CI} \text { ) }\end{array}$ & $52.61[-0.21,105.42]$ \\
\hline 1.12.2 Cilomilast & 4 & 1948 & $\begin{array}{l}\text { Mean Difference (IV, Fixed, 95\% } \\
\mathrm{CI})\end{array}$ & $1.92[-7.58,11.41]$ \\
\hline $\begin{array}{l}1.13 \text { Number of participants experiencing } \\
\text { an adverse event }\end{array}$ & 30 & 21310 & Odds Ratio (M-H, Fixed, 95\% Cl) & $1.30[1.22,1.38]$ \\
\hline 1.13.1 Roflumilast $500 \mu \mathrm{g}$ & 15 & 14684 & Odds Ratio (M-H, Fixed, 95\% Cl) & $1.34[1.24,1.43]$ \\
\hline 1.13.2 Cilomilast $15 \mathrm{mg}$ & 14 & 6542 & Odds Ratio (M-H, Fixed, 95\% Cl) & $1.21[1.08,1.36]$ \\
\hline 1.13.3 Tetomilast $50 \mu \mathrm{g}$ & 1 & 84 & Odds Ratio (M-H, Fixed, 95\% Cl) & $0.62[0.25,1.57]$ \\
\hline $\begin{array}{l}1.14 \text { Number of participants experiencing } \\
\text { an adverse event (roflumilast } 500 \mu \mathrm{g} \text { vs } \\
250 \mu \mathrm{g} \text { ) }\end{array}$ & 4 & 1977 & Odds Ratio (M-H, Fixed, 95\% Cl) & $1.21[1.01,1.46]$ \\
\hline 1.15 Diarrhoea & 29 & 20623 & Odds Ratio (M-H, Fixed, 95\% Cl) & $3.10[2.74,3.50]$ \\
\hline 1.15.1 Roflumilast & 14 & 13997 & Odds Ratio (M-H, Fixed, 95\% Cl) & $3.65[3.10,4.28]$ \\
\hline 1.15.2 Cilomilast & 14 & 6542 & Odds Ratio (M-H, Fixed, 95\% Cl) & $2.47[2.05,2.98]$ \\
\hline 1.15.3 Tetomilast & 1 & 84 & Odds Ratio (M-H, Fixed, 95\% Cl) & $1.68[0.31,9.24]$ \\
\hline 1.16 Nausea & 27 & 20949 & Odds Ratio (M-H, Fixed, 95\% Cl) & $3.79[3.24,4.43]$ \\
\hline 1.16.1 Roflumilast $500 \mu \mathrm{g}$ & 12 & 13467 & Odds Ratio (M-H, Fixed, 95\% Cl) & $3.25[2.60,4.07]$ \\
\hline 1.16.2 Roflumilast $250 \mu \mathrm{g}$ & 1 & 856 & Odds Ratio (M-H, Fixed, 95\% Cl) & $3.97[0.91,17.39]$ \\
\hline 1.16.3 Cilomilast $15 \mathrm{mg}$ & 14 & 6542 & Odds Ratio (M-H, Fixed, 95\% Cl) & $4.37[3.49,5.47]$ \\
\hline 1.16.4 Tetomilast $50 \mu \mathrm{g}$ & 1 & 84 & Odds Ratio (M-H, Fixed, 95\% Cl) & $2.00[0.20,20.09]$ \\
\hline 1.17 Vomiting & 12 & 5986 & Odds Ratio (M-H, Fixed, 95\% Cl) & $3.95[2.78,5.60]$ \\
\hline 1.17.1 Roflumilast & 2 & 993 & Odds Ratio (M-H, Fixed, 95\% Cl) & $2.32[0.53,10.23]$ \\
\hline 1.17.2 Cilomilast & 10 & 4993 & Odds Ratio (M-H, Fixed, 95\% Cl) & $4.06[2.83,5.82]$ \\
\hline 1.18 Dyspepsia & 13 & 6247 & Odds Ratio (M-H, Fixed, 95\% Cl) & $3.17[2.33,4.30]$ \\
\hline
\end{tabular}




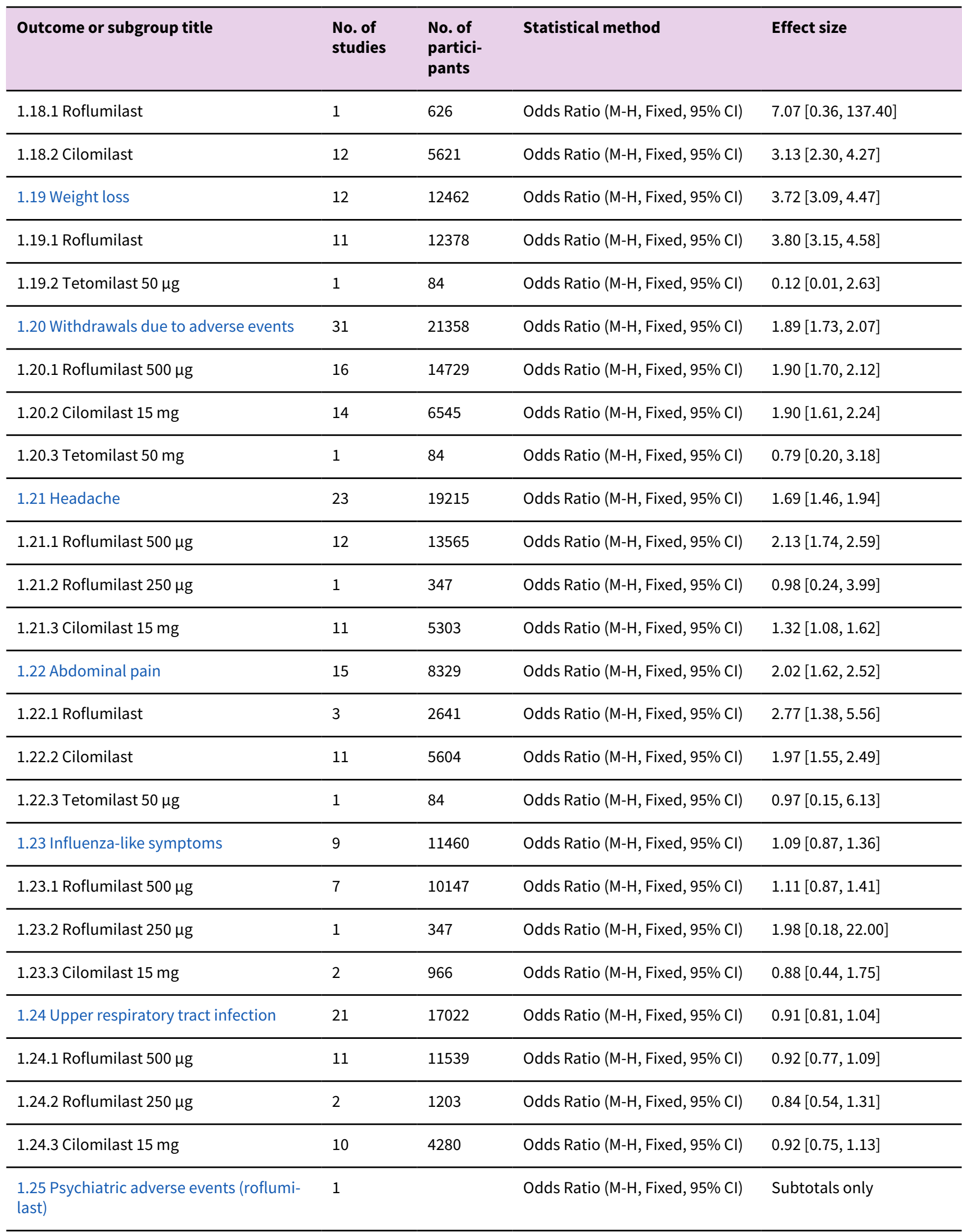




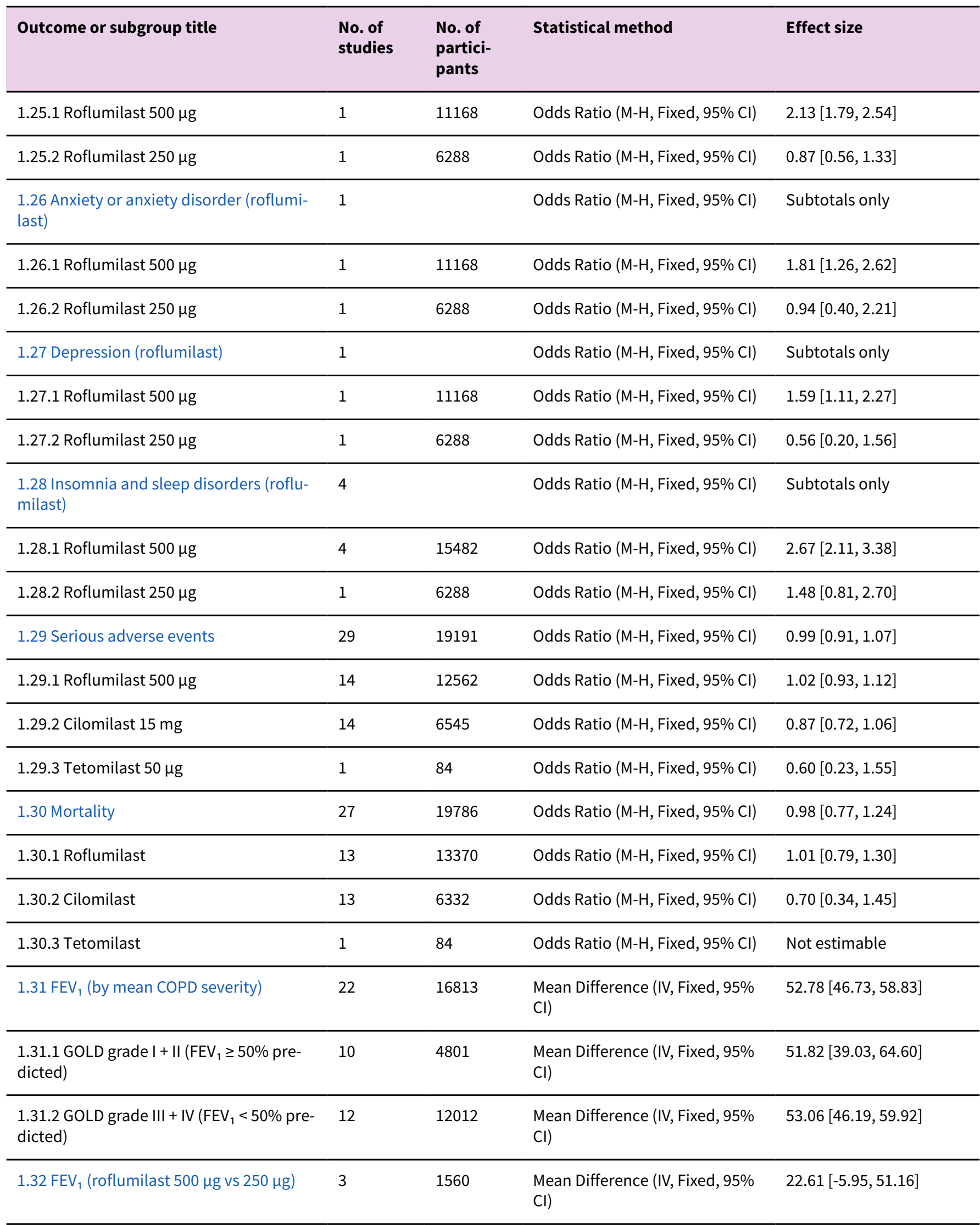




\begin{tabular}{|c|c|c|c|c|}
\hline Outcome or subgroup title & $\begin{array}{l}\text { No. of } \\
\text { studies }\end{array}$ & $\begin{array}{l}\text { No. of } \\
\text { partici- } \\
\text { pants }\end{array}$ & Statistical method & Effect size \\
\hline 1.32.1 Roflumilast 250 ug & 3 & 1560 & $\begin{array}{l}\text { Mean Difference (IV, Fixed, 95\% } \\
\mathrm{CI})\end{array}$ & $22.61[-5.95,51.16]$ \\
\hline $1.33 \mathrm{FEV}_{1}$ (by study duration) & 28 & 19939 & $\begin{array}{l}\text { Mean Difference (IV, Fixed, 95\% } \\
\mathrm{Cl} \text { ) }\end{array}$ & $49.09[43.86,54.32]$ \\
\hline 1.33.1 Duration $\leq 12$ weeks & 8 & 1191 & $\begin{array}{l}\text { Mean Difference (IV, Fixed, 95\% } \\
\mathrm{CI})\end{array}$ & $101.71[70.96,132.46]$ \\
\hline 1.33.2 Duration 24 to 26 weeks & 13 & 8086 & $\begin{array}{l}\text { Mean Difference (IV, Fixed, 95\% } \\
\mathrm{CI} \text { ) }\end{array}$ & $46.14[38.44,53.84]$ \\
\hline 1.33.3 Duration 52 weeks & 7 & 10662 & $\begin{array}{l}\text { Mean Difference (IV, Fixed, 95\% } \\
\mathrm{CI} \text { ) }\end{array}$ & $48.77[41.44,56.10]$ \\
\hline 1.34 $\mathrm{FEV}_{1}$ (additional medication) & 28 & 19719 & $\begin{array}{l}\text { Mean Difference (IV, Fixed, 95\% } \\
\mathrm{CI} \text { ) }\end{array}$ & $49.08[43.85,54.31]$ \\
\hline 1.34.1 Long-acting bronchodilator & 2 & 1645 & $\begin{array}{l}\text { Mean Difference (IV, Fixed, 95\% } \\
\mathrm{CI})\end{array}$ & $60.52[40.57,80.46]$ \\
\hline 1.34.2 Corticosteroids & 3 & 2904 & $\begin{array}{l}\text { Mean Difference (IV, Fixed, 95\% } \\
\mathrm{CI} \text { ) }\end{array}$ & $42.26[25.46,59.05]$ \\
\hline 1.34.3 $\mathrm{PDE}_{4} \mathrm{i}$ treatment only & 20 & 10323 & $\begin{array}{l}\text { Mean Difference (IV, Fixed, 95\% } \\
\mathrm{CI} \text { ) }\end{array}$ & $44.80[37.69,51.91]$ \\
\hline 1.34.4 Various concomitant treatments & 3 & 4847 & $\begin{array}{l}\text { Mean Difference (IV, Fixed, 95\% } \\
\mathrm{CI} \text { ) }\end{array}$ & $56.58[46.91,66.25]$ \\
\hline 1.35 FEV 1 (random-effects model) & 29 & 20015 & $\begin{array}{l}\text { Mean Difference (IV, Random, } \\
95 \% \mathrm{CI} \text { ) }\end{array}$ & $51.49[42.87,60.10]$ \\
\hline 1.36 $\mathrm{FEV}_{1}$ (published vs unpublished) & 29 & 20015 & $\begin{array}{l}\text { Mean Difference (IV, Fixed, 95\% } \\
\mathrm{CI} \text { ) }\end{array}$ & $49.28[44.05,54.51]$ \\
\hline 1.36.1 Published & 20 & 15398 & $\begin{array}{l}\text { Mean Difference (IV, Fixed, 95\% } \\
\mathrm{CI} \text { ) }\end{array}$ & $55.75[49.45,62.06]$ \\
\hline 1.36.2 Unpublished & 9 & 4617 & $\begin{array}{l}\text { Mean Difference (IV, Fixed, 95\% } \\
\mathrm{CI} \text { ) }\end{array}$ & $35.05[25.70,44.40]$ \\
\hline $\begin{array}{l}\text { 1.37 SGRQ total score (by mean COPD } \\
\text { severity) }\end{array}$ & 8 & 4851 & $\begin{array}{l}\text { Mean Difference (IV, Fixed, 95\% } \\
\mathrm{CI} \text { ) }\end{array}$ & $-1.56[-2.39,-0.74]$ \\
\hline 1.37.1 GOLD grade I + II & 3 & 2042 & $\begin{array}{l}\text { Mean Difference (IV, Fixed, 95\% } \\
\mathrm{CI} \text { ) }\end{array}$ & $-1.62[-2.80,-0.44]$ \\
\hline 1.37.2 GOLD grade III + IV & 5 & 2809 & $\begin{array}{l}\text { Mean Difference (IV, Fixed, 95\% } \\
\mathrm{Cl} \text { ) }\end{array}$ & $-1.51[-2.67,-0.34]$ \\
\hline 1.38 SGRQ total score (by duration) & 11 & 7069 & $\begin{array}{l}\text { Mean Difference (IV, Fixed, 95\% } \\
\mathrm{Cl} \text { ) }\end{array}$ & $-0.99[-1.65,-0.33]$ \\
\hline
\end{tabular}




\begin{tabular}{|c|c|c|c|c|}
\hline Outcome or subgroup title & $\begin{array}{l}\text { No. of } \\
\text { studies }\end{array}$ & $\begin{array}{l}\text { No. of } \\
\text { partici- } \\
\text { pants }\end{array}$ & Statistical method & Effect size \\
\hline 1.38.1 Duration $<12$ weeks & 2 & 240 & $\begin{array}{l}\text { Mean Difference (IV, Fixed, 95\% } \\
\mathrm{CI})\end{array}$ & $-4.19[-7.60,-0.78]$ \\
\hline 1.38.2 Duration 24 to 26 weeks & 7 & 4600 & $\begin{array}{l}\text { Mean Difference (IV, Fixed, 95\% } \\
\mathrm{CI})\end{array}$ & $-1.18[-1.94,-0.42]$ \\
\hline 1.38.3 Duration 52 weeks & 2 & 2229 & $\begin{array}{l}\text { Mean Difference (IV, Fixed, 95\% } \\
\mathrm{CI})\end{array}$ & $0.26[-1.18,1.69]$ \\
\hline $\begin{array}{l}\text { 1.39 SGRQ total score (by published vs } \\
\text { unpublished) }\end{array}$ & 11 & 7069 & $\begin{array}{l}\text { Mean Difference (IV, Fixed, 95\% } \\
\mathrm{CI})\end{array}$ & $-1.00[-1.65,-0.34]$ \\
\hline 1.39.1 Published & 5 & 3079 & $\begin{array}{l}\text { Mean Difference (IV, Fixed, 95\% } \\
\mathrm{CI})\end{array}$ & $-1.98[-3.07,-0.89]$ \\
\hline 1.39.2 Unpublished & 6 & 3990 & $\begin{array}{l}\text { Mean Difference (IV, Fixed, 95\% } \\
\mathrm{CI})\end{array}$ & $-0.43[-1.26,0.40]$ \\
\hline $\begin{array}{l}1.40 \text { Number of participants on roflumi- } \\
\text { last with } 1 \text { or more exacerbations (addi- } \\
\text { tional medication) }\end{array}$ & 15 & 14698 & Odds Ratio (M-H, Fixed, 95\% Cl) & $0.79[0.73,0.85]$ \\
\hline 1.40.1 Long-acting bronchodilators & 3 & 1834 & Odds Ratio (M-H, Fixed, 95\% Cl) & $0.69[0.54,0.88]$ \\
\hline 1.40.2 Corticosteroids & 1 & 2686 & Odds Ratio (M-H, Fixed, 95\% Cl) & $0.81[0.70,0.95]$ \\
\hline 1.40.3 Treatment only & 7 & 5145 & Odds Ratio (M-H, Fixed, 95\% Cl) & $0.79[0.67,0.93]$ \\
\hline 1.40.4 Various concomitant treatments & 4 & 5033 & Odds Ratio (M-H, Fixed, 95\% Cl) & $0.81[0.72,0.91]$ \\
\hline $\begin{array}{l}1.41 \mathrm{FVC} \mathrm{ML} \text { (roflumilast } 500 \mu \mathrm{g} \text {, end- } \\
\text { point) }\end{array}$ & 1 & 60 & $\begin{array}{l}\text { Mean Difference (IV, Fixed, 95\% } \\
\mathrm{CI})\end{array}$ & $0.52[0.25,0.79]$ \\
\hline $1.42 \mathrm{FEV}_{1}$ (by unknown COPD severity) & 1 & 76 & $\begin{array}{l}\text { Mean Difference (IV, Fixed, 95\% } \\
\mathrm{CI})\end{array}$ & $82.00[-50.84,214.84]$ \\
\hline 1.43 FEV 1 (by duration, endpoint) & 1 & 60 & $\begin{array}{l}\text { Mean Difference (IV, Fixed, 95\% } \\
\mathrm{CI})\end{array}$ & $0.52[0.25,0.79]$ \\
\hline $\begin{array}{l}1.44 \mathrm{FEV}_{1} \text { (random-effects model, end- } \\
\text { point data) }\end{array}$ & 1 & 60 & $\begin{array}{l}\text { Mean Difference (IV, Random, } \\
95 \% \mathrm{CI})\end{array}$ & $0.43[0.31,0.55]$ \\
\hline $\begin{array}{l}1.45 \mathrm{FEV}_{1} \text { (by moderate to severe COPD } \\
\text { severity, endpoint) }\end{array}$ & 1 & 60 & $\begin{array}{l}\text { Mean Difference (IV, Fixed, 95\% } \\
\mathrm{CI})\end{array}$ & $0.52[0.25,0.79]$ \\
\hline $1.46 \mathrm{FEV}_{1}$ (roflumilast $500 \mu \mathrm{g}$, endpoint) & 1 & 60 & $\begin{array}{l}\text { Mean Difference (IV, Fixed, 95\% } \\
\mathrm{CI} \text { ) }\end{array}$ & $0.43[0.31,0.55]$ \\
\hline $\begin{array}{l}\text { 1.47 } \mathrm{FEV}_{1} \mathrm{ML} \text { (additional medication } \\
\text { ( } \mathrm{PDE}_{4} \mathrm{i}_{\text {i only) endpoint) }}\end{array}$ & 1 & 60 & $\begin{array}{l}\text { Mean Difference (IV, Fixed, 95\% } \\
\mathrm{CI})\end{array}$ & $0.52[0.25,0.79]$ \\
\hline 1.48 FEV 1 (published, endpoint) & 1 & 60 & $\begin{array}{l}\text { Mean Difference (IV, Fixed, 95\% } \\
\mathrm{CI} \text { ) }\end{array}$ & $0.52[0.25,0.79]$ \\
\hline
\end{tabular}




\begin{tabular}{|c|c|c|c|c|}
\hline Outcome or subgroup title & $\begin{array}{l}\text { No. of } \\
\text { studies }\end{array}$ & $\begin{array}{l}\text { No. of } \\
\text { partici- } \\
\text { pants }\end{array}$ & Statistical method & Effect size \\
\hline $\begin{array}{l}\text { 1.49 FEV }{ }_{1} \text { (roflumilast } 500 \mu \mathrm{g} \text { by mean } \\
\text { COPD severity) }\end{array}$ & 16 & 13896 & $\begin{array}{l}\text { Mean Difference (IV, Fixed, 95\% } \\
\mathrm{CI})\end{array}$ & $55.51[48.88,62.14]$ \\
\hline $\begin{array}{l}\text { 1.49.1 GOLD grade I + II (FEV } 1 \geq 50 \% \text { pre- } \\
\text { dicted) }\end{array}$ & 7 & 3341 & $\begin{array}{l}\text { Mean Difference (IV, Fixed, 95\% } \\
\mathrm{CI})\end{array}$ & $69.83[53.34,86.33]$ \\
\hline $\begin{array}{l}\text { 1.49.2 GOLD grade III + IV }\left(\mathrm{FEV}_{1}<50 \% \text { pre- }\right. \\
\text { dicted) }\end{array}$ & 9 & 10555 & $\begin{array}{l}\text { Mean Difference (IV, Fixed, 95\% } \\
\mathrm{CI} \text { ) }\end{array}$ & $52.75[45.52,59.99]$ \\
\hline $\begin{array}{l}\text { 1.50 FEV } 1 \text { (unknown additional medica- } \\
\text { tion) }\end{array}$ & 1 & 76 & $\begin{array}{l}\text { Mean Difference (IV, Fixed, 95\% } \\
\mathrm{CI} \text { ) }\end{array}$ & $82.00[-50.84,214.84]$ \\
\hline $\begin{array}{l}1.51 \mathrm{FEV}_{1} \text { (by moderate to severe COPD } \\
\text { severity, roflumilast } 500 \mu \mathrm{g} \text { endpoint) }\end{array}$ & 1 & 60 & $\begin{array}{l}\text { Mean Difference (IV, Fixed, 95\% } \\
\text { CI) }\end{array}$ & $0.52[0.25,0.79]$ \\
\hline $\begin{array}{l}1.52 \mathrm{FEV}_{1} \text { (by unknown COPD severity, } \\
\text { roflumilast } 500 \mu \mathrm{g} \text { ) }\end{array}$ & 1 & 76 & $\begin{array}{l}\text { Mean Difference (IV, Fixed, 95\% } \\
\text { CI) }\end{array}$ & $82.00[-50.84,214.84]$ \\
\hline
\end{tabular}


Analysis 1.1. Comparison 1: $\mathrm{PDE}_{4}$ inhibitor versus placebo (2020 update), Outcome 1: FEV (by drug)

1.1.1 Tetomilast $50 \mu \mathrm{g}$ NCT00874497 (EMPHASIS) Subtotal (95\% CI) Mean $[\mathrm{mL}] \quad$ SD $[\mathrm{mL}] \quad$ Total $\quad$ Mean $[\mathrm{mL}] \quad$ SD $[\mathrm{mL}] \quad$ Total Weight $\quad$ IV, Fixed, 95\% CI [mL]
Heterogeneity: Not applicable

$82.00[-50.84,214.84]$

Test for overall effect: $\mathrm{Z}=1.21(\mathrm{P}=0.23)$

\subsubsection{Roflumilast $500 \mu \mathrm{g}$} RO-2455-301-RD (ACROSS) RO-2455-402-RD (ROBERT) (1) RO-2455-404-RD (REACT)

Roflumilast DAL-MD-01

Roflumilast FK1 101 (2)

Roflumilast FK1 103

Roflumilast FLUI-2011-77

Roflumilast IN-108 (2)

Roflumilast M2-107 (2)

Roflumilast M2-111

Roflumilast M2-112

Roflumilast M2-118

Roflumilast M2-119

Roflumilast M2-124

Roflumilast M2-125

Roflumilast M2-127

Roflumilast M2-128

Roflumilast ROF-MD-07(RE2SPOND)

Subtotal (95\% CI)

Heterogeneity: $\mathrm{Chi}^{2}=21.53, \mathrm{df}=17(\mathrm{P}=0.20) ; \mathrm{I}^{2}=21 \%$

Test for overall effect: $Z=16.56(P<0.00001)$

\subsubsection{Roflumilast $250 \mu \mathrm{g}$}

Roflumilast FK1 101 (2)

Roflumilast IN-108 (2)

Roflumilast M2-107 (2)

Subtotal (95\% CI)

Heterogeneity: $\mathrm{Chi}^{2}=1.08, \mathrm{df}=2(\mathrm{P}=0.58) ; \mathrm{I}^{2}=0 \%$

Test for overall effect: $\mathrm{Z}=3.43(\mathrm{P}=0.0006)$

\subsubsection{Cilomilast $15 \mathrm{mg}$}

Cilomilast 039

Cilomilast 042

Cilomilast 076

Cilomilast 091

Cilomilast 103657

Cilomilast 110

Cilomilast 121

Cilomilast 156

Cilomilast 157

Compton 2001

Subtotal (95\% CI)

$\begin{array}{rrrrrrr}49 & 159.5692 & 313 & -22 & 159.5692 & 313 & 4.3 \% \\ 63 & 861 & 77 & 0 & 861 & 77 & 0.0 \% \\ 52 & 194.9638 & 928 & -4 & 196.3246 & 941 & 8.5 \% \\ 41 & 91 & 11 & 28 & 250 & 16 & 0.1 \% \\ 109 & 273 & 169 & 57 & 213 & 86 & 0.7 \% \\ 78 & 240 & 200 & 39 & 245 & 186 & 1.1 \% \\ 66 & 120 & 30 & -59 & 71 & 11 & 0.7 \% \\ 28 & 486 & 42 & -124 & 281 & 12 & 0.1 \% \\ 49 & 283 & 555 & -39 & 189 & 140 & 1.7 \% \\ 30 & 182 & 545 & -12 & 178 & 596 & 6.1 \% \\ 9 & 303 & 760 & -27 & 302 & 753 & 2.9 \% \\ 55 & 282 & 127 & -27 & 311 & 123 & 0.5 \% \\ 54 & 289 & 189 & -42 & 298 & 201 & 0.8 \% \\ 46 & 218 & 745 & 8 & 218 & 745 & 5.4 \% \\ 33 & 189 & 730 & -25 & 194 & 766 & 7.1 \% \\ 39 & 192 & 456 & -10 & 193 & 460 & 4.3 \% \\ 65 & 229 & 365 & -16 & 229 & 364 & 2.4 \% \\ 53 & 160.836 & 1178 & 0 & 160.836 & 1174 & 15.8 \% \\ & & \mathbf{7 4 2 0} & & & \mathbf{6 9 6 4} & \mathbf{6 2 . 5 \%}\end{array}$

Heterogeneity: $\mathrm{Chi}^{2}=23.75, \mathrm{df}=9(\mathrm{P}=0.005) ; \mathrm{I}^{2}=62 \%$

Test for overall effect: $\mathrm{Z}=8.55(\mathrm{P}<0.00001)$

$\begin{array}{rrr}144 & 207 & 3.5 \% \\ 296 & 230 & 1.4 \% \\ 192 & 23 & 0.2 \% \\ 303 & 230 & 0.9 \% \\ 89 & 316 & 13.9 \% \\ 204 & 26 & 0.2 \% \\ 181 & 328 & 4.6 \% \\ 155 & 377 & 5.4 \% \\ 182 & 411 & 3.8 \% \\ 207 & 106 & 0.9 \% \\ & \mathbf{2 2 5 4} & \mathbf{3 4 . 8 \%}\end{array}$

$40.00[12.30,67.70]$ $30.00[-13.04,73.04]$ $20.00[-90.83,130.83]$ $30.00[-25.40,85.40]$ $44.00[30.13,57.87]$ $70.00[-40.92,180.92]$ $20.00[-3.93,43.93]$ $24.00[1.82,46.18]$ $34.00[7.70,60.30]$ $160.00[104.53,215.47]$ $38.15[29.41,46.90]$

$9485 \quad 100.0 \%$
$56.00[38.26,73.74]$

$3.00[-120.78,146.78]$

$52.00[-9.00,113.00]$

$39.00[-9.44,87.44]$

$125.00[64.96,185.04]$

$52.00[-64.52,368.52]$

$42.00[21.08,62.92]$

$36.00[5.52,66.48]$

$82.00[8.34,155.66]$

$38.00[15.86,60.14]$

$58.00[38.59,77.41]$

$[24.07,73.93]$

$55.18[48.65,61.71]$

$36.00[-24.52,96.52]$ $37.00[-79.38,353.38]$ $63.00[23.84,102.16]$ $56.88[24.38,89.38]$

11330
$53.00[40.00,66.00]$
Total (95\% CI)

Heterogeneity: $\mathrm{Chi}^{2}=56.15, \mathrm{df}=31(\mathrm{P}=0.004) ; \mathrm{I}^{2}=45 \%$

Test for overall effect: $\mathrm{Z}=18.73(\mathrm{P}<0.00001)$

Test for subgroup differences: $\mathrm{Chi}^{2}=9.80, \mathrm{df}=3(\mathrm{P}=0.02), \mathrm{I}^{2}=69.4 \%$
, Fixed, 95\% CI [mL]

\section{Footnotes}

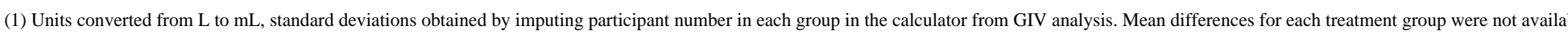

(2) The participant number in the placebo group was halved to avoid double counting 
Analysis 1.2. Comparison 1: $\mathrm{PDE}_{4}$ inhibitor versus placebo (2020 update), Outcome 2: FVC

\begin{tabular}{|c|c|c|c|c|c|c|c|c|c|c|}
\hline \multirow[b]{2}{*}{ Study or Subgroup } & \multicolumn{3}{|c|}{ PDE4i treatment } & \multicolumn{3}{|c|}{ Placebo } & \multicolumn{2}{|r|}{ Mean Difference } & \multirow{2}{*}{\multicolumn{2}{|c|}{$\begin{array}{c}\text { Mean Difference } \\
\text { IV, Fixed, 95\% CI }[\mathrm{mL}]\end{array}$}} \\
\hline & Mean [mL] & SD [mL] & Total & Mean [mL] & SD $[\mathrm{mL}]$ & Total & Weight & IV, Fixed, 95\% CI [mL] & & \\
\hline Cilomilast 039 & -10 & 397 & 394 & -120 & 433 & 208 & $3.0 \%$ & $110.00[39.29,180.71]$ & & 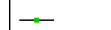 \\
\hline Cilomilast 042 & 30 & 635 & 448 & -20 & 445 & 220 & $2.2 \%$ & $50.00[-33.16,133.16]$ & & $\ldots$ \\
\hline Cilomilast 091 & -20 & 631 & 443 & -70 & 609 & 232 & $1.6 \%$ & $50.00[-47.95,147.95]$ & & - \\
\hline Cilomilast 103657 & 25 & 447 & 296 & -2 & 409 & 316 & $3.3 \%$ & $27.00[-41.02,95.02]$ & & $=$ \\
\hline Cilomilast 156 & 20 & 388 & 377 & -40 & 391 & 383 & $5.0 \%$ & $60.00[4.62,115.38]$ & & - \\
\hline Compton 2001 & 180 & 517 & 107 & -15 & 515 & 106 & $0.8 \%$ & $195.00[56.41,333.59]$ & & - \\
\hline RO-2455-301-RD (ACROSS) & 100 & 306.3729 & 313 & -9 & 306.3729 & 313 & $6.6 \%$ & $109.00[61.00,157.00]$ & & $=$ \\
\hline RO-2455-402-RD (ROBERT) (1) & 64 & 342.5 & 77 & 0 & 342.5 & 77 & $1.3 \%$ & $64.00[-44.19,172.19]$ & & - \\
\hline RO-2455-404-RD (REACT) & 36 & 347.2793 & 928 & -57 & 941 & 7187 & $15.6 \%$ & $93.00[61.81,124.19]$ & & $=$ \\
\hline Roflumilast M2-107 & 39 & 495 & 555 & -75 & 452 & 280 & $3.4 \%$ & $114.00[46.93,181.07]$ & & $\rightarrow-$ \\
\hline Roflumilast M2-112 & -33 & 716 & 760 & -80 & 713 & 753 & $2.9 \%$ & $47.00[-25.00,119.00]$ & & - \\
\hline Roflumilast M2-119 & 51 & 481 & 189 & -100 & 483 & 202 & $1.7 \%$ & $151.00[55.40,246.60]$ & & —- \\
\hline Roflumilast M2-124 & 76 & 405 & 729 & -25 & 407 & 736 & $8.8 \%$ & $101.00[59.42,142.58]$ & & - \\
\hline Roflumilast M2-125 & 58 & 350 & 724 & -45 & 359 & 764 & $11.7 \%$ & $103.00[66.97,139.03]$ & & $=$ \\
\hline Roflumilast M2-127 & 67 & 319 & 452 & 10 & 322 & 460 & $8.8 \%$ & $57.00[15.40,98.60]$ & & - \\
\hline Roflumilast M2-128 & 27 & 439 & 364 & -74 & 419 & 363 & $3.9 \%$ & $101.00[38.62,163.38]$ & & $=$ \\
\hline Roflumilast ROF-MD-07(RE2SPOND) & 83 & 346.416 & 1178 & 0 & 346.416 & 1174 & $19.4 \%$ & $83.00[55.00,111.00]$ & & $=$ \\
\hline Total $(95 \%$ CI) & & & 8334 & & & 13774 & $100.0 \%$ & $86.98[74.65,99.31]$ & & 1 \\
\hline \multicolumn{11}{|c|}{ Heterogeneity: $\mathrm{Chi}^{2}=16.06, \mathrm{df}=16(\mathrm{P}=0.45) ; \mathrm{I}^{2}=0 \%$} \\
\hline Test for overall effect: $\mathrm{Z}=13.82(\mathrm{P}<0$. & 001) & & & & & & & & $-500-250$ & 250 \\
\hline Test for subgroup differences: Not appli & & & & & & & & & Favours placebo & Favours \\
\hline
\end{tabular}

Footnotes

(1) Imputed participant numbers and calculated SDs in RevMan calculator

Analysis 1.3. Comparison 1: $\mathrm{PDE}_{4}$ inhibitor versus placebo (2020 update), Outcome 3: PEF

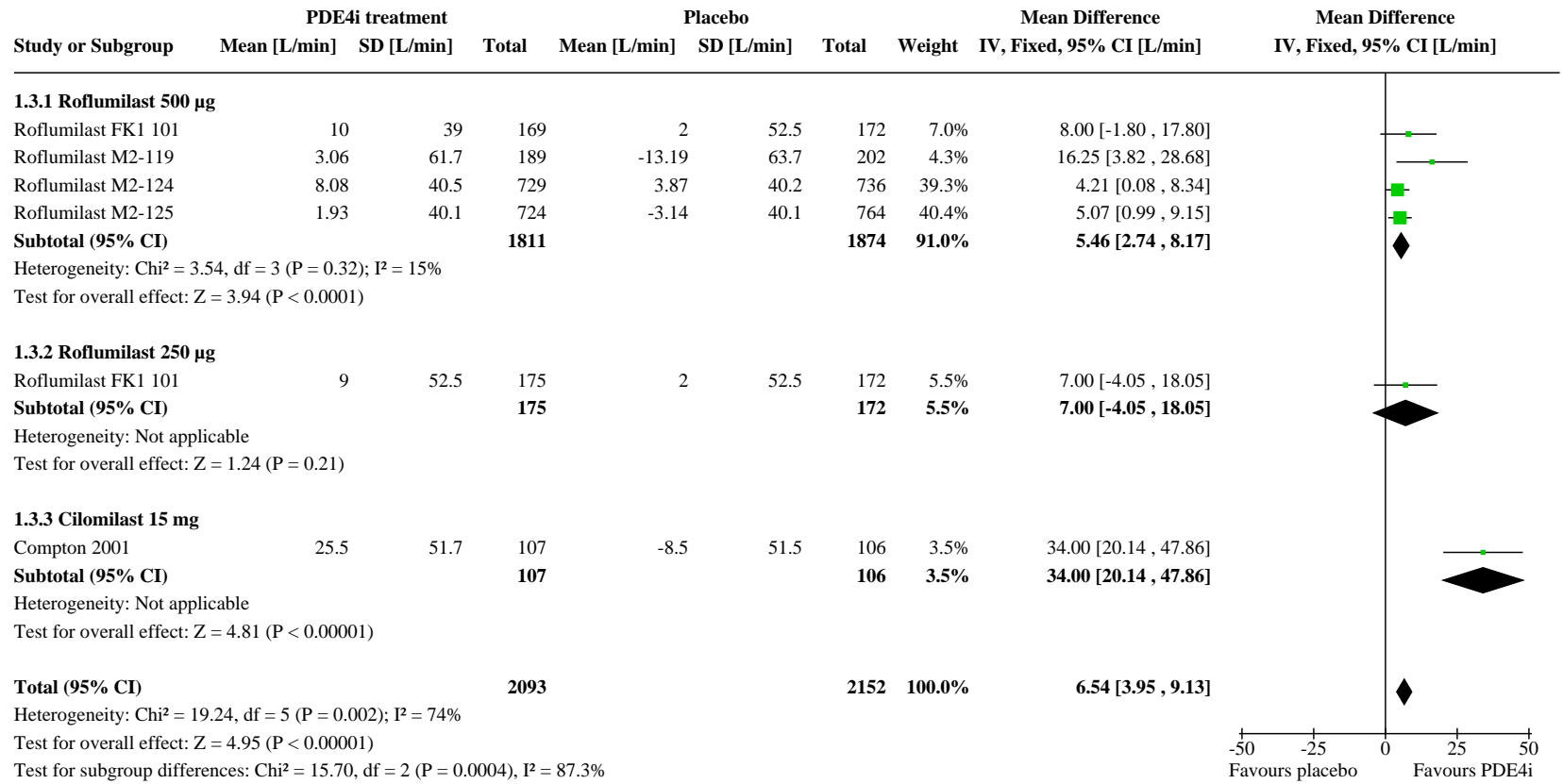


Analysis 1.4. Comparison 1: $\mathrm{PDE}_{4}$ inhibitor versus placebo (2020 update), Outcome 4: SGRQ total score

\begin{tabular}{|c|c|c|c|c|c|c|c|c|c|c|}
\hline \multirow{3}{*}{$\frac{\text { Study or Subgroup }}{1.4 .1 \text { Roflumilast } 500 \mu \mathrm{g}}$} & \multicolumn{3}{|c|}{ PDE4i treatment } & \multicolumn{3}{|c|}{ Placebo } & \multirow[b]{2}{*}{ Weight } & \multirow{2}{*}{$\begin{array}{c}\text { Mean Difference } \\
\text { IV, Fixed, 95\% CI }\end{array}$} & \multirow{2}{*}{\multicolumn{2}{|c|}{$\begin{array}{l}\text { Mean Difference } \\
\text { IV, Fixed, 95\% CI }\end{array}$}} \\
\hline & Mean & SD & Total & Mean & SD & Total & & & & \\
\hline & & & & & & & & & & \\
\hline Roflumilast DAL-MD-01 & -7.5 & 13.8 & 11 & -0.8 & 13.8 & 16 & $0.3 \%$ & $-6.70[-17.29,3.89]$ & & - \\
\hline Roflumilast M2-107 & -3.5 & 14.1 & 555 & -1.8 & 9.5 & 140 & $10.1 \%$ & $-1.70[-3.66,0.26]$ & & \\
\hline Subtotal $(95 \%$ CI $)$ & & & 566 & & & 156 & $10.5 \%$ & $-1.87[-3.80,0.06]$ & & \\
\hline \multicolumn{11}{|c|}{ Heterogeneity: $\mathrm{Chi}^{2}=0.83, \mathrm{df}=1(\mathrm{P}=0.36) ; \mathrm{I}^{2}=0 \%$} \\
\hline \multicolumn{11}{|c|}{ Test for overall effect: $\mathrm{Z}=1.89(\mathrm{P}=0.06)$} \\
\hline \multicolumn{11}{|l|}{ 1.4.2 Roflumilast $250 \mu \mathrm{g}$} \\
\hline Roflumilast M2-107 & -3.4 & 14.4 & 576 & -1.8 & 9.5 & 140 & $10.1 \%$ & $-1.60[-3.56,0.36]$ & & \\
\hline Roflumilast M2-112 & -1.7 & 19.3 & 760 & -2 & 19.2 & 753 & $10.4 \%$ & $0.30[-1.64,2.24]$ & & \\
\hline Subtotal (95\% CI) & & & 1336 & & & 893 & $20.4 \%$ & $-0.64[-2.02,0.74]$ & & \\
\hline \multicolumn{11}{|c|}{ Heterogeneity: $\mathrm{Chi}^{2}=1.82, \mathrm{df}=1(\mathrm{P}=0.18) ; \mathrm{I}^{2}=45 \%$} \\
\hline \multicolumn{11}{|c|}{ Test for overall effect: $\mathrm{Z}=0.91(\mathrm{P}=0.36)$} \\
\hline \multicolumn{11}{|l|}{ 1.4.3 Cilomilast $15 \mathrm{mg}$} \\
\hline Cilomilast 039 & -3.7 & 12.32 & 310 & 0.4 & 10.76 & 181 & $9.0 \%$ & $-4.10[-6.18,-2.02]$ & -- & \\
\hline Cilomilast 042 & -4.2 & 15.5 & 375 & -4.9 & 13.8 & 190 & $6.2 \%$ & $0.70[-1.81,3.21]$ & & \\
\hline Cilomilast 091 & -2.7 & 21.1 & 369 & -2.3 & 16.8 & 197 & $3.8 \%$ & $-0.40[-3.58,2.78]$ & & \\
\hline Cilomilast 103657 & -1.8 & 10.2 & 292 & -1.84 & 10 & 310 & $14.9 \%$ & $0.04[-1.57,1.65]$ & & \\
\hline Cilomilast 121 & -9 & 14.7 & 580 & -8.7 & 14.7 & 320 & $9.7 \%$ & $-0.30[-2.31,1.71]$ & - & \\
\hline Cilomilast 156 & -3.2 & 10.5 & 304 & -1.3 & 11 & 337 & $14.0 \%$ & $-1.90[-3.57,-0.23]$ & $\rightarrow$ & \\
\hline Cilomilast 157 & -1.29 & 14.9 & 347 & -1.49 & 14.4 & 369 & $8.4 \%$ & $0.20[-1.95,2.35]$ & & \\
\hline Compton 2001 & -3.9 & 13.4 & 107 & 0 & 13.4 & 106 & $3.0 \%$ & $-3.90[-7.50,-0.30]$ & & \\
\hline Subtotal $(95 \% \mathrm{CI})$ & & & 2684 & & & 2010 & $69.1 \%$ & $-1.06[-1.81,-0.31]$ & & \\
\hline \multicolumn{11}{|c|}{ Heterogeneity: $\mathrm{Chi}^{2}=17.26, \mathrm{df}=7(\mathrm{P}=0.02) ; \mathrm{I}^{2}=59 \%$} \\
\hline \multicolumn{11}{|c|}{ Test for overall effect: $\mathrm{Z}=2.76(\mathrm{P}=0.006)$} \\
\hline Total $(95 \% \mathrm{CI})$ & & & 4586 & & & 3059 & $100.0 \%$ & $-1.06[-1.68,-0.43]$ & 1 & \\
\hline \multicolumn{11}{|c|}{ Heterogeneity: $\mathrm{Chi}^{2}=20.93, \mathrm{df}=11(\mathrm{P}=0.03) ; \mathrm{I}^{2}=47 \%$} \\
\hline \multicolumn{9}{|c|}{ Test for overall effect: $\mathrm{Z}=3.32(\mathrm{P}=0.0009)$} & 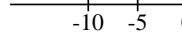 & 51 \\
\hline \multicolumn{9}{|c|}{ Test for subgroup differences: $\mathrm{Chi}^{2}=1.03, \mathrm{df}=2(\mathrm{P}=0.60), \mathrm{I}^{2}=0 \%$} & Favours PDE4i & Favour \\
\hline
\end{tabular}

Analysis 1.5. Comparison 1: $\mathrm{PDE}_{4}$ inhibitor versus placebo (2020 update), Outcome 5: SGRQ symptom score

\begin{tabular}{|c|c|c|c|c|c|c|c|c|c|}
\hline \multirow[b]{2}{*}{ Study or Subgroup } & \multicolumn{3}{|c|}{ PDE4i treatment } & \multicolumn{3}{|c|}{ Placebo } & \multirow[b]{2}{*}{ Weight } & \multirow{2}{*}{$\begin{array}{c}\text { Mean Difference } \\
\text { IV, Fixed, 95\% CI }\end{array}$} & \multirow{2}{*}{$\begin{array}{l}\text { Mean Difference } \\
\text { IV, Fixed, 95\% CI }\end{array}$} \\
\hline & Mean & SD & Total & Mean & SD & Total & & & \\
\hline \multicolumn{10}{|l|}{ 1.5.1 Roflumilast } \\
\hline Roflumilast M2-107 & -4.6 & 21.2 & 555 & -3.6 & 18.4 & 280 & $86.1 \%$ & $-1.00[-3.78,1.78]$ & - \\
\hline Subtotal $(95 \%$ CI) & & & 555 & & & 280 & $86.1 \%$ & $-1.00[-3.78,1.78]$ & \\
\hline \multicolumn{10}{|c|}{ Heterogeneity: Not applicable } \\
\hline \multicolumn{10}{|c|}{ Test for overall effect: $\mathrm{Z}=0.70(\mathrm{P}=0.48)$} \\
\hline \multicolumn{10}{|l|}{ 1.5.2 Cilomilast } \\
\hline Compton 2001 & -7.2 & 25.9 & 107 & -2.4 & 25.7 & 106 & $13.9 \%$ & $-4.80[-11.73,2.13]$ & - \\
\hline Subtotal $(95 \%$ CI $)$ & & & 107 & & & 106 & $13.9 \%$ & $-4.80[-11.73,2.13]$ & \\
\hline \multicolumn{10}{|c|}{ Heterogeneity: Not applicable } \\
\hline \multicolumn{10}{|c|}{ Test for overall effect: $\mathrm{Z}=1.36(\mathrm{P}=0.17)$} \\
\hline Total $(95 \%$ CI $)$ & & & 662 & & & 386 & $100.0 \%$ & $-1.53[-4.11,1.06]$ & \\
\hline \multicolumn{10}{|c|}{ Heterogeneity: $\mathrm{Chi}^{2}=0.99, \mathrm{df}=1(\mathrm{P}=0.32) ; \mathrm{I}^{2}=0 \%$} \\
\hline \multicolumn{9}{|c|}{ Test for overall effect: $\mathrm{Z}=1.16(\mathrm{P}=0.25)$} & $\begin{array}{cc}1 & 1 \\
-10 & -5\end{array}$ \\
\hline \multicolumn{9}{|c|}{ Test for subgroup differences: $\mathrm{Chi}^{2}=0.99, \mathrm{df}=1(\mathrm{P}=0.32), \mathrm{I}^{2}=0 \%$} & Favours PDE4i \\
\hline
\end{tabular}


Analysis 1.6. Comparison 1: $\mathrm{PDE}_{4}$ inhibitor versus placebo (2020 update), Outcome 6: Number of participants with 1 or more exacerbations (by drug)

\begin{tabular}{|c|c|c|c|c|c|c|c|c|}
\hline \multirow[b]{2}{*}{ Study or Subgroup } & \multicolumn{2}{|c|}{ PDE4i treatment } & \multicolumn{2}{|c|}{ Placebo } & \multirow[b]{2}{*}{ Weight } & \multirow{2}{*}{$\begin{array}{c}\text { Odds Ratio } \\
\text { M-H, Fixed, 95\% CI }\end{array}$} & \multirow{2}{*}{\multicolumn{2}{|c|}{$\begin{array}{c}\text { Odds Ratio } \\
\text { M-H, Fixed, 95\% CI }\end{array}$}} \\
\hline & Events & Total & Events & Total & & & & \\
\hline \multicolumn{9}{|l|}{ 1.6.1 Roflumilast $500 \mu \mathrm{g}$} \\
\hline Liu 2018 (1) & 5 & 60 & 7 & 60 & $0.3 \%$ & $0.69[0.21,2.30]$ & $\longrightarrow$ & - \\
\hline RO-2455-301-RD (ACROSS) & 12 & 313 & 7 & 313 & $0.3 \%$ & $1.74[0.68,4.49]$ & & \\
\hline RO-2455-402-RD (ROBERT) (1) & 6 & 79 & 9 & 79 & $0.4 \%$ & $0.64[0.22,1.89]$ & $\longrightarrow$ & - \\
\hline RO-2455-404-RD (REACT) & 380 & 969 & 432 & 966 & $12.5 \%$ & $0.80[0.67,0.96]$ & & \\
\hline Roflumilast FK1 101 & 19 & 169 & 25 & 172 & $1.0 \%$ & $0.74[0.39,1.41]$ & & \\
\hline Roflumilast IN-108 & 3 & 47 & 3 & 25 & $0.2 \%$ & $0.50[0.09,2.68]$ & & - \\
\hline Roflumilast JP-706 & 25 & 204 & 16 & 191 & $0.7 \%$ & $1.53[0.79,2.96]$ & & - \\
\hline Roflumilast M2-107 & 157 & 555 & 97 & 280 & $4.4 \%$ & $0.74[0.55,1.01]$ & $\rightarrow$ & \\
\hline Roflumilast M2-111+M2-112 & 569 & 1327 & 652 & 1359 & $17.5 \%$ & $0.81[0.70,0.95]$ & 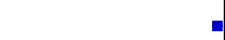 & \\
\hline Roflumilast M2-119 & 22 & 203 & 23 & 207 & $1.0 \%$ & $0.97[0.52,1.81]$ & $\rightarrow$ & - \\
\hline Roflumilast M2-124 & 70 & 769 & 82 & 755 & $3.6 \%$ & $0.82[0.59,1.15]$ & $\rightarrow$ & \\
\hline Roflumilast M2-125 & 87 & 778 & 122 & 790 & $5.1 \%$ & $0.69[0.51,0.93]$ & - & \\
\hline Roflumilast M2-127 & 74 & 466 & 111 & 467 & $4.4 \%$ & $0.61[0.44,0.84]$ & $\rightarrow$ & \\
\hline Roflumilast M2-128 & 58 & 374 & 67 & 369 & $2.7 \%$ & $0.83[0.56,1.22]$ & $\rightarrow$ & \\
\hline Roflumilast ROF-MD-07(RE2SPOND) & 539 & 1178 & 605 & 1174 & $15.6 \%$ & $0.79[0.67,0.93]$ &. & \\
\hline Urban 2018 (ELASTIC) (2) & 5 & 40 & 1 & 40 & $0.0 \%$ & $5.57[0.62,50.03]$ & -1 & \\
\hline Subtotal $(95 \%$ CI $)$ & & 7531 & & 7247 & $69.8 \%$ & $0.79[0.73,0.86]$ & & \\
\hline Total events: & 2031 & & 2259 & & & & & \\
\hline \multicolumn{9}{|c|}{ Heterogeneity: $\mathrm{Chi}^{2}=14.27, \mathrm{df}=15(\mathrm{P}=0.51) ; \mathrm{I}^{2}=0 \%$} \\
\hline \multicolumn{9}{|c|}{ Test for overall effect: $\mathrm{Z}=5.91(\mathrm{P}<0.00001)$} \\
\hline \multicolumn{9}{|l|}{ 1.6.2 Cilomilast } \\
\hline Cilomilast 039 & 95 & 431 & 76 & 216 & $3.8 \%$ & $0.52[0.36,0.75]$ & - & \\
\hline Cilomilast 042 & 176 & 474 & 83 & 226 & $3.4 \%$ & $1.02[0.73,1.41]$ & & \\
\hline Cilomilast 076 & 5 & 29 & 4 & 30 & $0.2 \%$ & $1.35[0.33,5.64]$ & $\longrightarrow$ & \\
\hline Cilomilast 091 & 151 & 469 & 107 & 242 & $4.6 \%$ & $0.60[0.44,0.82]$ & - & \\
\hline Cilomilast 111 & 15 & 79 & 15 & 77 & $0.6 \%$ & $0.97[0.44,2.15]$ & $\rightarrow$ & - \\
\hline Cilomilast 121 & 297 & 678 & 178 & 340 & $6.3 \%$ & $0.71[0.55,0.92]$ & - & \\
\hline Cilomilast 156 & 114 & 418 & 125 & 407 & $4.4 \%$ & $0.85[0.63,1.14]$ & - & \\
\hline Cilomilast 157 & 191 & 455 & 209 & 452 & $5.8 \%$ & $0.84[0.65,1.09]$ & $\rightarrow$ & \\
\hline Cilomilast 168 & 28 & 203 & 18 & 103 & $1.0 \%$ & $0.76[0.40,1.44]$ & $\rightarrow$ & \\
\hline Cilomilast 180 & 3 & 97 & 6 & 102 & $0.3 \%$ & $0.51[0.12,2.10]$ & 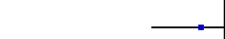 & - \\
\hline Subtotal (95\% CI) & & 3333 & & 2195 & $30.2 \%$ & $0.76[0.67,0.85]$ & 1 & \\
\hline Total events: & 1075 & & 821 & & & & & \\
\hline \multicolumn{9}{|c|}{ Heterogeneity: $\mathrm{Chi}^{2}=12.00, \mathrm{df}=9(\mathrm{P}=0.21) ; \mathrm{I}^{2}=25 \%$} \\
\hline \multicolumn{9}{|c|}{ Test for overall effect: $\mathrm{Z}=4.64(\mathrm{P}<0.00001)$} \\
\hline \multicolumn{9}{|l|}{ 1.6.3 Tetomilast $50 \mu \mathrm{g}$} \\
\hline NCT00874497 (EMPHASIS) (3) & 4 & 48 & 1 & 28 & $0.1 \%$ & $2.45[0.26,23.13]$ & & \\
\hline Subtotal $(95 \%$ CI $)$ & & 48 & & 28 & $0.1 \%$ & $2.45[0.26,23.13]$ & & \\
\hline Total events: & 4 & & 1 & & & & & \\
\hline \multicolumn{9}{|l|}{ Heterogeneity: Not applicable } \\
\hline \multicolumn{9}{|l|}{ Test for overall effect: $\mathrm{Z}=0.78(\mathrm{P}=0.43)$} \\
\hline Total $(95 \%$ CI $)$ & & 10912 & & 9470 & $100.0 \%$ & $0.78[0.73,0.84]$ & & \\
\hline Total events: & 3110 & & 3081 & & & & & \\
\hline Heterogeneity: $\mathrm{Chi}^{2}=27.71, \mathrm{df}=26(\mathrm{P}=$ & $37) ; I^{2}=6 \%$ & & & & & & $0.005 \quad 0.1$ & 10 \\
\hline Test for overall effect: $\mathrm{Z}=7.45(\mathrm{P}<0.0$ & & & & & & & Favours PDE4i & Favours \\
\hline
\end{tabular}

Footnotes

(1) New study data added 2019

(2) New data added 2019

(3) New data 2019: level 2 or more; requiring physician visit or admission to hospital 
Analysis 1.7. Comparison 1: $\mathrm{PDE}_{4}$ inhibitor versus placebo (2020 update), Outcome 7: Exacerbation rate (inverse variance)

Other

Other

Study or Subgroup

$\log [$ Other $] \quad$ SE $\quad$ Weight $\quad$ IV, Fixed, 95\% CI

IV, Fixed, $95 \%$ CI

1.7.1 Roflumilast

RO-2455-404-RD (REACT)

Roflumilast M2-111

Roflumilast M2-112

Roflumilast M2-124

Roflumilast M2-125

Roflumilast M2-127

Roflumilast M2-128

Roflumilast ROF-MD-07(RE2SPOND)

Subtotal (95\% CI)

Heterogeneity: $\mathrm{Chi}^{2}=2.71, \mathrm{df}=7(\mathrm{P}=0.91) ; \mathrm{I}^{2}=0 \%$

Test for overall effect: $\mathrm{Z}=4.64(\mathrm{P}<0.00001)$

\subsubsection{Cilomilast}

Cilomilast 157

Subtotal (95\% CI)

$-0.0473$

0.1057

$7.3 \%$

$0.95[0.78,1.17]$

$\mathbf{7 . 3 \%} \quad 0.95[0.78,1.17]$

Test for overall effect: $\mathrm{Z}=0.45(\mathrm{P}=0.65)$

Total (95\% CI)

Heterogeneity: $\mathrm{Chi}^{2}=3.39$, df $=8(\mathrm{P}=0.91) ; \mathrm{I}^{2}=0 \%$

Test for overall effect: $\mathrm{Z}=4.59(\mathrm{P}<0.00001)$

Test for subgroup differences: $\mathrm{Chi}^{2}=0.68, \mathrm{df}=1(\mathrm{P}=0.41), \mathrm{I}^{2}=0 \%$

$100.0 \% \quad 0.88[0.83,0.93]$

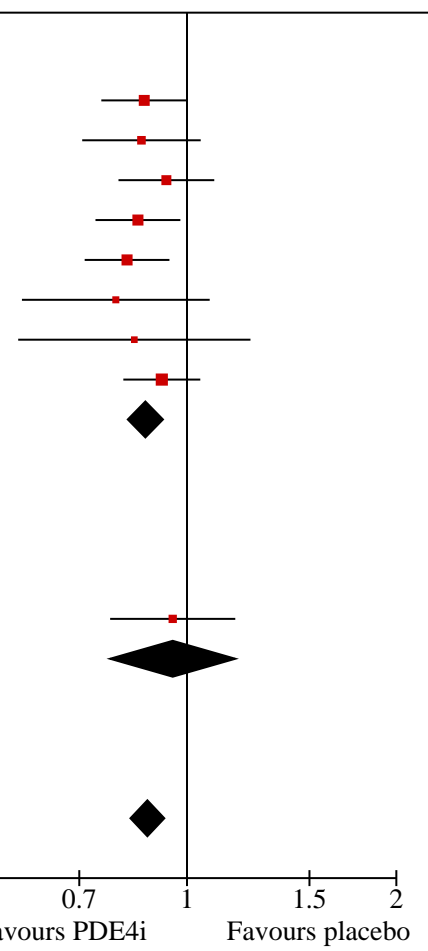

Analysis 1.8. Comparison 1: $\mathrm{PDE}_{4}$ inhibitor versus placebo (2020 update), Outcome 8: Borg Scale

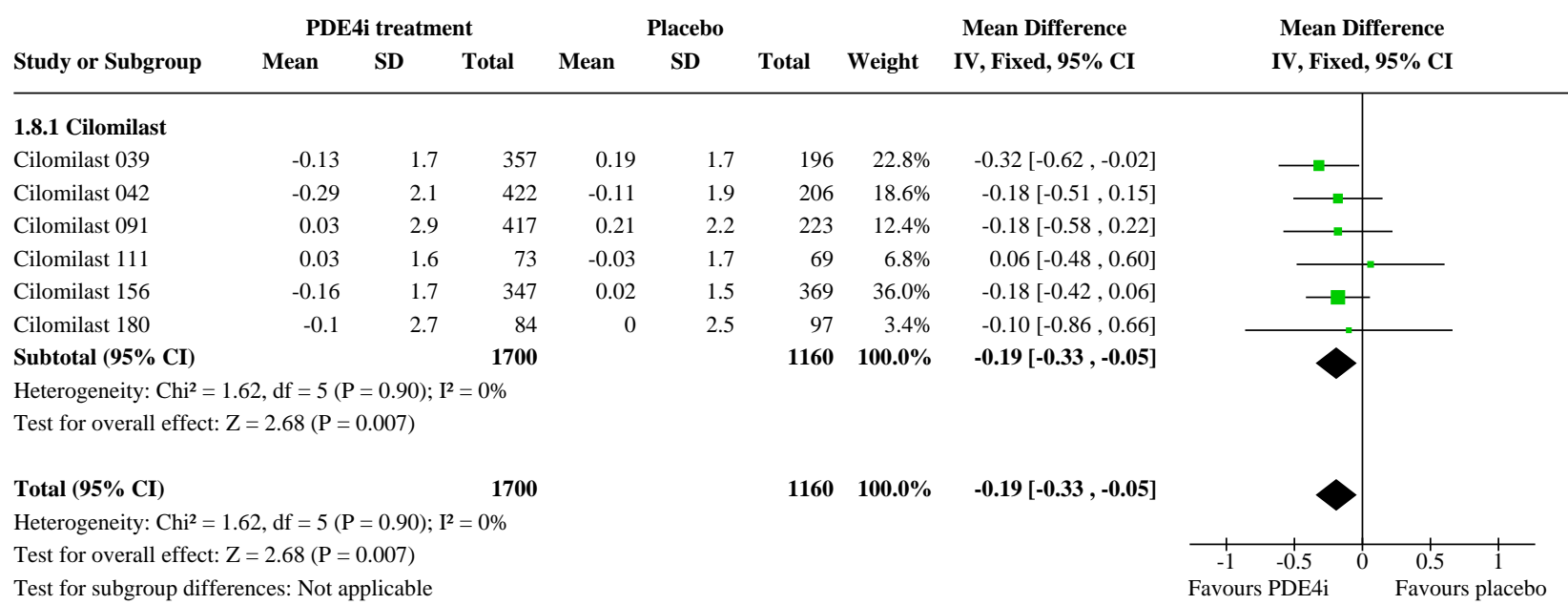


Analysis 1.9. Comparison 1: $\mathrm{PDE}_{4}$ inhibitor versus placebo (2020 update), Outcome 9: Shortness of Breath Questionnaire

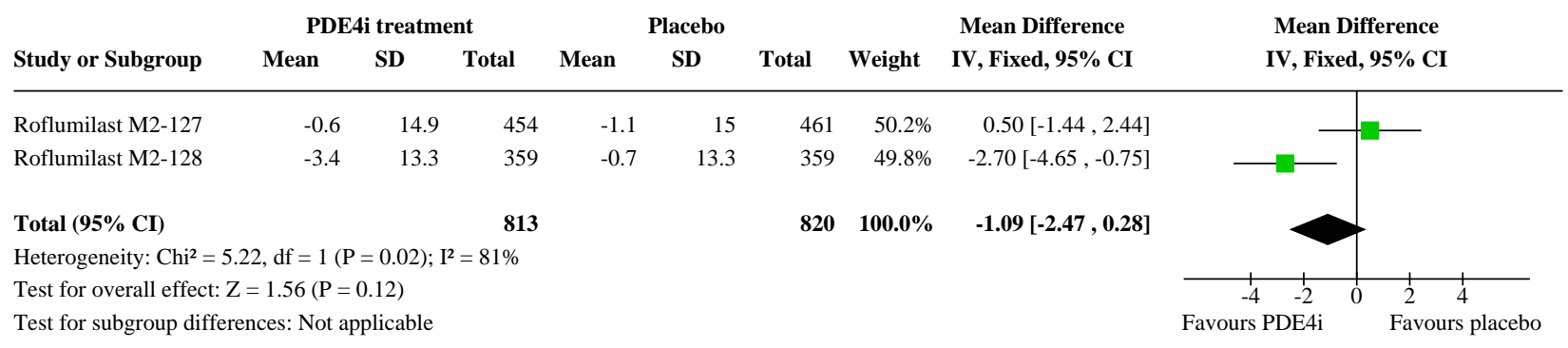

Analysis 1.10. Comparison 1: $\mathrm{PDE}_{4}$ inhibitor versus placebo (2020 update), Outcome 10: Summary symptom score

\begin{tabular}{|c|c|c|c|c|c|c|c|c|c|}
\hline \multirow[b]{2}{*}{ Study or Subgroup } & \multicolumn{3}{|c|}{ PDE4i treatment } & \multicolumn{3}{|c|}{ Placebo } & \multicolumn{2}{|r|}{ Std. Mean Difference } & \multirow{2}{*}{$\begin{array}{l}\text { Std. Mean Difference } \\
\text { IV, Fixed, 95\% CI }\end{array}$} \\
\hline & Mean & SD & Total & Mean & SD & Total & Weight & IV, Fixed, 95\% CI & \\
\hline \multicolumn{10}{|l|}{ 1.10.1 Roflumilast } \\
\hline RO-2455-404-RD (REACT) & -1.27 & 4.8436 & 969 & -0.985 & 4.718 & 966 & $32.3 \%$ & $-0.06[-0.15,0.03]$ & 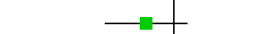 \\
\hline Roflumilast ROF-MD-07(RE2SPOND) & 0 & 4.3302 & 1178 & -0.06 & 4.3302 & 1174 & $39.3 \%$ & $0.01[-0.07,0.09]$ & \\
\hline Subtotal $(95 \%$ CI $)$ & & & 2147 & & & 2140 & $71.6 \%$ & $-0.02[-0.08,0.04]$ & \\
\hline \multicolumn{10}{|c|}{ Heterogeneity: $\mathrm{Chi}^{2}=1.43, \mathrm{df}=1(\mathrm{P}=0.23) ; \mathrm{I}^{2}=30 \%$} \\
\hline \multicolumn{10}{|c|}{ Test for overall effect: $Z=0.63(P=0.53)$} \\
\hline \multicolumn{10}{|l|}{ 1.10.2 Cilomilast } \\
\hline Cilomilast 039 & -0.21 & 1.8 & 382 & -0.12 & 1.7 & 202 & $8.8 \%$ & $-0.05[-0.22,0.12]$ & \\
\hline Cilomilast 042 & -0.41 & 2.3 & 435 & -0.59 & 1.9 & 212 & $9.5 \%$ & $0.08[-0.08,0.25]$ & \\
\hline Cilomilast 091 & -0.3 & 2.7 & 437 & 0.04 & 2.3 & 231 & $10.1 \%$ & $-0.13[-0.29,0.03]$ & \\
\hline Subtotal $(95 \% \mathrm{CI})$ & & & 1254 & & & 645 & $28.4 \%$ & $-0.04[-0.13,0.06]$ & \\
\hline \multicolumn{10}{|c|}{ Heterogeneity: $\mathrm{Ch}^{2}=3.43, \mathrm{df}=2(\mathrm{P}=0.18) ; \mathrm{I}^{2}=42 \%$} \\
\hline \multicolumn{10}{|c|}{ Test for overall effect: $\mathrm{Z}=0.72(\mathrm{P}=0.47)$} \\
\hline Total $(95 \% \mathrm{CI})$ & & & 3401 & & & 2785 & $100.0 \%$ & $-0.02[-0.07,0.03]$ & \\
\hline \multicolumn{10}{|c|}{ Heterogeneity: $\mathrm{Chi}^{2}=4.93, \mathrm{df}=4(\mathrm{P}=0.29) ; \mathrm{I}^{2}=19 \%$} \\
\hline $\begin{array}{l}\text { Test for overall effect: } \mathrm{Z}=0.92(\mathrm{P}=0.36) \\
\text { Test for subgroup differences: } \mathrm{Chi}^{2}=0.08\end{array}$ & $\mathrm{df}=1(\mathrm{P}=\mathrm{c}$ & 78) $\mathrm{I}^{2}=$ & & & & & & & $\begin{array}{r}-0.2 \quad-0.1 \\
\text { Favours PDE4i }\end{array}$ \\
\hline
\end{tabular}


Analysis 1.11. Comparison 1: $\mathrm{PDE}_{4}$ inhibitor versus placebo (2020 update), Outcome 11: Breathlessness Cough and Sputum Scale (BCSS) (tetomilast 50 $\mu \mathrm{g}$ )

\begin{tabular}{|c|c|c|c|c|c|c|c|}
\hline & \multicolumn{2}{|c|}{ Roflumilast } & \multicolumn{2}{|c|}{ Placebo } & \multicolumn{2}{|r|}{ Mean Difference } & Mean Difference \\
\hline Study or Subgroup & Mean & SD & Mean & Total & Weight & IV, Fixed, 95\% CI & IV, Fixed, 95\% CI \\
\hline
\end{tabular}

1.11.1 Breathlessness

NCT00874497 (EMPHASIS)

0.6

$\begin{array}{lll}13 & 0.2 & 0.95\end{array}$

$9 \quad 100.0 \%$

$-0.07[-0.77,0.63]$

Subtotal (95\% CI)

$\begin{array}{lll}0.13 & 0.6 & 13\end{array}$

13

$9 \quad \mathbf{1 0 0 . 0 \%}$

$-0.07[-0.77,0.63]$

Test for overall effect: $\mathrm{Z}=0.20(\mathrm{P}=0.84)$

1.11.2 Cough

NCT00874497 (EMPHASIS)

0.1

0.4

$\begin{array}{lll}13 & -0.13 \quad 1.13\end{array}$

$9 \quad 100.0 \%$

$0.23[-0.54,1.00]$

Subtotal (95\% CI)

$13 \quad 9 \quad 100.0 \%$

$0.23[-0.54,1.00]$

Heterogeneity: Not applicable

Test for overall effect: $Z=0.59(P=0.56)$

1.11.3 Sputum

NCT00874497 (EMPHASIS)

0.15

Subtotal (95\% CI)

Heterogeneity: Not applicable $-0.16[-0.97,0.65]$

Test for overall effect: $Z=0.39(P=0.70)$

Test for subgroup differences: $\mathrm{Chi}^{2}=0.53, \mathrm{df}=2(\mathrm{P}=0.77), \mathrm{I}^{2}=0 \%$

Analysis 1.12. Comparison 1: $\mathrm{PDE}_{4}$ inhibitor versus placebo (2020 update), Outcome 12: 6-minute walk test

\begin{tabular}{|c|c|c|c|c|c|c|c|c|c|}
\hline \multirow[b]{2}{*}{ Study or Subgroup } & \multicolumn{3}{|c|}{ PDE4i treatment } & \multicolumn{3}{|c|}{ Placebo } & \multirow[b]{2}{*}{ Weight } & \multirow{2}{*}{$\begin{array}{c}\text { Mean Difference } \\
\text { IV, Fixed, 95\% CI }\end{array}$} & \multirow{2}{*}{$\begin{array}{c}\text { Mean Difference } \\
\text { IV, Fixed, 95\% CI }\end{array}$} \\
\hline & Mean & SD & Total & Mean & SD & Total & & & \\
\hline \multicolumn{10}{|l|}{ 1.12.1 Roflumilast } \\
\hline Roflumilast DAL-MD-01 & 0 & 142 & 11 & 0 & 293 & 16 & $0.3 \%$ & $0.00[-166.29,166.29]$ & \\
\hline Urban 2018 (ELASTIC) (1) & 59.2 & 127.8862 & 40 & 0.69 & 126.2916 & 40 & $2.8 \%$ & $58.51[2.81,114.21]$ & \\
\hline Subtotal $(95 \% \mathrm{CI})$ & & & 51 & & & 56 & $3.1 \%$ & $52.61[-0.21,105.42]$ & \\
\hline \multicolumn{10}{|c|}{ Heterogeneity: $\mathrm{Chi}^{2}=0.43, \mathrm{df}=1(\mathrm{P}=0.51) ; \mathrm{I}^{2}=0 \%$} \\
\hline \multicolumn{10}{|c|}{ Test for overall effect: $\mathrm{Z}=1.95(\mathrm{P}=0.05)$} \\
\hline \multicolumn{10}{|l|}{ 1.12.2 Cilomilast } \\
\hline Cilomilast 039 & 16.1 & 79 & 356 & 9 & 77 & 194 & $47.3 \%$ & $7.10[-6.49,20.69]$ & 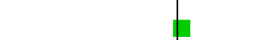 \\
\hline Cilomilast 042 & 5.8 & 125 & 423 & 22.2 & 109 & 207 & $24.1 \%$ & $-16.40[-35.44,2.64]$ & $-=$ \\
\hline Cilomilast 091 & 5.4 & 178 & 408 & 4.6 & 139 & 218 & $13.7 \%$ & $0.80[-24.47,26.07]$ & - \\
\hline Cilomilast 111 & 16.1 & 82 & 73 & -3.7 & 83 & 69 & $11.8 \%$ & $19.80[-7.35,46.95]$ & - \\
\hline Subtotal $(95 \%$ CI $)$ & & & 1260 & & & 688 & $96.9 \%$ & $1.92[-7.58,11.41]$ & $\gamma$ \\
\hline \multicolumn{10}{|c|}{ Heterogeneity: $\mathrm{Chi}^{2}=5.79, \mathrm{df}=3(\mathrm{P}=0.12) ; \mathrm{I}^{2}=48 \%$} \\
\hline \multicolumn{10}{|c|}{ Test for overall effect: $Z=0.40(P=0.69)$} \\
\hline Total $(95 \%$ CI $)$ & & & 1311 & & & 744 & $100.0 \%$ & $3.50[-5.84,12.85]$ & 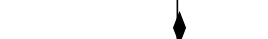 \\
\hline \multicolumn{10}{|c|}{ Heterogeneity: $\mathrm{Chi}^{2}=9.64, \mathrm{df}=5(\mathrm{P}=0.09) ; \mathrm{I}^{2}=48 \%$} \\
\hline \multicolumn{9}{|c|}{ Test for overall effect: $\mathrm{Z}=0.74(\mathrm{P}=0.46)$} & $-200-100$ \\
\hline Test for subgroup difference & $\mathrm{Chi}^{2}=3$. & $3, \mathrm{df}=1(\mathrm{P}$ & $=0.06), \mathrm{I}^{2}$ & $=70.8 \%$ & & & & & Favours placebo \\
\hline
\end{tabular}

Footnotes

(1) New data 2019 


\section{Analysis 1.13. Comparison 1: $\mathrm{PDE}_{4}$ inhibitor versus placebo (2020 update), Outcome 13: Number of participants experiencing an adverse event}

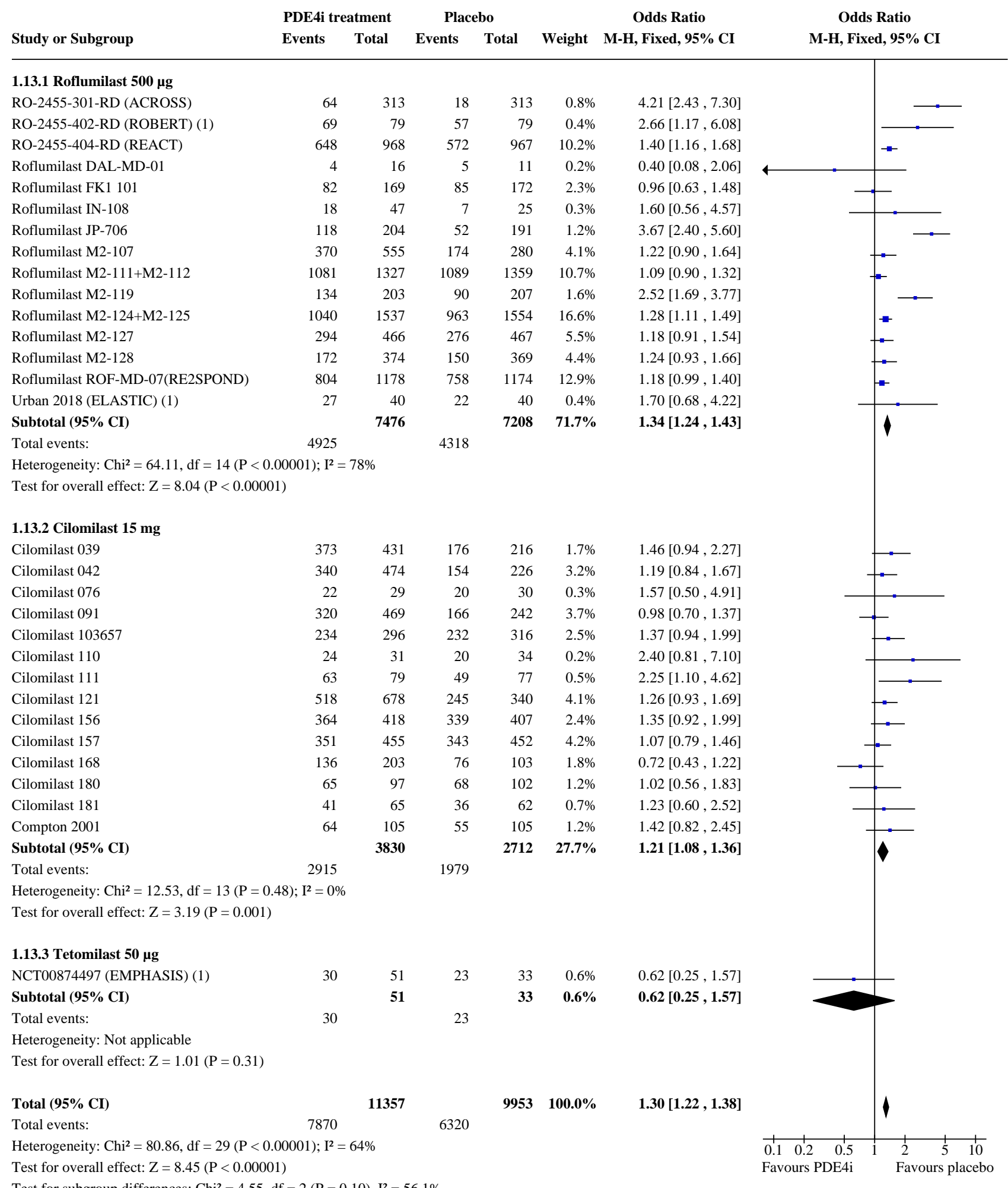

Footnotes

(1) New study data added 2019 
Analysis 1.14. Comparison 1: $\mathrm{PDE}_{4}$ inhibitor versus placebo (2020 update), Outcome 14: Number of participants experiencing an adverse event (roflumilast $500 \mu \mathrm{g} v \mathrm{~s} 250 \mathrm{\mu g}$ )

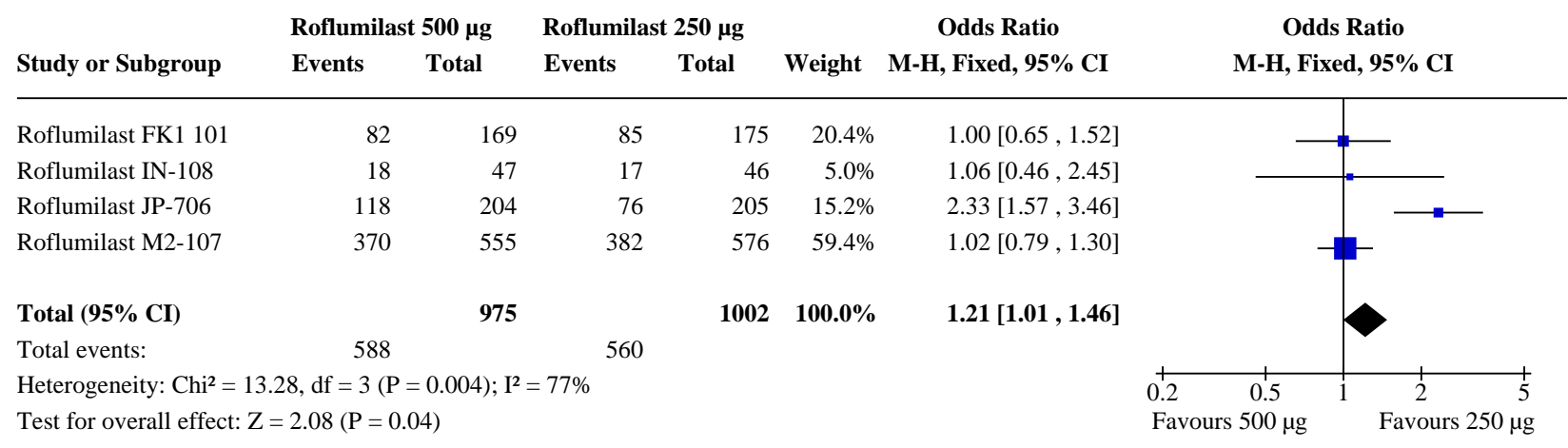


Analysis 1.15. Comparison 1: $\mathrm{PDE}_{4}$ inhibitor versus placebo (2020 update), Outcome 15: Diarrhoea

\begin{tabular}{|c|c|c|c|c|c|c|}
\hline \multirow[b]{2}{*}{ Study or Subgroup } & \multicolumn{2}{|c|}{ PDE4i treatment } & \multicolumn{2}{|c|}{ Placebo } & \multirow[b]{2}{*}{ Weight } & \multirow{2}{*}{$\begin{array}{c}\text { Odds Ratio } \\
\text { M-H, Fixed, 95\% CI }\end{array}$} \\
\hline & Events & Total & Events & Total & & \\
\hline \multicolumn{7}{|l|}{ 1.15.1 Roflumilast } \\
\hline Liu 2018 (1) & 8 & 60 & 6 & 60 & $1.5 \%$ & $1.38[0.45,4.26]$ \\
\hline RO-2455-301-RD (ACROSS) & 19 & 313 & 3 & 313 & $0.8 \%$ & $6.68[1.96,22.80]$ \\
\hline RO-2455-402-RD (ROBERT) (1) & 11 & 79 & 4 & 79 & $1.0 \%$ & $3.03[0.92,9.98]$ \\
\hline RO-2455-404-RD (REACT) & 99 & 968 & 35 & 967 & $9.3 \%$ & $3.03[2.04,4.51]$ \\
\hline Roflumilast DAL-MD-01 & 1 & 11 & 0 & 16 & $0.1 \%$ & $4.71[0.18,126.90]$ \\
\hline Roflumilast M2-107 & 50 & 555 & 6 & 280 & $2.1 \%$ & $4.52[1.91,10.68]$ \\
\hline Roflumilast M2-111+M2-112 & 161 & 1327 & 39 & 1359 & $10.0 \%$ & $4.67[3.27,6.69]$ \\
\hline Roflumilast M2-119 & 23 & 203 & 1 & 207 & $0.3 \%$ & $26.32[3.52,196.86]$ \\
\hline Roflumilast M2-124 & 63 & 769 & 26 & 755 & $7.1 \%$ & $2.50[1.57,4.00]$ \\
\hline Roflumilast M2-125 & 67 & 778 & 23 & 790 & $6.2 \%$ & $3.14[1.94,5.10]$ \\
\hline Roflumilast M2-127 & 38 & 466 & 16 & 467 & $4.3 \%$ & $2.50[1.37,4.56]$ \\
\hline Roflumilast M2-128 & 33 & 374 & 2 & 369 & $0.5 \%$ & $17.76[4.23,74.57]$ \\
\hline Roflumilast ROF-MD-07(RE2SPOND) & 119 & 1178 & 38 & 1174 & $10.1 \%$ & $3.36[2.31,4.89]$ \\
\hline Urban 2018 (ELASTIC) (1) & 3 & 40 & 0 & 40 & $0.1 \%$ & $7.56[0.38,151.28]$ \\
\hline Subtotal $(95 \%$ CI) & & 7121 & & 6876 & $53.6 \%$ & $3.65[3.10,4.28]$ \\
\hline
\end{tabular}

Total events:

Heterogeneity: $\mathrm{Chi}^{2}=19.96, \mathrm{df}=13(\mathrm{P}=0.10) ; \mathrm{I}^{2}=35 \%$

Test for overall effect: $\mathrm{Z}=15.69(\mathrm{P}<0.00001)$

1.15.2 Cilomilast
Cilomilast 039
Cilomilast 042
Cilomilast 076
Cilomilast 091
Cilomilast 103657
Cilomilast 110
Cilomilast 111
Cilomilast 121
Cilomilast 156
Cilomilast 157
Cilomilast 168
Cilomilast 180
Cilomilast 181
Compton 2001
Subtotal $(95 \%$ CI)
Total events:

Total events: 509

Heterogeneity: $\mathrm{Chi}^{2}=4.44, \mathrm{df}=13(\mathrm{P}=0.99) ; \mathrm{I}^{2}=0 \%$

Test for overall effect: $\mathrm{Z}=9.40(\mathrm{P}<0.00001)$

1.15.3 Tetomilast

NCT00874497 (EMPHASIS) (2)

Subtotal $(95 \%$ CI $)$

Total events:

Heterogeneity: Not applicable

Test for overall effect: $\mathrm{Z}=0.60(\mathrm{P}=0.55)$

\section{Total (95\% CI)}

Total events:

Heterogeneity: $\mathrm{Chi}^{2}=31.97, \mathrm{df}=28(\mathrm{P}=0.28) ; \mathrm{I}^{2}=12 \%$

Test for overall effect: $\mathrm{Z}=18.13(\mathrm{P}<0.00001)$

Test for subgroup differences: $\mathrm{Chi}^{2}=9.92, \mathrm{df}=2(\mathrm{P}=0.007), \mathrm{I}^{2}=79.8 \%$

Footnotes

(1) New data 2019

(2) New study data 2019
$2.21[1.36,3.62]$

$2.38[1.09,5.18]$

$1.70[0.42,6.77]$

$2.58[1.28,5.21]$

$3.01[1.74,5.19]$

$2.37[0.40,13.96]$

$5.31[1.46,19.31]$

$2.58[1.56,4.25]$

$2.01[1.36,2.99]$

$2.64[1.37,5.09]$

$2.19[0.92,5.21]$

$3.38[0.89,12.86]$

$2.50[0.47,13.39]$

$4.83[1.02,22.91]$

2.47 [2.05, 2.98]
Odds Ratio

M-H, Fixed, 95\% CI 
Analysis 1.16. Comparison 1: $\mathrm{PDE}_{4}$ inhibitor versus placebo (2020 update), Outcome 16: Nausea

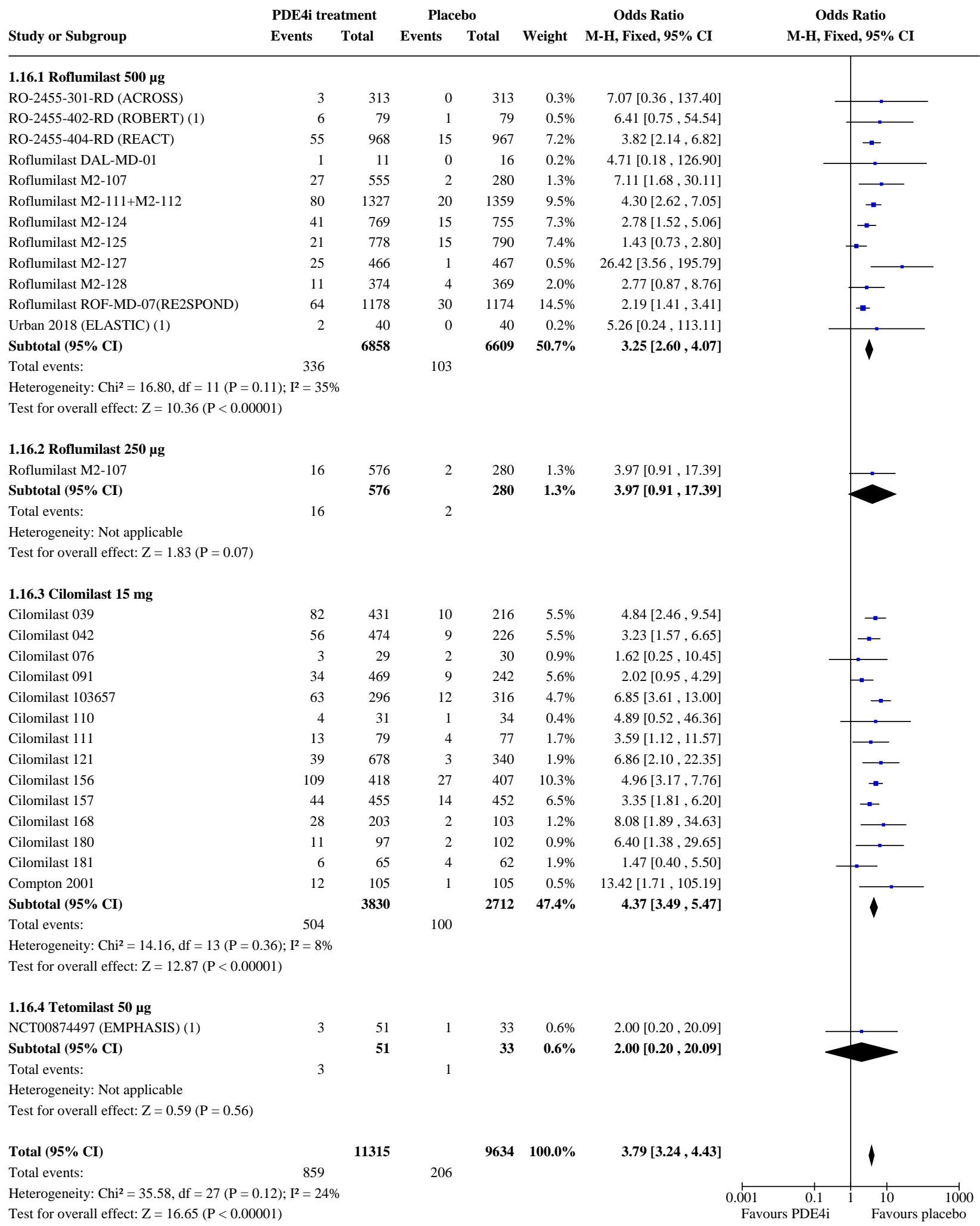

Footnotes 
Analysis 1.16. (Continued)

Footnotes

(1) New data 2019

\section{Analysis 1.17. Comparison 1: $\mathrm{PDE}_{4}$ inhibitor versus placebo (2020 update), Outcome 17: Vomiting}

\begin{tabular}{|c|c|c|c|c|c|c|c|}
\hline \multicolumn{3}{|r|}{ atment } & \multicolumn{2}{|c|}{ Placebo } & \multicolumn{2}{|r|}{ Odds Ratio } & \multirow{2}{*}{$\begin{array}{c}\text { Odds Ratio } \\
\text { M-H, Fixed, 95\% CI }\end{array}$} \\
\hline & Events & Total & Events & Total & Weight & M-H, Fixed, 95\% CI & \\
\hline
\end{tabular}

\subsubsection{Roflumilast}

RO-2455-402-RD (ROBERT) (1)

Roflumilast M2-107

Subtotal (95\% CI)

79
555
$\mathbf{6 3 4}$

2

$79 \quad 4.7 \%$

$280 \quad 1.7 \%$

$2.60[0.49,13.83]$

Subtotal $(95 \%$ CI)

$359 \quad 6.3 \%$

$1.52[0.06,37.37]$

Heterogeneity: $\mathrm{Chi}^{2}=0.09, \mathrm{df}=1(\mathrm{P}=0.77) ; \mathrm{I}^{2}=0 \%$

Test for overall effect: $\mathrm{Z}=1.11(\mathrm{P}=0.27)$

\subsubsection{Cilomilast}

Cilomilast 039

Cilomilast 042

Cilomilast 076

Cilomilast 091

Cilomilast 103657

Cilomilast 156

Cilomilast 157

Cilomilast 168

Cilomilast 180

Cilomilast 181

Subtotal (95\% CI)

Total events:

$\begin{array}{rr}37 & 431 \\ 17 & 474 \\ 4 & 29 \\ 22 & 369 \\ 28 & 296 \\ 33 & 418 \\ 21 & 455 \\ 9 & 203 \\ 4 & 97 \\ 5 & 65 \\ & \mathbf{2 8 3 7}\end{array}$

180

Heterogeneity: $\mathrm{Chi}^{2}=4.95, \mathrm{df}=9(\mathrm{P}=0.84) ; \mathrm{I}^{2}=0 \%$

Test for overall effect: $\mathrm{Z}=7.60(\mathrm{P}<0.00001)$

Total $(95 \%$ CI $)$

3471

Total events:

186

$2515100.0 \%$

$3.95[2.78,5.60]$

Heterogeneity: $\mathrm{Chi}^{2}=5.39, \mathrm{df}=11(\mathrm{P}=0.91) ; \mathrm{I}^{2}=0 \%$

Test for overall effect: $\mathrm{Z}=7.68(\mathrm{P}<0.00001)$

Test for subgroup differences: $\mathrm{Chi}^{2}=0.51, \mathrm{df}=1(\mathrm{P}=0.47), \mathrm{I}^{2}=0 \%$

$\begin{array}{rrr}216 & 18.2 \% & 3.29[1.37,7.91] \\ 226 & 1.6 \% & 17.33[1.04,289.44] \\ 30 & 1.0 \% & 10.76[0.55,209.55] \\ 242 & 2.8 \% & 15.28[2.05,114.12] \\ 316 & 17.5 \% & 4.02[1.80,8.98] \\ 407 & 25.6 \% & 3.09[1.54,6.19] \\ 452 & 19.1 \% & 2.69[1.18,6.13] \\ 103 & 3.2 \% & 4.73[0.59,37.87] \\ 102 & 2.3 \% & 4.34[0.48,39.57] \\ 62 & 2.4 \% & 5.08[0.58,44.81] \\ \mathbf{2 1 5 6} & \mathbf{9 3 . 7 \%} & \mathbf{4 . 0 6}[\mathbf{2 . 8 3}, \mathbf{5 . 8 2}]\end{array}$

Footnotes

(1) New data 2019 
Analysis 1.18. Comparison 1: $\mathrm{PDE}_{4}$ inhibitor versus placebo (2020 update), Outcome 18: Dyspepsia

\begin{tabular}{|c|c|c|c|c|c|c|}
\hline \multirow[b]{2}{*}{ Study or Subgroup } & \multicolumn{2}{|c|}{ PDE4i treatment } & \multicolumn{2}{|c|}{ Placebo } & \multirow[b]{2}{*}{ Weight } & \multirow{2}{*}{$\begin{array}{c}\text { Odds Ratio } \\
\text { M-H, Fixed, } 95 \% \text { CI }\end{array}$} \\
\hline & Events & Total & Events & Total & & \\
\hline \multicolumn{7}{|l|}{ 1.18.1 Roflumilast } \\
\hline RO-2455-301-RD (ACROSS) & 3 & 313 & 0 & 313 & $0.9 \%$ & $7.07[0.36,137.40]$ \\
\hline Subtotal $(95 \%$ CI $)$ & & 313 & & 313 & $0.9 \%$ & $7.07[0.36,137.40]$ \\
\hline Total events: & 3 & & 0 & & & \\
\hline \multicolumn{7}{|l|}{ Heterogeneity: Not applicable } \\
\hline \multicolumn{7}{|c|}{ Test for overall effect: $\mathrm{Z}=1.29(\mathrm{P}=0.20)$} \\
\hline \multicolumn{7}{|l|}{ 1.18.2 Cilomilast } \\
\hline Cilomilast 039 & 42 & 431 & 8 & 216 & $17.0 \%$ & $2.81[1.29,6.09]$ \\
\hline Cilomilast 042 & 29 & 474 & 8 & 226 & $17.9 \%$ & $1.78[0.80,3.95]$ \\
\hline Cilomilast 076 & 5 & 29 & 1 & 30 & $1.4 \%$ & $6.04[0.66,55.30]$ \\
\hline Cilomilast 103657 & 14 & 296 & 5 & 316 & $8.1 \%$ & $3.09[1.10,8.68]$ \\
\hline Cilomilast 110 & 4 & 31 & 0 & 34 & $0.7 \%$ & $11.29[0.58,218.85]$ \\
\hline Cilomilast 111 & 10 & 79 & 2 & 77 & $3.1 \%$ & $5.43[1.15,25.68]$ \\
\hline Cilomilast 121 & 40 & 678 & 4 & 340 & $8.8 \%$ & $5.27[1.87,14.84]$ \\
\hline Cilomilast 156 & 38 & 418 & 10 & 407 & $16.3 \%$ & $3.97[1.95,8.08]$ \\
\hline Cilomilast 157 & 18 & 455 & 6 & 452 & $10.2 \%$ & $3.06[1.20,7.79]$ \\
\hline Cilomilast 168 & 15 & 203 & 6 & 103 & $13.0 \%$ & $1.29[0.49,3.43]$ \\
\hline Cilomilast 180 & 4 & 97 & 1 & 102 & $1.6 \%$ & $4.34[0.48,39.57]$ \\
\hline Cilomilast 181 & 3 & 65 & 0 & 62 & $0.9 \%$ & $7.00[0.35,138.35]$ \\
\hline Subtotal $(95 \%$ CI) & & 3256 & & 2365 & $99.1 \%$ & $3.13[2.30,4.27]$ \\
\hline Total events: & 222 & & 51 & & & \\
\hline
\end{tabular}

Heterogeneity: $\mathrm{Chi}^{2}=8.48, \mathrm{df}=11(\mathrm{P}=0.67) ; \mathrm{I}^{2}=0 \%$

Test for overall effect: $\mathrm{Z}=7.26(\mathrm{P}<0.00001)$

Total $(95 \%$ CI $)$

3569

Total events: 225

$2678 \quad 100.0 \%$

$3.17[2.33,4.30]$

Heterogeneity: $\mathrm{Chi}^{2}=8.80, \mathrm{df}=12(\mathrm{P}=0.72) ; \mathrm{I}^{2}=0 \%$

Test for overall effect: $\mathrm{Z}=7.37(\mathrm{P}<0.00001)$

Test for subgroup differences: $\mathrm{Chi}^{2}=0.29, \mathrm{df}=1(\mathrm{P}=0.59), \mathrm{I}^{2}=0 \%$

\section{Odds Ratio}

M-H, Fixed, $95 \%$ CI 
Analysis 1.19. Comparison 1: $\mathrm{PDE}_{4}$ inhibitor versus placebo (2020 update), Outcome 19: Weight loss

\begin{tabular}{|c|c|c|c|c|c|c|c|c|}
\hline \multirow{2}{*}{ Study or Subgroup } & \multicolumn{2}{|c|}{ PDE4i treatment } & \multicolumn{2}{|c|}{ Placebo } & \multirow{2}{*}{ Weight } & \multirow{2}{*}{$\begin{array}{c}\text { Odds Ratio } \\
\text { M-H, Fixed, 95\% CI }\end{array}$} & \multirow{2}{*}{\multicolumn{2}{|c|}{$\begin{array}{c}\text { Odds Ratio } \\
\text { M-H, Fixed, 95\% CI }\end{array}$}} \\
\hline & Events & Total & Events & Total & & & & \\
\hline \multicolumn{9}{|l|}{ 1.19.1 Roflumilast } \\
\hline Liu 2018 (1) & 4 & 60 & 1 & 60 & $0.7 \%$ & $4.21[0.46,38.86]$ & & \\
\hline RO-2455-404-RD (REACT) & 88 & 968 & 27 & 967 & $18.0 \%$ & $3.48[2.24,5.41]$ & & $\rightarrow$ \\
\hline Roflumilast DAL-MD-01 & 1 & 11 & 0 & 16 & $0.3 \%$ & $4.71[0.18,126.90]$ & & \\
\hline Roflumilast M2-111+M2-112 & 100 & 1327 & 38 & 1359 & $25.4 \%$ & $2.83[1.93,4.15]$ & & $\rightarrow$ \\
\hline Roflumilast M2-119 & 11 & 203 & 1 & 207 & $0.7 \%$ & $11.80[1.51,92.28]$ & & \\
\hline Roflumilast M2-124 & 92 & 769 & 24 & 755 & $15.6 \%$ & $4.14[2.61,6.56]$ & & $\rightarrow$ \\
\hline Roflumilast M2-125 & 65 & 778 & 20 & 790 & $13.3 \%$ & $3.51[2.10,5.85]$ & & $\rightarrow-$ \\
\hline Roflumilast M2-127 & 40 & 466 & 5 & 467 & $3.3 \%$ & $8.68[3.39,22.19]$ & & $\longrightarrow$ \\
\hline Roflumilast M2-128 & 21 & 374 & 2 & 369 & $1.4 \%$ & $10.92[2.54,46.90]$ & & $\longrightarrow$ \\
\hline Roflumilast ROF-MD-07(RE2SPOND) & 91 & 1178 & 28 & 1174 & $18.9 \%$ & $3.43[2.23,5.28]$ & & $\rightarrow$ \\
\hline Urban 2018 (ELASTIC) (1) & 6 & 40 & 0 & 40 & $0.3 \%$ & $15.26[0.83,280.72]$ & & \\
\hline Subtotal $(95 \%$ CI $)$ & & 6174 & & 6204 & $\mathbf{9 7 . 8 \%}$ & $3.80[3.15,4.58]$ & & 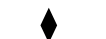 \\
\hline Total events: & 519 & & 146 & & & & & \\
\hline \multicolumn{9}{|c|}{ Heterogeneity: $\mathrm{Chi}^{2}=9.92, \mathrm{df}=10(\mathrm{P}=0.45) ; \mathrm{I}^{2}=0 \%$} \\
\hline \multicolumn{9}{|c|}{ Test for overall effect: $Z=14.00(P<0.00001)$} \\
\hline \multicolumn{9}{|l|}{ 1.19.2 Tetomilast $50 \mu \mathrm{g}$} \\
\hline NCT00874497 (EMPHASIS) (1) & 0 & 51 & 2 & 33 & $2.2 \%$ & $0.12[0.01,2.63]$ & $\longleftarrow$ & \\
\hline Subtotal $(95 \%$ CI $)$ & & 51 & & 33 & $2.2 \%$ & $0.12[0.01,2.63]$ & & \\
\hline Total events: & 0 & & 2 & & & & & \\
\hline \multicolumn{9}{|l|}{ Heterogeneity: Not applicable } \\
\hline \multicolumn{9}{|l|}{ Test for overall effect: $\mathrm{Z}=1.34(\mathrm{P}=0.18)$} \\
\hline Total $(95 \%$ CI $)$ & & 6225 & & 6237 & $100.0 \%$ & $3.72[3.09,4.47]$ & & $\theta$ \\
\hline Total events: & 519 & & 148 & & & & & \\
\hline \multicolumn{7}{|c|}{ Heterogeneity: $\mathrm{Chi}^{2}=14.56, \mathrm{df}=11(\mathrm{P}=0.20) ; \mathrm{I}^{2}=24 \%$} & $0.01 \quad 0.1$ & 10 \\
\hline Test for overall effect: $Z=13.88(P<0$. & & & & & & & Favours PDE4i & Favours \\
\hline
\end{tabular}

Footnotes

(1) New data 
Analysis 1.20. Comparison 1: $\mathrm{PDE}_{4}$ inhibitor versus placebo (2020 update), Outcome 20: Withdrawals due to adverse events

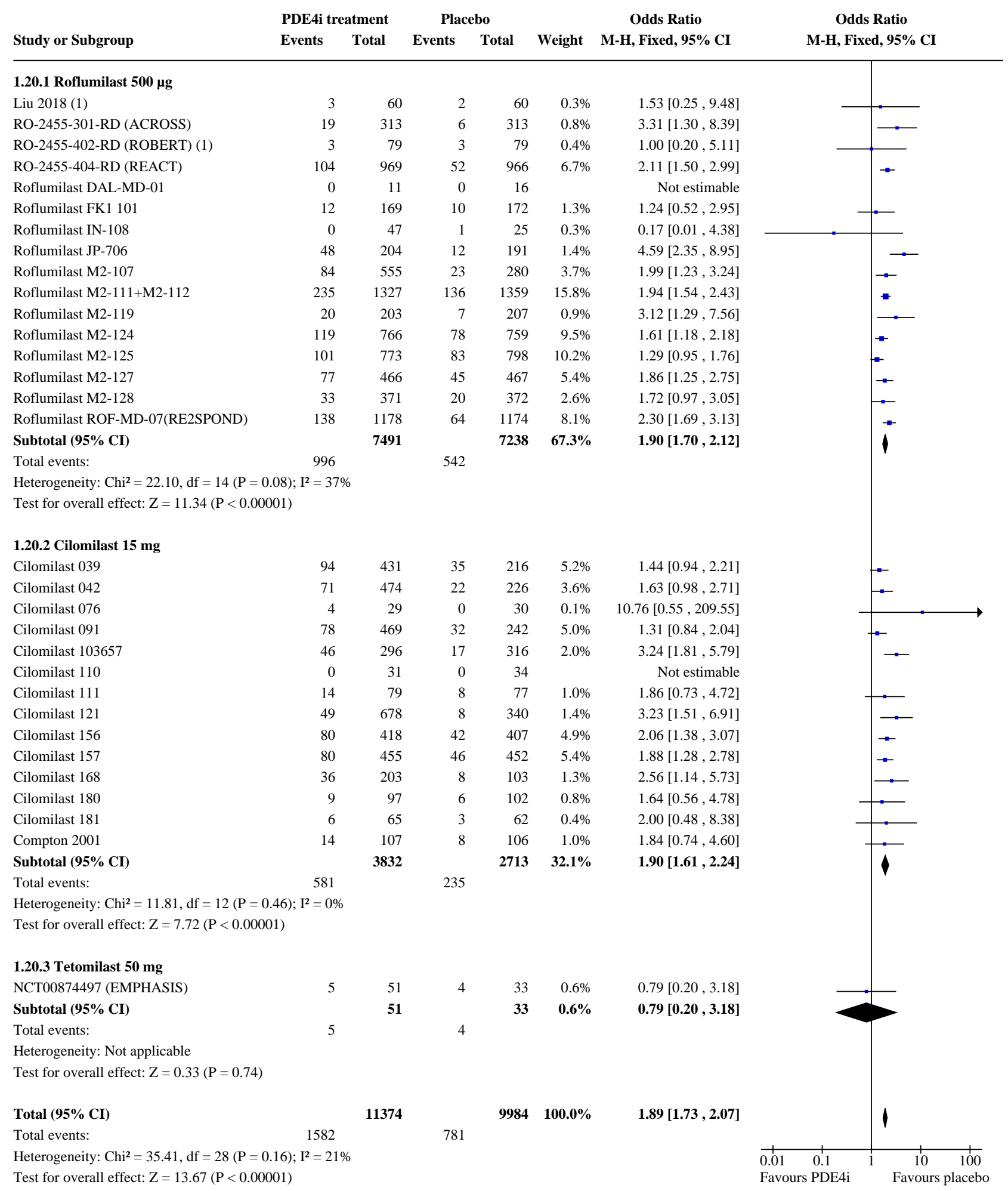

Footnotes

(1) New data added 2019 
Analysis 1.21. Comparison 1: $\mathrm{PDE}_{4}$ inhibitor versus placebo (2020 update), Outcome 21: Headache

\begin{tabular}{|c|c|c|c|c|c|c|}
\hline \multirow[b]{2}{*}{ Study or Subgroup } & \multicolumn{2}{|c|}{ Favours PDE4i } & \multicolumn{2}{|c|}{ placebo } & \multirow[b]{2}{*}{ Weight } & \multirow{2}{*}{$\begin{array}{c}\text { Odds Ratio } \\
\text { M-H, Fixed, 95\% CI }\end{array}$} \\
\hline & Events & Total & Events & Total & & \\
\hline \multicolumn{7}{|l|}{ 1.21.1 Roflumilast $500 \mu \mathrm{g}$} \\
\hline RO-2455-402-RD (ROBERT) & 3 & 79 & 4 & 79 & $1.2 \%$ & $0.74[0.16,3.42]$ \\
\hline RO-2455-404-RD (REACT) & 40 & 968 & 21 & 967 & $6.5 \%$ & $1.94[1.14,3.32]$ \\
\hline Roflumilast FK1 101 & 6 & 169 & 4 & 172 & $1.2 \%$ & $1.55[0.43,5.58]$ \\
\hline Roflumilast M2-107 & 10 & 555 & 1 & 280 & $0.4 \%$ & $5.12[0.65,40.19]$ \\
\hline Roflumilast M2-111+M2-112 & 92 & 1327 & 41 & 1359 & $12.1 \%$ & $2.39[1.64,3.49]$ \\
\hline Roflumilast M2-119 & 7 & 203 & 1 & 207 & $0.3 \%$ & $7.36[0.90,60.34]$ \\
\hline Roflumilast M2-124 & 26 & 769 & 17 & 755 & $5.3 \%$ & $1.52[0.82,2.82]$ \\
\hline Roflumilast M2-125 & 25 & 778 & 8 & 790 & $2.5 \%$ & $3.25[1.45,7.24]$ \\
\hline Roflumilast M2-127 & 14 & 466 & 5 & 467 & $1.6 \%$ & $2.86[1.02,8.01]$ \\
\hline Roflumilast M2-128 & 8 & 374 & 0 & 369 & $0.2 \%$ & $17.14[0.99,298.03]$ \\
\hline Roflumilast ROF-MD-07(RE2SPOND) & 80 & 1178 & 48 & 1174 & $14.4 \%$ & $1.71[1.18,2.47]$ \\
\hline Urban 2018 (ELASTIC) & 2 & 40 & 0 & 40 & $0.2 \%$ & $5.26[0.24,113.11]$ \\
\hline Subtotal $(95 \%$ CI $)$ & & 6906 & & 6659 & $45.7 \%$ & $2.13[1.74,2.59]$ \\
\hline Total events: & 313 & & 150 & & & \\
\hline
\end{tabular}

Heterogeneity: $\mathrm{Chi}^{2}=10.85, \mathrm{df}=11(\mathrm{P}=0.46) ; \mathrm{I}^{2}=0 \%$

Test for overall effect: $\mathrm{Z}=7.46(\mathrm{P}<0.00001)$

\subsubsection{Roflumilast $250 \mu \mathrm{g}$}

Roflumilast FK1 101

Subtotal (95\% CI)

$\begin{array}{ll}172 & 1.3 \% \\ \mathbf{1 7 2} & \mathbf{1 . 3 \%}\end{array}$

$0.98[0.24,3.99]$

Total events:

Heterogeneity: Not applicable

Test for overall effect: $\mathrm{Z}=0.02(\mathrm{P}=0.98)$

\subsubsection{Cilomilast $15 \mathrm{mg}$}

Cilomilast 039

Cilomilast 042

Cilomilast 076

Cilomilast 091

Cilomilast 103657

Cilomilast 156

Cilomilast 157

Cilomilast 168

Cilomilast 180

Cilomilast 181

Compton 2001

Subtotal (95\% CI)

Total events:

Heterogeneity: $\mathrm{Chi}^{2}=8.82, \mathrm{df}=10(\mathrm{P}=0.55) ; \mathrm{I}^{2}=0 \%$

Test for overall effect: $\mathrm{Z}=2.69(\mathrm{P}=0.007)$

Total $(95 \%$ CI)

10123

Total events:

Heterogeneity: $\mathrm{Chi}^{2}=29.69, \mathrm{df}=23(\mathrm{P}=0.16) ; \mathrm{I}^{2}=23 \%$

Test for overall effect: $\mathrm{Z}=7.28(\mathrm{P}<0.00001)$

Test for subgroup differences: $\mathrm{Chi}^{2}=11.37, \mathrm{df}=2(\mathrm{P}=0.003), \mathrm{I}^{2}=82.4 \%$ 324

$\begin{array}{rrr}216 & 5.5 \% & 1.32[0.69,2.49] \\ 226 & 5.5 \% & 1.55[0.83,2.89] \\ 30 & 0.3 \% & 6.04[0.66,55.30] \\ 242 & 6.1 \% & 0.71[0.36,1.40] \\ 316 & 8.9 \% & 1.57[0.98,2.51] \\ 407 & 9.5 \% & 1.40[0.88,2.24] \\ 452 & 6.5 \% & 1.63[0.94,2.82] \\ 103 & 1.6 \% & 1.02[0.30,3.45] \\ 102 & 3.7 \% & 1.24[0.57,2.70] \\ 62 & 3.4 \% & 0.67[0.26,1.72] \\ 105 & 2.1 \% & 1.00[0.34,2.96] \\ \mathbf{2 2 6 1} & \mathbf{5 3 . 0 \%} & \mathbf{1 . 3 2}[\mathbf{1 . 0 8} \mathbf{1 . 6 2}]\end{array}$

170

$9092100.0 \%$

$1.69[1.46,1.94]$

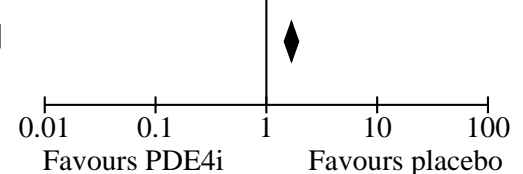


Analysis 1.22. Comparison 1: $\mathrm{PDE}_{4}$ inhibitor versus placebo (2020 update), Outcome 22: Abdominal pain

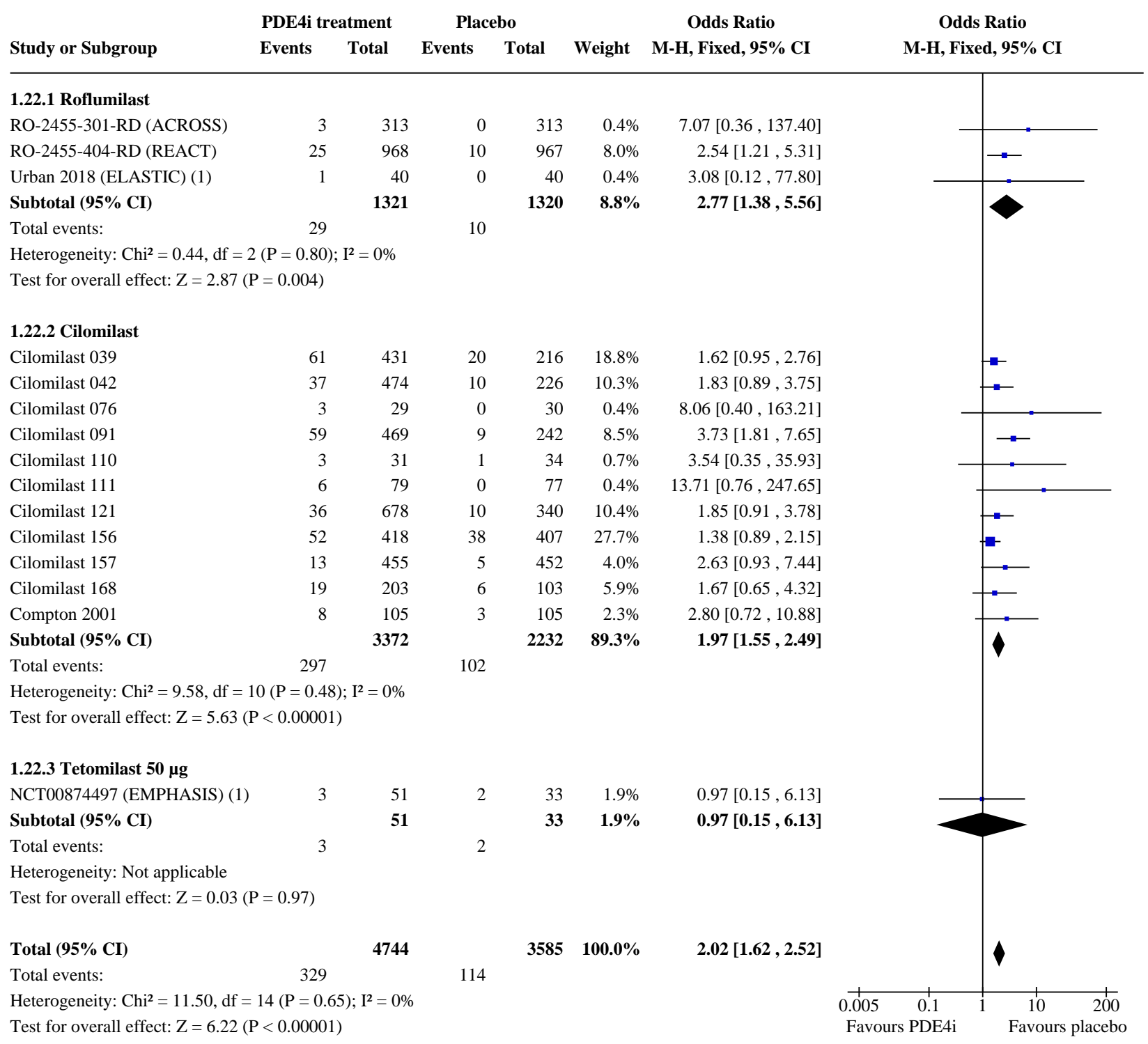

Test for subgroup differences: $\mathrm{Chi}^{2}=1.45, \mathrm{df}=2(\mathrm{P}=0.48), \mathrm{I}^{2}=0 \%$

Footnotes

(1) New data added 2019 


\section{Analysis 1.23. Comparison 1: $\mathrm{PDE}_{4}$ inhibitor versus placebo (2020 update), Outcome 23: Influenza-like symptoms}

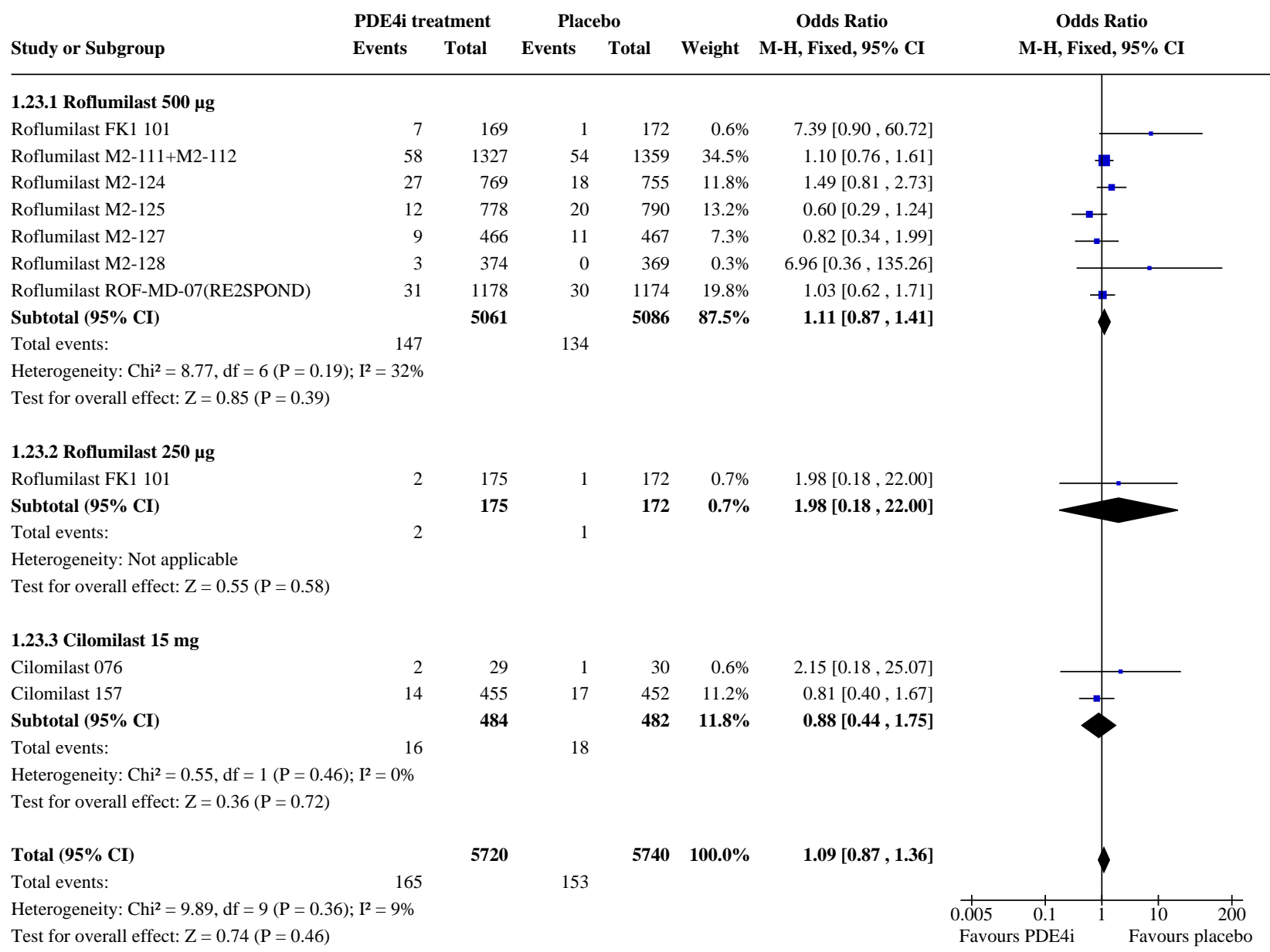


Analysis 1.24. Comparison 1: $\mathrm{PDE}_{4}$ inhibitor versus placebo

(2020 update), Outcome 24: Upper respiratory tract infection

\begin{tabular}{|c|c|c|c|c|c|c|}
\hline \multirow[b]{2}{*}{ Study or Subgroup } & \multicolumn{2}{|c|}{ PDE4i treatment } & \multicolumn{2}{|c|}{ Placebo } & \multirow[b]{2}{*}{ Weight } & \multirow{2}{*}{$\begin{array}{c}\text { Odds Ratio } \\
\text { M-H, Fixed, 95\% CI }\end{array}$} \\
\hline & Events & Total & Events & Total & & \\
\hline \multicolumn{7}{|l|}{ 1.24.1 Roflumilast $500 \mu \mathrm{g}$} \\
\hline Liu 2018 (1) & 13 & 60 & 7 & 60 & $1.1 \%$ & $2.09[0.77,5.69]$ \\
\hline Roflumilast DAL-MD-01 & 1 & 11 & 2 & 16 & $0.3 \%$ & $0.70[0.06,8.82]$ \\
\hline Roflumilast FK1 101 & 26 & 169 & 27 & 172 & $4.5 \%$ & $0.98[0.54,1.75]$ \\
\hline Roflumilast M2-107 & 23 & 555 & 14 & 280 & $3.5 \%$ & $0.82[0.42,1.62]$ \\
\hline Roflumilast M2-111+M2-112 & 72 & 1327 & 86 & 1359 & $15.9 \%$ & $0.85[0.62,1.17]$ \\
\hline Roflumilast M2-119 & 18 & 203 & 6 & 207 & $1.1 \%$ & $3.26[1.27,8.39]$ \\
\hline Roflumilast M2-124 & 16 & 769 & 21 & 755 & $4.1 \%$ & $0.74[0.38,1.43]$ \\
\hline Roflumilast M2-125 & 33 & 778 & 38 & 790 & $7.1 \%$ & $0.88[0.54,1.41]$ \\
\hline Roflumilast M2-127 & 9 & 466 & 19 & 467 & $3.7 \%$ & $0.46[0.21,1.04]$ \\
\hline Roflumilast M2-128 & 4 & 374 & 2 & 369 & $0.4 \%$ & $1.98[0.36,10.90]$ \\
\hline Roflumilast ROF-MD-07(RE2SPOND) & 60 & 1178 & 66 & 1174 & $12.4 \%$ & $0.90[0.63,1.29]$ \\
\hline Subtotal $(95 \%$ CI $)$ & & 5890 & & 5649 & $54.1 \%$ & $0.92[0.77,1.09]$ \\
\hline Total events: & 275 & & 288 & & & \\
\hline
\end{tabular}

Heterogeneity: $\mathrm{Chi}^{2}=13.93, \mathrm{df}=10(\mathrm{P}=0.18) ; \mathrm{I}^{2}=28 \%$

Test for overall effect: $\mathrm{Z}=0.96(\mathrm{P}=0.34)$

\subsubsection{Roflumilast $250 \mu \mathrm{g}$}

Roflumilast FK1 101

Roflumilast M2-107

22

Subtotal (95\% CI)

Heterogeneity: $\mathrm{Chi}^{2}=0.17, \mathrm{df}=1(\mathrm{P}=0.68) ; \mathrm{I}^{2}=0 \%$

Test for overall effect: $\mathrm{Z}=0.76(\mathrm{P}=0.45)$

\subsubsection{Cilomilast $15 \mathrm{mg}$}

Cilomilast 039

Cilomilast 042

Cilomilast 076

Cilomilast 091

Cilomilast 103657

Cilomilast 110

Cilomilast 111

Cilomilast 156

Cilomilast 168

Cilomilast 180

Subtotal (95\% CI)

$\begin{array}{rr}431 & 3 \\ 474 & 1 \\ 29 & \\ 469 & \\ 296 & 4 \\ 31 & \\ 79 & \\ 418 & 6 \\ 203 & 18 \\ 97 & \\ \mathbf{2 5 2 7} & \end{array}$

Total events:

244

Heterogeneity: $\mathrm{Chi}^{2}=12.11, \mathrm{df}=9(\mathrm{P}=0.21) ; \mathrm{I}^{2}=26 \%$

Test for overall effect: $\mathrm{Z}=0.78(\mathrm{P}=0.44)$

Total (95\% CI)

9168

Total events: 568

Heterogeneity: $\mathrm{Chi}^{2}=26.33, \mathrm{df}=22(\mathrm{P}=0.24) ; \mathrm{I}^{2}=16 \%$

Test for overall effect: $\mathrm{Z}=1.40(\mathrm{P}=0.16)$

Test for subgroup differences: $\mathrm{Chi}^{2}=0.14, \mathrm{df}=2(\mathrm{P}=0.93), \mathrm{I}^{2}=0 \%$

\section{Footnotes}

(1) New data added 2019
Odds Ratio M-H, Fixed, $95 \%$ CI 


\section{Analysis 1.25. Comparison 1: $\mathrm{PDE}_{4}$ inhibitor versus placebo (2020 update), Outcome 25: Psychiatric adverse events (roflumilast)}

\begin{tabular}{|c|c|c|c|c|c|c|c|}
\hline & Roflu & last & Pla & & & Odds Ratio & Odds Ratio \\
\hline Study or Subgroup & Events & Total & Events & Total & Weight & M-H, Fixed, 95\% CI & M-H, Fixed, 95\% C \\
\hline
\end{tabular}

\begin{tabular}{lcccccc}
\hline $\mathbf{1 . 2 5 . 1}$ Roflumilast $\mathbf{5 0 0} \boldsymbol{\mu g}$ & & & & & & \\
COPD safety pool & 403 & 5677 & 190 & 5491 & $100.0 \%$ & $2.13[1.79,2.54]$ \\
Subtotal (95\% CI) & & $\mathbf{5 6 7 7}$ & & $\mathbf{5 4 9 1}$ & $\mathbf{1 0 0 . 0 \%}$ & $\mathbf{2 . 1 3}[\mathbf{1 . 7 9}, \mathbf{2 . 5 4}$ \\
Total events: & 403 & & 190 & & &
\end{tabular}

Heterogeneity: Not applicable

Test for overall effect: $Z=8.40(P<0.00001)$

1.25.2 Roflumilast $250 \mu \mathrm{g}$

COPD safety pool

24
797
$\quad 797$

Subtotal $(\mathbf{9 5 \%} \mathrm{CI})$

$5491 \quad 100.0 \%$

$0.87[0.56,1.33]$

Total events:

24

Heterogeneity: Not applicable

Test for overall effect: $\mathrm{Z}=0.65(\mathrm{P}=0.51)$

Test for subgroup differences: $\mathrm{Chi}^{2}=14.35, \mathrm{df}=1(\mathrm{P}=0.0002), \mathrm{I}^{2}=93.0 \%$

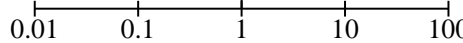

\section{Analysis 1.26. Comparison 1: $\mathrm{PDE}_{4}$ inhibitor versus placebo (2020 update), Outcome 26: Anxiety or anxiety disorder (roflumilast)}

\begin{tabular}{|c|c|c|c|c|c|c|c|}
\hline & Roflu & ilast & Pla & & & Odds Ratio & Odds Ratio \\
\hline Study or Subgroup & Events & Total & Events & Total & Weight & M-H, Fixed, 95\% CI & M-H, Fixed, $95 \%$ CI \\
\hline
\end{tabular}

1.26.1 Roflumilast $500 \mu \mathrm{g}$

COPD safety pool

Subtotal (95\% CI)

$82 \quad 5677$

44

$5491 \quad 100.0 \%$

$1.81[1.26,2.62]$

Total events:

82

$5491 \quad 100.0 \%$

$1.81[1.26,2.62]$

Heterogeneity: Not applicable

Test for overall effect: $\mathrm{Z}=3.17(\mathrm{P}=0.002)$

1.26.2 Roflumilast $250 \mu \mathrm{g}$

COPD safety pool

Subtotal (95\% CI)

$6 \quad 797$

Total events:

6

797

$44 \quad 5491 \quad 100.0 \%$

$0.94[0.40,2.21]$

Heterogeneity: Not applicable

Test for overall effect: $\mathrm{Z}=0.14(\mathrm{P}=0.89)$

Test for subgroup differences: $\mathrm{Chi}^{2}=1.92, \mathrm{df}=1(\mathrm{P}=0.17), \mathrm{I}^{2}=47.9 \%$

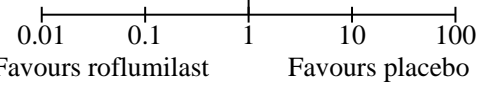


Analysis 1.27. Comparison 1: $\mathrm{PDE}_{4}$ inhibitor versus placebo (2020 update), Outcome 27: Depression (roflumilast)

Roflumilast

Placebo
Study or Subgroup Events Total Events Total Weight M-H, Fixed, 95\% C

Odds Ratio

ents Tota

eight
Odds Ratio M-H, Fixed, $95 \%$ C

\subsubsection{Roflumilast $500 \mu \mathrm{g}$}

COPD safety pool

$80 \quad 5677$

Total events:

Heterogeneity: Not applicable

Test for overall effect: $\mathrm{Z}=2.53(\mathrm{P}=0.01)$

\subsubsection{Roflumilast $250 \mu \mathrm{g}$}

$\begin{array}{lcccccc}\text { COPD safety pool } & 4 & 797 & 49 & 5491 & 100.0 \% & 0.56[0.20,1.56] \\ \text { Subtotal (95\% CI) } & & \mathbf{7 9 7} & & \mathbf{5 4 9 1} & \mathbf{1 0 0 . 0 \%} & \mathbf{0 . 5 6}[\mathbf{0 . 2 0}, \mathbf{1 . 5 6}] \\ \text { Total events: } & 4 & & 49 & & & \end{array}$

Heterogeneity: Not applicable

Test for overall effect: $\mathrm{Z}=1.11(\mathrm{P}=0.27)$

Test for subgroup differences: $\mathrm{Chi}^{2}=3.56, \mathrm{df}=1(\mathrm{P}=0.06), \mathrm{I}^{2}=71.9 \%$

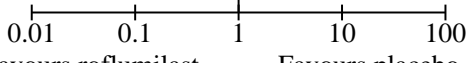

Favours roflumilast Favours placebo

Analysis 1.28. Comparison 1: $\mathrm{PDE}_{4}$ inhibitor versus placebo (2020 update), Outcome 28: Insomnia and sleep disorders (roflumilast)

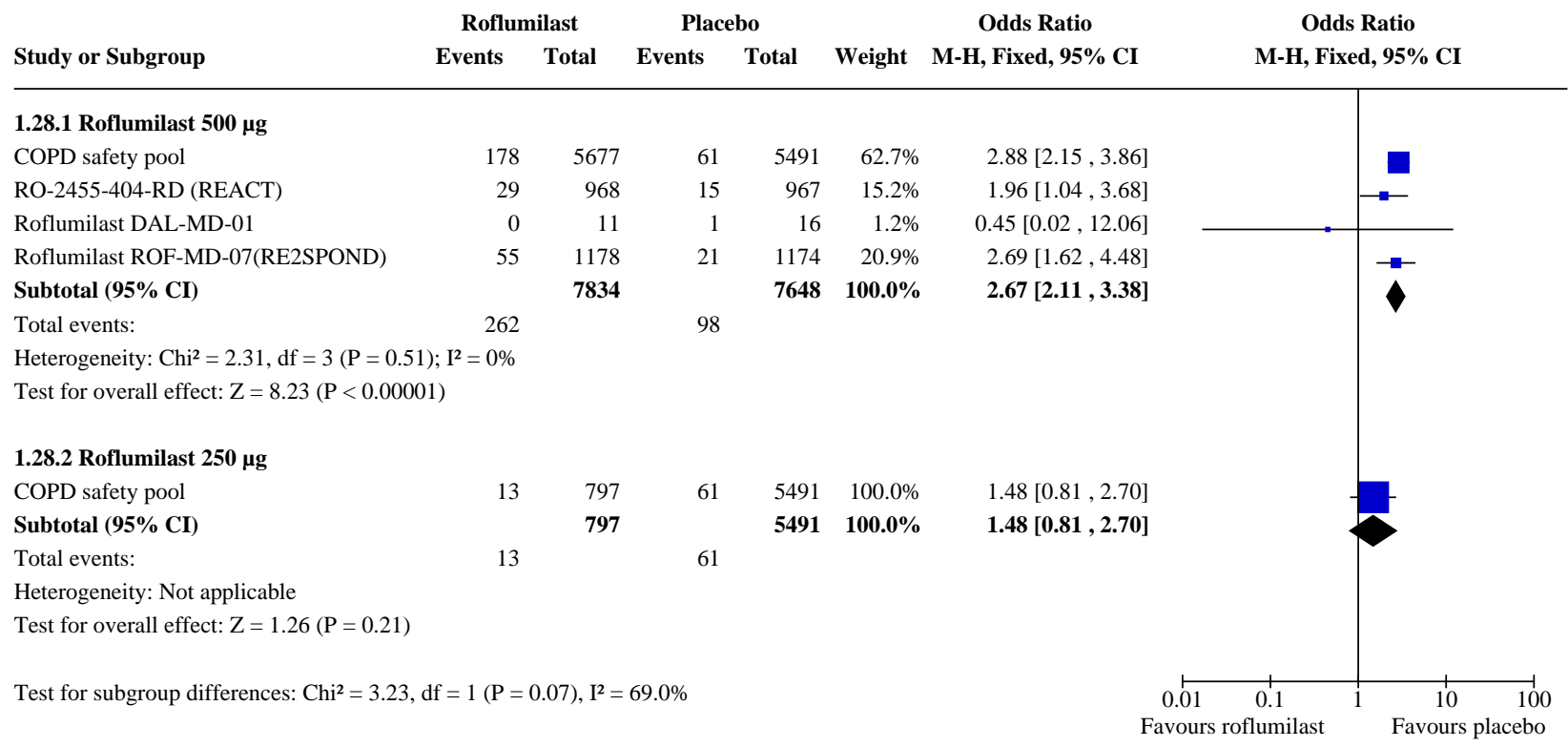


Analysis 1.29. Comparison 1: $\mathrm{PDE}_{4}$ inhibitor versus placebo (2020 update), Outcome 29: Serious adverse events

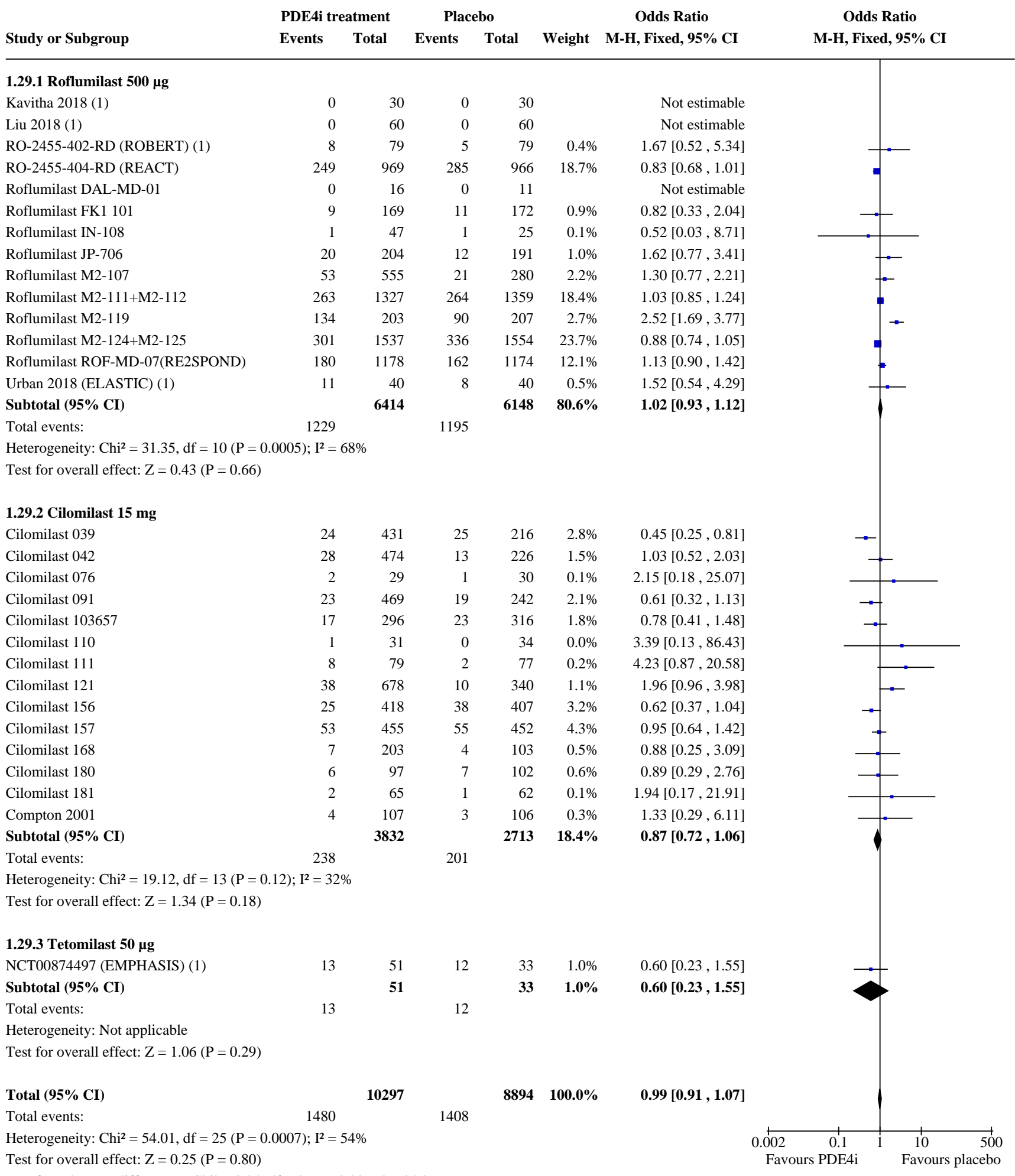

Footnotes

(1) New study data added 2019 
Analysis 1.30. Comparison 1: $\mathrm{PDE}_{4}$ inhibitor versus placebo (2020 update), Outcome 30: Mortality

\begin{tabular}{|c|c|c|c|c|c|c|}
\hline \multirow[b]{2}{*}{ Study or Subgroup } & \multicolumn{2}{|c|}{ PDE4i treatment } & \multicolumn{2}{|c|}{ Placebo } & \multirow[b]{2}{*}{ Weight } & \multirow{2}{*}{$\begin{array}{c}\text { Odds Ratio } \\
\text { M-H, Fixed, } 95 \% \text { CI }\end{array}$} \\
\hline & Events & Total & Events & Total & & \\
\hline \multicolumn{7}{|l|}{ 1.30.1 Roflumilast } \\
\hline Liu 2018 (1) & 0 & 60 & 0 & 60 & & Not estimable \\
\hline RO-2455-402-RD (ROBERT) (1) & 0 & 79 & 0 & 79 & & Not estimable \\
\hline RO-2455-404-RD (REACT) & 17 & 969 & 18 & 966 & $12.7 \%$ & $0.94[0.48,1.84]$ \\
\hline Roflumilast DAL-MD-01 & 0 & 16 & 0 & 11 & & Not estimable \\
\hline Roflumilast M2-107 & 5 & 555 & 2 & 280 & $1.9 \%$ & $1.26[0.24,6.55]$ \\
\hline Roflumilast M2-111+M2-112 & 22 & 1327 & 32 & 1359 & $22.3 \%$ & $0.70[0.40,1.21]$ \\
\hline Roflumilast M2-119 & 2 & 203 & 0 & 207 & $0.4 \%$ & $5.15[0.25,107.91]$ \\
\hline Roflumilast M2-124 & 17 & 765 & 17 & 758 & $12.0 \%$ & $0.99[0.50,1.96]$ \\
\hline Roflumilast M2-125 & 25 & 772 & 25 & 796 & $17.1 \%$ & $1.03[0.59,1.81]$ \\
\hline Roflumilast M2-127 & 5 & 466 & 4 & 467 & $2.8 \%$ & $1.26[0.34,4.70]$ \\
\hline Roflumilast M2-128 & 2 & 374 & 0 & 369 & $0.4 \%$ & $4.96[0.24,103.66]$ \\
\hline Roflumilast ROF-MD-07(RE2SPOND) & 30 & 1178 & 25 & 1174 & $17.5 \%$ & $1.20[0.70,2.05]$ \\
\hline Urban 2018 (ELASTIC) (1) & 2 & 40 & 1 & 40 & $0.7 \%$ & $2.05[0.18,23.59]$ \\
\hline Subtotal $(95 \% \mathrm{CI})$ & & 6804 & & 6566 & $87.7 \%$ & $1.01[0.79,1.30]$ \\
\hline Total events: & 127 & & 124 & & & \\
\hline
\end{tabular}

Heterogeneity: $\mathrm{Chi}^{2}=4.84, \mathrm{df}=9(\mathrm{P}=0.85) ; \mathrm{I}^{2}=0 \%$

Test for overall effect: $\mathrm{Z}=0.12(\mathrm{P}=0.91)$

\subsubsection{Cilomilast}

Cilomilast 039

Cilomilast 042

Cilomilast 076

Cilomilast 091

Cilomilast 103657

Cilomilast 110

Cilomilast 111

Cilomilast 121

Cilomilast 156

Cilomilast 157

Cilomilast 168

Cilomilast 180

Cilomilast 181

Subtotal $(95 \%$ CI $)$

Total events:

Heterogeneity: $\mathrm{Chi}^{2}=4.08, \mathrm{df}=5(\mathrm{P}=0.54) ; \mathrm{I}^{2}=0 \%$

Test for overall effect: $\mathrm{Z}=0.95(\mathrm{P}=0.34)$

$\begin{array}{rrrr}431 & 2 & 216 & 1.9 \% \\ 474 & 2 & 226 & 1.9 \% \\ 29 & 0 & 30 & \\ 469 & 0 & 242 & 0.5 \% \\ 296 & 0 & 316 & \\ 31 & 0 & 34 & \\ 79 & 0 & 77 & 0.4 \% \\ 678 & 2 & 340 & 1.9 \% \\ 418 & 0 & 407 & \\ 455 & 8 & 452 & 5.7 \% \\ 203 & 0 & 103 & \\ 97 & 0 & 102 & \\ 65 & 0 & 62 & \\ \mathbf{3 7 2 5} & & \mathbf{2 6 0 7} & \mathbf{1 2 . 3 \%}\end{array}$

$0.50[0.07,3.57]$

$0.47[0.07,3.39]$

Not estimable

$3.64[0.19,70.73]$

Not estimable

Not estimable

$5.00[0.24,105.86]$

$0.25[0.02,2.76]$

Not estimable

$0.49[0.15,1.65]$

Not estimable

Not estimable

Not estimable

$0.70[0.34,1.45]$
Odds Ratio

M-H, Fixed, $95 \%$ CI

\subsubsection{Tetomilast}

NCT00874497 (EMPHASIS) (2)

Subtotal $(95 \%$ CI $)$

Total events:

Not estimable

Not estimable

Heterogeneity: Not applicable

Test for overall effect: Not applicable

Total $(95 \%$ CI $)$

10580

$9206100.0 \%$

$0.98[0.77,1.24]$

Total events:

Heterogeneity: $\mathrm{Chi}^{2}=10.18, \mathrm{df}=15(\mathrm{P}=0.81) ; \mathrm{I}^{2}=0 \%$

Test for overall effect: $\mathrm{Z}=0.20(\mathrm{P}=0.84)$

Test for subgroup differences: $\mathrm{Chi}^{2}=0.88, \mathrm{df}=1(\mathrm{P}=0.35), \mathrm{I}^{2}=0 \%$

Footnotes

(1) New study data added 2019

(2) New data added 2019 
Analysis 1.31. Comparison 1: $\mathrm{PDE}_{4}$ inhibitor versus placebo (2020 update), Outcome 31: FEV 1 (by mean COPD severity)

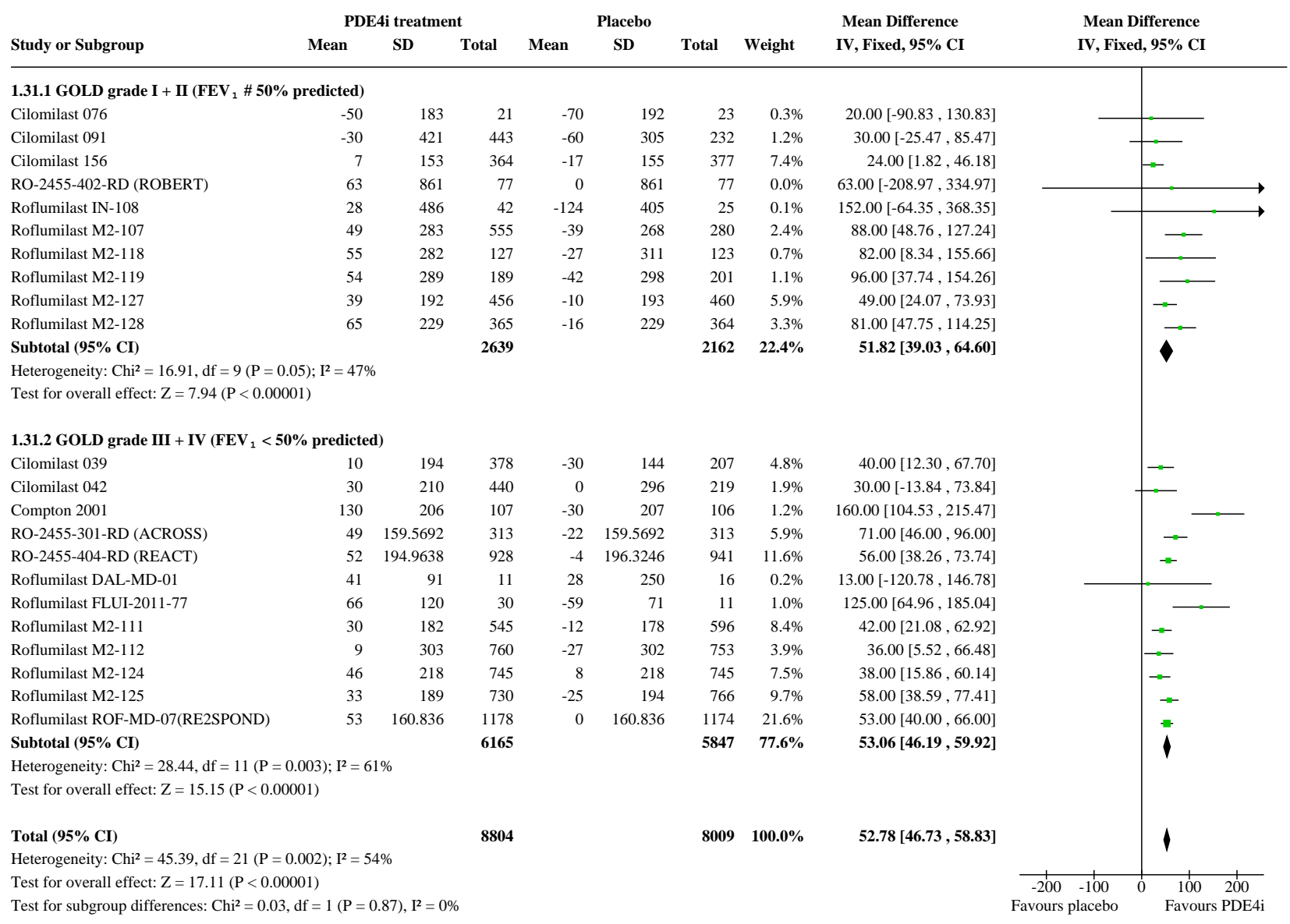

Analysis 1.32. Comparison 1: $\mathrm{PDE}_{4}$ inhibitor versus placebo (2020 update), Outcome 32: FEV (roflumilast $500 \mu \mathrm{g}$ vs $250 \mu \mathrm{g}$ )

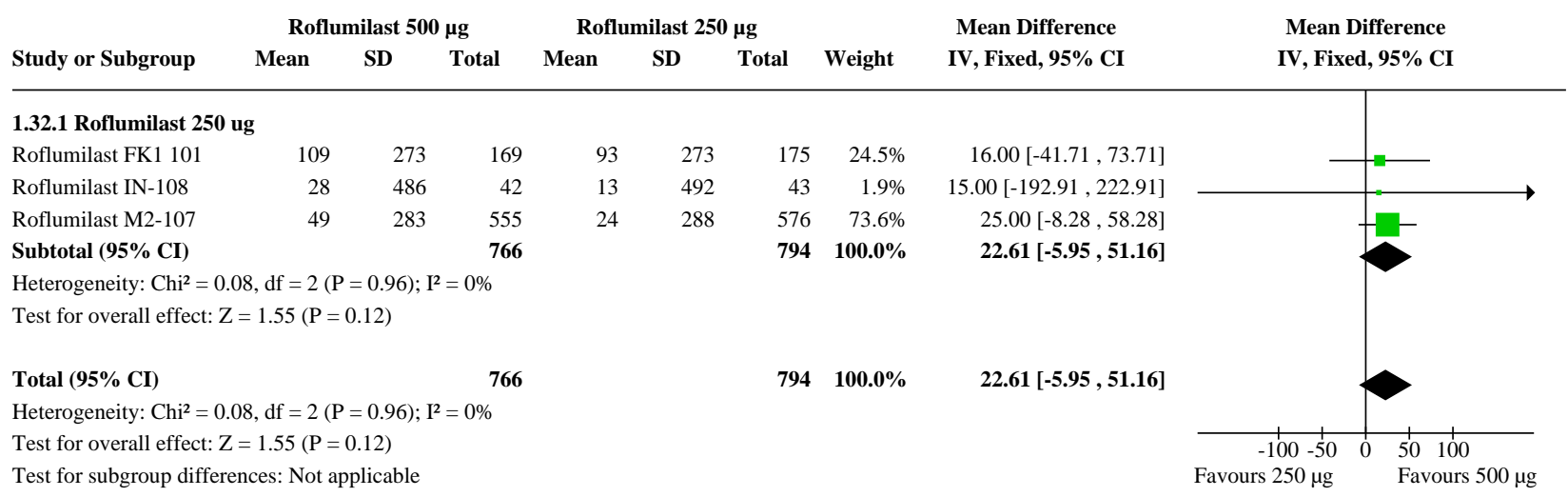


Analysis 1.33. Comparison 1: $\mathrm{PDE}_{4}$ inhibitor versus placebo (2020 update), Outcome 33: $\mathrm{FEV}_{1}$ (by study duration)

\begin{tabular}{|c|c|c|c|c|c|c|c|}
\hline \multirow[b]{2}{*}{ Study or Subgroup } & \multicolumn{3}{|c|}{ PDE4i treatment } & \multicolumn{3}{|c|}{ Placebo } & \multirow[b]{2}{*}{ Weight } \\
\hline & Mean & SD & Total & Mean & SD & Total & \\
\hline \multicolumn{8}{|l|}{ 1.33.1 Duration \# 12 weeks } \\
\hline Cilomilast 076 & -50 & 183 & 21 & -70 & 192 & 23 & $0.2 \%$ \\
\hline Cilomilast 110 & 10 & 179 & 20 & -60 & 204 & 26 & $0.2 \%$ \\
\hline Compton 2001 & 130 & 206 & 107 & -30 & 207 & 106 & $0.9 \%$ \\
\hline RO-2455-402-RD (ROBERT) (1) & 63 & 861 & 77 & 0 & 861 & 77 & $0.0 \%$ \\
\hline Roflumilast DAL-MD-01 & 41 & 91 & 11 & 28 & 250 & 16 & $0.2 \%$ \\
\hline Roflumilast IN-108 & 28 & 486 & 42 & -124 & 405 & 25 & $0.1 \%$ \\
\hline Roflumilast M2-118 & 55 & 282 & 127 & -27 & 311 & 123 & $0.5 \%$ \\
\hline Roflumilast M2-119 & 54 & 289 & 189 & -42 & 298 & 201 & $0.8 \%$ \\
\hline Subtotal (95\% CI) & & & 594 & & & 597 & $2.9 \%$ \\
\hline
\end{tabular}

Mean Difference

Mean Difference

Fixed, 95\% CI

1.33.2 Duration 24 to 26 weeks

Cilomilast 042

Cilomilast 091

Cilomilast 103657

Cilomilast 121

Cilomilast 156

RO-2455-301-RD (ACROSS)

Roflumilast FK1 101

Roflumilast FK1 103

Roflumilast FLUI-2011-77

Roflumilast M2-107

Roflumilast M2-127

Roflumilast M2-128

Subtotal (95\% CI)

$\begin{array}{rrrrrrr}10 & 194 & 378 & -30 & 144 & 207 & 3.6 \% \\ 30 & 210 & 440 & 0 & 296 & 219 & 1.4 \% \\ 0 & 417 & 435 & -30 & 303 & 230 & 0.9 \% \\ 50 & 86 & 296 & 6 & 89 & 316 & 14.2 \% \\ 14 & 175 & 622 & -6 & 181 & 328 & 4.8 \% \\ 7 & 153 & 364 & -17 & 155 & 377 & 5.6 \% \\ 49 & 159.5692 & 313 & -22 & 159.5692 & 313 & 4.4 \% \\ 109 & 273 & 169 & 57 & 302 & 172 & 0.7 \% \\ 78 & 240 & 200 & 39 & 245 & 186 & 1.2 \% \\ 66 & 120 & 30 & -59 & 71 & 11 & 0.8 \% \\ 49 & 283 & 555 & -39 & 268 & 280 & 1.8 \% \\ 39 & 192 & 456 & -10 & 193 & 460 & 4.4 \% \\ 65 & 229 & 365 & -16 & 229 & 364 & 2.5 \% \\ & & 4623 & & & \mathbf{3 4 6 3} & \mathbf{4 6 . 2 \%}\end{array}$

$20.00[-90.83,130.83]$

$70.00[-40.92,180.92]$

$160.00[104.53,215.47]$

$63.00[-208.97,334.97]$

$13.00[-120.78,146.78]$

$152.00[-64.35,368.35]$

$82.00[8.34,155.66]$

$96.00[37.74,154.26]$

101.71 [70.96, 132.46]

Heterogeneity: $\mathrm{Chi}^{2}=28.73, \mathrm{df}=12(\mathrm{P}=0.004) ; \mathrm{I}^{2}=58 \%$

$3463 \quad 46.2 \%$

$40.00[12.30,67.70]$

$30.00[-13.84,73.84]$

$30.00[-25.40,85.40]$

$44.00[30.13,57.87]$

$20.00[-3.93,43.93]$

$24.00[1.82,46.18]$

$71.00[46.00,96.00]$

$52.00[-9.08,113.08]$

$39.00[-9.44,87.44]$

$125.00[64.96,185.04]$

$88.00[48.76,127.24]$

$49.00[24.07,73.93]$

$81.00[47.75,114.25]$

$46.14[38.44,53.84]$

Fixed, $95 \%$ CI

1.33.3 Duration 52 weeks

Cilomilast 157

RO-2455-404-RD (REACT)

Roflumilast M2-111

Roflumilast M2-112

Roflumilast M2-124

Roflumilast M2-125

Roflumilast ROF-MD-07(RE2SPOND)

$\begin{array}{rrr}32 & 197 & 390 \\ 52 & 194.9638 & 928 \\ 30 & 182 & 5 \\ 9 & 303 & 760 \\ 46 & 218 & 745 \\ 33 & 189 & 730 \\ 53 & 160.836 & 1178\end{array}$

Subtotal (95\% CI)

$\begin{array}{rrrr}-2 & 182 & 411 & 4.0 \% \\ -4 & 196.3246 & 941 & 8.7 \% \\ -12 & 178 & 596 & 6.3 \% \\ -27 & 302 & 753 & 2.9 \% \\ 8 & 218 & 745 & 5.6 \% \\ -25 & 194 & 766 & 7.3 \% \\ 0 & 160.836 & 1174 & 16.2 \% \\ & & \mathbf{5 3 8 6} & \mathbf{5 0 . 9 \%}\end{array}$

$34.00[7.70,60.30]$ $56.00[38.26,73.74]$ $42.00[21.08,62.92]$ $36.00[5.52,66.48]$ $38.00[15.86,60.14]$ $58.00[38.59,77.41]$ $53.00[40.00,66.00]$ $48.77[41.44,56.10]$

政 $=5.11, \mathrm{df}=6(\mathrm{P}=0.53) ; \mathrm{I}^{2}=0 \%$

Test for overall effect: $\mathrm{Z}=13.03(\mathrm{P}<0.00001)$

Total (95\% CI)

10493

$9446 \quad 100.0 \%$

49.09 $[43.86,54.32]$

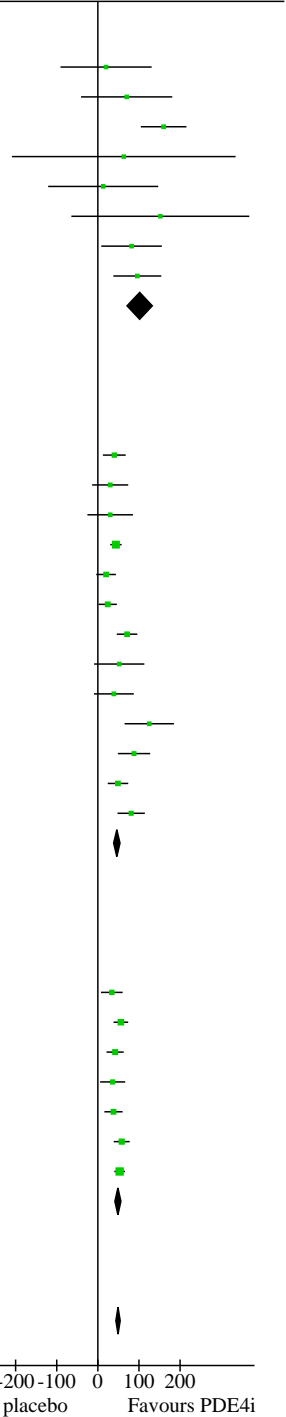

Test for overall effect: $\mathrm{Z}=18.39(\mathrm{P}<0.00001)$

Test for subgroup differences: $\mathrm{Chi}^{2}=11.82, \mathrm{df}=2(\mathrm{P}=0.003), \mathrm{I}^{2}=83.1 \%$

Footnotes

(1) Converted L to $\mathrm{mL}$, SDs obtained from imputing participants in each group, mean for each group obtained from difference in mean between roflumilast and placebo and standard error reported ii 
Analysis 1.34. Comparison 1: $\mathrm{PDE}_{4}$ inhibitor versus placebo (2020 update), Outcome 34: FEV $_{1}$ (additional medication)

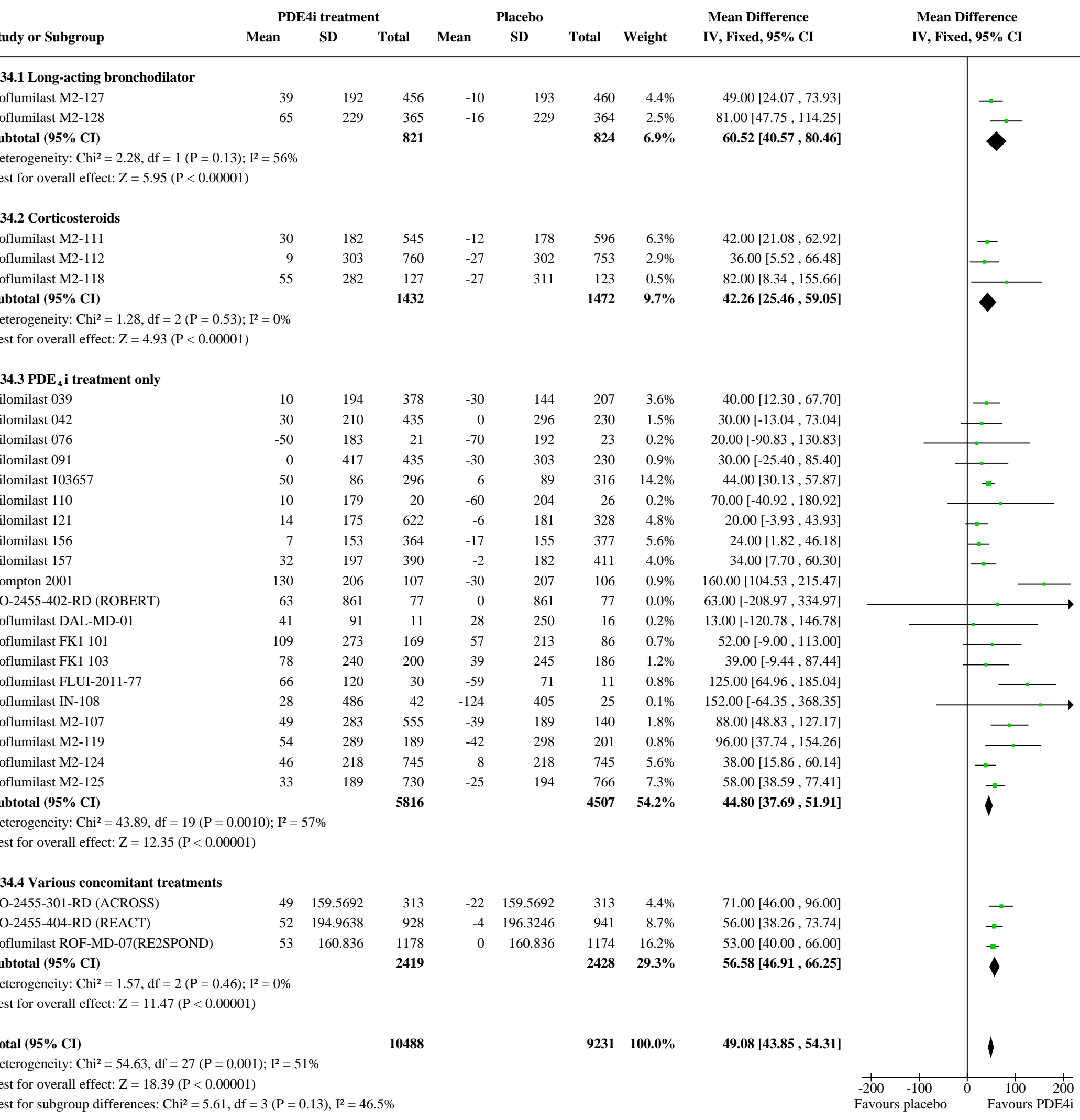




\section{Analysis 1.35. Comparison 1: $\mathrm{PDE}_{4}$ inhibitor versus placebo (2020 update), Outcome 35: FEV (random-effects model)}

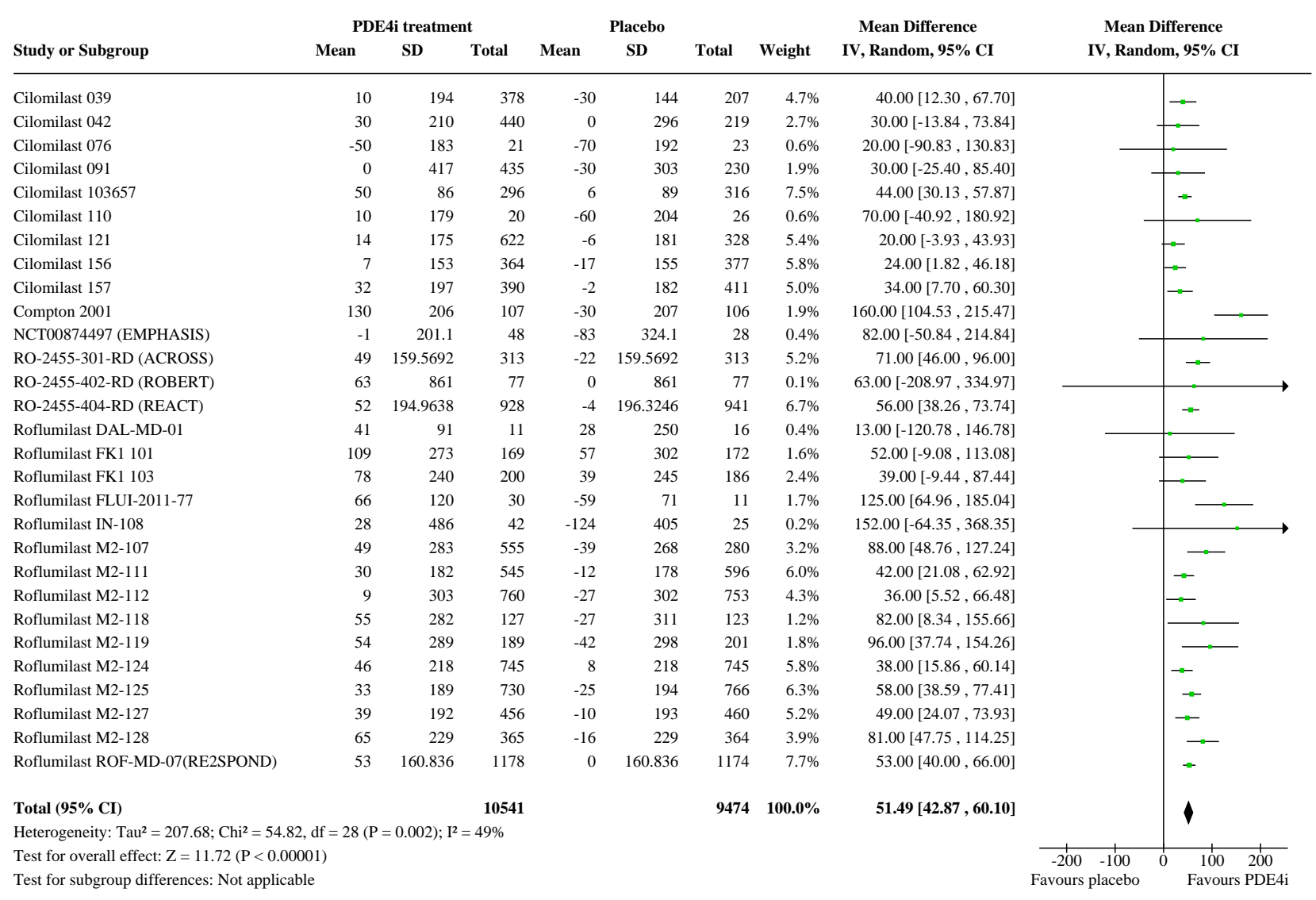


Analysis 1.36. Comparison 1: $\mathrm{PDE}_{4}$ inhibitor versus placebo (2020 update), Outcome 36: FEV 1 (published vs unpublished)

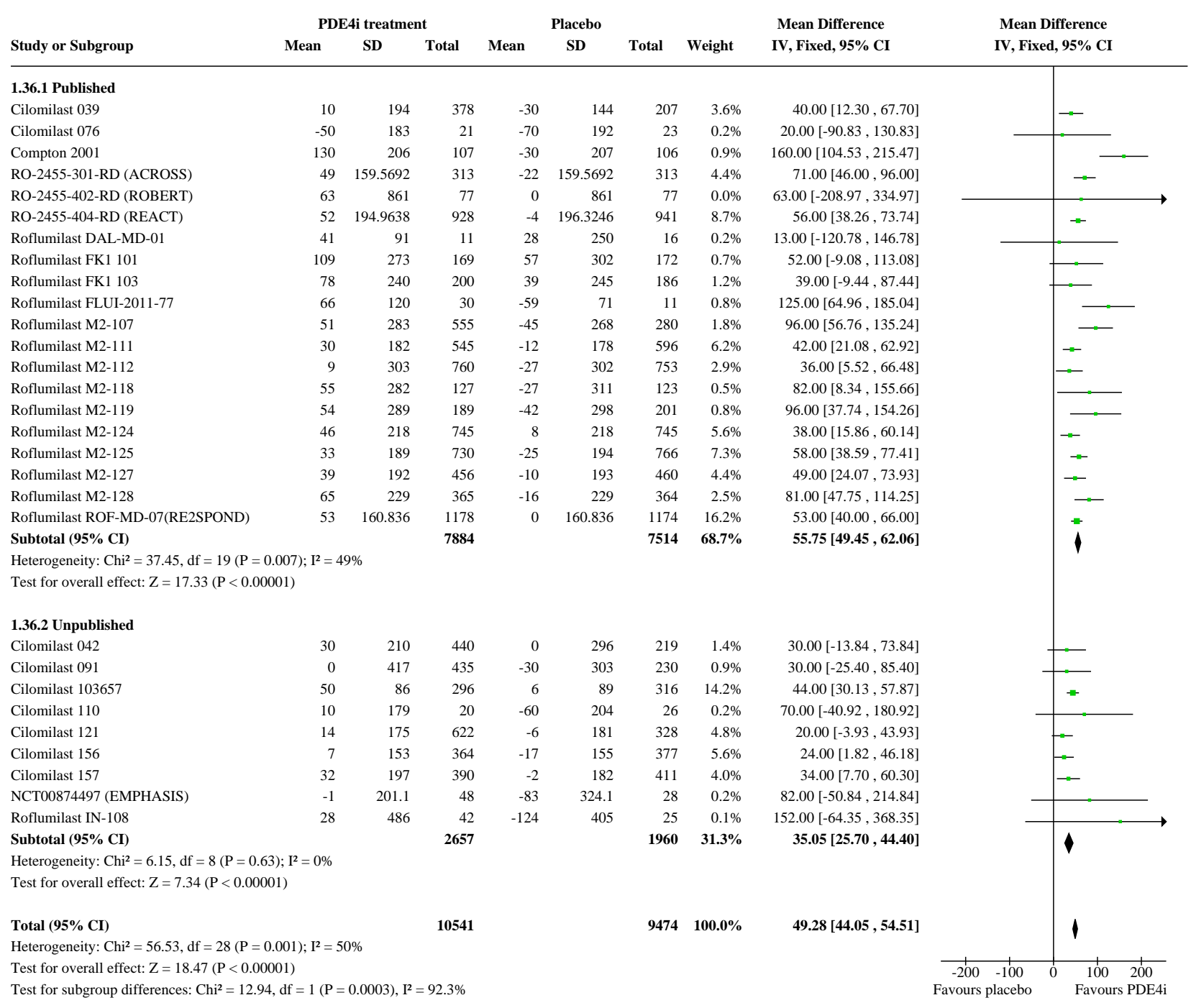




\section{Analysis 1.37. Comparison 1: $\mathrm{PDE}_{4}$ inhibitor versus placebo (2020 update), Outcome 37: SGRQ total score (by mean COPD severity)}

\begin{tabular}{lcccccccc}
\multicolumn{4}{c}{ PDE4i treatment } & \multicolumn{2}{c}{ Placebo } & & \multicolumn{2}{c}{ Mean Difference } \\
Study or Subgroup & Mean & SD & Total & Mean & SD & Total & Weight & IV, Fixed, 95\% CI
\end{tabular}

1.37.1 GOLD grade I + II

$-2.7 \quad 21.1$

Cilomilast 156

$-3.2 \quad 10.5$

369

$-2.3$

Roflumilast M2-107

$-3.5$

14.1

304

$-1.3$

Subtotal (95\% CI)

14.1
$\mathbf{1 2 2 8}$

$-1.8 \quad 13.4$

Heterogeneity: $\mathrm{Chi}^{2}=0.68, \mathrm{df}=2(\mathrm{P}=0.71) ; \mathrm{I}^{2}=0 \%$

Test for overall effect: $\mathrm{Z}=2.70(\mathrm{P}=0.007)$

\subsubsection{GOLD grade III + IV}

$\begin{array}{lrrrrrrrr}\text { Cilomilast 039 } & -3.7 & 12.32 & 310 & 0.4 & 10.76 & 181 & 15.8 \% & -4.10[-6.18,-2.02] \\ \text { Cilomilast 042 } & -4.2 & 15.5 & 375 & -4.9 & 13.8 & 190 & 10.8 \% & 0.70[-1.81,3.21] \\ \text { Compton 2001 } & -3.9 & 13.4 & 107 & 0 & 13.4 & 106 & 5.3 \% & -3.90[-7.50,-0.30] \\ \text { Roflumilast DAL-MD-01 } & -7.5 & 13.8 & 11 & -0.8 & 13.8 & 16 & 0.6 \% & -6.70[-17.29,3.89] \\ \text { Roflumilast M2-112 } & -1.7 & 19.3 & 760 & -2 & 19.2 & 753 & 18.2 \% & 0.30[-1.64,2.24] \\ \text { Subtotal (95\% CI) } & & & \mathbf{1 5 6 3} & & & \mathbf{1 2 4 6} & \mathbf{5 0 . 7 \%} & \mathbf{- 1 . 5 1 [ - 2 . 6 7 , - 0 . 3 4}]\end{array}$

Heterogeneity: $\mathrm{Chi}^{2}=14.87, \mathrm{df}=4(\mathrm{P}=0.005) ; \mathrm{I}^{2}=73 \%$

Test for overall effect: $\mathrm{Z}=2.54(\mathrm{P}=0.01)$

Heterogeneity: $\mathrm{Chi}^{2}=15.57, \mathrm{df}=7(\mathrm{P}=0.03) ; \mathrm{I}^{2}=55 \%$

Test for overall effect: $\mathrm{Z}=3.70(\mathrm{P}=0.0002)$

Test for subgroup differences: $\mathrm{Chi}^{2}=0.02, \mathrm{df}=1(\mathrm{P}=0.89), \mathrm{I}^{2}=0 \%$

$-0.40[-3.58,2.78]$
$-1.90[-3.57,-0.23]$
$-1.70[-3.66,0.26]$
$\mathbf{- 1 . 6 2}[-\mathbf{2 . 8 0}, \mathbf{- 0 . 4 4}]$

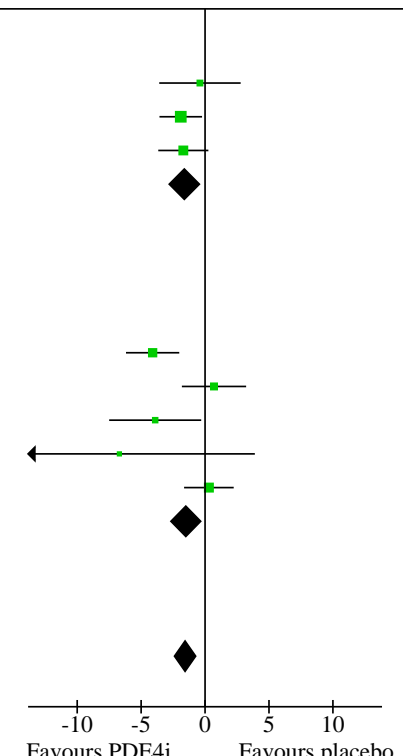

Favours PDE4i $\quad$ Favours placebo 
Analysis 1.38. Comparison 1: $\mathrm{PDE}_{4}$ inhibitor versus placebo

(2020 update), Outcome 38: SGRQ total score (by duration)

\begin{tabular}{|c|c|c|c|c|c|c|c|c|c|}
\hline \multirow{2}{*}{ Study or Suboroup } & \multicolumn{3}{|c|}{ PDE4i treatment } & \multicolumn{3}{|c|}{ Placebo } & \multicolumn{2}{|r|}{ Mean Difference } & Mean Difference \\
\hline & Mean & SD & Total & Mean & SD & Total & Weight & IV, Fixed, 95\% CI & IV, Fixed, 95\% CI \\
\hline
\end{tabular}

1.38.1 Duration $<\mathbf{1 2}$ weeks
Compton 2001

$\begin{array}{llll}\text { Roflumilast DAL-MD-01 } & -7.5 & 13.8 & 11\end{array}$

$\begin{array}{lll}0 & 13.4 \quad 106\end{array}$

$\begin{array}{llll}11 & -0.8 & 13.8 & 16\end{array}$

Subtotal (95\% CI)

118

16
122

$3.3 \%$

IV, Fixed, 95\% CI

Heterogeneity: $\mathrm{Chi}^{2}=0.24, \mathrm{df}=1(\mathrm{P}=0.62) ; \mathrm{I}^{2}=0 \%$

Test for overall effect: $\mathrm{Z}=2.41(\mathrm{P}=0.02)$

1.38.2 Duration 24 to 26 weeks

$\begin{array}{lrrrrrrrr}\text { Cilomilast 039 } & -3.7 & 12.32 & 310 & 0.4 & 10.76 & 181 & 10.0 \% & -4.10[-6.18,-2.02] \\ \text { Cilomilast 042 } & -4.2 & 15.5 & 375 & -4.9 & 13.8 & 190 & 6.9 \% & 0.70[-1.81,3.21] \\ \text { Cilomilast 091 } & -2.7 & 21.1 & 369 & -2.3 & 16.8 & 197 & 4.3 \% & -0.40[-3.58,2.78] \\ \text { Cilomilast 103657 } & -1.8 & 10.2 & 292 & -1.84 & 10 & 310 & 16.6 \% & 0.04[-1.57,1.65] \\ \text { Cilomilast 121 } & -9 & 14.7 & 580 & -8.7 & 14.7 & 320 & 10.8 \% & -0.30[-2.31,1.71] \\ \text { Cilomilast 156 } & -3.2 & 10.5 & 304 & -1.32 & 11 & 337 & 15.6 \% & -1.88[-3.55,-0.21] \\ \text { Roflumilast M2-107 } & -3.5 & 14.1 & 555 & -1.8 & 13.4 & 280 & 11.3 \% & -1.70[-3.66,0.26] \\ \text { Subtotal (95\% CI) } & & & \mathbf{2 7 8 5} & & & \mathbf{1 8 1 5} & \mathbf{7 5 . 4 \%} & \mathbf{- 1 . 1 8}[-\mathbf{1 . 9 4}, \mathbf{- 0 . 4 2}]\end{array}$

Heterogeneity: $\mathrm{Chi}^{2}=13.81, \mathrm{df}=6(\mathrm{P}=0.03) ; \mathrm{I}^{2}=57 \%$

Test for overall effect: $\mathrm{Z}=3.05(\mathrm{P}=0.002)$

1.38.3 Duration 52 weeks

$\begin{array}{lrrrrrrrr}\text { Cilomilast 157 } & -1.29 & 14.9 & 347 & -1.49 & 14.4 & 369 & 9.4 \% & 0.20[-1.95,2.35] \\ \text { Roflumilast M2-112 } & -1.7 & 19.3 & 760 & -2 & 19.2 & 753 & 11.5 \% & 0.30[-1.64,2.24] \\ \text { Subbtotal (95\% CI) } & & & \mathbf{1 1 0 7} & & & \mathbf{1 1 2 2} & \mathbf{2 0 . 9 \%} & \mathbf{0 . 2 6}[-\mathbf{1 . 1 8}, \mathbf{1 . 6 9}]\end{array}$

Heterogeneity: $\mathrm{Chi}^{2}=0.00, \mathrm{df}=1(\mathrm{P}=0.95) ; \mathrm{I}^{2}=0 \%$

Test for overall effect: $\mathrm{Z}=0.35(\mathrm{P}=0.73)$

Total (95\% CI) 4010

$3059100.0 \%$

$-0.99[-1.65,-0.33]$

Test for overall effect: $\mathrm{Z}=2.96(\mathrm{P}=0.003)$

Test for subgroup differences: $\mathrm{Chi}^{2}=6.50, \mathrm{df}=2(\mathrm{P}=0.04), \mathrm{I}^{2}=69.2 \%$

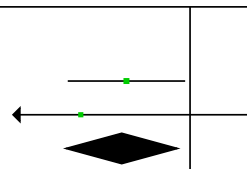

$70[-17.29$

$\mathbf{- 4 . 1 9}[-7.60,-0.78]$

$0.26[-1.18,1.69]$

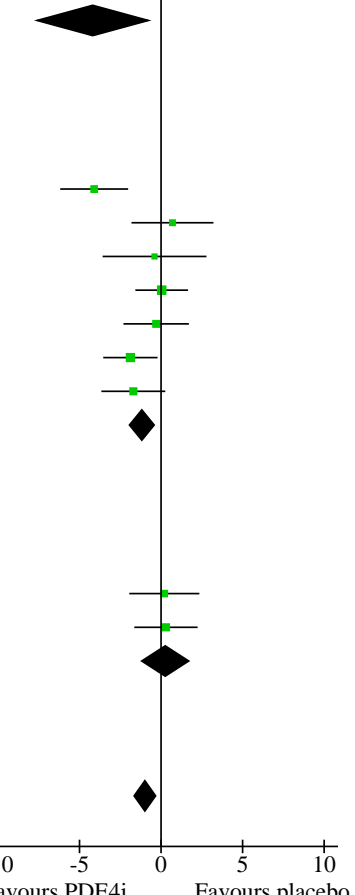


Analysis 1.39. Comparison 1: $\mathrm{PDE}_{4}$ inhibitor versus placebo (2020 update), Outcome 39: SGRQ total score (by published vs unpublished)

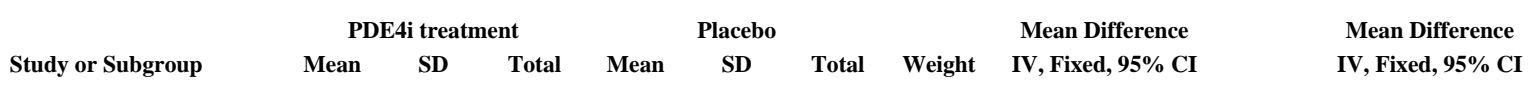

1.39.1 Published

Cilomilast 039

Compton 2001

Roflumilast DAL-MD-01

Roflumilast M2-107

Roflumilast M2-112

Subtotal $(95 \%$ CI $)$

Heterogeneity: $\mathrm{Chi}^{2}=11.22, \mathrm{df}=4(\mathrm{P}=0.02) ; \mathrm{I}^{2}=64 \%$

Test for overall effect: $\mathrm{Z}=3.56(\mathrm{P}=0.0004)$

\subsubsection{Unpublished}

Cilomilast 042

Cilomilast 091

Cilomilast 103657

Cilomilast 121

Cilomilast 156

Cilomilast 157

-4.2
-2.7

15.5

375

$-4.9$

-4.9
-2.3

13.8

Subtotal $(95 \%$ CI)

$14.7-58-8.7$

$14.9 \quad 347$

2267

Heterogeneity: $\mathrm{Chi}^{2}=4.44, \mathrm{df}=5(\mathrm{P}=0.49) ; \mathrm{I}^{2}=0 \%$

Test for overall effect: $\mathrm{Z}=1.02(\mathrm{P}=0.31)$

Total $(95 \%$ CI)

4010

Heterogeneity: $\mathrm{Chi}^{2}=20.61, \mathrm{df}=10(\mathrm{P}=0.02) ; \mathrm{I}^{2}=51 \%$

Test for overall effect: $\mathrm{Z}=2.96(\mathrm{P}=0.003)$

Test for subgroup differences: $\mathrm{Chi}^{2}=4.94, \mathrm{df}=1(\mathrm{P}=0.03), \mathrm{I}^{2}=79.8 \%$
190

197

$6.9 \%$

$4.3 \%$

$16.6 \%$

$10.8 \%$

$15.6 \%$

$9.4 \%$

$63.5 \%$

$0.70[-1.81,3.21]$

$-0.40[-3.58,2.78]$

$0.04[-1.57,1.65]$

$-0.30[-2.31,1.71]$

$-1.90[-3.57,-0.23]$

$0.20[-1.95,2.35]$

$\mathbf{- 0 . 4 3}[-1.26,0.40]$

$3059 \quad 100.0 \% \quad-1.00[-1.65,-0.34]$

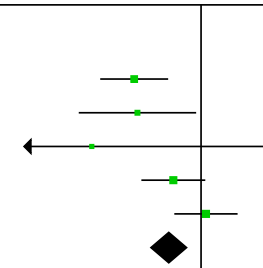


Analysis 1.40. Comparison 1: $\mathrm{PDE}_{4}$ inhibitor versus placebo (2020 update), Outcome 40: Number of participants on roflumilast with 1 or more exacerbations (additional medication)

Study or Subgroup

PDE4i treatment

Placebo

Events Total
Odds Ratio

Events Total Weight M-H, Fixed, 95\% CI
Odds Ratio

M-H, Fixed, 95\% CI
1.40.1 Long-acting bronchodilators RO-2455-402-RD (ROBERT) (1)

Roflumilast M2-127

Roflumilast M2-128

Subtotal (95\% CI)

Total events:

Heterogeneity: $\mathrm{Chi}^{2}=1.48, \mathrm{df}=2(\mathrm{P}=0.48) ; \mathrm{I}^{2}=0 \%$

Test for overall effect: $\mathrm{Z}=3.03(\mathrm{P}=0.002)$

\subsubsection{Corticosteroids}

Roflumilast M2-111+M2-112

Subtotal (95\% CI)

Total events:

Heterogeneity: Not applicable

Test for overall effect: $\mathrm{Z}=2.65(\mathrm{P}=0.008)$

\subsubsection{Treatment only}

Roflumilast FK1 101

Roflumilast IN-108

Roflumilast JP-706

Roflumilast M2-107

Roflumilast M2-119

Roflumilast M2-124

Roflumilast M2-125

Subtotal (95\% CI)

Total events:

Heterogeneity: $\mathrm{Chi}^{2}=5.59, \mathrm{df}=6(\mathrm{P}=0.47) ; \mathrm{I}^{2}=0 \%$

Test for overall effect: $\mathrm{Z}=2.89(\mathrm{P}=0.004)$

1.40.4 Various concomitant treatments

Liu 2018 (1)

RO-2455-301-RD (ACROSS)

RO-2455-404-RD (REACT)

Roflumilast ROF-MD-07(RE2SPOND)

Subtotal (95\% CI)

Total events: $\quad 937$

Heterogeneity: $\mathrm{Chi}^{2}=2.66, \mathrm{df}=3(\mathrm{P}=0.45) ; \mathrm{I}^{2}=0 \%$

Test for overall effect: $\mathrm{Z}=3.55(\mathrm{P}=0.0004)$

Total $(95 \%$ CI $)$

Total events:

2027

7491

Heterogeneity: $\mathrm{Chi}^{2}=11.23, \mathrm{df}=14(\mathrm{P}=0.67) ; \mathrm{I}^{2}=0 \%$

Test for overall effect: $\mathrm{Z}=5.98(\mathrm{P}<0.00001)$

Test for subgroup differences: $\mathrm{Chi}^{2}=1.53, \mathrm{df}=3(\mathrm{P}=0.67), \mathrm{I}^{2}=0 \%$

\section{Footnotes}

(1) New study data added 2019 2258

$0.79[0.73,0.85]$

$0.64[0.22,1.89]$

$0.61[0.44,0.84]$

$0.83[0.56,1.22]$

$0.69[0.54,0.88]$

$0.81[0.70,0.95]$

$0.81[0.70,0.95]$

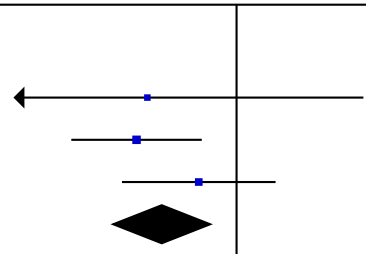

$0.74[0.39,1.41]$

$0.50[0.09,2.68]$

$1.53[0.79,2.96]$

$0.74[0.55,1.01]$

$0.97[0.52,1.81]$

$0.82[0.59,1.15]$

$0.69[0.51,0.93]$

$0.79[0.67,0.93]$

$0.69[0.21,2.30]$

$1.74[0.68,4.49]$

$0.80[0.67,0.96]$

$0.80[0.68,0.94]$

$0.81[0.72,0.91]$

1051

2513

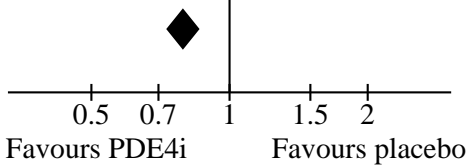


Analysis 1.41. Comparison 1: $\mathrm{PDE}_{4}$ inhibitor versus placebo (2020 update), Outcome 41: FVC ML (roflumilast $500 \mu \mathrm{g}$, endpoint)

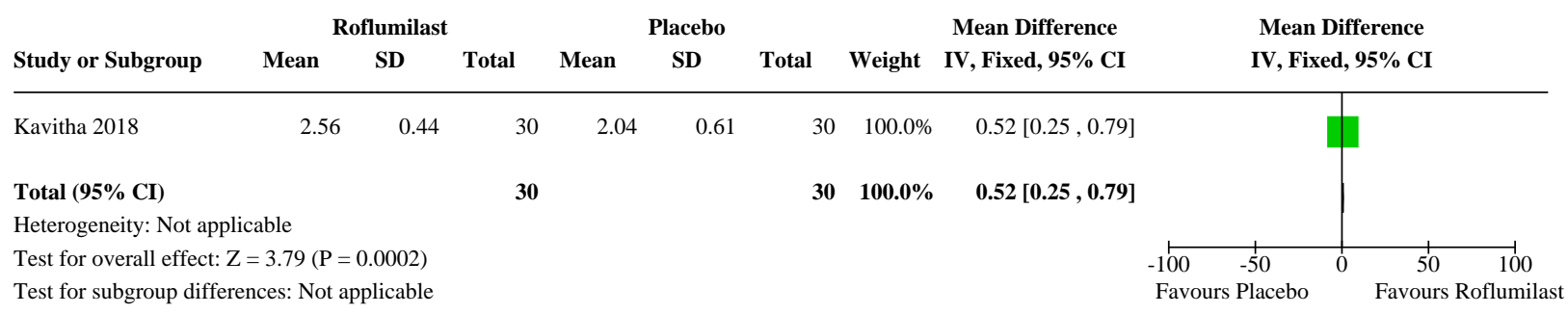

Analysis 1.42. Comparison 1: $\mathrm{PDE}_{4}$ inhibitor versus placebo

(2020 update), Outcome 42: FEV 1 (by unknown COPD severity)

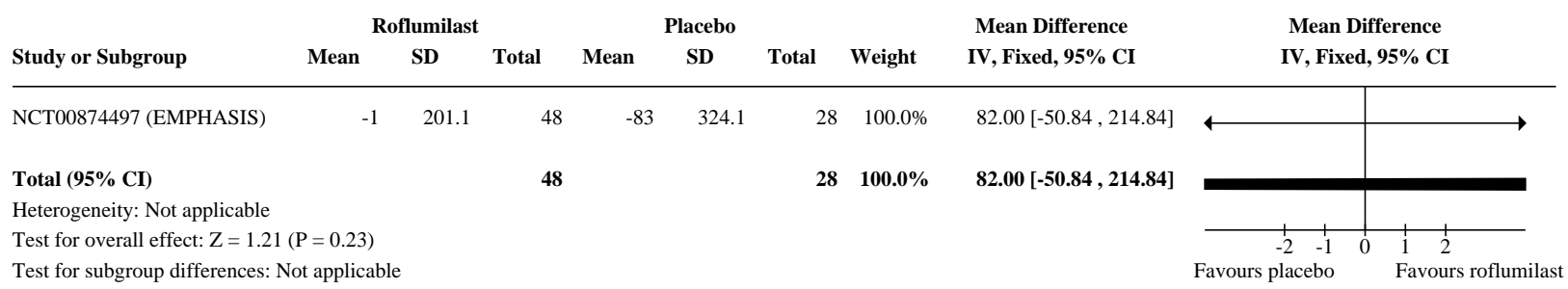

Analysis 1.43. Comparison 1: $\mathrm{PDE}_{4}$ inhibitor versus placebo (2020 update), Outcome 43: FEV 1 (by duration, endpoint)

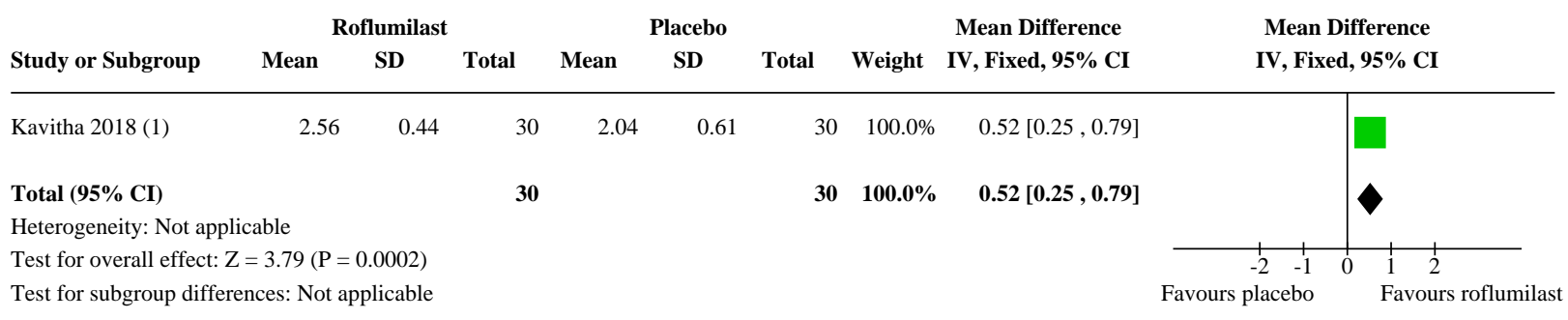

Footnotes

(1) Roflumilast $500 \mu \mathrm{g}$, duration 12 weeks

Analysis 1.44. Comparison 1: $\mathrm{PDE}_{4}$ inhibitor versus placebo (2020 update), Outcome 44: FEV (random-effects model, endpoint data)

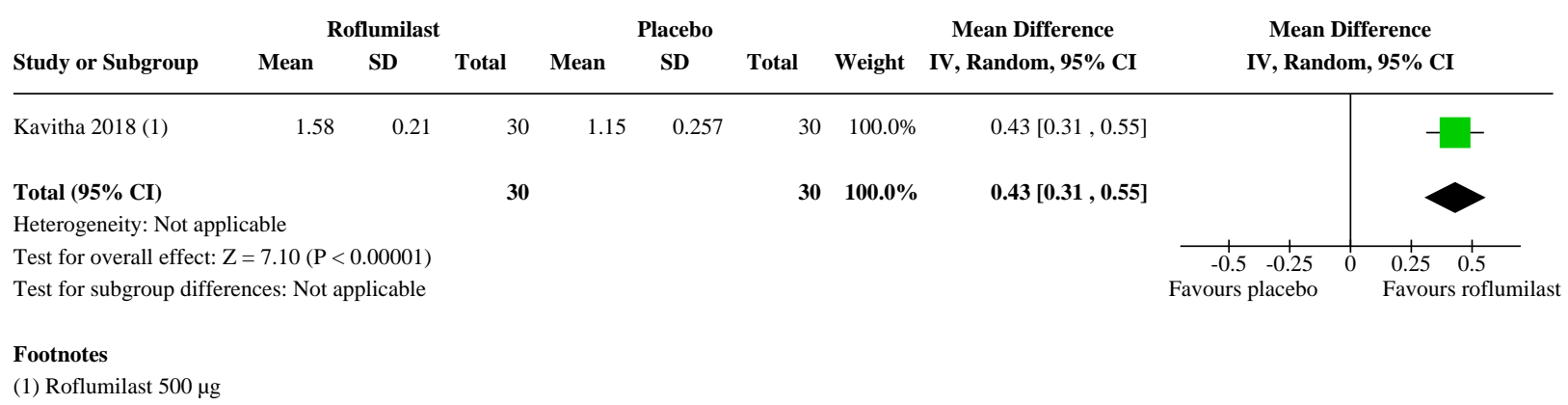


Analysis 1.45. Comparison 1: $\mathrm{PDE}_{4}$ inhibitor versus placebo (2020 update), Outcome 45: FEV (by moderate to severe COPD severity, endpoint)

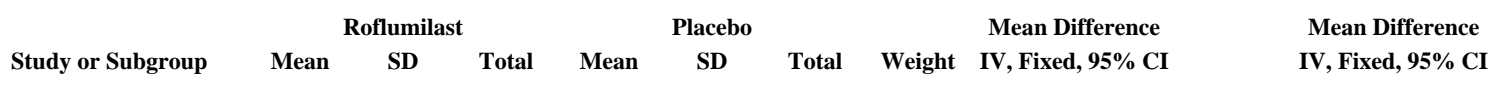

$\begin{array}{llllllllll}\text { Kavitha } 2018(1) & 2.56 & 0.44 & 30 & 2.04 & 0.61 & 30 & 100.0 \% & 0.52[0.25,0.79]\end{array}$

Total $(95 \%$ CI $)$

30

$30 \quad \mathbf{1 0 0 . 0 \%}$

$0.52[0.25,0.79]$

Heterogeneity: Not applicable

Test for overall effect: $\mathrm{Z}=3.79(\mathrm{P}=0.0002)$

Test for subgroup differences: Not applicable

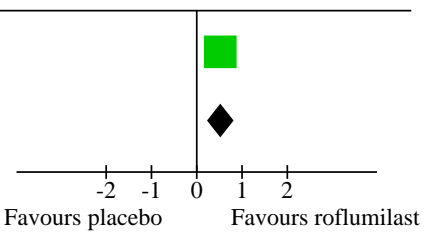

Footnotes

(1) Roflumilast $500 \mu \mathrm{g}$, duration 12 weeks

Analysis 1.46. Comparison 1: $\mathrm{PDE}_{4}$ inhibitor versus placebo (2020 update), Outcome 46: FEV (roflumilast $500 \mu \mathrm{g}$, endpoint)

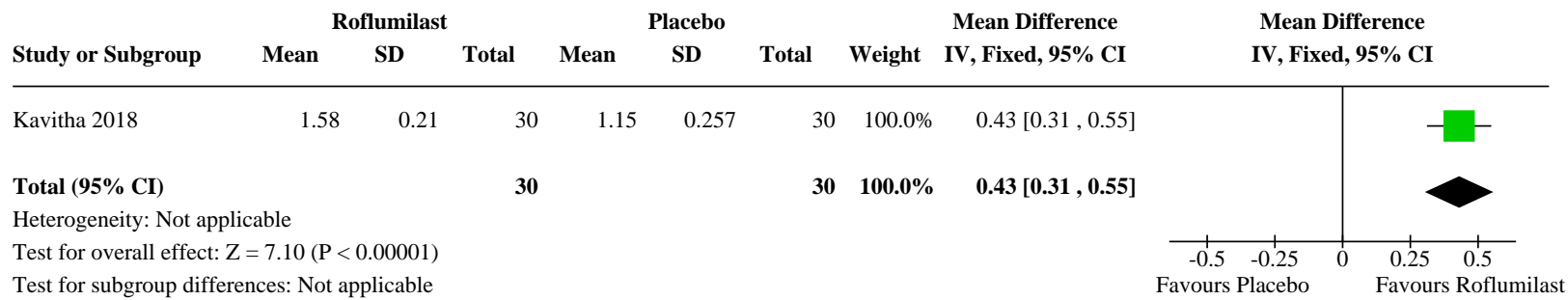

\section{Analysis 1.47. Comparison 1: $\mathrm{PDE}_{4}$ inhibitor versus placebo (2020 update), Outcome 47: $\mathrm{FEV}_{1} \mathrm{ML}$ (additional medication ( $\mathrm{PDE}_{4} \mathrm{i}$ only) endpoint)}

\begin{tabular}{|c|c|c|c|c|c|c|c|c|c|}
\hline & \multicolumn{3}{|c|}{ Roflumilast } & \multicolumn{3}{|c|}{ Placebo } & \multicolumn{3}{|c|}{ Mean Difference } \\
\hline & Mean & SD & Total & Mean & SD & Total & Weight & IV, Fixed, $95 \%$ CI & \\
\hline
\end{tabular}

$\begin{array}{lllllllll}\text { Kavitha } 2018(1) & 2.56 & 0.44 & 30 & 2.04 & 0.61 & 30 & 100.0 \% & 0.52[0.25,0.79]\end{array}$

Total $(95 \%$ CI)

30

$30 \quad 100.0 \% \quad 0.52[0.25,0.79]$

Heterogeneity: Not applicable

Test for overall effect: $\mathrm{Z}=3.79(\mathrm{P}=0.0002)$

Test for subgroup differences: Not applicable

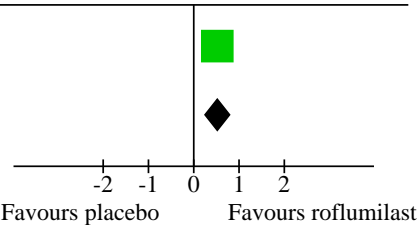

Footnotes

(1) Roflumilast $500 \mu \mathrm{g}$ only 
Analysis 1.48. Comparison 1: $\mathrm{PDE}_{4}$ inhibitor versus placebo (2020 update), Outcome 48: $\mathrm{FEV}_{1}$ (published, endpoint)

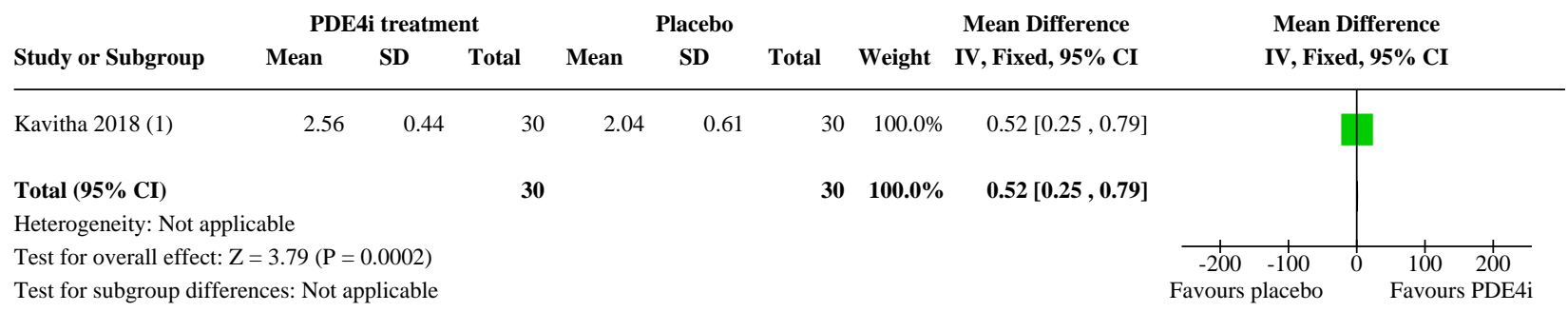

Footnotes

(1) Roflumilast $500 \mu \mathrm{g}$, duration 12 weeks

Analysis 1.49. Comparison 1: $\mathrm{PDE}_{4}$ inhibitor versus placebo (2020 update), Outcome 49: FEV $_{1}$ (roflumilast $500 \mu \mathrm{g}$ by mean COPD severity)

\begin{tabular}{|c|c|c|c|c|c|c|c|c|c|c|}
\hline \multirow[b]{2}{*}{ Study or Subgroup } & \multicolumn{3}{|c|}{ PDE4i treatment } & \multicolumn{3}{|c|}{ Placebo } & \multirow[b]{2}{*}{ Weight } & \multirow{2}{*}{$\begin{array}{l}\text { Mean Difference } \\
\text { IV, Fixed, 95\% CI }\end{array}$} & \multirow{2}{*}{\multicolumn{2}{|c|}{$\begin{array}{l}\text { Mean Difference } \\
\text { IV, Fixed, 95\% CI }\end{array}$}} \\
\hline & Mean & SD & Total & Mean & SD & Total & & & & \\
\hline \multicolumn{11}{|c|}{ 1.49.1 GOLD grade I + II $\left(\mathbf{F E V}_{1} \# \mathbf{5 0} \%\right.$ predicted $)$} \\
\hline RO-2455-402-RD (ROBERT) & 63 & 861 & 77 & 0 & 861 & 77 & $0.1 \%$ & $63.00[-208.97,334.97]$ & & \\
\hline Roflumilast IN-108 & 28 & 486 & 42 & -124 & 405 & 25 & $0.1 \%$ & $152.00[-64.35,368.35]$ & & $\longrightarrow$ \\
\hline Roflumilast M2-107 & 49 & 283 & 555 & -39 & 268 & 280 & $2.9 \%$ & $88.00[48.76,127.24]$ & & 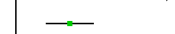 \\
\hline Roflumilast M2-118 & 55 & 282 & 127 & -27 & 311 & 123 & $0.8 \%$ & $82.00[8.34,155.66]$ & & \\
\hline Roflumilast M2-119 & 54 & 289 & 189 & -42 & 298 & 201 & $1.3 \%$ & $96.00[37.74,154.26]$ & & $\longrightarrow$ \\
\hline Roflumilast M2-127 & 39 & 192 & 456 & -10 & 193 & 460 & $7.1 \%$ & $49.00[24.07,73.93]$ & & -- \\
\hline Roflumilast M2-128 & 65 & 229 & 365 & -16 & 229 & 364 & $4.0 \%$ & $81.00[47.75,114.25]$ & & 一 \\
\hline Subtotal $(95 \%$ CI) & & & 1811 & & & 1530 & $16.2 \%$ & $69.83[53.34,86.33]$ & & 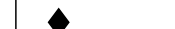 \\
\hline \multicolumn{11}{|c|}{ Heterogeneity: $\mathrm{Chi}^{2}=5.38, \mathrm{df}=6(\mathrm{P}=0.50) ; \mathrm{I}^{2}=0 \%$} \\
\hline \multicolumn{11}{|c|}{ Test for overall effect: $\mathrm{Z}=8.30(\mathrm{P}<0.00001)$} \\
\hline \multicolumn{11}{|c|}{ 1.49.2 GOLD grade III + IV $\left(\mathrm{FEV}_{1}<50 \%\right.$ predicted $)$} \\
\hline RO-2455-301-RD (ACROSS) & 49 & 159.5692 & 313 & -22 & 159.5692 & 313 & $7.0 \%$ & $71.00[46.00,96.00]$ & & - \\
\hline RO-2455-404-RD (REACT) & 52 & 194.9638 & 928 & -4 & 196.3246 & 941 & $14.0 \%$ & $56.00[38.26,73.74]$ & & - \\
\hline Roflumilast DAL-MD-01 & 41 & 91 & 11 & 28 & 250 & 16 & $0.2 \%$ & $13.00[-120.78,146.78]$ & & \\
\hline Roflumilast FLUI-2011-77 & 66 & 120 & 30 & -59 & 71 & 11 & $1.2 \%$ & $125.00[64.96,185.04]$ & & - \\
\hline Roflumilast M2-111 & 30 & 182 & 545 & -12 & 178 & 596 & $10.0 \%$ & $42.00[21.08,62.92]$ & & - \\
\hline Roflumilast M2-112 & 9 & 303 & 760 & -27 & 302 & 753 & $4.7 \%$ & $36.00[5.52,66.48]$ & & $\Longrightarrow$ \\
\hline Roflumilast M2-124 & 46 & 218 & 745 & 8 & 218 & 745 & $9.0 \%$ & $38.00[15.86,60.14]$ & & - \\
\hline Roflumilast M2-125 & 33 & 189 & 730 & -25 & 194 & 766 & $11.7 \%$ & $58.00[38.59,77.41]$ & & $\rightarrow$ \\
\hline Roflumilast ROF-MD-07(RE2SPOND) & 53 & 160.836 & 1178 & 0 & 160.836 & 1174 & $26.0 \%$ & $53.00[40.00,66.00]$ & & 量 \\
\hline Subtotal $(95 \% \mathrm{CI})$ & & & 5240 & & & 5315 & $\mathbf{8 3 . 8 \%}$ & $52.75[45.52,59.99]$ & & 1 \\
\hline \multicolumn{11}{|c|}{ Heterogeneity: $\mathrm{Chi}^{2}=12.24, \mathrm{df}=8(\mathrm{P}=0.14) ; \mathrm{I}^{2}=35 \%$} \\
\hline \multicolumn{11}{|c|}{ Test for overall effect: $Z=14.28(P<0.00001)$} \\
\hline Total $(95 \%$ CI) & & & 7051 & & & 6845 & $100.0 \%$ & $55.51[48.88,62.14]$ & & 1 \\
\hline \multicolumn{11}{|c|}{ Heterogeneity: $\mathrm{Chi}^{2}=21.07, \mathrm{df}=15(\mathrm{P}=0.13) ; \mathrm{I}^{2}=29 \%$} \\
\hline Test for overall effect: $Z=16.41(P<0$. & & & & & & & & & $\begin{array}{cc} & 1 \\
-200 & -100\end{array}$ & $100 \quad 200$ \\
\hline Test for subgroup differences: $\mathrm{Chi}^{2}=3.4$ & If $=1(P=$ & $.06), \mathrm{I}^{2}=71$ & $.0 \%$ & & & & & & Favours placebo & Favours PDE4i \\
\hline
\end{tabular}

\section{Analysis 1.50. Comparison 1: $\mathrm{PDE}_{4}$ inhibitor versus placebo (2020 update), Outcome 50: $\mathrm{FEV}_{1}$ (unknown additional medication)}

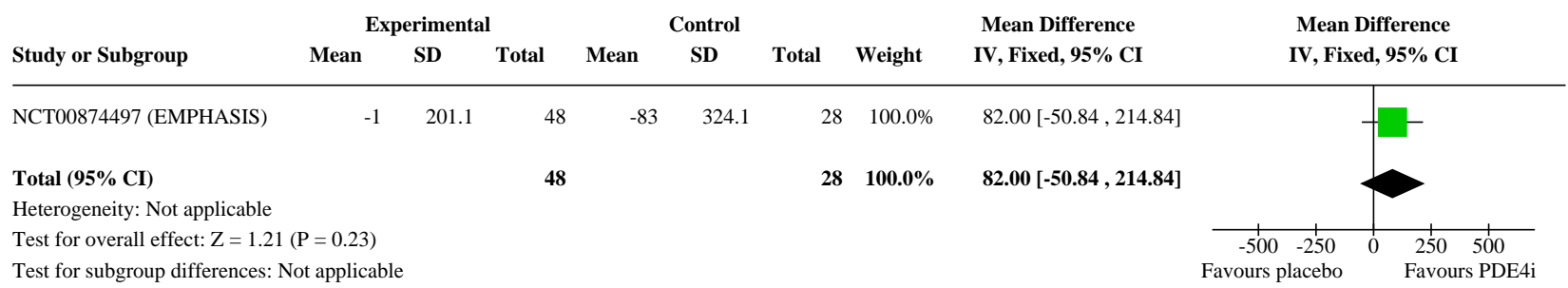


Analysis 1.51. Comparison 1: $\mathrm{PDE}_{4}$ inhibitor versus placebo (2020 update), Outcome

51: FEV $_{1}$ (by moderate to severe COPD severity, roflumilast $500 \mu \mathrm{g}$ endpoint)

\begin{tabular}{|c|c|c|c|c|c|c|c|c|c|}
\hline & \multicolumn{3}{|c|}{ Roflumilast } & \multicolumn{3}{|c|}{ Placebo } & \multicolumn{2}{|r|}{ Mean Difference } & Mean Difference \\
\hline Study or Subgroup & Mean & SD & Total & Mean & SD & Total & Weight & IV, Fixed, 95\% CI & IV, Fixed, 95\% CI \\
\hline
\end{tabular}

\begin{tabular}{llllllllll}
\hline Kavitha 2018 (1) & 2.56 & 0.44 & 30 & 2.04 & 0.61 & 30 & $100.0 \%$ & $0.52[0.25,0.79]$ \\
Total (95\% CI) & & & $\mathbf{3 0}$ & & & $\mathbf{3 0}$ & $\mathbf{1 0 0 . 0 \%}$ & $\mathbf{0 . 5 2}[\mathbf{0 . 2 5}, \mathbf{0 . 7 9}]$
\end{tabular}

Heterogeneity: Not applicable

Test for overall effect: $\mathrm{Z}=3.79(\mathrm{P}=0.0002)$

Test for subgroup differences: Not applicable

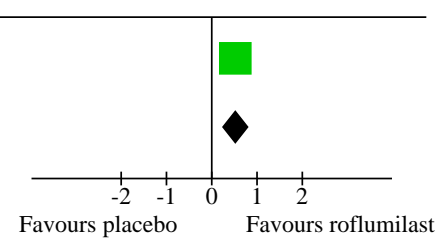

Footnotes

(1) Roflumilast $500 \mu \mathrm{g}$, duration 12 weeks

Analysis 1.52. Comparison 1: $\mathrm{PDE}_{4}$ inhibitor versus placebo (2020 update), Outcome 52: $\mathrm{FEV}_{1}$ (by unknown COPD severity, roflumilast $500 \mu \mathrm{g}$ )

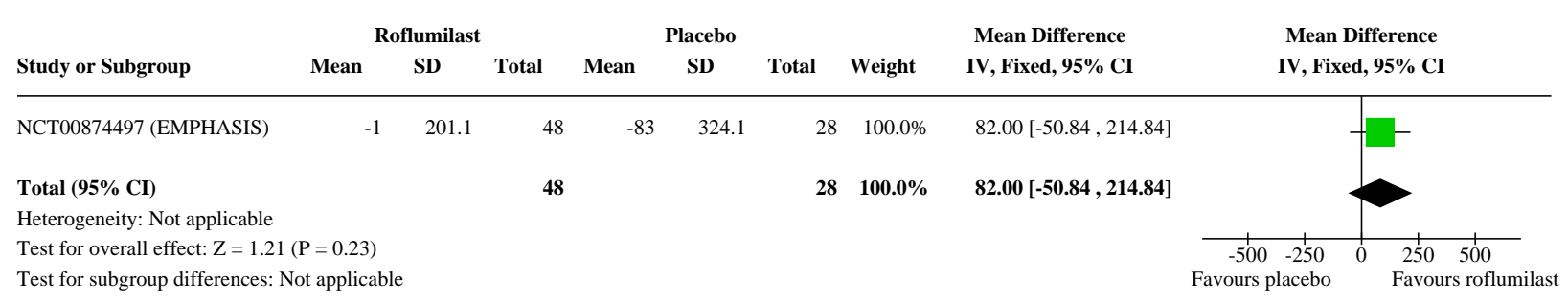

\section{ADDITIONAL TABLES}

Table 1. Number of references for which we sought full text

\begin{tabular}{ll}
\hline Search date: & No. of references for which we sought full text \\
\hline December 2008 & 53 \\
\hline January 2010 & 5 \\
\hline August 2010 & 12 \\
\hline June 2013 & 20 \\
\hline October 2016 & 28 \\
\hline April 2020 & 42 \\
\hline
\end{tabular}

Table 2. Studies reporting severe exacerbation rates per patient per year

\begin{tabular}{llll}
\hline Study ID & $\begin{array}{l}\text { Percentage reduction } \\
\text { (treatment vs placebo) }\end{array}$ & Rate ratio (95\% Cl) & P value \\
\hline Cilomilast 039 & 45 & - & 0.001 \\
\hline
\end{tabular}


Table 2. Studies reporting severe exacerbation rates per patient per year (Continued)

\begin{tabular}{lccc} 
RO-2455-404-RD (REACT) & 24.3 & 0.757 (0.601 to 0.952) & 0.0175 \\
\hline Roflumilast M2-124+M2-125 & 17 & 0.82 (0.63 to 1.06) & 0.163 \\
\hline Roflumilast ROF-MD-07(RE2SPOND) & 8.5 & 0.95 (0.75 to 1.19) & 0.635 \\
\hline
\end{tabular}

\section{APPENDICES}

\section{Appendix 1. Sources and search methods for the Cochrane Airways Trials Register}

\section{Electronic searches: core databases}

\begin{tabular}{ll}
\hline Database & Frequency of search \\
\hline CENTRAL (The Cochrane Library) & Monthly \\
\hline MEDLINE (Ovid SP) ALL & Weekly \\
\hline Embase (Ovid SP) & Weekly \\
\hline PSycINFO (Ovid SP) & Monthly \\
\hline CINAHL (EBSCO) & Monthly \\
\hline AMED (EBSCO) & Monthly \\
\hline
\end{tabular}

Handsearches: core respiratory conference abstracts

\begin{tabular}{ll}
\hline Conference & Years searched \\
\hline American Academy of Allergy, Asthma and Immunology (AAAAI) & 2001 onwards \\
\hline American Thoracic Society (ATS) & 2001 onwards \\
\hline Asia Pacific Society of Respirology (APSR) & 2004 onwards \\
\hline British Thoracic Society Winter Meeting (BTS) & 2000 onwards \\
\hline Chest Meeting & 2003 onwards \\
\hline European Respiratory Society (ERS) & $1992,1994,2000$ onwards \\
\hline International Primary Care Respiratory Group Congress (IPCRG) & 2002 onwards \\
\hline Thoracic Society of Australia and New Zealand (TSANZ) & 1999 onwards \\
\hline
\end{tabular}


MEDLINE search strategy used to identify trials for the Cochrane Airways Trials Register

\section{COPD search}

1. Lung Diseases, Obstructive/

2. exp Pulmonary Disease, Chronic Obstructive/

3. emphysema\$.mp.

4. (chronic\$ adj3 bronchiti\$).mp.

5. (obstruct\$ adj3 (pulmonary or lung\$ or airway\$ or airflow\$ or bronch\$ or respirat\$)).mp.

6. COPD.mp.

7. COAD.mp.

8. COBD.mp.

9. AECB.mp.

10. or $/ 1-9$

\section{Filter to identify RCTs}

1. exp "clinical trial [publication type]"/

2. (randomised or randomised).ab,ti.

3. placebo.ab,ti.

4. dt.fs.

5. randomly.ab,ti.

6. trial.ab,ti.

7. groups.ab,ti.

8. or/1-7

9. Animals/

10. Humans/

11.9 not (9 and 10)

12. 8 not 11

The MEDLINE strategy and RCT filter are adapted to identify trials in other electronic databases

\section{Appendix 2. Search strategy to identify relevant trials from the Cochrane Airways Trials Register}

\#1 MeSH DESCRIPTOR Pulmonary Disease, Chronic Obstructive Explode All

\#2 MeSH DESCRIPTOR Bronchitis, Chronic

\#3 (obstruct*) near3 (pulmonary or lung* or airway* or airflow* or bronch* or respirat*)

\#4 COPD:MISC1

\#5 (COPD OR COAD OR COBD):TI,AB,KW

\#6 \#1 OR \#2 OR \#3 OR \#4 OR \#5

\#7 MeSH DESCRIPTOR Phosphodiesterase 4 Inhibitors

\#8 Phosphodiesterase*

\#9 PDE4*

\#10 roflumilast

\#11 rolipram

\#12 cilomilast

Phosphodiesterase-4 inhibitors for chronic obstructive pulmonary disease (Review) 
\#13 ariflo

\#14 SB207499

\#15 Tetomilast

\#16 ORIC485

\#17 Oglemilast

\#18 GRC-3886

\#19 QAK423

\#20 Arofylline

\#21 AWD12-281

$\# 22 \# 7$ or \#8 or \#9 or \#10 or \#11 or \#12 or \#13 or \#14 or \#15 or \#16 or \#17 or \#18 or \#19 or \#20 or \#21

$\# 23 \# 6$ and \#22

\section{Appendix 3. Airways Group Trials Register search strategy (sensitive search)}

$\mathrm{PDE}^{\star}$ or phosphodiesterase* or isoenzyme ${ }^{\star}$ or theophylline or rolipram or pentoxifylline or papaverine or milrinone or etazolate or etazolate or dyphylline or dipyridamole or caffeine or amrinone or aminophylline or isobutylxanthine or cilomilast or ariflo or cilostazol or enoximone or milrinone or olprinone or roflumilast or sb207499 or zardaverine or cilostamide or enoximone or trequinsin or Telomilast or IC485 or Oglemilast or QAK423 or GRC-3886 or Arofylline or AWD12-281

\section{WHAT'S NEW}

\begin{tabular}{lll}
\hline Date & Event & Description \\
\hline 9 March 2020 & $\begin{array}{l}\text { New citation required but conclusions } \\
\text { have not changed }\end{array}$ & $\begin{array}{l}\text { The 2020 update of this review includes 4 new trials of roflumi- } \\
\text { last - Kavitha 2018; Liu 2018; RO-2455-402-RD (ROBERT); Urban }\end{array}$ \\
& $\begin{array}{l}2018 \text { (ELASTIC) - and 1 new trial of tetomilast - NCTO0874497 } \\
\text { (EMPHASIS). Two new review authors (SJ and RF) were added, } \\
\end{array}$ \\
& and 2 review authors (JC and BL) stepped down \\
\hline
\end{tabular}

9 March $2020 \quad$ New search has been performed Literature search was run

\section{HISTORY}

Protocol first published: Issue 4, 2000

Review first published: Issue 5, 2011

\begin{tabular}{|c|c|c|}
\hline Date & Event & Description \\
\hline 11 October 2016 & New search has been performed & New literature search was run \\
\hline 11 October 2016 & $\begin{array}{l}\text { New citation required but conclusions } \\
\text { have not changed }\end{array}$ & $\begin{array}{l}\text { Five new eligible studies of roflumilast } 500 \mu \mathrm{g} \text { were included } \\
\text { - RO-2455-301-RD (ACROSS); RO-2455-404-RD (REACT); Roflu- } \\
\text { milast DAL-MD-01; Roflumilast FLUI-2011-77; Roflumilast ROF- } \\
\text { MD-07(RE2SPOND). No substantive changes were made to re- } \\
\text { view findings }\end{array}$ \\
\hline 17 December 2013 & Amended & Typo in plain language summary title was amended \\
\hline 4 November 2013 & Amended & Risk of bias for Cilomilast 076 was added \\
\hline 6 June 2013 & New search has been performed & New literature search was run \\
\hline 6 June 2013 & $\begin{array}{l}\text { New citation required and conclusions } \\
\text { have changed }\end{array}$ & $\begin{array}{l}\text { We included } 7 \text { new studies in this update and excluded } 1 \text { cross- } \\
\text { over trial. FDA report on psychiatric adverse events and suicides } \\
\text { was included }\end{array}$ \\
\hline
\end{tabular}




\begin{tabular}{lll}
\hline Date Event Description & Den
\end{tabular}

Text was revised to take account of Cochrane reporting standards

'Summary of findings' table was added

\section{CONTRIBUTIONS OF AUTHORS}

Phillippa Poole: protocol initiation and development, checking of content of current update, corresponding author.

Sadia Janjua: screening, data extraction, risk of bias assessment, and write-up of the 2020 review update.

Rebecca Fortescue: data extraction and risk of bias assessment.

\section{Contributions of editorial team}

Chris Cates (Co-ordinating Editor): checked data entry before the full write-up of the review, edited the protocol, advised on methods, and approved the updated review prior to publication.

Emma Dennett (Managing Editor): co-ordinated the editorial process, advised on interpretation and content, and edited the review.

Emma Jackson (Assistant Managing Editor): conducted peer review and edited various sections and references in the protocol and in the review.

Elizabeth Stovold (Information Specialist): designed the search strategy, ran the searches, and edited the search methods section.

\section{DECLARATIONS OF INTEREST}

Phillippa Poole: none known.

Sadia Janjua is funded full-time as a systematic reviewer by a National Institute for Health Research (NIHR) Programme Grant to complete work on this review.

Rebecca Fortescue is Co-ordinating Editor for Cochrane Airways.

\section{SOURCES OF SUPPORT}

\section{Internal sources}

- University of Auckland provided salary support for Professor Phillippa Poole, New Zealand

\section{External sources}

- The authors declare that no such funding was received for this systematic review, Other

\section{DIFFERENCES BETWEEN PROTOCOL AND REVIEW}

We added the comparison between published and unpublished results when we discovered the large number of unpublished studies but before we extracted data from the studies and carried out the analysis.

We excluded cross-over trials, as carry-over effects and disease progression cannot be adequately controlled for in people with COPD.

We updated the methods section in accordance with MECIR standards.

We separated mortality from non-fatal serious adverse events in the methods section for clarity of presentation in the 'Summary of findings' table and in other sections of the review.

\section{INDEX TERMS}

\section{Medical Subject Headings (MeSH)}

Administration, Oral; Aminopyridines [*administration \& dosage] [adverse effects]; Benzamides [*administration \& dosage] [adverse effects]; Cyclohexanecarboxylic Acids [ ${ }^{\star}$ administration \& dosage] [adverse effects]; Cyclopropanes [administration \& dosage] [adverse effects]; Disease Progression; Forced Expiratory Volume [drug effects]; Nitriles [ ${ }^{\star}$ administration \& dosage] [adverse effects]; 
Phosphodiesterase 4 Inhibitors [ ${ }^{\star}$ administration \& dosage] [adverse effects]; Pulmonary Disease, Chronic Obstructive [ ${ }^{\star}$ drug therapy]; Quality of Life; Randomized Controlled Trials as Topic

\section{MeSH check words}

Humans 